\title{
COMPORTAMENTO DE ÍONS Pb, Zn E Cu EM ÁREA IMPACTADA POR ESCÓRIA, PRODUTO DA RECICLAGEM DE BATERIAS CHUMBO-ÁCIDO
}

\author{
JANAINA FERREIRA MARQUES
}

Orientador: Prof. Dr. Raphael Hypólito

DISSERTAÇÃO DE MESTRADO

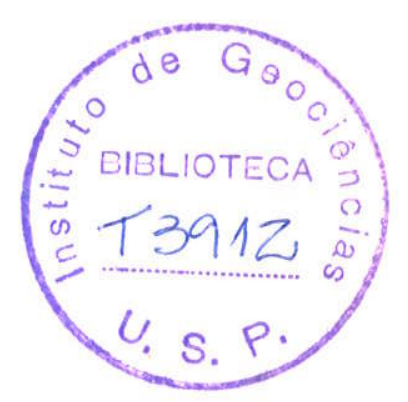

COMISSÃO JULGADORA

Nome

Presidente: Prof. Dr. Raphael Hypólito

Examinadores: Dr. Reginaldo Antonio Bertolo

Prof. Dr. Uriel Duarte

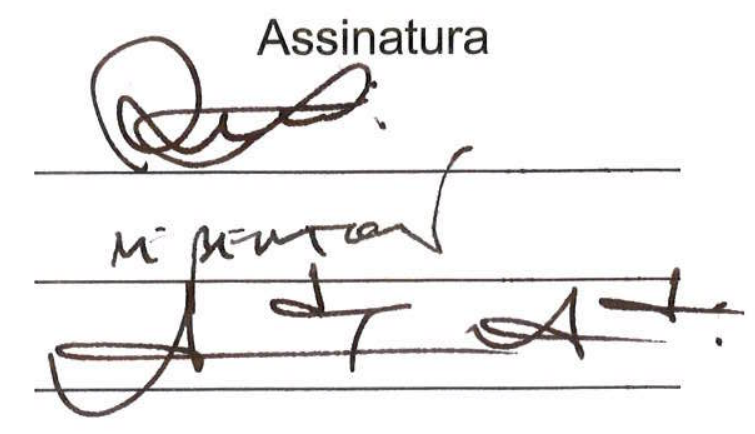

SÃO PAULO

2003 


\section{UNIVERSIDADE DE SÃO PAULO \\ INSTITUTO DE GEOCIÊNCIAS}

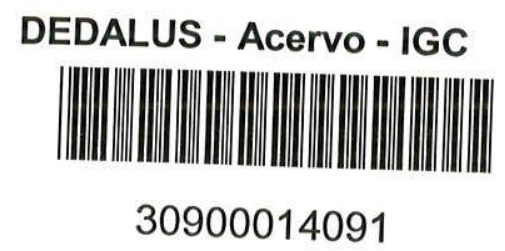

\section{COMPORTAMENTO DE ÍONS Pb, Zn E Cu EM ÁREA IMPACTADA POR ESCÓRIA, PRODUTO DA RECICLAGEM DE BATERIAS CHUMBO-ÁCIDO.}

Janaina Ferreira Marques

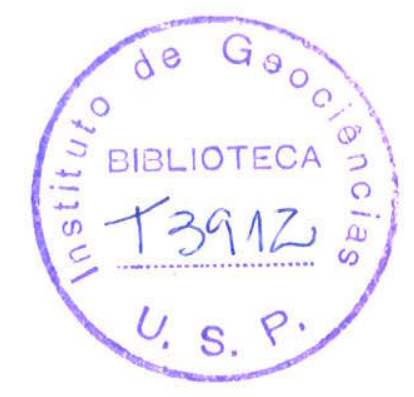

Orientador: Prof. Dr. Raphael Hypolito

DISSERTAÇÃO DE MESTRADO

Programa de Pós-Graduação em Recursos Minerais e Hidrogeologia

SÃO PAULO

2003 


\section{Marques, Janaina Ferreira}

Comportamento de íons $\mathrm{Pb}, \mathrm{Zn}$ e $\mathrm{Cu}$ em área impactada por escória, produto da reciclagem de baterias chumbo-ácido./ Janaina Ferreira Marques - São Paulo, 2003.

120p.:il.

Dissertação (Mestrado): IGc/USP

Orientador: Raphael Hypolito

1. Extrações Seqüenciais. 2. Metais Pesados. 3. Resíduo Sólido Industrial 4. Bateriais chumbo-ácido. 5. Título.

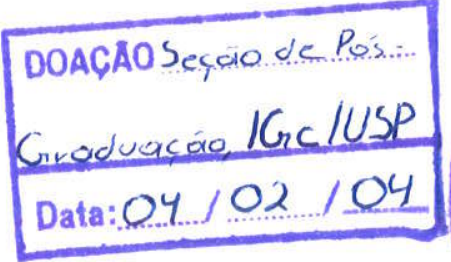


Nosso maior erro, a meu ver é pensar que a espiritualidade humana já tenha sido entendida e definida. Se a história nos diz alguma coisa, é que a cultura e o conhecimento estão sempre evoluindo. Somente as opiniões individuais são imutáveis e dogmáticas. A verdade é mais dinâmica, e a grande alegria da vida está em nos soltarmos, em descobrirmos a verdade especial e individual que cabe a cada um de nós contar, e depois observar a forma sincrônica pela qual esta verdade evolui e fica mais nítida, exatamente quando precisamos dela para influenciar a vida de alguém. Justos, estamos caminhando para algum lugar, cada geração se aprimorando graças às realizações da anterior, com um destino do qual temos apenas uma vaga lembrança. Estamos todos vivendo um processo de despertar e de abertura para descobrir quem realmente somos e o que viemos fazer neste mundo, tarefa às vezes dificílima. No entanto tenho a firme convicçấo de que, se integrarmos a melhor das tradições de nossos ancestrais e tivermos em mente o processo, a noção de milagre e destino nos fará superar os percalços do caminho e os atritos com o nosso próximo. Năo tenho intenção de minimizar os enormes problemas que a humanidade continua enfrentando. Apenas desejo sugerir que cada um de nós está à sua maneira envolvido na solução desses problemas. Se estivermos sempre conscientes e reconhecermos que esta vida é um grande mistério, veremos que cada um de nós está perfeitamente colocado, na posição exatamente certa...,para fazer toda diferença. 
Aos meus pais,

Eovard Marques e Anésia Ferreira Marques, cujo carinho e dedicação pode sustentar meu desenvolvimento desde a mais tenra idade, não só pela estrutura moral e material mas, sobretudo, pelo exemplo vivenciado no lar em todos os dias da minha vida.

É imensurável todo esse valor, assim como também é meu amor por vocêsi

Há, na história de todos nós, a presença constante de educadores que foram, são e serão nossos marcos mais significativos de referência.

Quando a Bíblia fala em anjos, nâo sel se refere-se d̀queles seres diáfanos, alados, imateriais, ou a essas criaturas divinas e tão humanas que mudam o curso de nossas existências.

Fui maravilhosamente agraciada com a presença de um deles, representado pelo Prof. Dr. Raphael Hypolito, orientador das minhas caminhadas não só científicas mas como também de vida. 


\section{AGRADECIMENTOS}

Ao Prof. Dr. Raphael Hypolito, são poucas as palavras para expressar os agradecimentos de toda a dedicação na sua segura orientação no decorrer deste trabalho, além da amizade $e$ companheirismo;

Aos meus pais, Anésia Ferreira Marques e Edvard Marques, agradeço por toda minha existência, auxilio, carinho, compreensáo, amor...acreditando que essa vitória é mais de vocês do que minha, espero sempre poder retribuir com muito mais ...

À Fundação de Amparo à Pesquisa do Estado de São Paulo - FAPESP (Processo: 01/1 1498-2), ao Centro de Aperfeiçoamento de Professores do Ensino Superior - CAPES e a Pró-Reitoria de PósGraduação da Universidade de São Paulo por viabilizarem economicamente este projeto;

Ao Curso de Pós-Graduação do Instituto de Geociências da Universidade de Säo Paulo e Centro de Pesquisa de Águas Subterrâneas (CEPAS), pela infra-estrutura oferecida;

Às secretárias da Pós-graduaçăo, Ana Paula e Magali, sempre muito gentis e alegres, não esquecendo da Rita (CEPAS) e também da Soninha (GSA);

À Promotora de Justiça Dra. Cristina Godoy de Araújo Freitas que viabilizou a coleta das amostras na área de estudos;

Aos policiais Calderaro, Luiz Carlos, Madona, Dorival e Valdeci do $3^{\circ}$ Pelotäo de Policiamento Ambiental - Săo José dos Campos pela segurança oferecida nos trabalhos de campo;

A todos os professores do Instituto de Geociências que colaboraram de uma forma ou de outra;

Ao Prof. Élio Lopes da Universidade Santa Cecília, pela ajuda indispensável, sempre muito gentil, atencioso, verdadeiro amigo;

Ao Seu Geraldo e Dona Marli, que não só abriram os portöes do Sítio Santa Rita como também as portas do coração:

À Lúcia Helena do Laboratório de Hidrogeoquímica !, pelas análises químicas e também pelo coleguismo do dia-dia;

Cleide e Sueli (Geoquímica/USP) e Flávio (Difração de raios X) pelos trabalhos realizados em laboratório:

Ao Paulinho e ao Sívio (CEPAS) pelos serviços de campo prestados e também pela amizade conquistada. Ao Biotita, sempre disposto a improvisar e realizar suas famosas "gambiarras";

Aos amigos pós-graduandos: Alexandra, Ivanety, José Coelho, Márcia, Val, Arłur (Metanol), George (Cece), Ivo, Mika, Cristiane (de balada e Congresso), Paula e Neide que muito contribuíram nos momentos "científicos" e de descontraçẵo;

À Claúdia (Valiser) e Zeca pela boa vontade e carinho em um dos momentos que mais precisei durante a dissertaçäo;

Aos amigos do Laboratório de Hidrogeoquímica III, Claudia, André, Marta, Douglas, Débora e principalmente à Marisa pelo apoio neste trabalho, sempre tão dedicada;

Às amigas Silvia (de balada e Congresso) e Sibele, inesquecíveis por participarem e orientarem o primeiro "frabalho de campo" e também pelo companheirismo e dedicaçäo, sempre amigas; 
Às geólogas Luciana Ferrer e Miriam Shieko Shinzato pela amizade, ensinamentos e atenção, sempre torceram pelo meu trabaho;

A todos os meus amigos (do ônibus), com quem tive o prazer de compartilhar o cotidiano de vinda à USP e com certeza os melhores momentos de descontraçáo durante todos esses anos (Fernanda, Glaciene, Bia, Ricardo, Edson, Renê, Carol, Patrícia, Alessandro (motorista), Adriana Yurie e Vânia) Em especial ao amigo Roberto (companheiro de banco a mais ou menos quatro anos) pelas fotos escaneadas e a "minha irmá gêmea" Adriana Rosemary pela amizade conquistada;

Ao Engenheiro mecânico Ubirajara, pelas palavas de ânimo, incentivo e progresso sempre presentes e a todos da minha família (tios e primos) que compartilharam comigo e com meus pais esta viłória;

À Engenheira civil Gisele, sempre tão atenciosa e amiga:

À advogada Catarina, o meu muito obrigado por todas as palavras de incentivo e companheirismo e também aos amigos João de Santa Bárbara, Graça e Gabriela sempre tão positivos em minha vida;

Ao jornalista Eduardo Cruz (meu namorado "DUDU") pelo incentivo, apoio e principalmente pela companhia durante todo o período deste trabalho;

À babá Eny e sua familia pela força e incentivo durante esses anos de curso;

Ao Joäo Curisco, Zé da Marinha, Maria Joana, Zé Baiano, sempre presentes neste trabalho;

Ao Vale do Sol, contribuindo de maneira essencial, progressiva e construtiva neste projeto.

A todas as pessoas que direta ou indiretamente contribuíram de alguma maneira para que este projeto pudesse ser realizado.

Ao meu Deus por todas as oportunidades, inclusive pela vida... 


\section{RESUMO}

$\mathrm{O}$ estudo da disponibilidade dos metais pesados $\mathrm{Pb}, \mathrm{Zn}$ e $\mathrm{Cu}$ nos diferentes compartimentos do solo, foi enfatizado através de Extrações Seqüencial e Total, tomando como estudo de caso uma Empresa de reciclagem de chumbo a partir de baterias chumbo-ácido, no Município de Jacareí.

Esta Empresa tem armazenado em seu pátio cerca de 150000 toneladas de rejeito, a céu aberto, diretamente no solo. São escórias resultantes do processo da reciclagem que formam pilhas, chegando a $10 \mathrm{~m}$ de altura. A ganga é constituída essencialmente por $\mathrm{Fe}$ e $\mathrm{Pb}$ metálicos, principalmente sob a forma de $\mathrm{S}^{2-}$, apresentando teores de $\mathrm{Zn}$ e Cu da ordem de $\mathrm{mg} \cdot \mathrm{kg}^{-1}$.

Para este trabalho, foram coletadas amostras sólidas (escória, solo e solo/sedimento) e líquidas (águas superficiais, subterrâneas e de chuvas).

O comportamento dos íons metálicos da escória foi estudado, simulando lixiviações naturais através do extrator do tipo sohxlet em experimentos com $\mathrm{H}_{2} \mathrm{O} e$ $\mathrm{H}_{2} \mathrm{O} / \mathrm{CO}_{2}$, mostrando claramente que o chumbo está muito mais disponível em relação ao zinco e cobre.

Devido a solubilidade dos ions de interesse em $\mathrm{HNO}_{3}$, principalmente o chumbo, estudou-se Extração Total do solo com esse ácido e os resultados obtidos mostrou altos teores de $\mathrm{Pb}^{2+}$ no material associado às pilhas de resíduos (foco da contaminação) e também nas porções superiores dos perfis estudados. Os teores de cobre e zinco apresentaram-se bastante baixos, certamente acham-se ligados aos produtos da ganga, portanto, não disponíveis.

A distribuição dos cátions $\mathrm{Pb}, \mathrm{Zn}$ e Cu no solo foi testada através de Extração Seqüencial pelo método TESSIER (1979). No entanto, o método não se mostrou adequado, através do somatório dos resultados parciais das Extrações Seqüenciais, apresentando valores superiores àqueles da Extração Total. Assim, buscou-se nova metodologia variando as seqüências de operação e utilizando novas condições de reação, que originou o método $\mathrm{RJ}$.

Os ions intersticiais, nos processos de lixiviação, são os mais disponiveis e os primeiros a migrarem para a zona saturada, assim sendo, foram realizados experimentos com lisímetros de sucção, comparados com o método RJ (Extração com água) e os resultados da Extração apresentaram-se superiores, indicando coleta quantitativa das soluções intersticiais com maior rapidez e representatividade. 
Graças as características do solo, que nem sempre representam o material original, a adsorção dos ions metálicos foi bastante variada. O chumbo apresentouse associado às frações carbonática e orgânica, o zinco encontra-se distribuído em todas as frações e o cobre à fração carbonática.

Apesar do fluxo descendente dos íons no solo ser muito lento sua migração é fortemente influenciada pela presença de eletrólitos, de íons complexantes e, principalmente, do $\mathrm{pH}$ uma vez que sua fixação ocorre principalmente junto aos carbonatos.

A influência do $\mathrm{pH}$ é ressaltada pela presença de $\mathrm{Pb}^{2+}$ nas águas subterrâneas e ausência de $\mathrm{Zn}^{2+} \mathrm{e} \mathrm{Cu}^{2+}$ devido a formação de óxidos/hidróxidos.

Dos cátions estudados, o chumbo é o que apresentou as maiores concentrações na área estudada e devido às suas características nocivas ao homem, pelo efeito cumulativo no organismo indica perigo potencial, uma vez que quaisquer alterações nas condições de $\mathrm{pH}$ e Eh do meio podem disponibilizá-lo tanto para águas superficiais como subterrâneas. 


\section{ABSTRACT}

The study of availability of $\mathrm{Pb}, \mathrm{Zn}$ and $\mathrm{Cu}$ heavy metals in differente sections of the soil was emphasized through Total and Sequential Extractions taking as case study a Company recycling lead from acid-lead batteries in the City of Jacarei - SP, Brazil.

This Company has around 150000 tons of waste stored in open dumps and put directly on the soil. These are slags resulting from recycling processes generating piles of $10 \mathrm{~m}$ in height. The gangue is essencially composed of metalic $\mathrm{Fe}$ and $\mathrm{Pb}$, specially in the form of $\mathrm{S}^{2-}$, presenting $\mathrm{Zn}$ and $\mathrm{Cu}$ levels of $\mathrm{mg} \cdot \mathrm{kg}^{-1}$.

For the purposes of this work, solid samples (gangue, soil and soil/sediment) and liquid samples (superficial, subterranean and rain waters) were collected.

The behavior of metalic ions of gangue was studied simulating natural lixiviations through a sohxlet extractor in $\mathrm{H}_{2} \mathrm{O}$ e $\mathrm{H}_{2} \mathrm{O} / \mathrm{CO}_{2}$ experiments, clearly showing that lead is much more available compared to zinc and copper.

Due to the interest ions solubility in $\mathrm{HNO}_{3}$, more specifically lead, we have studied the Total Extraction with this acid and results obtained showed high levels of $\mathrm{Pb}^{2+}$ in the material associated to the piles of waste (point of contamination) and superior portions of the studied profiles. Copper and zinc levels were very low, probably linked to the gangue products, thus unavailable.

$\mathrm{Pb}, \mathrm{Zn}$ and $\mathrm{Cu}$ cations distribution in the soil was tested through the Sequential Extraction through the TESSIER (1979) method. However, the method was not proven adequate through the sum of partial results of the Sequential Extractions, presenting superior values compared to values of Total Extraction. Therefore, a new technology was tried varying the sequence of operation and using new reaction conditions, which originated the $\mathrm{RJ}$ method.

Interstitial ions in the processes of lixiviation are the most available and the first to migrate to the saturated zone. Therefore, experiments with suction lisimeters were conducted for comparisons with the RJ method (Extraction with water) and the results of this Extraction were superior, indicating quantitative collection of interstitial solutions with higher speed and representativity.

Due to the soil characteristics - not always representative of the original material - the metalic ions adsortion varied very much. Lead was presented 
associated with organic and carbonatic fractions, zinc was found distributed among all fractions and copper was related to the carbonatic fraction.

Despite the low flow of ions in the soil, its migration is highly influenced by the presence of eletrolytes, complexing ions and, mainly $\mathrm{pH}$, since its fixation occurs mostly with the carbonates.

The $\mathrm{pH}$ influence is emphasized by the presence of $\mathrm{Pb}^{2+}$ in groundwater and absence of $\mathrm{Zn}^{2+} \mathrm{e} \mathrm{Cu}^{2+}$ due formation of oxide/hydroxide.

Among the studied cations, lead is the one to present higher concentrations within the studied area and due to its nocive characteristics and cumulative effect in the human body, it means potential danger, since any alterations in environmental $\mathrm{pH}$ and Eh conditions may turn it available to superficial and groundwater. 


\section{LISTA DE FIGURAS}

FIGURA 3.1.1: Mapa de localização e acessos à área de Estudos em Jacareí - SP. FIGURA 3.2.1: Bacia Taubaté e em detalhe a área de estudos.

FIGURA 3.2.2 a: Descrição dos perfis.

FIGURA 3.2.2 b: Localização das seções.

FIGURA 3.5.1: Pluviosidade acumulada média mensal de 1990 a 2000 em Jacareí.

FIGURA 3.7.1: Vista frontal da Empresa.

FIGURA 3.7.2: Cinturão verde junto a Empresa e o Sítio Santa Rita.

FIGURAS 4.1.1 a e b: Especiação do chumbo em função do $\mathrm{pH}$.

FIGURAS 4.1.2 a e b: Especiação do zinco em função do pH

FIGURAS 4.1.3 a e b : Especiação do cobre em função do $\mathrm{pH}$.

FIGURA 5.2.1: Operação de descarregamento de sucatas de baterias no galpão da Empresa

FIGURA 5.2.2: Fluxograma do processo de reciclagem de sucata das baterias chumbo-ácido.

FIGURA 5.3.1: Escória armazenada a céu aberto, no pátio da Empresa.

FIGURA 5.3.2: Transporte do efluente.

FIGURA 5.3.3: Pilha de rejeito com líquido, produto da lixiviação.

FIGURA 5.3.4: Tanque de rejeito.

FIGURA 5.3.5: Tanques da Estação de "tratamento".

FIGURA 6.1.1: Mapa de localização das amostragens de solo, solo/sedimento, águas superficiais, subterrâneas, efluentes e estação de tratamento na área de estudos.

FIGURA 6.2.1: Coleta de água no Rio Paratei $\left(A_{R P 1}\right)$.

FIGURA 6.2.2: Coleta de água na Lagoa $(\mathrm{AL})$.

FIGURA 6.2.3: Coleta de água subterrânea, no poço de monitoramento (P2) com amostrador do tipo bailer.

FIGURA 6.2.4: Poço cacimba ( $\left.\mathrm{PC}_{1}\right)$ no sitio Santa Rita.

FIGURA 7.1.1: Projeção dos dados granulométricos em diagrama Triangular de Sheppard em amostras sólidas da área de estudo.

FIGURAS 7.1.3: Difratogramas representativos das amostras do material sólido estudado.

FIGURA 8.1.1: Extratores do tipo sohxlet.

FIGURAS 8.1.2: pH da solução em função do somatório de volume lixiviado. 
LISTA DE FIGURAS

FIGURAS 8.1.3: Comportamento dos íons sódio e potássio em função do somatório do volume lixiviado.

FIGURAS 8.1.4: Concentração total $\left(\mathrm{mg}^{\left.-\mathrm{dm}^{-3}\right)}\right.$ de chumbo, zinco, cobre, $\mathrm{SO}_{4}{ }^{2-}, \mathrm{Cl}^{-} \mathrm{e}$ $\mathrm{NO}_{3}{ }^{2-}$ na solução lixiviada no topo, meio e base da pilha.

FIGURAS 8.2.1: Extração total de $\mathrm{Pb}$, Zn e Cu com $\mathrm{HNO}_{3} 0,1 \mathrm{M} ; 1,0 \mathrm{M} ; 3,0 \mathrm{M} ; 8,0$ $\mathrm{Me} 16,0 \mathrm{M}$ na amostra S-5 (fração $<2 \mathrm{~mm}$ ).

FIGURAS 8.2.2: Extração Total de $\mathrm{Pb}^{2+}$ nos perfis S-3, S-4, S-6, S-9 e S-11.

FIGURA 8.3.1: Difratograma da amostra SL evidenciando a predominância de quartzo e caulinita.

FIGURA 8.3.2: Projeção dos dados granulométricos em diagrama Triangular de Sheppard da amostra SL.

FIGURA 8.3.3: Média dos teores extraídos de $\mathrm{Na}^{+}, \mathrm{K}^{+}$e $\mathrm{Cu}{ }^{2+}\left(\mathrm{mg}^{2} \mathrm{dm}^{-3}\right)$ com fisímetro (amostra $\mathrm{AL}$ ) e com água (amostra $\mathrm{SL}_{45}$ ).

FIGURAS 8.3.4: Teores de $\mathrm{Na}^{+}$e $\mathrm{K}^{+}$em função do volume adicionado de água em 1,0000 e $3,0000 \mathrm{~g}$ da amostra S-5.

FIGURA 8.3.5: Teores de $\mathrm{Na}^{+}$e $\mathrm{K}^{+}$extraídos da amostra S-5 em função do tempo.

FIGURAS 8.3.6: Teores de $\mathrm{Pb}^{2+}, \mathrm{Zn}^{2+}$ e $\mathrm{Cu}^{2+}$ extraídos com $\mathrm{MgCl}_{2}, \mathrm{KCl}$ e $\mathrm{CaCl}_{2}$ em função dos volumes de soluções.

FIGURAS 8.3.6: Teores de chumbo, zinco e cobre $\left(\mathrm{mg} . \mathrm{dm}^{-3}\right)$ extraídos pelos métodos RJ e MT na amostra S-5.

FIGURA 8.3.7: Dados obtidos $\left(\mathrm{mg} \cdot \mathrm{dm}^{-3}\right)$, através de Extrações Seqüenciais (RJ), do perfil S-3.

FIGURA 8.3.8: Dados obtidos $\left(m g \cdot \mathrm{dm}^{-3}\right)$, através de Extrações Seqüenciais (RJ), do perfil S-4.

FIGURA 8.3.9: Dados obtidos $\left(\mathrm{mg} \mathrm{dm}^{-3}\right)$, através de Extrações Seqüenciais (RJ), do perfil S-6.

FIGURA 8.3.10: Dados obtidos $\left(\mathrm{mg}^{\mathrm{dm}}{ }^{-3}\right)$, através de Extrações Seqüenciais (RJ), do perfil S-9 (referência).

FIGURA 8.3.11: Dados obtidos $\left(\mathrm{mg}^{\mathrm{d} \mathrm{dm}^{-3}}\right)$, através de Extrações Seqüenciais (RJ), do perfil S-11. 
TABELA 3.3.1: Principais características dos aqüiferos locais.

TABELA 5.1.1: Materiais recicláveis presentes em baterias chumbo-ácido.

TABELA 5.2.1: Materiais utilizados (\%) na recuperação de chumbo a partir de sucata de bateria em forno rotativo

TABELA 5.3.1: Análise química da escória resultante da reciclagem do chumbo.

TABELA 7.1.1: Distribuição das frações granulométricas nos solos e solo/sedimento respectiva classificação textural de Sheppard e conteúdo de matéria orgânica.

TABELA 7.1.2: Constituintes mineralógicos das amostras na fração $<2 \mathrm{~mm}$.

TABELA 7.1.4: Valores de $\mathrm{pH}_{\mathrm{CaCl} 2}, \mathrm{pH}_{\mathrm{KCl}}$ e $\Delta \mathrm{pH}$ das amostras representativas S-A, S4, S6 e S9.

TABELA 7.1.5: Valores de CTC $\left(\mathrm{mmol}_{\mathrm{C}} \mathrm{dm}^{-3}\right)$ das amostras sólidas representativas.

TABELA 7.2.1: Dados físicos, químicos e físico-químicos, nos períodos de seca e chuva, das águas subterrâneas dos poços de monitoramento e tubular da Empresa.

TABELA 7.2.2: Dados físicos, químicos e físico-químicos de amostras de águas dos poços cacimba - Sítio Santa Rita (área de referência).

TABELAS 7.2.3: Resultados físico-químicos das amostras de águas superficiais.

TABELAS 7.2.4: Resultados químicos e físico-químicos das amostras dos efluentes 28 e da água "tratada".

TABELAS 7.2.5: Dados químicos $\left(\mathrm{mg}^{\mathrm{dm}} \mathrm{dm}^{-3}\right)$ das águas subterrâneas dos poços de monitoramento e tubular no periodo de seca (a) e chuva (b).

TABELAS 7.2.6: Resultado das análises químicas $\left(\mathrm{mg} \mathrm{dm}^{-3}\right)$ de amostras de águas dos poços cacimbas e de chuvas coletadas no Sítio Santa Rita período de chuva (a) e seca (b).

TABELAS 7.2.7: Dados químicos $\left(\mathrm{mg}^{\mathrm{d}} \mathrm{dm}^{-3}\right)$ das amostras de águas superficiais no periodo de chuva (a) e seca (b).

TABELAS 7.2.8: Dados químicos $\left(\mathrm{mg}^{\mathrm{dm}} \mathrm{dm}^{-3}\right)$ das amostras dos efluentes e da água "tratada" (chuva (a) e Seca (b)).

TABELA 8.1.1:Dados de $\mathrm{pH}\left(\mathrm{pH}_{\mathrm{H} 2 \mathrm{O}}\right.$ e $\left.\mathrm{pH}_{\mathrm{CO}}\right)$ e somatório do volume (L) nas soluções de lixiviação das amostras de escória da base $(E b)$, meio $(E m)$ e topo (Et) da pilha.

TABELAS 8.1.2: Teores de sódio e potássio $\left(\mathrm{mg}^{\mathrm{d}} \mathrm{dm}^{-3}\right)$ das soluções lixiviadas diariamente com água pura e gás carbônico. 
TABELA 8.1.3: Análise química total $\left(\mathrm{mg} \cdot \mathrm{dm}^{-3}\right)$ de $\mathrm{Pb}^{2+}, \mathrm{Zn}^{2+}, \mathrm{Cu}^{2+}, \mathrm{SO}_{4}^{2-}, \mathrm{Cl}^{-} \mathrm{e} \mathrm{NO}_{3}^{-}$

da solução lixiviada $\left(\mathrm{H}_{2} \mathrm{O}\right.$ e $\left.\mathrm{H}_{2} \mathrm{O} / \mathrm{CO}_{2}\right)$ nas amostras de escória do topo, do meio e da base.

TABELAS 8.2.1: Resultados (mg.dm ${ }^{-3}$ ) da Extração Total com $\mathrm{HNO}_{3} 0.1 \mathrm{M} ; 1,0 \mathrm{M}$;

$3,0 \mathrm{M} ; 8,0 \mathrm{M}$ e $16,0 \mathrm{M}$ nas frações $<2,00 \mathrm{~mm}$ (a) e $<0.063 \mathrm{~mm}$ (b) - amostra S-5.

TABELA 8.2.2: Resultado (mg.dm ${ }^{-3}$ ) da Extração Total com $\mathrm{HNO}_{3} 8 \mathrm{M}$ - amostras S3, S4, S-6, S-9 e S-11.

TABELA 8.3.1: Valores de $\mathrm{pH}, \triangle \mathrm{pH}$ e CTC $\left(\mathrm{mmol}_{\mathrm{c}} \mathrm{dm}^{-3}\right)$ da amostra SL.

82

TABELA 8.3.2 : Distribuição das frações granulométricas no solo da amostra SL e respectiva classificação textural de Sheppard (1954).

TABELA 8.3.3: Teores de $\mathrm{Na}^{+}, \mathrm{K}^{+}$e $\mathrm{Cu}^{2+}\left(\mathrm{mg} . \mathrm{dm}^{-3}\right)$ da extração dos íons intersticiais com lisímetro $(A L)$ e com água $\left(S L_{45}\right)$.

TABELA 8.3.4: resultados analíticos de extrações de $\mathrm{Na}^{+}$e $\mathrm{K}^{+}$da amostra S-5

$\left(\mathrm{mg} \cdot \mathrm{dm}^{-3}\right)$, com diferentes volumes de água e massas de $1,0000 \mathrm{~g}$.

TABELA 8.3.5: Influencia do tempo na extração de $\mathrm{Na}^{+}$e $\mathrm{K}^{+}$com água da amostra S-5.

TABELA 8.3.6: Reagentes e condições utilizados nas extrações de íns de metais 90 trocáveis com respectivas referências bibliográficas.

TABELA 8.3.7: Teores extraídos de chumbo, zinco e cobre com diferentes soluções de sais de $\mathrm{Mg}^{2+}, \mathrm{K}^{+}$e $\mathrm{Ca}^{2+}$, e respectivos $\mathrm{pH}$ de equilibrio.

TABELA 8.3.8: Resultados das análises químicas $\left(\mathrm{mg} . \mathrm{dm}^{-3}\right)$ das Extrações Seqüenciais da fração trocável, pelos métodos RJ, MT e TR.

TABELA 8.3.9: Resultados das análises químicas (mg. $\mathrm{dm}^{-3}$ ) das Extrações Seqüenciais da fração carbonática, pelos métodos RJ e MT.

TABELA 8.3.10: Resultados das análises químicas $\left(\mathrm{mg}^{\mathrm{d}} \mathrm{dm}^{-3}\right)$ das Extrações Seqüenciais da fração redutora, pelos métodos RJ e MT.

TABELA 8.3.11: Teores extraídos de chumbo, zinco e cobre da amostra S-5 - fração 99 orgânica.

TABELA 8.3.12: Resultados das análises químicas $\left(\mathrm{mg} . \mathrm{dm}^{-3}\right.$ ) das Extrações 99 Seqüenciais da fração orgânica, pelo método MT. 


\section{ÍNDICE}

\begin{tabular}{l|l}
\hline DEDICATORIA & i \\
AGRADECIMENTOS & ii \\
RESUMO & iv \\
ABSTRACT & vi \\
LISTA DE FIGURAS & viii \\
LISTA DE TABELAS & $x$ \\
1. INTRODUÇÃO & 1 \\
2. OBJETIVOS & 3 \\
3. LOCAL DE ESTUDOS & 4 \\
3.1 LOCALIZAÇÃO E ACESSO & 4 \\
3.2 GEOLOGIA & 6 \\
3.3 HIDROGEOLOGIA & 10 \\
3.4 GEOMORFOLOGIA & 11 \\
3.5 CLIMA & 12 \\
3.6 DADOS SÓCIO ECONÔMICOS & 13 \\
3.7 ÁREA DE PESQUISA & 13 \\
4. SINTESE BIBLIOGRÁFICA & 15 \\
4.1 METAIS PESADOS DE INTERESSE & 15 \\
5. RECICLAGEM DO CHUMBO & 22 \\
5.1 BATERIAS CHUMBO-ÁCIDO & 22 \\
5.2 RECICLAGEM DO CHUMBO NA EMPRESA ESTUDADA & 23 \\
5.3 ESCÓRIA & 27 \\
\hline
\end{tabular}


6. MATERIAIS E MÉTODOS

6.1 AMOSTRAS SÓLIDAS

6.2 AMOSTRAS LIQQUIDAS

7. RESULTADOS E DISCUSSÕES

7.1 AMOSTRAS SÓLIDAS

7.2 AMOSTRAS LÍQUIDAS

8. TRABALHOS EXPERIMENTAIS

8.1 EXTRAÇÃO COM SOHXLET

8.2 EXTRAÇÃO TOTAL DE CHUMBO, ZINCO E COBRE NO SOLO E 71 SOLO/SEDIMENTO

8.3 EXTRAÇÃO SEQUENCIAL DE CHUMBO, ZINCO E COBRE

9. CONCLUSÕES

10. BIBLIOGRAFIA 


\section{INTRODUÇÃO}

A contaminação por metais pesados em solos realiza-se através de mecanismos que regem sistemas ion $/ \mathrm{H}_{2} \mathrm{O} /$ solo; desta forma, torna-se imprescindivel ter como um dos instrumentos de estudos técnicas de Extrações Seqüenciais.

A área escolhida para estudo tem sofrido contínua contaminação pela disposição inadequada de resíduos sólidos industriais gerados por uma Empresa localizada no Município de Jacareí -SP. Esta tem como atividade principal a recuperação de chumbo, proveniente de baterias chumbo-ácido, para produção de ligas e lingotes do metal.

As fábricas de reciclagem das baterias surgiram para atender a RESOLUÇÃO CONAMA 257, que normaliza a reciclagem, tratamento e disposição final de resíduos CLASSE I (NBR-10004, ABNT 1987).

A tecnologia utilizada para recuperação do chumbo gera um de resíduo sólido que consiste numa escória classificada também como Classe I cujos contaminantes, além do chumbo, são ions de metais pesados como zinco, cobre e cádmio.

Todos os componentes das baterias chumbo-ácido, desde o chumbo metálico, seus sais e óxidos, até materiais plásticos, como ebonite, polipropileno etc. são recicláveis.

O chumbo é um dos metais mais utilizados na área industrial, sendo ultrapassado apenas pelo alumínio, cobre, zinco e ferro.

Atualmente, no Estado de São Paulo, as principais empresas de grande porte, licenciadas para operar plantas de fusão e refino de chumbo, são: Tonolli do Brasil, Acumuladores Ajax, Acumuladores Moura e Baterias Cral, Delphy Automotive Systems e Incometal Frey Stuchi. A maioria encontra-se autuada pelo Ministério Público acusada por crime ambiental por descartar, de maneira irregular, as escórias geradas no processo de reciclagem.

Neste trabalho, será dado destaque à contaminação ambiental gerada por uma Empresa que armazena em seu pátio, a céu aberto, diretamente no solo esse tipo de escória desde 1977.

O passivo ambiental é de 150000 toneladas de rejeito, formando pilhas de 3 a $10 \mathrm{~m}$ de altura.

O solo associado ao meio ambiente contaminado da Tonolli e suas circunvizinhanças tornou-se o principal meio receptor de íns metálicos poluentes 
que, através dos fenômenos hidrogeoquímicos de advecção, são transportados para as águas subterrâneas e superficiais, constituindo-se num excepcional sistema para estudos do comportamento, mobilidade e fixação desses metais.

Estudou-se o comportamento dos ions metálicos $\mathrm{Pb}, \mathrm{Zn}$ e $\mathrm{Cu}$ associados ao meio ambiente da Empresa objetivando determinar suas principais formas de associações e mecanismos de disponibilidade.

Foram analisadas quimicamente águas subterrâneas dos poços de monitoramento e testadas e desenvolvidas novas técnicas de extrações (seqüencial e total) dos íns metálicos nos diferentes componentes do solo. 


\section{OBJETIVOS}

Estudar o comportamento dos íons $\mathrm{Pb}, \mathrm{Zn}$ e $\mathrm{Cu}$ em solo, águas subterrâneas, superficiais e de chuvas em ambiente impactado por uma Empresa de reciclagem de chumbo, no Município de Jacareí - SP.

Selecionar, testar técnicas já conhecidas e adaptar novos métodos de Extrações Seletivas (Seqüencial e Total) para determinação dos mecanismos de fixação, mobilidade e distribuição de $\mathrm{Pb}^{2+}, \mathrm{Zn}^{2+}$ e $\mathrm{Cu}^{2+}$ no solo da área de estudos. 


\section{LOCAL DE ESTUDOS E CARACTERIZAÇÃO}

\subsection{LOCALIZAÇÃO E ACESSO}

O Município de Jacareí, onde localiza-se a área de estudos, está situado na porção leste do Estado de São Paulo, contido entre os paralelos $23^{\circ} 18^{\prime} 10^{\prime \prime} \mathrm{S}$ e os meridianos $45^{\circ} 17^{\prime} 31^{\prime \prime} \mathrm{W}$.

Localizado no médio Vale do Paraíba, a $78 \mathrm{~km}$ da cidade de São Paulo, tem como limite os Municípios de São José dos Campos, Santa Branca, Jambeiro, Guararema, Santa Isabel e Igaratá.

$\mathrm{O}$ acesso à área pode ser efetuado pelas Rodovias Presidente Dutra (BR 116) e D. Pedro I (SP 65) como mostra a FIGURA 3.1.1. 

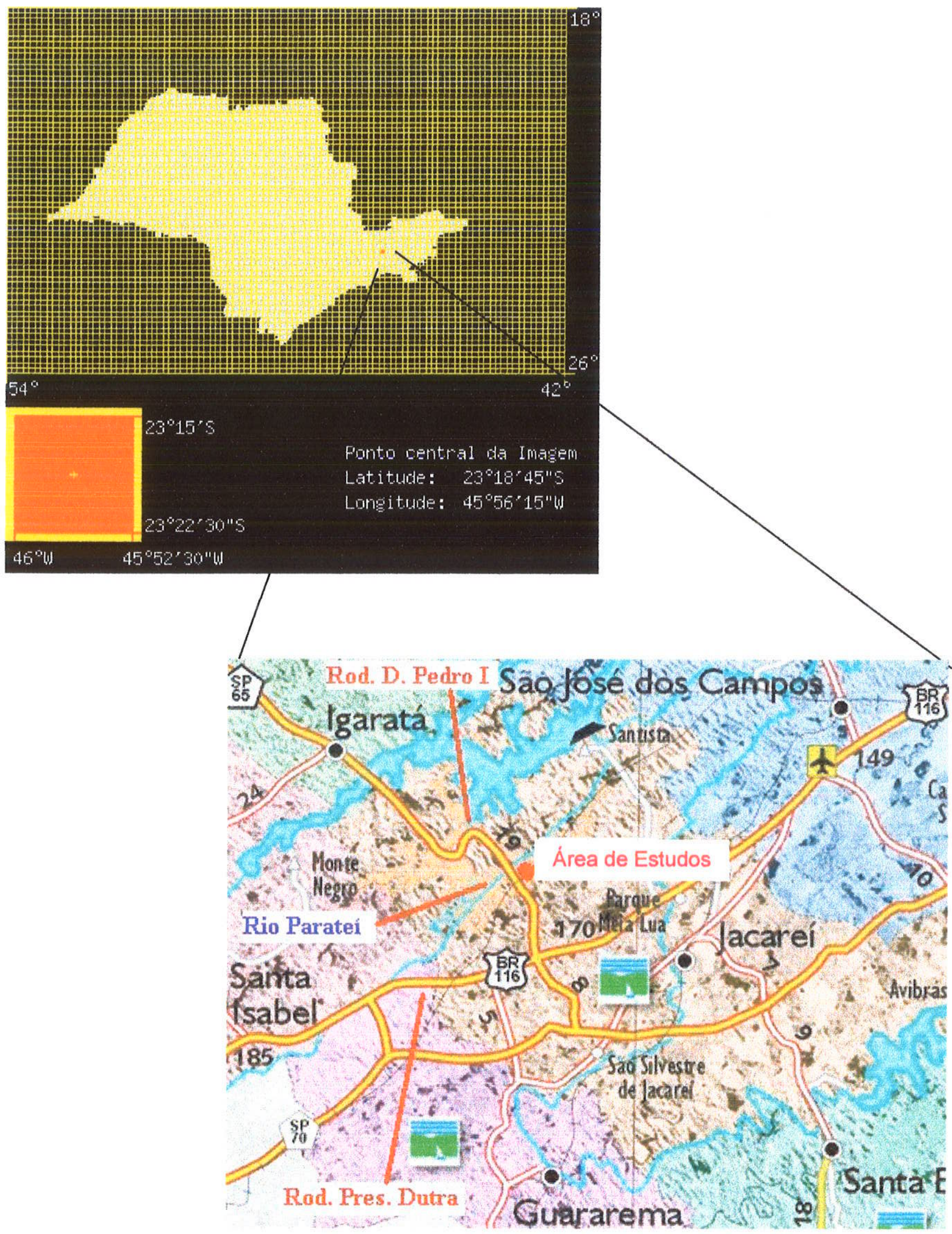

FIGURA 3.1.1: Mapa de localização e acessos à área de Estudos em Jacarei - SP.

Fonte: http://www.conelestepaulista.com.br/jacarei/mapas e : http://www.cdbrasil.cnpm.embrapa.br/ 


\subsection{Geologia}

A área de estudos insere-se num contexto geológico associado a bacia tectônica do Vale do Paraíba que se instalou sobre o embasamento cristalino Précambriano do Planalto Atlântico. Esta bacia denomina-se Taubaté e constitui-se predominantemente por sedimentos Terciários do Grupo Taubaté e aluviões Quaternários ou recentes (IPT, 1981a) (FIGURA 3.2.1).

O embasamento cristalino corresponde ao Complexo Embu (PS e M) - Grupo Açungui, no qual distinguem-se migmatitos heterogêneos e estruturas variadas com predomínio de estromatitos de paleossoma xistoso, gnáissico ou anfibotítico; migmatitos homogêneos variados, com ocorrência subordinada de corpos metabásicos (IPT, op.cit.).

O Grupo Taubaté é constituído por sedimentos pelíticos (folhelhos e argilitos) da Formação Tremembé ( $\mathrm{Tt}$ ) (inferior) e por sedimentos arenosos e siltosos da Formação Caçapava (superior) (IPT, op.cit.).

$\mathrm{Na}$ porção ocidental da bacia Taubaté, onde se situa a área de estudos, ocorre somente a Formação Caçapava (TQc), composta por depósitos fluviais incluindo arenitos e siltitos com lentes subordinadas pelíticas de cores cinza amarela e vermelha, apresentando termos arcosianos e conglomeráticos restritos (IPT op. cit).

Os aluviões Quartenários ocupam as calhas fluviais, planícies de inundação e terraços dos rios sobre os sedimentos Terciários e rochas pré-cambrianas. São sedimentos de naturezas diversas, geralmente inconsolidados e de granulação areno-argilosa e subordinadamente grosseiros (DAEE, 1977).

A COMPANHIA DE TECNOLOGIA DE SANEAMENTO AMBIENTAL (1999) realizou sondagens em toda área do terreno da Empresa para caracterização geológica e geotécnica, elaborando as seções SP-1 a SP-11 com descrição dos perfis (FIGURA 3.2.2a); o mapa de localização das seções é apresentado na FIGURA 3.2.2b, identificando, do topo para a base, uma seqüência de depósitos Coluvionares, Aluvionais e Sedimentos Terciários.

Estes sedimentos foram sobrepostos a um solo residual originado da alteração das rochas do embasamento cristalino. 


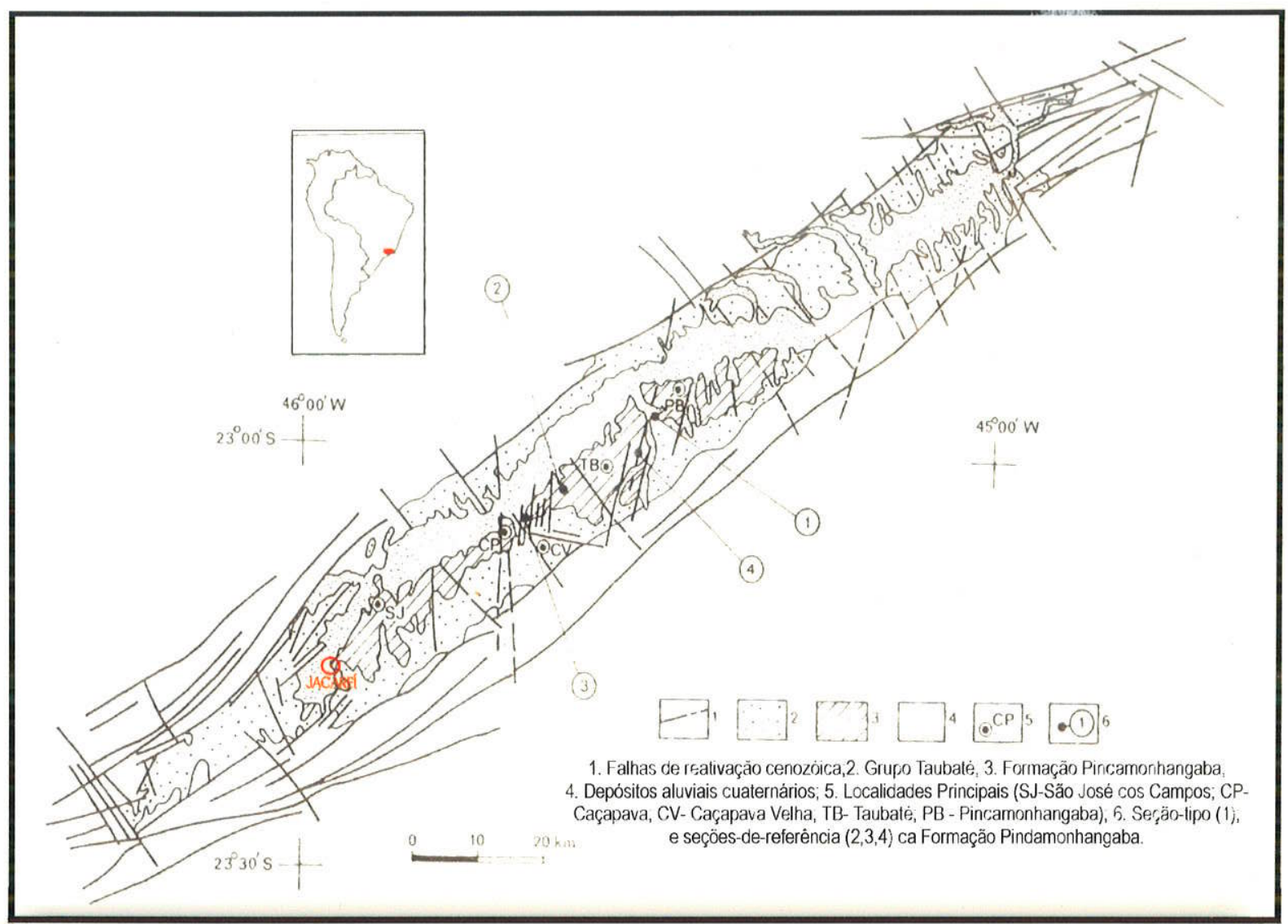

Fonte: RICCOMINI et. al (1991)

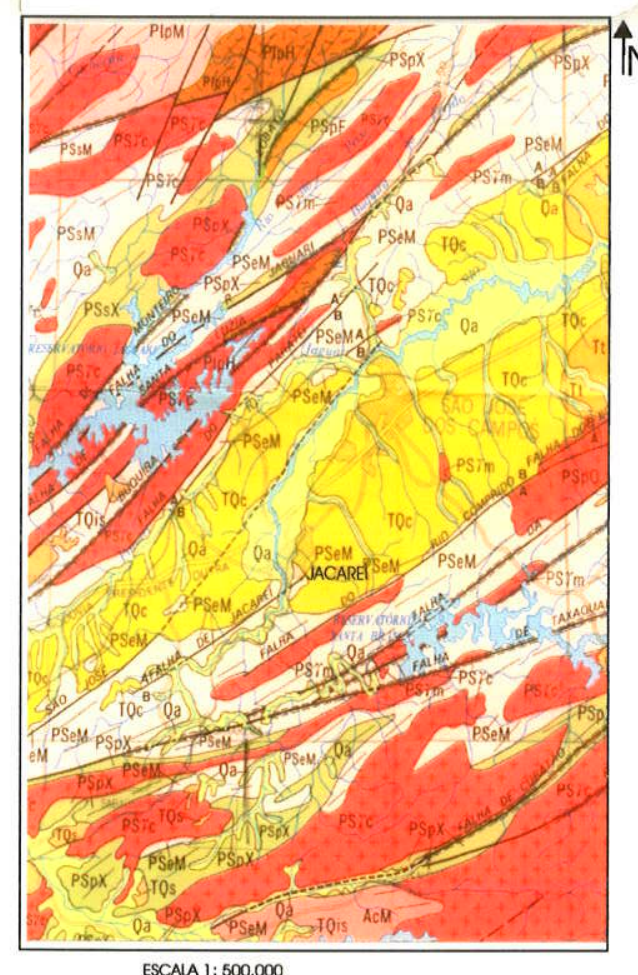

ESCALA 1: 500.000

PROJEÇÃO UNIVERSAL IRANSVERSA DE MERCATOR

Fonte: IPT (1981a)

\section{Legenda}

Qa Sedimentos Aluvionares Quaternários

TQc Formação Caçapava

Suítes Graníticas Sintectonicas:

Psic Fáceis Cantareira

Psom Fáceis Migmática

Grupo Açungui:

Psox Complexo Pilar

Psom Complexo Embu

FIGURA 3.2.1: Bacia Taubaté, em detalhe a área de estudos. 


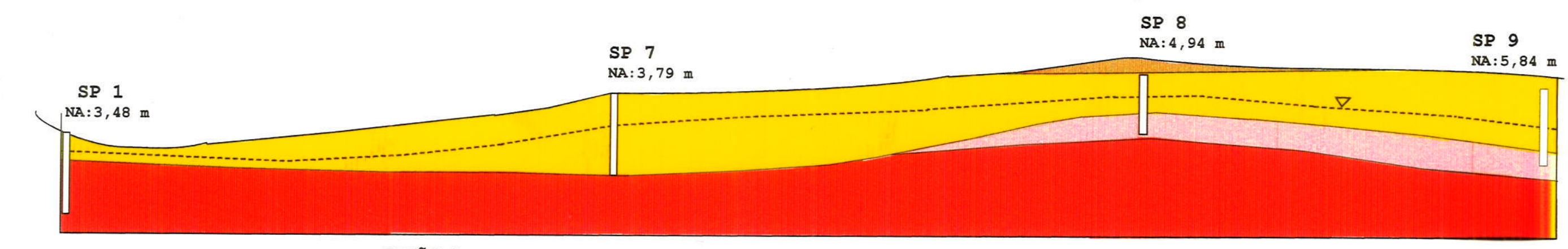

SEÇÃO A

ESC. H- $1: 100$

V: $1: 500$

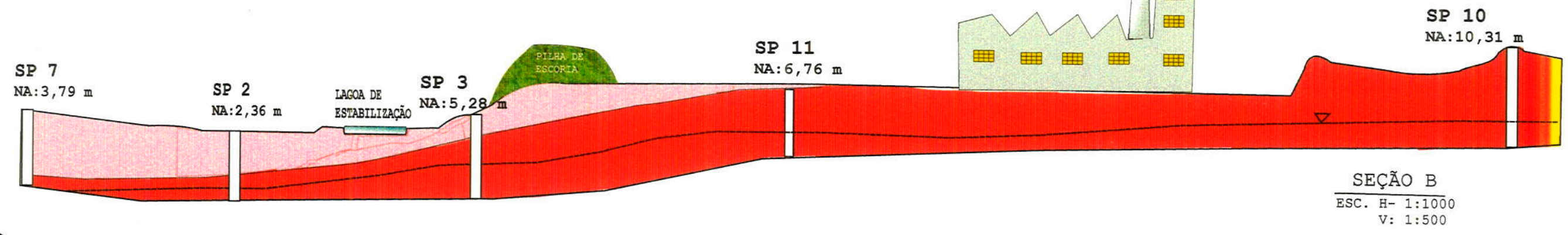

SP 8

$\mathrm{NA}: 4,98 \mathrm{~m} \quad \mathrm{SP} 4$

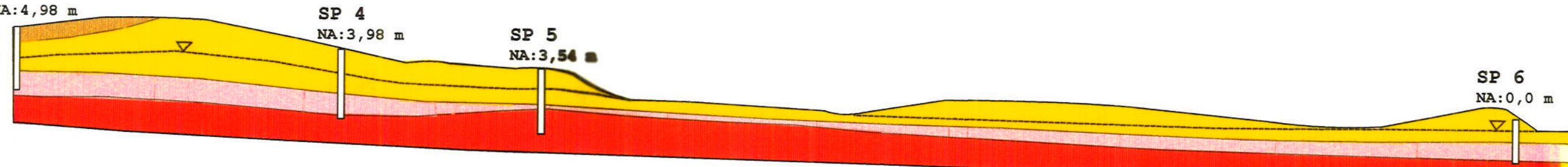

\section{Legenda}

Coluvião - Silte arenoso

Aluvião- argila siltosa com matéria orgânica/silte micáceo e argila siltosa pouco arenosa/areia fina e média siltosa cinza Sedimento Terciário- areia média/grossa, siltosa com pedregulhos finos, amarela e cinza e areia fina siltosa

Solo Residual-silte arenoso (fino), micáceo, vermelho e cinza a silte argiloso pouco arenoso

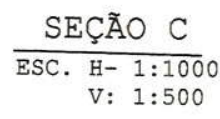

FIGURA 3.2.2 a: Descrição dos perfis das Seções SP-1 a SP-11

Fonte: modificado de CETESB (1999) Processo 38/ 00020/00, Folha 186 


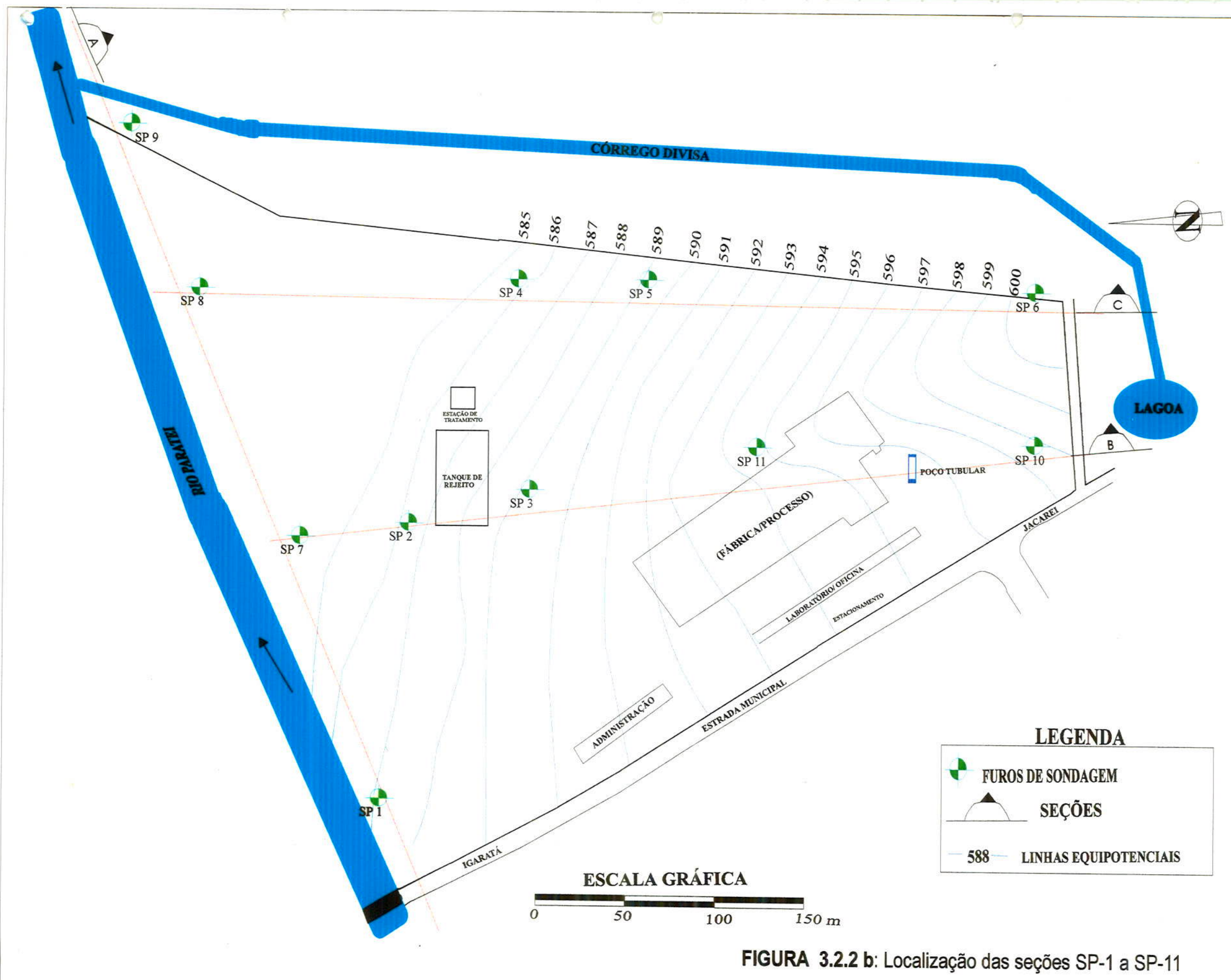

Fonte: modificado de CETESB (1999) Processo 38/00020/00 Folha 186 


\subsection{Hidrogeologia}

A hidrogeologia da área, cujas principais características encontram-se na TABELA 3.3.1 (CETESB, 1997), é formada por três aqüíferos: Cristalino, Taubaté e das Coberturas Cenozóicas.

TABELA 3.3.1: PRINCIPAIS CARACTERISTICAS DOS AQÜIFFEROS LOCAIS (CETESB, op. cit.).

\begin{tabular}{|c|c|c|c|}
\hline Aqüifero & Cristalino & Taubaté & $\begin{array}{l}\text { Coberturas. } \\
\text { Cenozóicas }\end{array}$ \\
\hline $\begin{array}{c}\text { Características } \\
\text { hidrogeológicas principais }\end{array}$ & $\begin{array}{r}\text { Extensão } \\
\text { regional; } \\
\text { fissurado; } \\
\text { descontinuo; } \\
\text { heterogêneo; } \\
\text { anisotrópico }\end{array}$ & $\begin{array}{l}\text { Extensão limitada; granular; } \\
\text { livre; descontínuo; } \\
\text { heterogêneo; anisotrópico }\end{array}$ & $\begin{array}{c}\text { Extensão limitada; } \\
\text { granular; livre a semi- } \\
\text { confl; descontínuo; } \\
\text { heterogêneo; anisotrópico }\end{array}$ \\
\hline Unidade Geológica & PS e M & $T Q C$ & Qa \\
\hline Espessura média (m) & 200 & 500 & 30 \\
\hline $\begin{array}{l}\text { Vazão média por poço } \\
\qquad\left(\mathrm{m}^{3} \cdot \mathrm{h}^{-1}\right)\end{array}$ & 5 a 30 & 15 a 20 & 1 a 30 \\
\hline $\begin{array}{l}\text { Capacidade especifica } \\
\left(m^{3} \cdot h^{-1} \cdot m\right)\end{array}$ & 0,001 a 7 & 0,01 a 2,0 & 0,1 a 5,0 \\
\hline Transmissividade $\left(m^{2} \cdot d^{-1}\right)$ & 0,1 a 200 & 0,5 a 100 & - \\
\hline $\begin{array}{l}\text { Permeabilidade aparente } \\
\qquad\left(m \cdot d^{-1}\right)\end{array}$ & - & 0,01 a 1 & - \\
\hline $\begin{array}{l}\text { Coeficiente de } \\
\text { armazenamento }\end{array}$ & - & 0,0001 a 1 & - \\
\hline $\mathrm{pH}$ & Ácido a neutro & 4,5 a 8,5 & - \\
\hline
\end{tabular}

Segundo o Plano Estadual de Recursos Hídricos (2003 a) as zonas aqüíferas do cristalino no embasamento pré-cambriano estão associadas a fraturas e falhas. Este aqüífero é explotado por cerca de 6500 poços, com profundidades variáveis de 50 a $150 \mathrm{~m}$ e vazões que atingem de 2 a $40 \mathrm{~m}^{3} \cdot \mathrm{h}^{-1}$ e média de $5 \mathrm{~m}^{3} \cdot \mathrm{h}^{-1}$.

$O$ aqüífero Taubaté é uma fossa tectônica na qual foram depositados argilitos, folhelhos e arenitos argilosos com intercalações delgadas de areias. No centro da bacia a espessura máxima do pacote sedimentar chega a $500 \mathrm{~m}$, no entanto o aqüífero é captado a profundidades que variam de 100 a $300 \mathrm{~m}$. Existem cerca de 1500 poços com vazão média de $15 \mathrm{~m}^{3} \cdot \mathrm{h}^{-1}$, variando de 10 a $270 \mathrm{~m}^{3} \cdot \mathrm{h}^{-1}$ que abastecem principalmente cidades e indústrias. 
Ainda, segundo o Plano Estadual de Recursos Hídricos (op. cit.) o aqǘfero do Cenozóico é composto por arenitos argilosos, argilas e areia com espessura média de 100 metros, podendo alcançar 230 metros com explotação superior a 8 mil poços tubulares com produtividade média de $6 \mathrm{~m}^{3} \cdot \mathrm{h}^{-1}$, que abastecem indústrias, hospitais, escolas, residências e condomínios.

A área de estudo situa-se na bacia do rio Parateí, afluente da margem direita do Rio Jaguari que deságua no rio Paraíba do Sul, pela sua margem esquerda, na altura da cidade de São José dos Campos (IPT, 1981a). Esta bacia de drenagem insere-se na UGRHI Paraiba do Sul.

Nas proximidades da área de estudos localiza-se uma lagoa com cerca de $250 \mathrm{~m}^{2}$ de espelho d'água que serve de carga para o Córrego Divisa; este córrego serve de limite a leste da Empresa.

\subsection{Geomorfologia}

No mapa geomorfológico do Estado de São Paulo é mencionado Jacareí como fazendo parte da Zona do Médio Vale do Paraiba, da Província Geomorfológica do Planalto Atlântico. Nela, o relevo de morros desenvolveu-se sobre rochas Pré-Cambrianas (Morros Cristalinos) e Colinas Sedimentares. Os tipos de relevo predominantes são: mar de morros, morros paralelos e planícies aluvionares. A decividade da região é média a alta, acima de 15\%; as amplitudes locais topográficas variam de 100 a $300 \mathrm{~m}$ (IPT, 1981b).

As encostas apresentam vertentes com perfis convexos a retilíneos com interflúvios arredondados e pouco expressivos com desenvolvimento restrito de planícies aluvionares interiores. A drenagem apresenta densidade alta com padrão dendrítico a retangular e vales abertos a fechados.

O Vale do Rio Parateí é conhecido por situar-se sobre a falha de mesmo nome e direção N45E, com caráter normal, com abatimento do Bloco Sul. Essa falha condiciona o contato entre terrenos do embasamento cristalino a noroeste e sedimentares a sudeste que marca forte contraste entre a morfologia mais movimentada do cristalino em relação aos terrenos sedimentares que são mais suaves (CETESB, 1999). 


\subsection{Clima}

O Município de Jacareí apresenta tipo climático temperado brando, com inverno seco e verão quente segundo Koppen.

A variação de temperatura apresenta grande uniformidade na distribuição durante $\mathrm{o}$ ano, ocorrendo as máximas em fevereiro e as mínimas em julho.

A temperatura média anual é de $18-20^{\circ} \mathrm{C}$ enquanto a mínima média é de 12 $14^{\circ} \mathrm{C}$ e a máxima média de $26-28^{\circ} \mathrm{C}$ (PLANO ESTADUAL DE RECURSOS HÍDRICOS, 2003 b).

A precipitação anual média é de 1360,8 mm com distribuição heterogênea, forte concentração no período de janeiro a março, outubro e dezembro e escassez nos demais períodos, elevando-se acentuadamente no período de junho a agosto conforme observar-se no gráfico da FIGURA 3.5.1 (PLANO ESTADUAL DE RECURSOS HÍDRICOS, op.cit.).

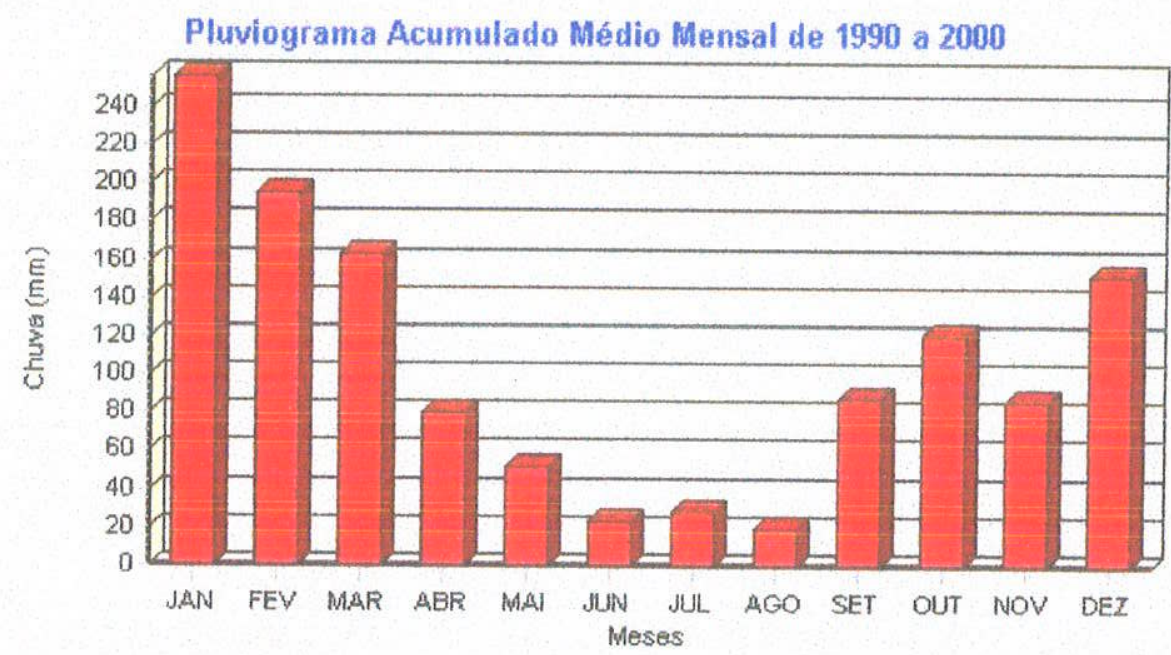

FIGURA 3.5.1: Pluviosidade acumulada média mensal de 1990 a 2000 em Jacarei.

Fonte: hitp://sigrh.sp.gov.br/cgi-bin/regnetexe/calcgeoott) 


\subsection{Dados Sócio Econômicos}

A cidade de Jacareí possui 191358 habitantes, dos quais 183444 moram na zona urbana e o restante, na zona rural. A área total do Município é $460 \mathrm{~km}^{2}$ apresentando densidade demográfica de 416,00 hab. $\mathrm{km}^{-1}$ (PREFEITURA MUNICIPAL DE JACAREÍ, 2003).

Jacareí é a cidade com o segundo maior índice de desenvolvimento do Vale do Paraiba, possuindo moderno complexo industrial, que abriga mais de 800 empresas, sendo 91 importadoras e 63 exportadoras.

\section{7 Área de Estudos}

A Empresa estudada (FIGURA 3.7.1), localiza-se próximo à Rodovia D. Pedro I no Município de Jacareí, SP.

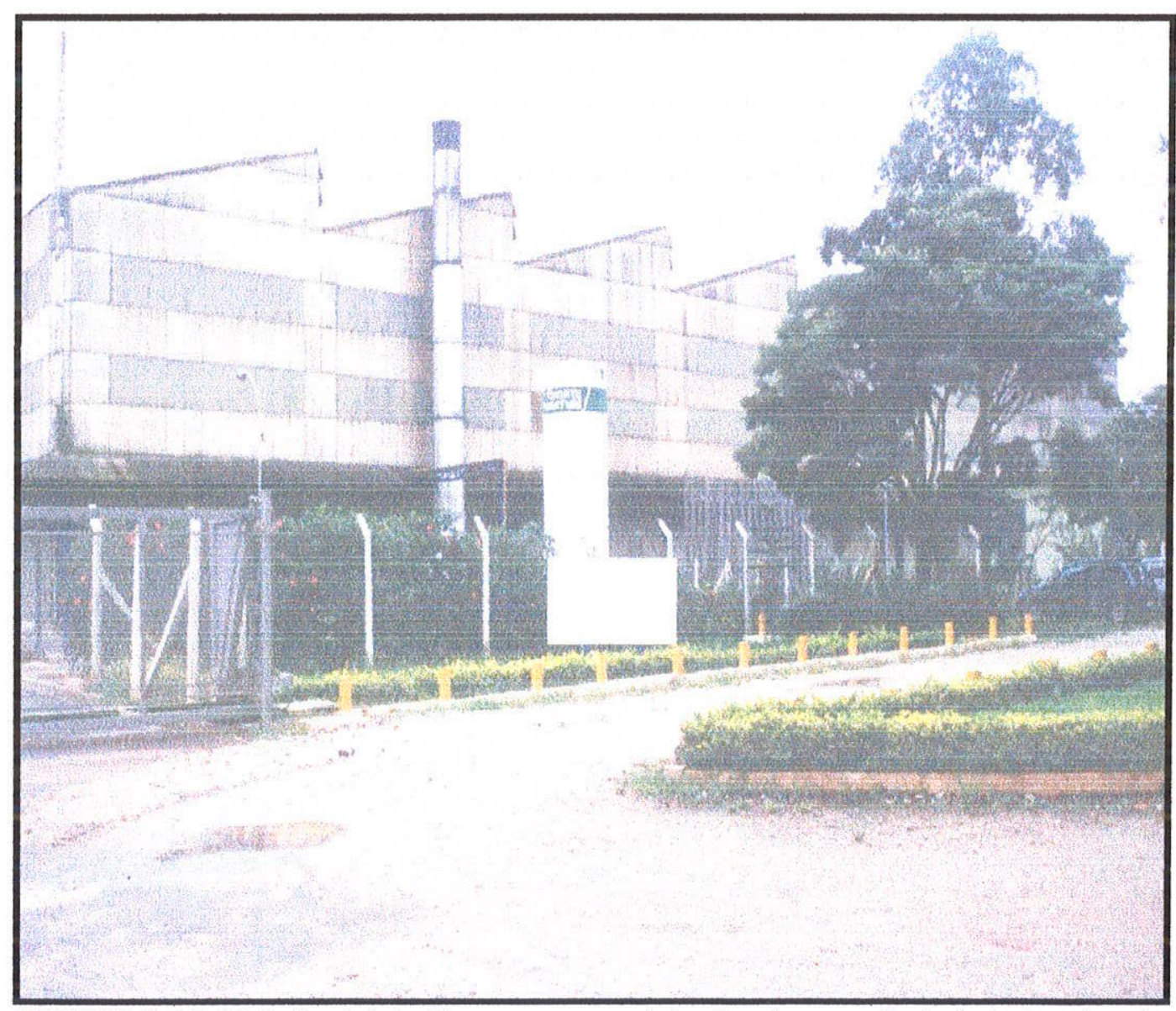

FIGURA 3.7.1: Vista frontal da Empresa que recicla chumbo a partir de baterias chumboácido. 
O terreno da Empresa apresenta forma trapezoidal cuja base corresponde ao limite norte da área da propriedade, representado pelo Rio Parateí e a base menor, ao sul, pela Estrada Municipal. A área ocupa uma porção central artificialmente aplainada para implantação da unidade, restando uma área mais elevada ao sul e outra mais baixa na periferia de norte a leste (FIGURA 3.2.2b).

A área industrial da Empresa foi implantada junto ao cinturão verde da região, sujeito às emissões aéreas de agentes poluentes (Figura 3.7.2). Esses produtos hortifrutigranjeiros são comercializados na região do Município de Jacareí e parte vendida ao CEAGESP, sem sofrer qualquer tipo de controle.

A área de Estudos compreende, além da Empresa e seus arredores, um sítio "Sítio Santa Rita" que faz divisa com a Empresa.

Localiza-se do lado superior a 100 metros da empresa (Figura 3.7.2.)

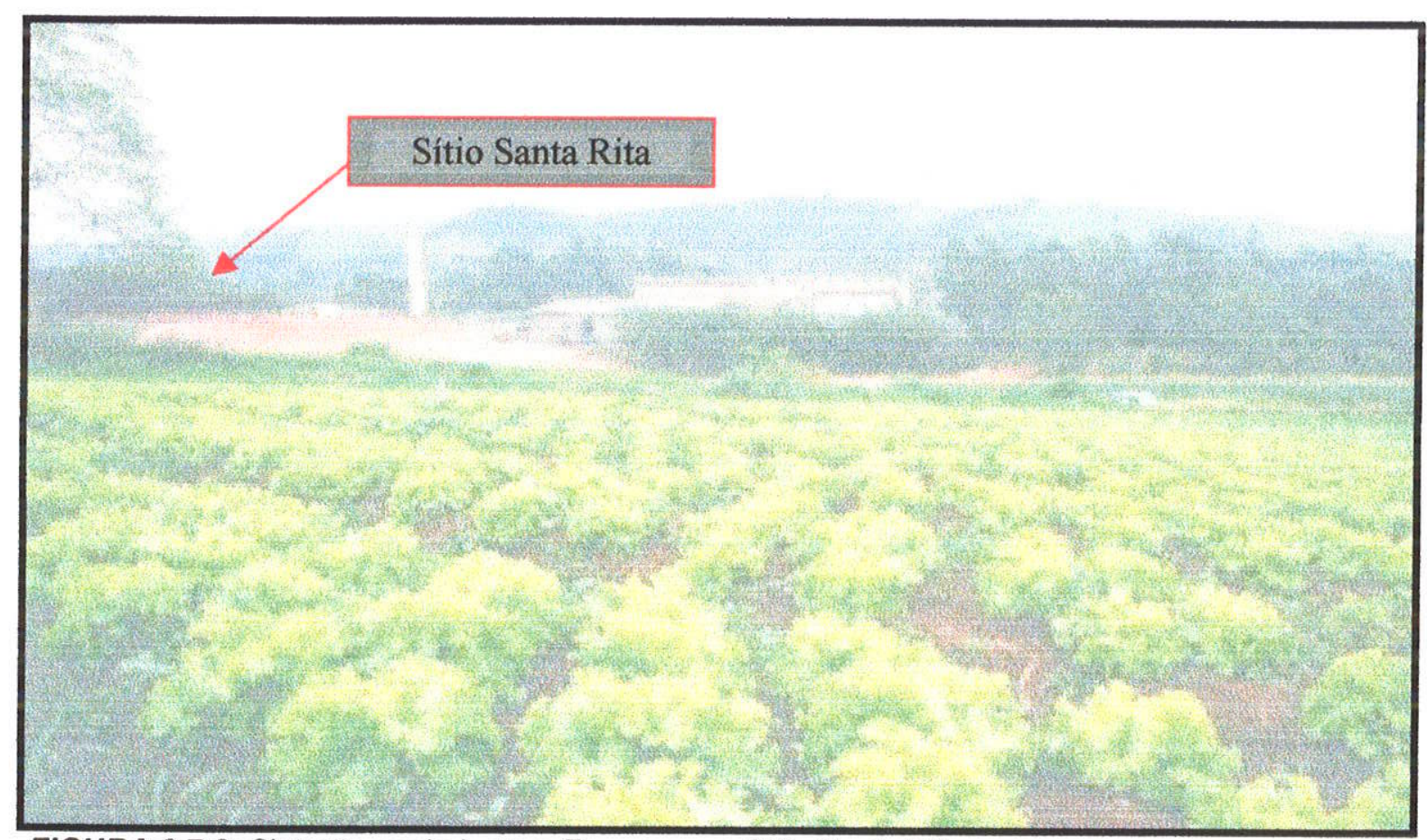

FIGURA 3.7.2: Cinturão verde junto a Empresa e o Sítio Santa Rita. 


\section{SÍNTESE BIBLIOGRÁFICA}

\subsection{METAIS PESADOS DE INTERESSE}

Associados à poluição ambiental encontra-se, quase sempre, o termo metal pesado que é aplicado a um grupo de elementos-traço considerados poluentes do ar, água, solo, alimentos etc. Metais pesados, neste trabalho, serão considerados apenas aqueles com densidades superiores a $5 \mathrm{~g}^{\mathrm{cm}} \mathrm{cm}^{-3}$ (HYPOLITO, 2003).

\section{Chumbo}

A presença de chumbo no solo se explica pela contribuição natural de rochas, através do intemperísmo e também por fontes antropogênicas.

No meio natural o mais importante dos minérios de chumbo é galena ( $\mathrm{PbS}$ ) cerusita $\left(\mathrm{PbCO}_{3}\right)$ e anglesita $\left(\mathrm{PbSO}_{4}\right)$, minerais de importância secundária.

As emissões antropogênicas são, principalmente, provenientes de atividades associadas à fusão e refino do metal, produção e uso de produtos contendo chumbo, queima de combustivel etc.

O chumbo pode ser transportado pelo ar associado a material particulado e espalhado por longas distâncias. Emissões muito elevadas chegam ser constatadas até $3 \mathrm{~km}$ de distância, a partir da fonte emissora (ALLOWAY, 1995).

O conteúdo de chumbo, oriundo por emissão aérea, na superfície dos solos em países do Hemisfério Norte, localizados em área industrial, chega a $120 \mathrm{~g} \cdot \mathrm{kg}^{-1}$ (Adriano,1986).

A textura dos solos, assim como a mineralogia são fatores de grande importância na disponibilidade dos íons metálicos de chumbo.

$\mathrm{Na}$ fase líquida, no meio natural, o chumbo ocorre, na grande maioria das vezes, sob a forma de chumbo (II) sendo sua estabilidade função de parâmetros como pH, Eh, concentração etc.

Os íns chumbo podem reagir com $\mathrm{CO}_{3}{ }^{2-}, \mathrm{PO}_{4}{ }^{3-}, \mathrm{SO}_{4}{ }^{2-}, \mathrm{Cl}^{-}$e S ${ }^{2-}$, insolúveis em água, tornando-se indisponível. A reatividade desses ânions, entretanto, depende essencialmente do $\mathrm{pH}$ e Eh do meio como, por exemplo, o chumbo que é estável na forma de $\mathrm{CO}_{3}{ }^{2-} \mathrm{em} \mathrm{pH}$ entre 6,0 e 11,0 . 
$\mathrm{Em} \mathrm{pH}<6, \mathrm{oS}^{-2}$ passa a formas mais solúveis como sulfatos e em $\mathrm{pH}>6,0$ o chumbo combina-se com $\mathrm{CO}_{3}{ }^{2-}$ e ainda pode formar hidróxidos insolúveis quando o pH torna-se bastante elevado. É encontrado sob a forma $\mathrm{Pb}^{2+}$ somente em $\mathrm{pH}<$ 0,4 (FIGURAS 4.1.1a e b).
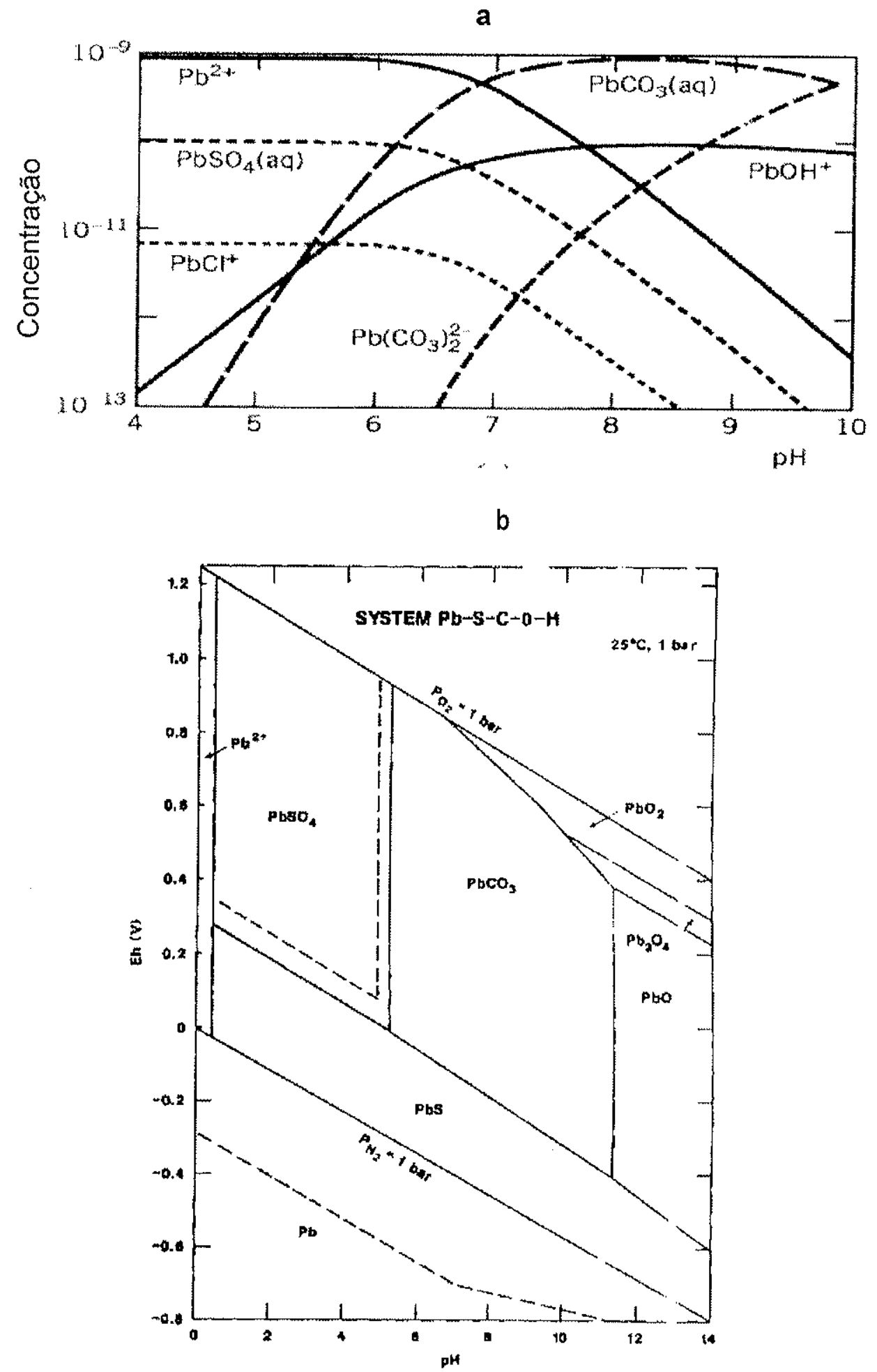

FIGURAS 4.1.1 a e b: Especiação do chumbo em função do pH. Fonte a: STUMM \& MORGAN (1996) e b: BROOKINS (1988). 
Os valores orientadores do chumbo para solos e águas subterrâneas, são respectivamente de $17 \mathrm{mg} \mathrm{kg}^{-1}$ e $0,01 \mathrm{mg} \cdot \mathrm{dm}^{-3}$ (CETESB, 2002).

Quaisquer que sejam as vias de absorção, o chumbo chega ao fígado; parte é excretada através da bile, outra parte é armazenada e uma terceira fração entra na circulação sob a forma de fosfato de chumbo depositando nos ossos (95\%), fígado, rim, baço, gengiva, cérebro, músculos etc. (SANTOS et al., 1992).

É um metal que tem efeito cumulativo no organismo, provocando doença crônica (saturnismo), cujos efeitos tóxicos podem ser exemplificados como hematológicos, neurológicos, encefalopatia com sintomas de coma e convulsões, efeitos sobre o sistema nervoso central, psicológicos, renais, mutagenecidade e sobre reprodução (PAOLIELLO et al., 2001).

Nos processos de descalcificação ou sob a ação de medicamentos, o chumbo ósseo pode ser mobilizado, ocasionando episódios agudos de intoxicação. (SANTOS et al., 1992).

\section{Zinco}

O zinco é um metal pesado que atende aos critérios de essencialidade para plantas e microorganismos, sendo classificado como micronutriente.

O zinco na litosfera é estimado em aproximadamente $80 \mathrm{mg} \cdot \mathrm{kg}^{-1}$ sendo a fonte mais abundante os sulfetos, como a esfalerita ( $\mathrm{ZnS}$ ) e wurtzita ( $\mathrm{ZnFeS}$ ) (ALLOWAY, 1995).

É usado na produção de ligas e galvanização de estruturas de aço. Uma das ligas mais importantes do zinco é o bronze - mistura com cobre.

Dentre seus compostos pode-se citar o óxido de zinco, utilizado nas indústrias cerâmicas e de borrachas e ainda na fabricação de tintas, sulfato que tem aplicação na indústria têxtil e no enriquecimento de solos pobres desse micronutriente. Sob a forma de cloreto é usado para preservar madeiras e também pode ser usado em pilhas secas.

Ele pode apresenta-se, sob a forma trocável, adsorvido nas partículas do solo, retido em sítios da matéria orgânica e de minerais não acessiveis aos extratores da fração trocável, ocluso em óxidos hidratados, precipitado e na rede cristalina de minerais primários e secundários (ADRIANO, 1986). 
Em ambientes redutores como, por exemplo, aqueles ricos em matéria orgânica, pode ocorrer liberação dos íns zinco adsorvidos devido a dissolução de óxidos de ferro e manganês. Em condiçōes ácidas o $\mathrm{Zn}^{2+}$ é, dentre os metais pesados, um dos mais solúveis (ALLOWAY, 1995).

Os valores orientadores para zinco no solo e na água subterrânea são respectivamente de $60 \mathrm{mg} \mathrm{kg}^{-1}$ e $5000 \mu \mathrm{g} \cdot \mathrm{dm}^{-3}$ (CETESB, 2002).

Os íons zinco reagem com $\mathrm{CO}_{3}{ }^{2-}, \mathrm{PO}_{4}{ }^{3-}, \mathrm{SO}_{4}{ }^{2-}, \mathrm{Cl}^{-}$e $\mathrm{S}^{2-}$ formando compostos insolúveis em água, tornando-se indisponivel. A reatividade desses ânions depende essencialmente do $\mathrm{pH}$ e Eh do meio (FIGURAS 4.1.2 a e b).

a

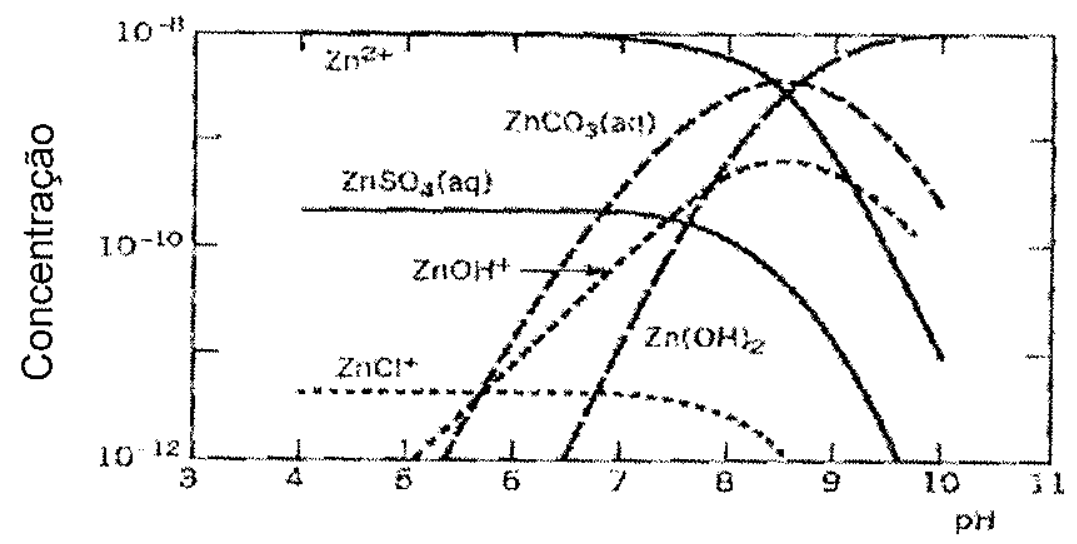

b

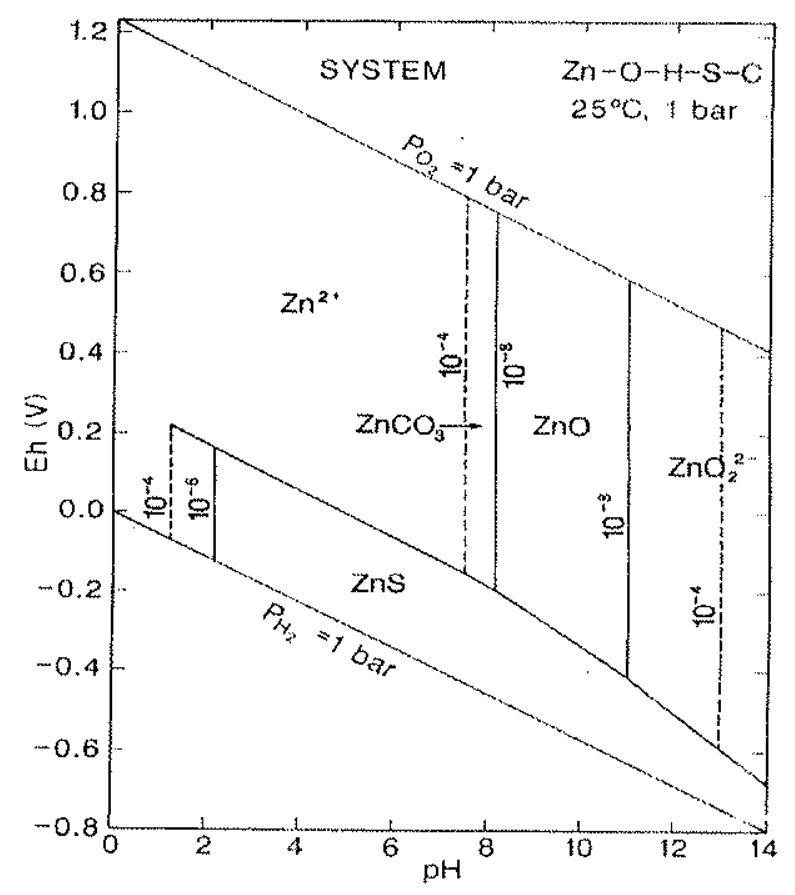

FIGURAS 4.1.2 a e b: Especiação do zinco em função do pH. Fonte a: STUMM \& MORGAN (1996) e Fonte b: BROOKINS (1988). 
$\mathrm{Na}$ agricultura, sis de zinco são usados como suplementos nutritivos promovendo crescimento de plantas. A concentração de zinco em fosfatos inorgânicos situa-se entre $50-1450 \mathrm{mg}^{\mathrm{kg}}{ }^{-1} \mathrm{e}$, em alguns pesticidas as concentrações são acima de $25 \%$. Este micronutriente desempenha papel vital no desenvolvimento animal - uma dieta rica em zinco, por exemplo, diminui riscos de hemorragias e melhora a cicatrização de feridas (ALLOWAY, 1995).

MATTIAZZO-PREZOTTO (1994) descreve que o zinco é importante em diversas funções enzimáticas, no metabolismo de carboidratos, na divisão e crescimento das células etc. A inalação de óxido de zinco pode provocar lesões nos pulmões e, de modo geral, em todo o sistema respiratório.

\section{Cobre}

O cobre, essencial à nutrição de plantas, também é considerado como micronutriente. Pequena quantidade deste ín na água potável é benéfica, tornando uma exigência do corpo humano para boa nutrição podendo, no entanto, apresentarse em caráter tóxico, quando presente em altas concentrações tanto na água como no solo (PEDROZO \& LIMA, 2001).

Para a maioria das espécies cultivadas, o cobre é tóxico quando a concentração foliar situa-se entre 20 e $30 \mu \mathrm{g} \cdot \mathrm{g}^{-1}$ (ROBSON \& REUTER, 1981).

McBRIDE (1994) menciona que a concentração média de cobre no solo é 20 $\mu \mathrm{g} \cdot \mathrm{g}^{-1}$ com variações entre de 6 e $80 \mu \mathrm{g} \cdot \mathrm{g}^{-1}$.

A calcopirita $\left(\mathrm{CuFeS}_{2}\right)$ é o principal minério de cobre e a calcocita $\left(\mathrm{Cu}_{2} \mathrm{~S}\right)$ é o mais rico dos sulfetos, com $80 \%$ em cobre (ALLOWAY,1995).

Os compostos de cobre apresentam vasto campo de aplicação, sendo utilizado como catalisador, agente dessulfurizante, como branqueador na indústria petrolífera, mordente na indústria têxtil, agente oxidante em corantes e fungicidas, pintura de cascos de navios, madeira ou aço, em baterias, eletrodos etc.

$\mathrm{Na}$ agricultura o $\mathrm{Cu}^{2+}$, sob a forma de $\mathrm{CuSO}_{4}$, é usado como fungicida, inseticida e como aditivo para solos; é utilizado para inibir o crescimento de algas em reservatórios, equipamento de irrigação, piscinas e sistemas de refrigeração industrial (WHO, 1998).

Apresenta, no solo, uma dinâmica bastante complexa e altamente afetada por inúmeros fatores do meio, como composições química, física e mineralógica do solo, 
quantidade de matéria orgânica, força lônica e $\mathrm{pH}$, afetando cargas superficiais influenciando a interação iônica. Em geral, o cobre associa-se aos carbonatos, óxidos/hidróxidos de ferro, manganês e alumínio, argilominerais etc. (McBRIDE, 1994).

A maior parte do cobre depositado no solo é oriundo da atmosfera resultado de aplicação agrícola e disposição de resíduos sólidos. (ADRIANO op.cit.).

As principais formas solúveis do cobre encontradas nas águas são $\left[\left(\mathrm{Cu}\left(\mathrm{H}_{2} \mathrm{O}\right)_{6}\right]^{2+},\left[\mathrm{Cu}\left(\mathrm{HCO}_{3}\right)\right]^{+}\right.$. Em valores de $\mathrm{pH}$ e concentração de carbonato característico de águas naturais a maior parte do $\mathrm{Cu}^{2+}$ dissolvido acha-se preponderantemente sob a forma de complexos e a sua reatividade depende essencialmente do $\mathrm{pH}$ e Eh do meio (FIGURAS 4.1.3 a e b).

a
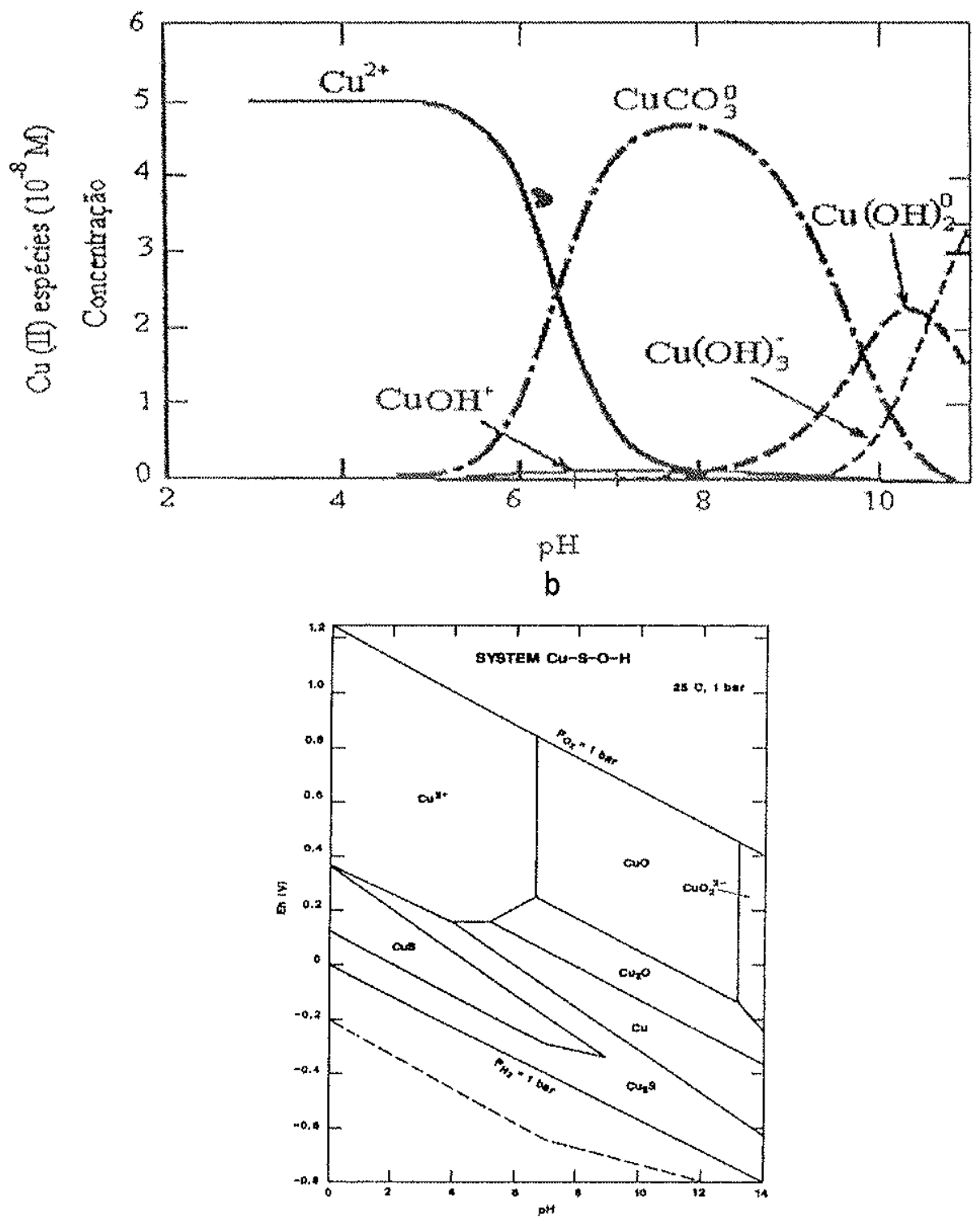

FIGURAS 4.1.3 a e b: Especiação do cobre em função do $\mathrm{pH}$.

Fonte a: PEDROZO \& LIMA (2001) e b: BROOKINS (1988). 
A exposição a poeiras e fumos de cobre pode irritar os olhos, nariz e garganta, provocando tosse, espirros e sangramentos nasais. Os fumos metálicos podem promover a "febre dos fumos", caracterizada por sintomas semelhantes à gripe associados ao sabor metálico na boca, febre e calafrios, broncoconstrição e tosse (BARCELOUX, 1999).

A exposição crônica pode levar a espessamento e esverdeamento da pele, dentes e cabelo. Em nível pulmonar, tem-se irritação das fossas nasais, úlceras e perfuração de septo, além de hepatoxicidade. Há evidências de carcinoma pulmonar entre trabalhadores e fundições que utilizam cobre (BARCELOUX, op.cit.). 


\section{RECICLAGEM DO CHUMBO}

\subsection{BATERIAS CHUMBO-ÁCIDO}

Baterias chumbo-ácido são destinadas a aplicações estacionárias (telecomunicações, usinas elétricas etc.), tracionárias (empilhadeiras, carrinhos para golfe, transporte de malas em aeroportos etc.), especiais (aplicações de caráter científico, médico etc.), genéricas (utilizadas em ferramentas e utensílios portáteis como alarmes domésticos contra incêndio ou roubo, luz de emergência etc.) e automotivas (energia em veículos automotores).

Nos países do ocidente, em $1993,53 \%$ do chumbo consumido foram oriundos da reciclagem de sucata; nos Estados Unidos esses valores chegaram a 96,5\% (LICCO, 2000) - as mais recicladas são baterias chumbo-ácido automotivas.

Sob condições ideais a bateria chumbo-ácido automotiva, possui vida útil de aproximadamente 6 anos. Elas são constituídas por um conjunto de elementos imersos em solução diluída de ácido sulfúrico e, como eletrodos, grelhas de chumbo metálico empastadas em mistura de $\mathrm{PbO}, \mathrm{Pb}$, água e ácido sulfúrico. Nessas grelhas o chumbo pode conter antimônio, arsênio, cádmio, cobre, cálcio, estanho; nelas são aplicados expansores como sulfato de bário, negro de fumo e lignina. (LICCO op. cit.).

$\mathrm{Na}$ TABELA 5.1.1 tem-se a porcentagem dos principais constituintes de uma bateria chumbo-ácido, lembrando que todos componentes são recicláveis.

TABELA 5.1.1: MATERIAIS RECICLÁVEIS PRESENTES EM BATERIAS CHUMBO-ÁCIDO.

\begin{tabular}{c|c}
\hline $\begin{array}{c}\text { MATERIAIS } \\
\text { RECICLÁVEIS }\end{array}$ & \% PESO \\
\hline $\begin{array}{c}\text { Chumbo (terminais, conectores, } \\
\text { placas positivas e negativas) }\end{array}$ & 17 \\
\hline Sais e óxidos de chumbo & 50 \\
\hline Plásticos ( tampa) & 5 \\
\hline $\begin{array}{c}\text { Caixa de ebonite e separadores de } \\
\text { placas }\end{array}$ & 4 \\
\hline $\begin{array}{c}\text { Eletrólito (solução diluída de ácido } \\
\text { sulfúrico) }\end{array}$ & 24 \\
\hline
\end{tabular}

Fonte: modificado de LICCO (2000). 


\subsection{RECICLAGEM DO CHUMBO NA EMPRESA ESTUDADA}

As baterias são recebidas e empilhadas parte em um galpão (FIGURA 5.2.1) e parte a céu aberto, permanecendo acumuladas diretamente sobre o solo sem proteção ácido-resistente e à mercê das águas de chuvas e vazamentos.

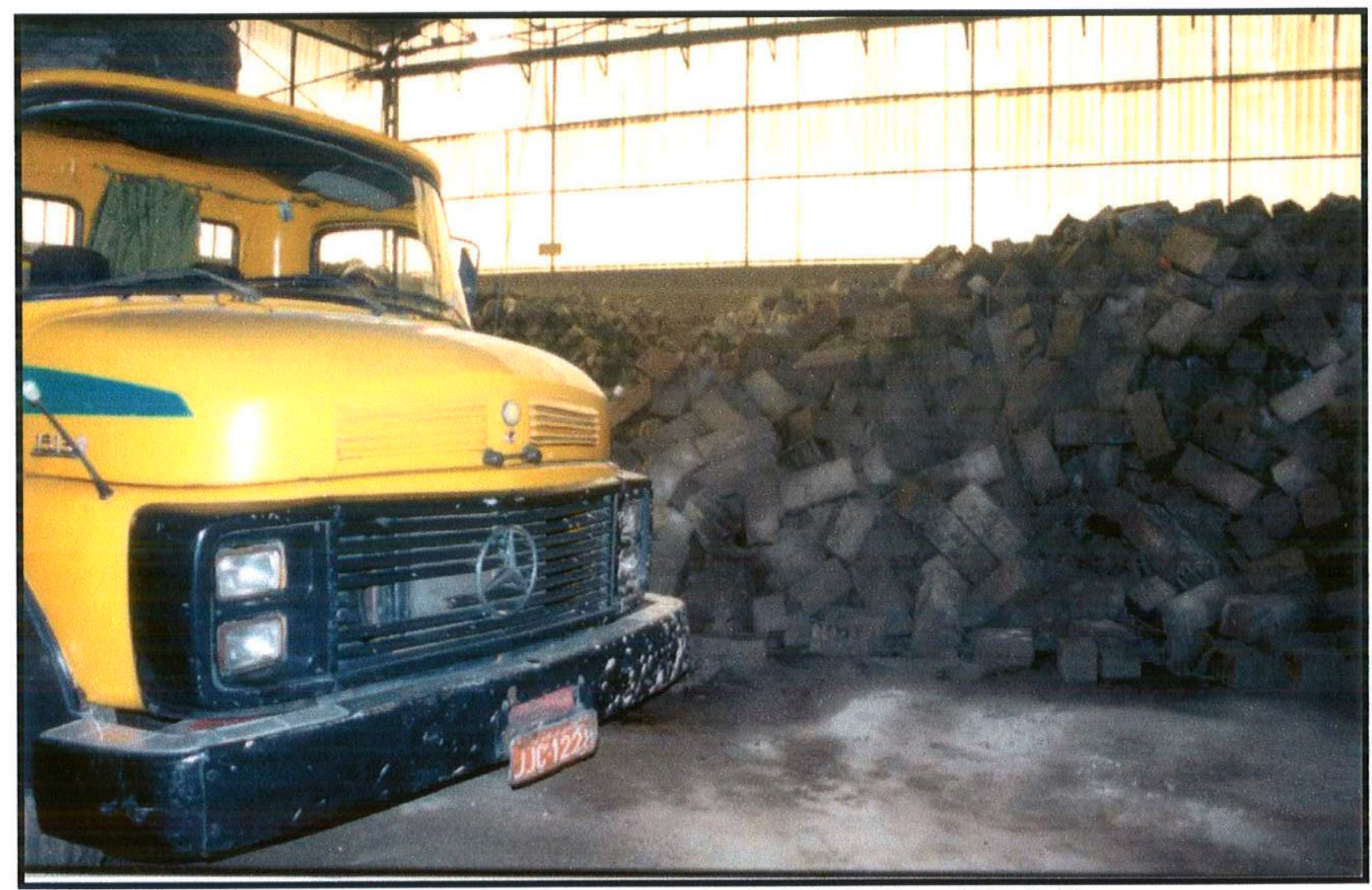

FIGURA 5.2.1: Operação de descarregamento de sucatas de baterias no galpão da Empresa. 
A abertura das baterias é mecanizada, nem sempre sofrendo separação da fração ácida.

São, em seguida, conduzidas a sistemas de moagem (moinho tipo martelos) e de peneiras rotativas e de classificação por diferença de densidade em tanques com água.

Os materiais plásticos são reduzidos a fragmentos menores que $50 \mathrm{~mm}$ fazendo parte de uma mistura, constituída por ácido, óxido e sais de chumbo e separada em peneira de $1 \mathrm{~mm}$.

O chumbo metálico é separado por flotação e a fase líquida, rica em sais, é destinada a um tanque onde sofre tratamento, gerando lodo que contém chumbo.

O processamento do chumbo é efetuado em fornos rotativos utilizando barrilha, carvão vegetal, sucata de ferro, vidro e calcário (TABELA 5.2.1). O consumo de cada um desses componentes é calculado com base no rendimento metálico da sucata que compõem a carga.

A preparação da carga que alimenta o forno é efetuada junto à planta de fusão, a partir de uma mistura calculada de sucata de chumbo e reagentes. É neste ponto que todas as matérias primas são descarregadas, dosadas e misturadas, de acordo com normas que orientam a composição da carga a ser processada no forno.

TABELA 5.2.1: MATERIAIS UTILIZADOS (\%) NA RECUPERAÇÃO DE CHUMBO A PARTIR DE SUCATA DE BATERIA EM FORNO ROTATIVO

\begin{tabular}{c|c}
\hline MATERIAL & CARGA (\%) \\
\hline Placas de baterias & 93.50 \\
\hline Minério de antimônio & 2.15 \\
\hline Barrilha & 1.00 \\
\hline Carvão vegetal & 1.40 \\
\hline Sucata de ferro & 1.50 \\
\hline Vidro (silicato) & 0.20 \\
\hline Calcário & 0.20
\end{tabular}

Fonte: modificado de LICCO (2000).

Nos fornos rotativos, a queima do óleo combustível fornece calor para secagem, aquecimento e fusão da carga.

Durante a fusão, pela ação do carbono, o óxido de chumbo é reduzido a chumbo metálico e o sulfato a sulfeto. 


$$
\begin{aligned}
& \mathrm{PbO}_{2(\mathrm{~s})}+\mathrm{C}_{(\mathrm{s})} \leftrightarrows \mathrm{Pb}_{(\mathrm{s})}+\mathrm{CO}_{2(\mathrm{~g})} \\
& \mathrm{PbSO}_{4(\mathrm{~s})}+4 \mathrm{C}_{(\mathrm{s})} \leftrightarrows \mathrm{PbS}_{(\mathrm{s})}+4 \mathrm{CO}_{(\mathrm{g})} \\
& \mathrm{PbSO}_{4(\mathrm{~s})}+2 \mathrm{C}_{(\mathrm{s})} \leftrightarrows \mathrm{PbS}_{(\mathrm{s})}+2 \mathrm{CO}_{2(\mathrm{~g})}
\end{aligned}
$$

O sulfeto de chumbo sofre redução a chumbo pela reação com carbonato de sódio.

$$
\begin{aligned}
& \mathrm{PbS}_{(\mathrm{s})}+\mathrm{Na}_{2} \mathrm{CO}_{3(\mathrm{~s})} \leftrightarrows \mathrm{PbO}_{(\mathrm{s})}+\mathrm{Na}_{2} \mathrm{~S}_{(\mathrm{s})}+\mathrm{CO}_{2(\mathrm{~g})} \\
& 2 \mathrm{PbO}_{(\mathrm{s})}+\mathrm{PbS}_{(\mathrm{s})} \leftrightarrows 3 \mathrm{~Pb}_{(\mathrm{s})}+\mathrm{SO}_{2(\mathrm{~g})}
\end{aligned}
$$

A sílica adicionada à carga, na forma de vidro, reage com o ferro formando silicatos que é removido na escória.

Ao final das reações da carga vaza-se primeiramente o chumbo diretamente nos fornos copellos de refino e posteriormente a escória.

O fluxograma da FIGURA 5.2.2 mostra, de modo esquemático, o processo de reciclagem da sucata de chumbo. 


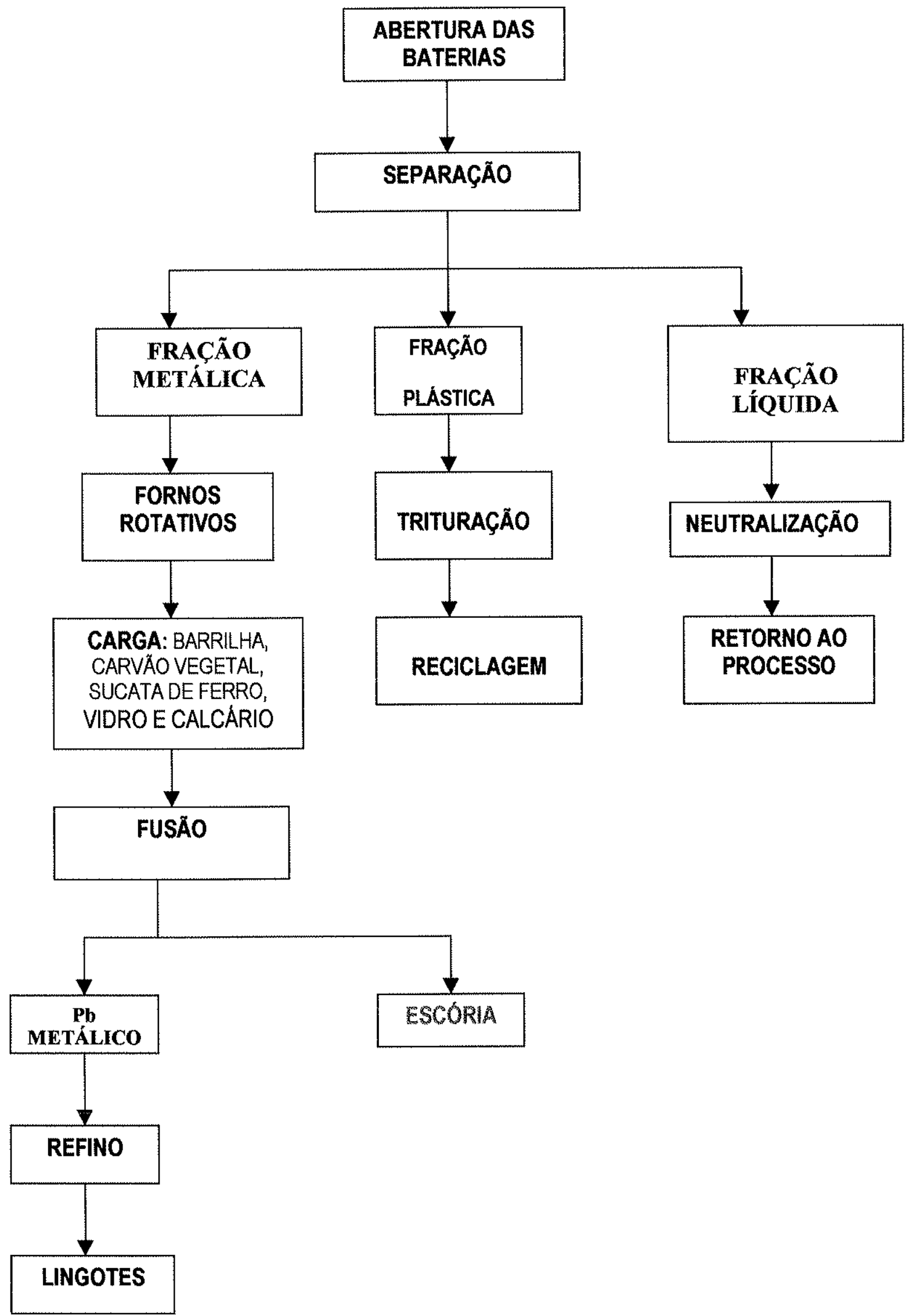

FIGURA 5.2.2: Fluxograma do processo de reciclagem de sucata das baterias chumbo-ácido. 


\subsection{ESCÓRIA}

A escória é retirada dos fornos rotativos, apresentando-se desde a forma em pó até blocos que chegam ser superiores a $1 \mathrm{~m}^{3}$. Possuem coloração acastanhada escura com tonalidades avermelhadas. Ela é armazenada no pátio da empresa, a céu aberto, ocupando uma área de cerca de $7000 \mathrm{~m}^{2}$ com altura que varia de três a dez metros (FIGURA 5.3.1).

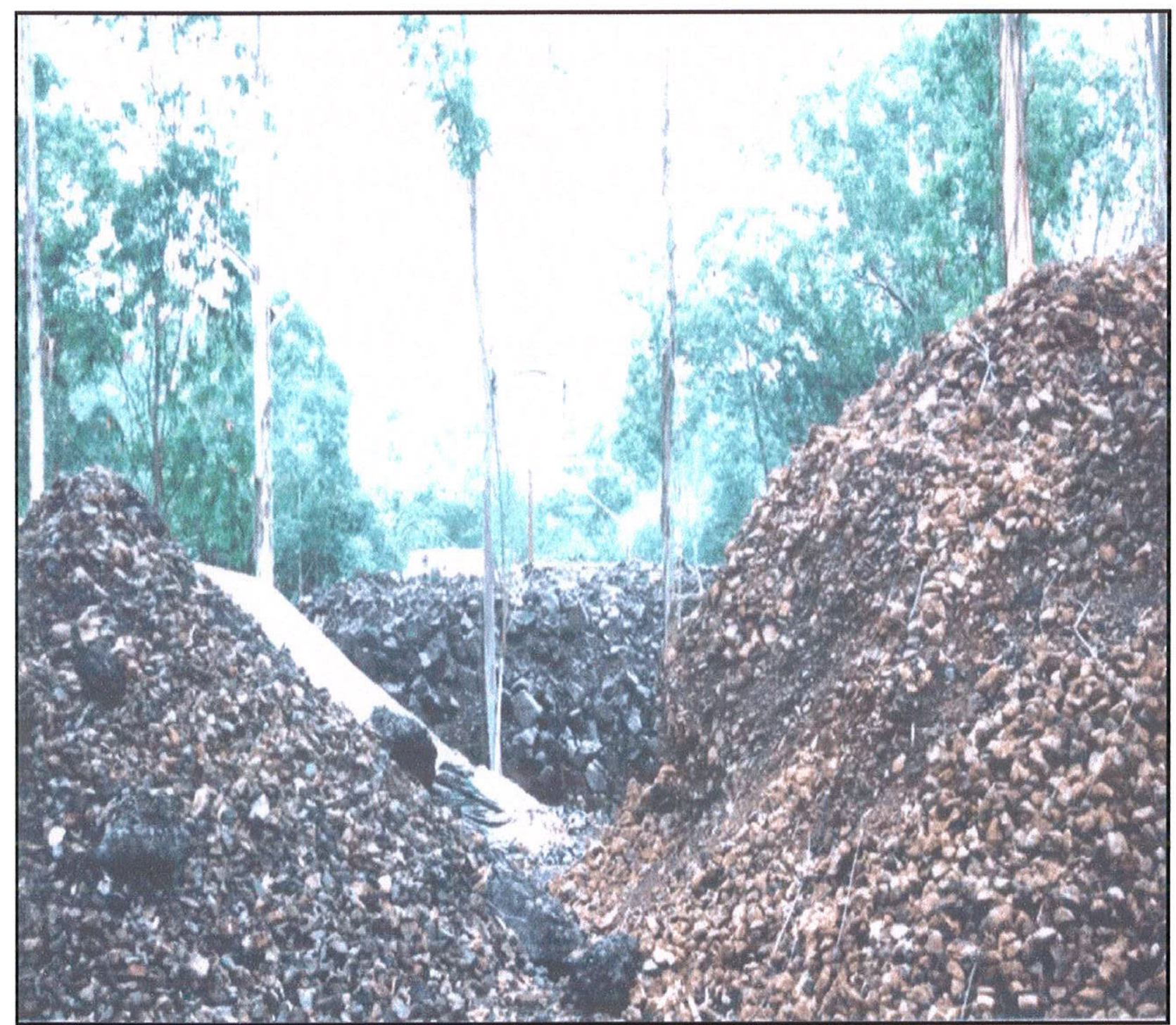

FIGURA 5.3.1: Escória armazenada a céu aberto, no pátio da Empresa. 
No local onde se armazena a escória, exala forte odor de gás sulfídrico que se intensifica nos períodos chuvosos.

As amostras da escória foram analisadas quimicamente e os resultados, sob a forma de porcentagem de íons, são apresentados na TABELA 5.3.1.

TABELA 5.3.1: ANÁLISE QUIMICA DA ESCÓRIA RESULTANTE DA RECICLAGEM DO CHUMBO.

\begin{tabular}{|c|c|c|c|c|c|c|c|c|c|c|c|c|c|c|c|c|}
\hline \multicolumn{11}{|c|}{ porcentagem (\%) } & \multicolumn{6}{|c|}{$\mathrm{mg} \cdot \mathrm{kg}^{-1}$} \\
\hline $\mathrm{Si}^{4+}$ & $\mathrm{Al}^{13+}$ & $\mathrm{Fe}^{3+}$ & $\mathrm{Ca}^{2+}$ & $\mathrm{Na}^{+}$ & $\mathrm{K}^{+}$ & $P$ & $\mathrm{Mn}^{2+}$ & $\mathrm{Mg}^{2+}$ & $\mathrm{Pb}^{+2}$ & $\mathrm{~S}^{2+}$ & $\mathrm{Cr}$ & $\mathrm{Cr}_{(t)}$ & $\mathrm{Ni}^{2+}$ & $\mathrm{Cu}^{2+}$ & $\mathrm{Zn}^{2+}$ & $\mathrm{Ba}^{2+}$ \\
\hline 4,14 & 0,84 & 46,2 & 2,78 & 0,68 & 0,13 & 0,10 & 0,23 & 0,64 & 5,29 & 5,60 & 573,00 & 811,00 & 331,00 & 2218,00 & 1100,00 & 1081,00 \\
\hline
\end{tabular}

Com objetivo de evitar emissão via aérea de material particulado, seguindo exigências da CETESB a Empresa instalou torniquetes com aspersão de água, que funcionaram em tempo integral por longo período. Este sistema gerou misturas líquidas que parcialmente infiltraram-se no solo e parte foi transportada, através de canaletas, a um tanque de efluentes para posterior tratamento. (FIGURAS 5.3.2, 5.3.3 e 5.3.4). 


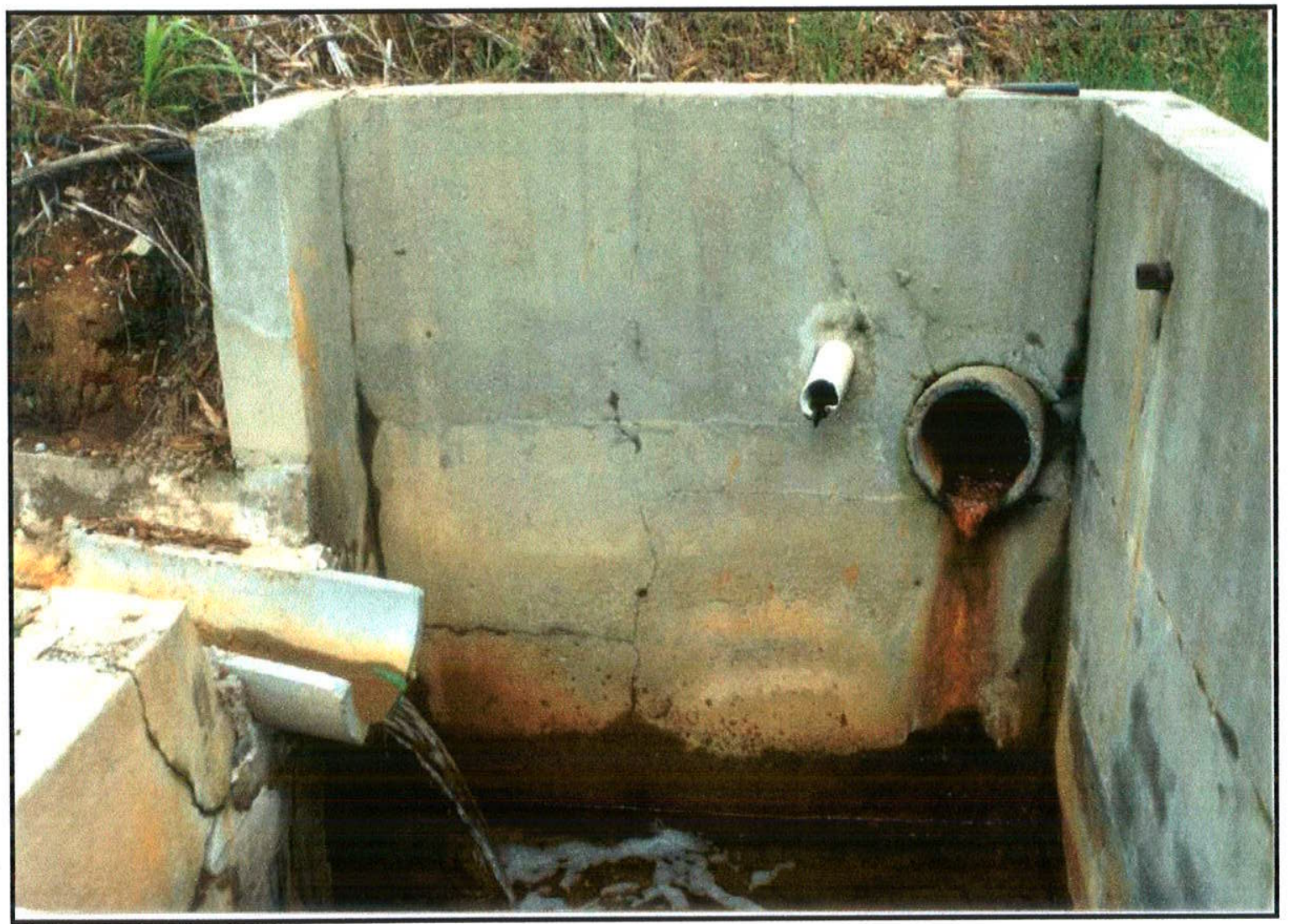

FIGURA 5.3.2: Entrada do efluente no tanque.

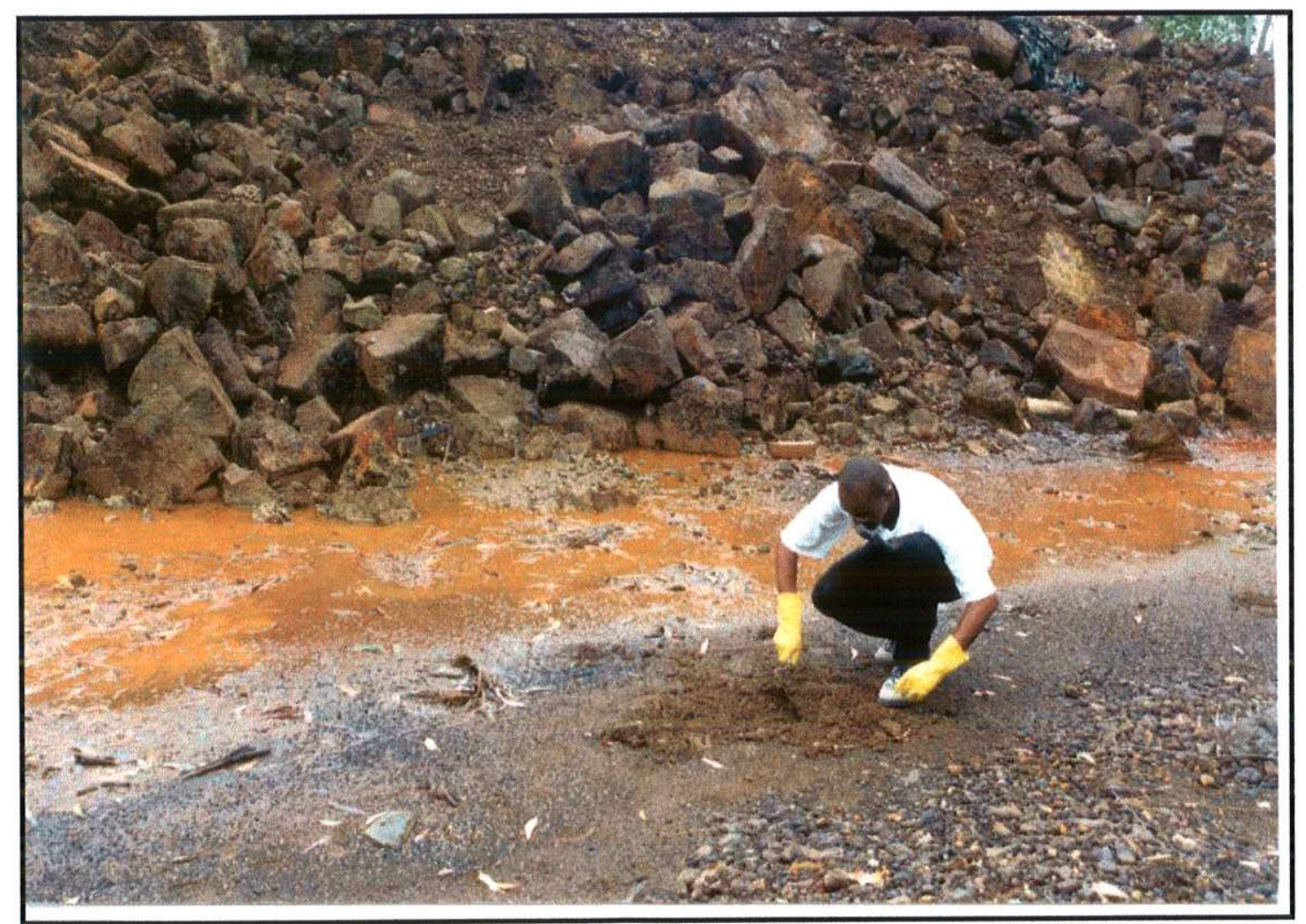

FIGURA 5.3.3:Pilha de rejeito com líquido, produto da lixiviação. 


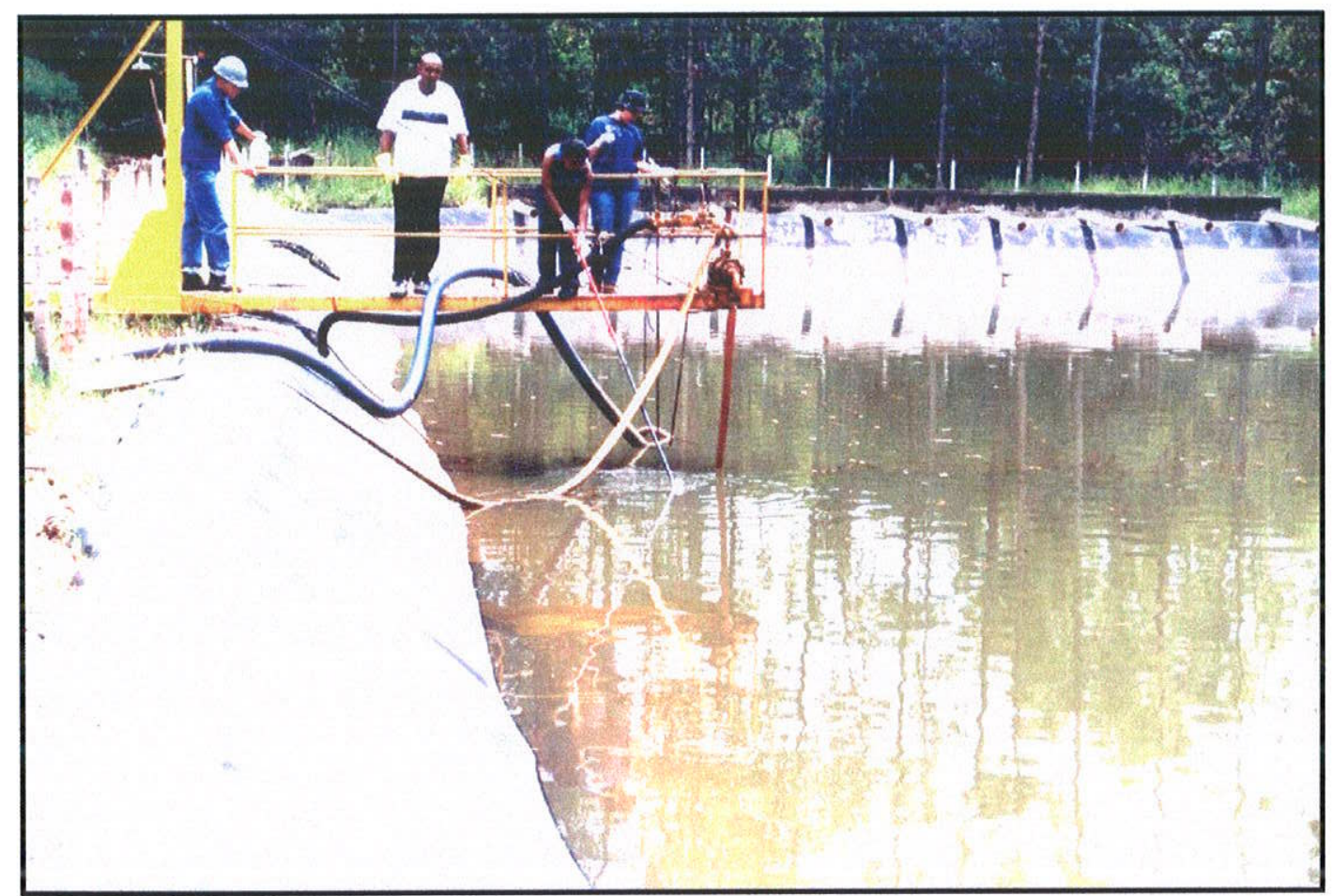

FIGURA 5.3.4: Tanque de rejeito.

Por bombeamento o efluente é levado a uma, muito precária, estação de tratamento, situada ao lado do tanque de rejeitos que, depois de "tratado", é descartado no Córrego Divisa por tubulações subterrâneas (FIGURA 5.3.5). 


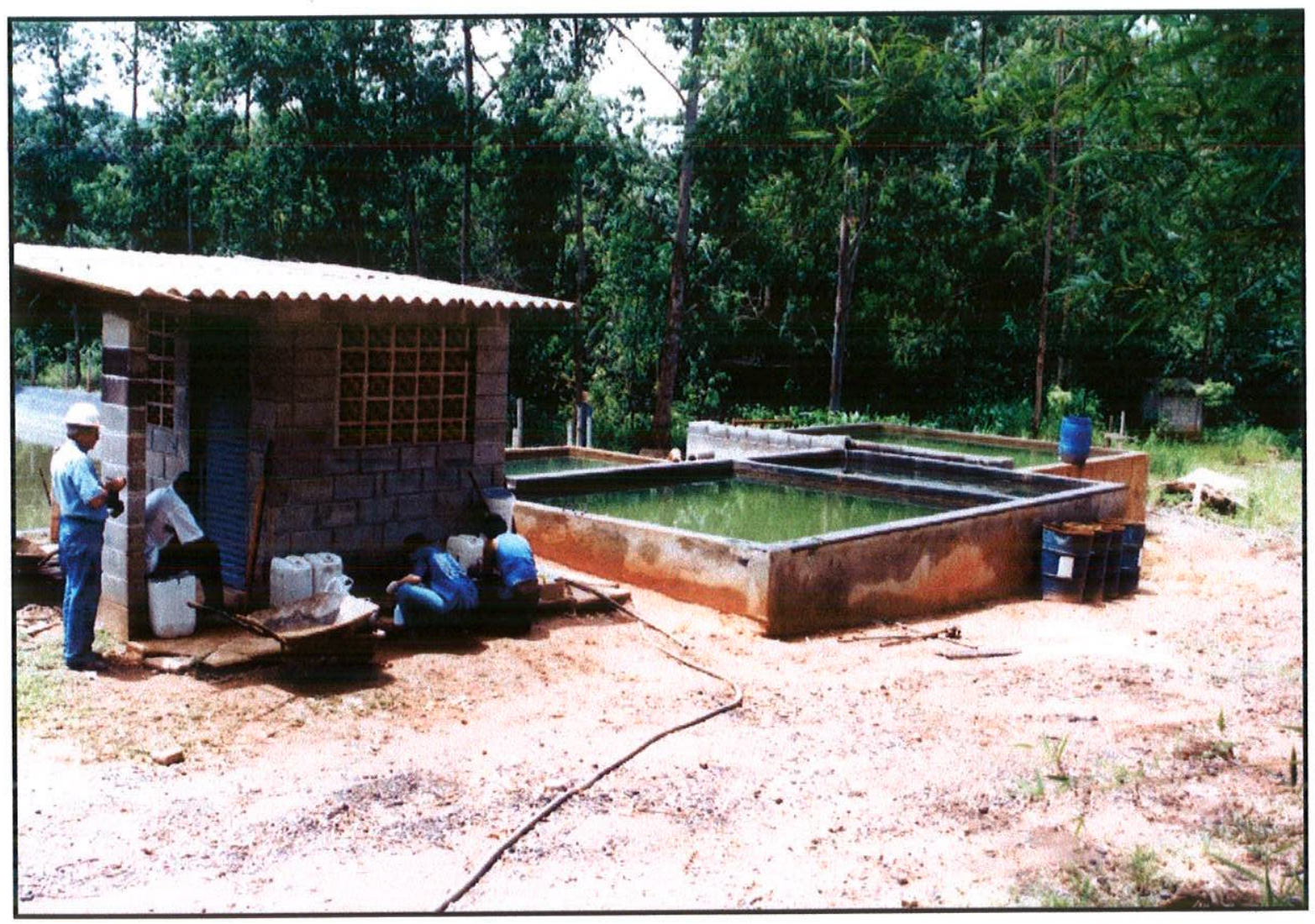

FIGURA 5.3.5: Tanques da Estação de "tratamento". 


\section{MATERIAIS E MÉTODOS}

Os trabalhos de campo foram desenvolvidos em duas campanhas, no período de seca (setembro de 2002) e durante a estação das chuvas (março de 2003); foram coletadas amostras de solo/sedimento, escória, águas superficiais, subterrâneas (zona saturada) e de chuva. As amostras foram coletadas em pontos estrategicamente selecionados, na área da Empresa e suas circunvizinhanças.

\subsection{AMOSTRAS SÓLIDAS}

Os locais onde foram coletadas as amostras de solo estão indicadas no mapa da FIGURA 6.1.1.

Usou-se a notação $\mathbf{E}$ para escória e $\mathbf{S}$ para as amostras de solo e solo/sedimento com índices indicando as profundidades em centímetros.

Amostras de solo e solo/sedimento foram coletadas com trado manual $\left(\varnothing=6^{\prime \prime}\right)$, em diferentes profundidades, conforme mudanças litológicas do perfil e, quando possivel, até o nível d'água como nos pontos S-3 e S-4. A presença de blocos de escória em S-2 impediu a coleta de amostras de solo.

No ponto S-5, solo associado a pilha de escória, devido o excesso de cascalho, material plástico (ebonite) e, principalmente, de fragmentos de escória, soterrados desde $o$ início das atividades da Empresa, foi possível apenas coletas até $20 \mathrm{~cm}$ de profundidade.

Em S6, localizado cerca de $50 \mathrm{~m}$ abaixo das pilhas de escória, a perfuração alcançou $215 \mathrm{~cm}$, possibilitando coleta de seis amostras: S-6 $\mathbf{6}_{\mathbf{1 0}}, \mathbf{S}-\mathbf{6}_{\mathbf{2 0}}, \mathbf{S}-\mathbf{6}_{\mathbf{8 0}}, \mathbf{S}-\mathbf{6}_{\mathbf{1 3 5}}$, S-6 160 $_{16}$ e S-6 6 215.

No Sitio Santa Rita também foram coletadas amostras de solo catalogadas como S-9 $9_{10}$ S-9 $9_{45}$ S-9 $9_{70}$.

$\mathrm{Na}$ margem direita do Córrego Divisa coletaram-se mostras de solo/sedimento, até o nível d'água (S-11 10 e S-11 150).

As amostras coletadas, cerca de $2 \mathrm{Kg}$, foram acondicionadas em sacos plásticos, parte delas foram mantidas à temperatura ambiente e parte em isopor com gelo $\left(4^{\circ} \mathrm{C}\right)$ para uso em experimentos de extrações com água.

Dada a homogeneidade do material sólido, para as caracterizações referentes ao $\mathrm{pH}$ e CTC utilizaram-se amostras simples, representativas. 


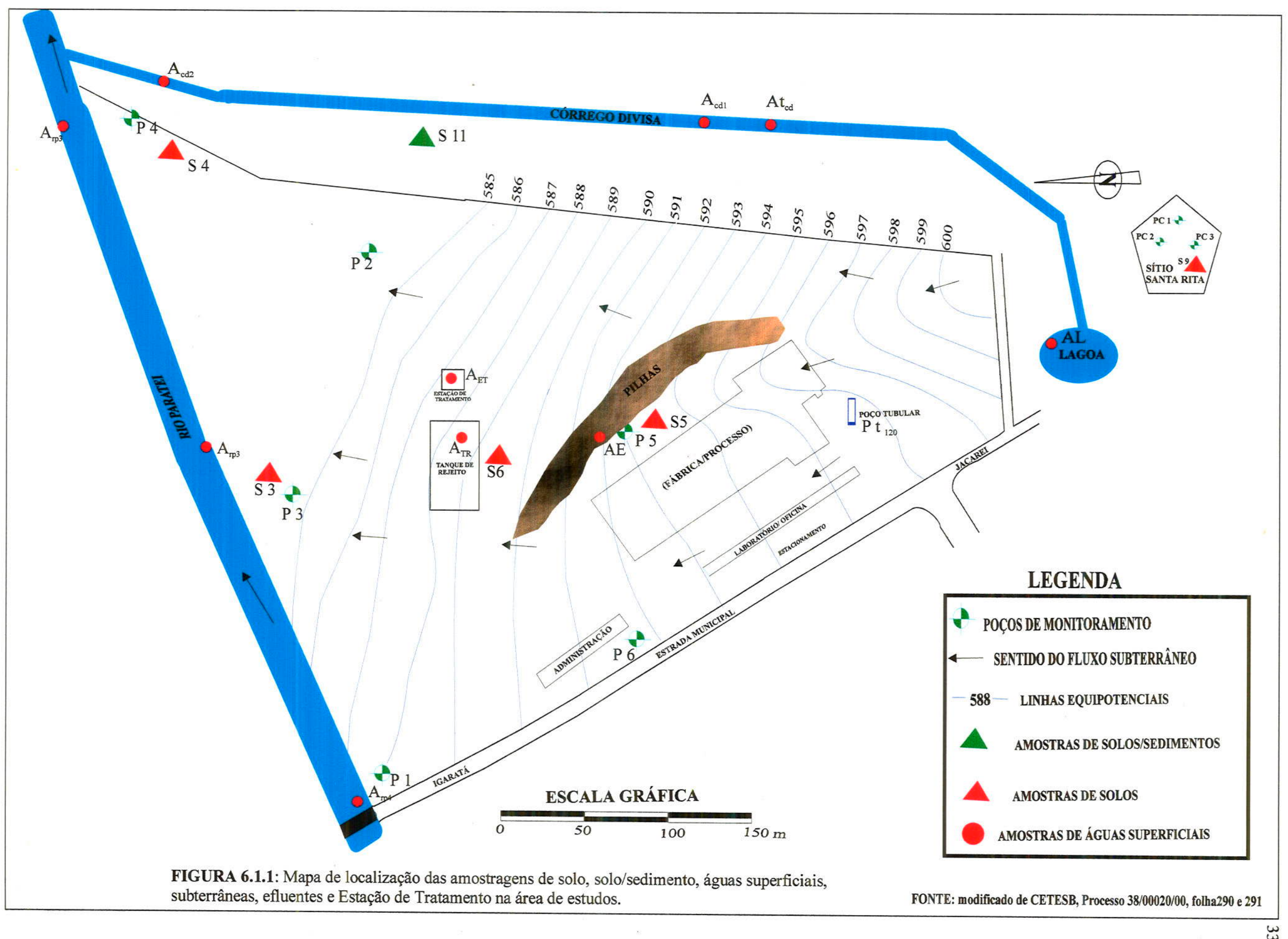


Amostras da escória foram coletadas em locais da pilha com fragmentos uniformemente distribuídos. Coletaram-se, em perfil, amostras em três pontos igualmente distanciados entre si, topo $\left(E_{t}\right)$, meio $\left(E_{m}\right)$, e base $\left(E_{b}\right)$.

\section{Tratamento das amostras}

Os materiais sólidos foram colocados separadamente em caixas de madeira para secagem à temperatura ambiente. Em seguida, as amostras foram destorroadas, homogeneizadas, pesadas e quarteadas. Separaram-se frações menores que $2,0 \mathrm{~mm}$ e inferiores a $0,063 \mathrm{~mm}$.

Para as análises mineralógicas (Difratrometria de raios $X$ ) as amostras foram moidas e peneiradas a $200 \#$.

A fração menor que $2 \mathrm{~mm}$ foram destinadas à extrações seqüenciais, análises granulométricas, determinações de $\mathrm{pH}\left(\mathrm{H}_{2} \mathrm{O}\right.$ e $\left.\mathrm{KCl} 1 \mathrm{~N}\right)$, de matéria orgânica e capacidade de troca cationica (CTC).

\section{Análise granulométrica}

Foram realizadas nos Laboratórios de Geoquimica - GSA/IGc USP utilizando os métodos de pipetagem (qualitativa) e peneiramento (quantitativa).

Os resultados foram normalizados e, para caracterização textural, projetados em diagrama triangular e classificados segundo SHEPPARD.

Como os perfis, de modo em geral, apresentaram grande homogeneidade foram escolhidos para as análises granulométricas os pontos mais representativos.

\section{pH e CTC}

A medida do $\mathrm{pH}$ em água representa a concentração de íons $\mathrm{H}^{+}$da solução que preenche os poros e que se acham em equilíbrio dinâmico com as superfícies de cargas negativas das partículas do solo.

Para as medidas de pH Foi utilizada a metodologia do Instituto Agronômico de Campinas (1986) modificada por Hypolito (2003).

A Capacidade de Troca Catiônica (CTC) do solo é o quanto o ele é capaz de reter cátions a $\mathrm{pH} 7$, indica a quantidade de cargas existentes nas frações 
(argilominerais, matéria orgânica, óxidos/hidróxidos de ferro, manganês e alumínio e fração coloidal) do solo que poderão ser disponiveis para a retenção de cátions além desse valor de $\mathrm{pH}$.

Na prática a CTC é a soma das Bases $\left(\mathrm{Na}^{+}, \mathrm{K}^{+}, \mathrm{Mg}^{2+}\right.$ e $\left.\mathrm{Ca}^{2+}\right)$ e o $\mathrm{Al}^{3+}+\mathrm{H}^{+}$.

As análises da Capacidade de Troca Cationica (CTC) foram efetuadas na Escola Superior Luiz de Queirós (ESALQ).

\section{Difratrometria de raios $X$}

As determinações mineralógicas das amostras de solo, e solo/sedimentos foram realizadas no Laboratório de Difração de raios $X$ do Instituto de Geociências da USP, por difração de raios X (D5000/SIEMENS) com radiação Cu Ka; obtendo-se difratogramas de 3 a 65 graus, passo $0,050^{\circ}$, contagem de 0,5 s/passo.

\section{Extrações Seqüenciais e Total}

Com o material sólido, foram efetuados estudos de métodos de Extrações Seqüenciais e Total, cujos andamentos acham-se detalhados no Capítulo 8.

O comportamento dos íons metálicos da escória também foi analisado através de extrações com sohxlet sob várias condições de lixiviação.

\subsection{AMOSTRAS LIQQUIDAS}

As notações utilizadas para as amostras líquidas foram: ArR, para as amostras do efluente no tanque de rejeito; $A_{E T}$, para a estação de tratamento e $\mathbf{A E}$ para a água associada a pilha de escória.

No Rio Parateí e Córrego Divisa as amostras receberam notação $\mathbf{A}_{R P}$ e $\mathbf{A}_{\mathbf{C D}}$ respectivamente; o índice indica o ponto de coleta nos cursos d'água.

Os poços de monitoramento foram catalogados como $\mathbf{P}$ e o poço tubular como $\mathbf{P t}_{120}$. As amostras de águas de chuva foram nomeadas como $\mathbf{A C h}$.

O mapa com os pontos de coletas das águas superficiais, efluentes e da Estação de Tratamento encontra-se na FIGURA 6.1.1.

A amostra da água associada a pilha de escória (AE) foi coletada com frasco plástico de $500 \mathrm{~mL}$ e o efluente do tanque de rejeito (ATR), bem como da Estação de 
Tratamento $\left(\boldsymbol{A}_{\mathrm{ET}}\right)$ foram coletadas com auxílio de frascos de polietileno descartáveis fixos em uma haste de madeira de $2 m$ de comprimento.

As amostras de águas superficiais foram coletadas na lagoa, Rio Parateí e Córrego Divisa, segundo o Standard Methods for Examination of Water and Wasterwater (1995).

No Rio Parateí foram coletadas amostras próximo ao Poço $4\left(\mathbf{A}_{\mathrm{rp} 2}\right)$, na margem direita; próximo ao Poço 5 ( $\left.\boldsymbol{A}_{\mathrm{rp3}}\right)$, na margem esquerda; a $20 \mathrm{~m}$ da desembocadura do Córrego Divisa $\left(A_{\text {rp1 }}\right)$ (FIGURA 6.2.1) e na ponte da Rodovia D.Pedro I, na margem direita $\left(\mathbf{A}_{\mathrm{rp} 4}\right)$.

No Córrego Divisa a amostra $\mathbf{A}_{\mathbf{c d} 1}$ foi coletada próximo ao descarte da tubulação subterrânea da Tonolli, do líquido da tubulação ( $\mathbf{A t}_{\mathbf{c d}}$ ) e próximo ao poço P5 $\left(\mathbf{A}_{\mathbf{c d} 2}\right)$. Na lagoa a coleta da amostra AL foi realizada na margem próxima a estrada (FIGURA 6.2.2).

Os 6 poços de monitoramento já existentes (P1 a P6), foram construídos em 1988 por meio de sondagens a percussão e revestidos com tubo geomecânico $\left(\varnothing=4^{\prime \prime}\right)$ (FIGURA 6.1.1).

Testes de permeabilidade executados em campo apresentaram valor médio de $3,31 \cdot 10^{-3} \mathrm{~m} \cdot \mathrm{s}^{-1} \mathrm{e}$, devido a rápida recarga dos poços, foram esgotados com mini bomba de purgeamento, três vezes o seu volume (CETESB, 2002). A coleta da água foi realizada com coletor do tipo bailer (FIGURA 6.2.3). 


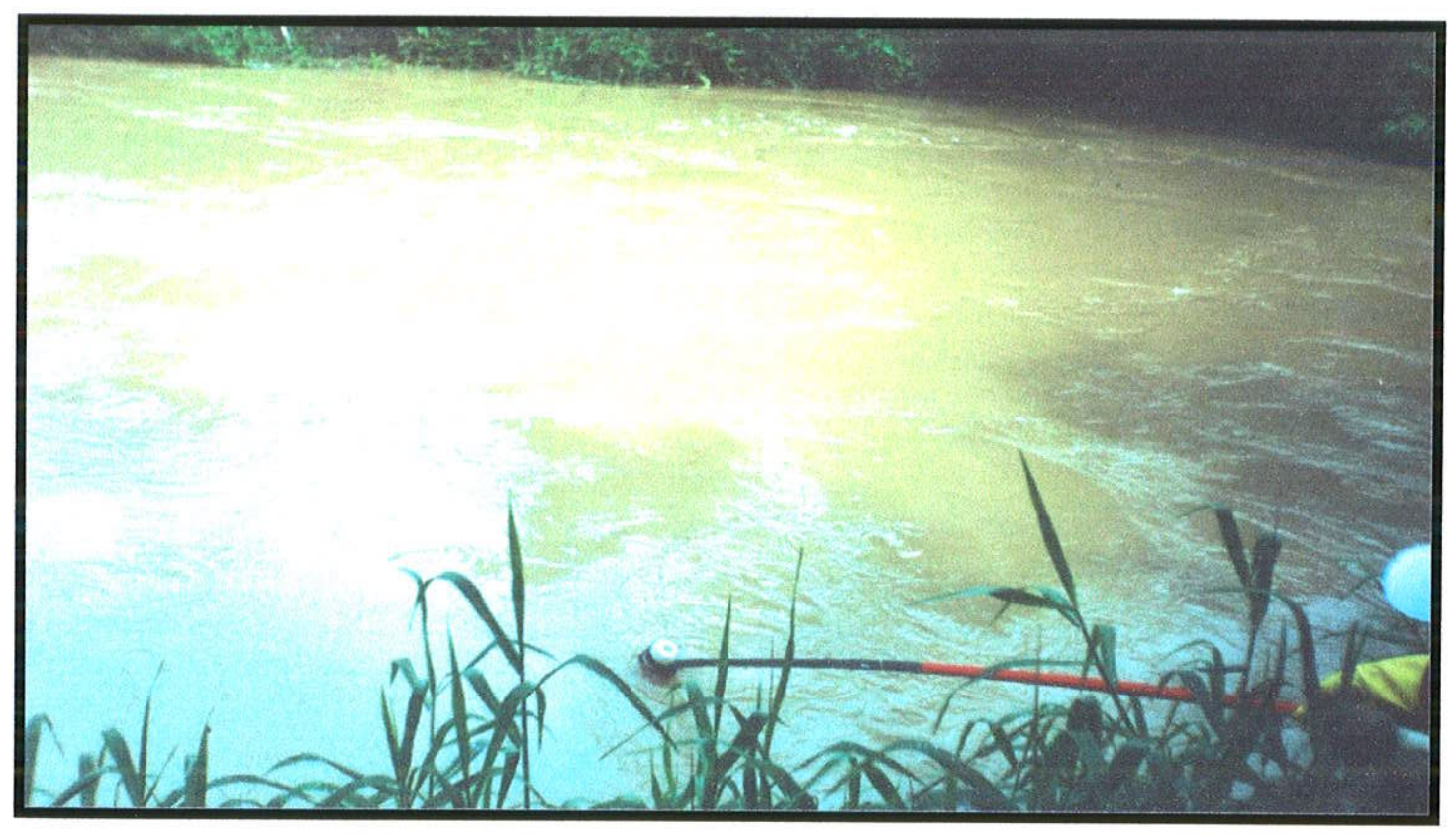

Figura 6.2.1: Coleta de água no Rio Paratei ( $\left.A_{R P 1}\right)$.

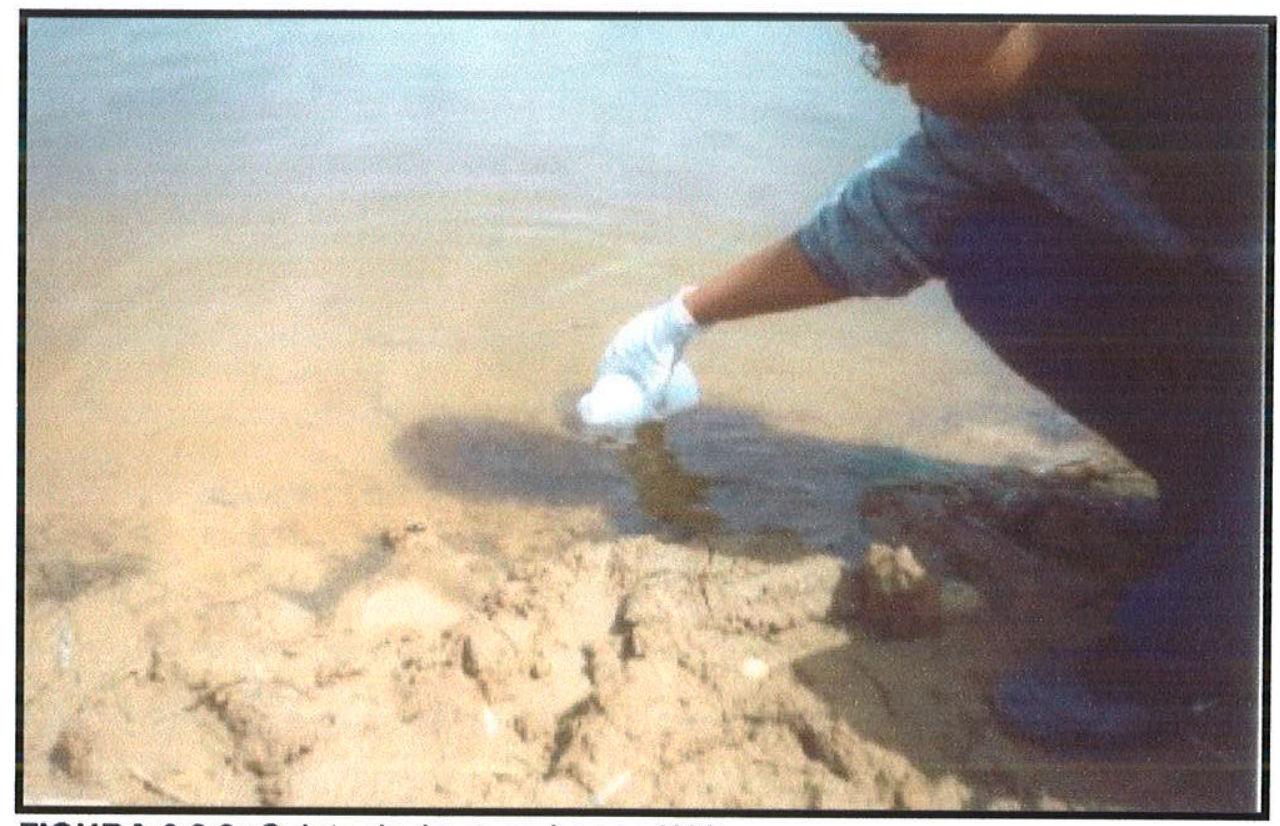

FIGURA 6.2.2: Coleta de água na Lagoa (AL). 


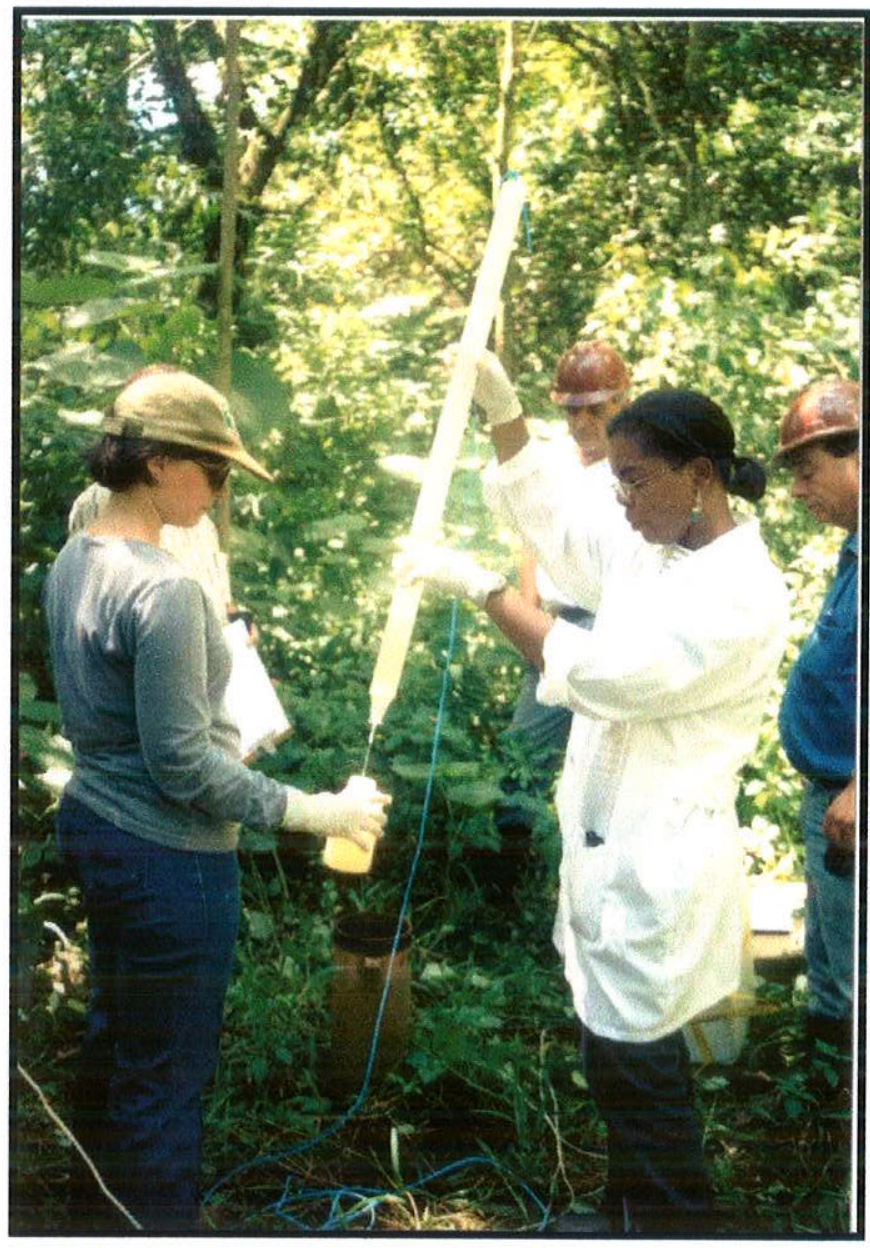

FIGURA 6.2.3: Coleta de água subterrânea, no poço de monitoramento (P2) com amostrador do tipo bailer. 
Para consumo de águas a Empresa, em 1982, foi instalou um poço tubular com $120 \mathrm{~m}$ de profundidade (CPRM, 2003) do qual também foram coletadas amostras (PT $\left.{ }_{120}\right)$.

No sítio Santa Rita tem-se 3 poços cacimbas $\left(\mathrm{PC}_{1}, \mathbf{P C}_{2}\right.$ e $\left.\mathrm{PC}_{3}\right)$, distribuídos ao longo do terreno, ao redor da residência, sendo apenas um deles, PC, ${ }_{1}$ (FIGURA 6.2.4), utilizado para consumo; os outros dois acham-se desativados.

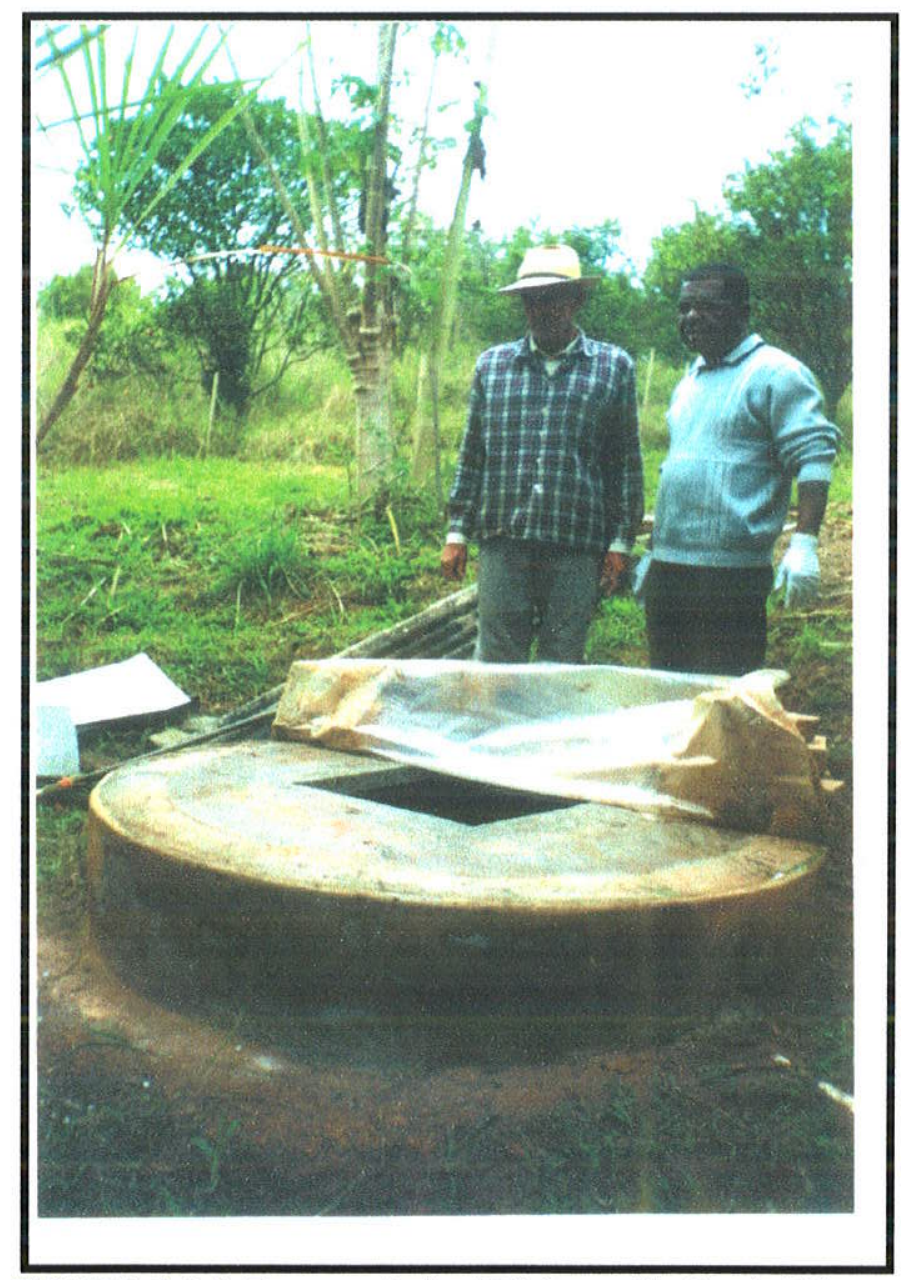

FIGURA 6.2.4: Poço cacimba $\left(\mathrm{PC}_{1}\right)$ no sítio Santa Rita. 
Com pluviômetro instalado no Sítio Santa Rita foram coletadas águas de chuva no período de janeiro a fevereiro de 2002 (ACh1) e de agosto de 2002 a março de 2003(ACh2); ele foi instalado segundo as normas do DAEE, 2000.

Durante as coletas das amostras mediu-se alcalinidade, condutividade elétrica, oxigênio dissolvido, $\mathrm{pH}$, Eh e temperatura.

As amostras líquidas, mesmo apresentando-se límpidas, foram filtradas (milipore de $0,45 \mu \mathrm{m}$ ), acondicionadas em frascos plásticos, aciduladas com $\mathrm{HNO}_{3}$ ( $\mathrm{pH}<2$ ) para leitura em Espectrofotômetro de Absorção Atômica (AA7000BC/CG) e com $\mathrm{H}_{2} \mathrm{SO}_{4}$ para leitura dos íons $\mathrm{Na}^{+}$e $\mathrm{K}^{+}$por Fotometria de Chama (B262/Micronal). Para leituras por Cromatografia líquida (Dionex - 2010i) as amostras foram mantidas a $4^{\circ} \mathrm{C}$, sem conservantes. 


\section{RESULTADOS E DISCUSSÕES}

\subsection{AMOSTRAS SÓLIDAS}

\section{Análise Granulométrica}

Os resultados das análises granulométricas (TABELA 7.1.1) foram projetados em diagrama triangular de Sheppard (FIGURA 7.1.1).

TABELA 7.1.1: DISTRIBUIÇÃO DAS FRAÇÕES GRANULOMÉTRICAS DOS SOLOS E SOLO/SEDIMENTO, RESPECTIVA CLASSIFICAÇÃO TEXTURAL E CONTEÚDO DE MATÉRIA ORGÂNICA.

\begin{tabular}{|c|c|c|c|c|c|}
\hline \multicolumn{4}{|c|}{ FRAÇÅO GRANULOMÉTRICA (\%) } & \multirow{2}{*}{$\begin{array}{l}\text { CLASSIFICAÇÃO } \\
\text { DE SHEPPARD }\end{array}$} & \multirow{2}{*}{$\begin{array}{c}\text { MATÉRIA } \\
\text { ORGÂNICA } \\
(\%)\end{array}$} \\
\hline Amostra & Argila & Silte & Areia & & \\
\hline S-340 & 15.19 & 17.00 & 67.81 & Areia siltica & 0,9 \\
\hline S-3 $380-420$ & 13.66 & 1.78 & 84.56 & Areia & 0,1 \\
\hline S-410 & 14.80 & 10.59 & 74.61 & Areia & 1,3 \\
\hline$S-4_{200-250}$ & 13.55 & 0.68 & 85.78 & Areia argilosa & 0,5 \\
\hline S-5 & 14.05 & 7.70 & 78.25 & Areia & 6,9 \\
\hline S-6 20 & 15.38 & 4.71 & 79.90 & Areia argilosa & 0,1 \\
\hline S-6 60 & 14.44 & 12.34 & 73.21 & Areia & 0,3 \\
\hline S-6 ${ }_{135}$ & 15.50 & 10.27 & 74.23 & Areia argilosa & 1,1 \\
\hline S-6160 & 14.97 & 12.18 & 72.86 & Areia argilosa & 1,4 \\
\hline S-6 6215 & 15.40 & 11.63 & 72.97 & Areia argilosa & 1,1 \\
\hline$S-9_{10}$ & 15.83 & 8.14 & 76.03 & Areia argilosa & 5,5 \\
\hline$S-945$ & 18.63 & 11.81 & 69.56 & Areia argilosa & 7,3 \\
\hline$S-970$ & 20.81 & 14.11 & 65.08 & Areia argilosa & 6,2 \\
\hline$S-11_{10}$ & 14.11 & 32.19 & 53.70 & Areia & 5,5 \\
\hline
\end{tabular}




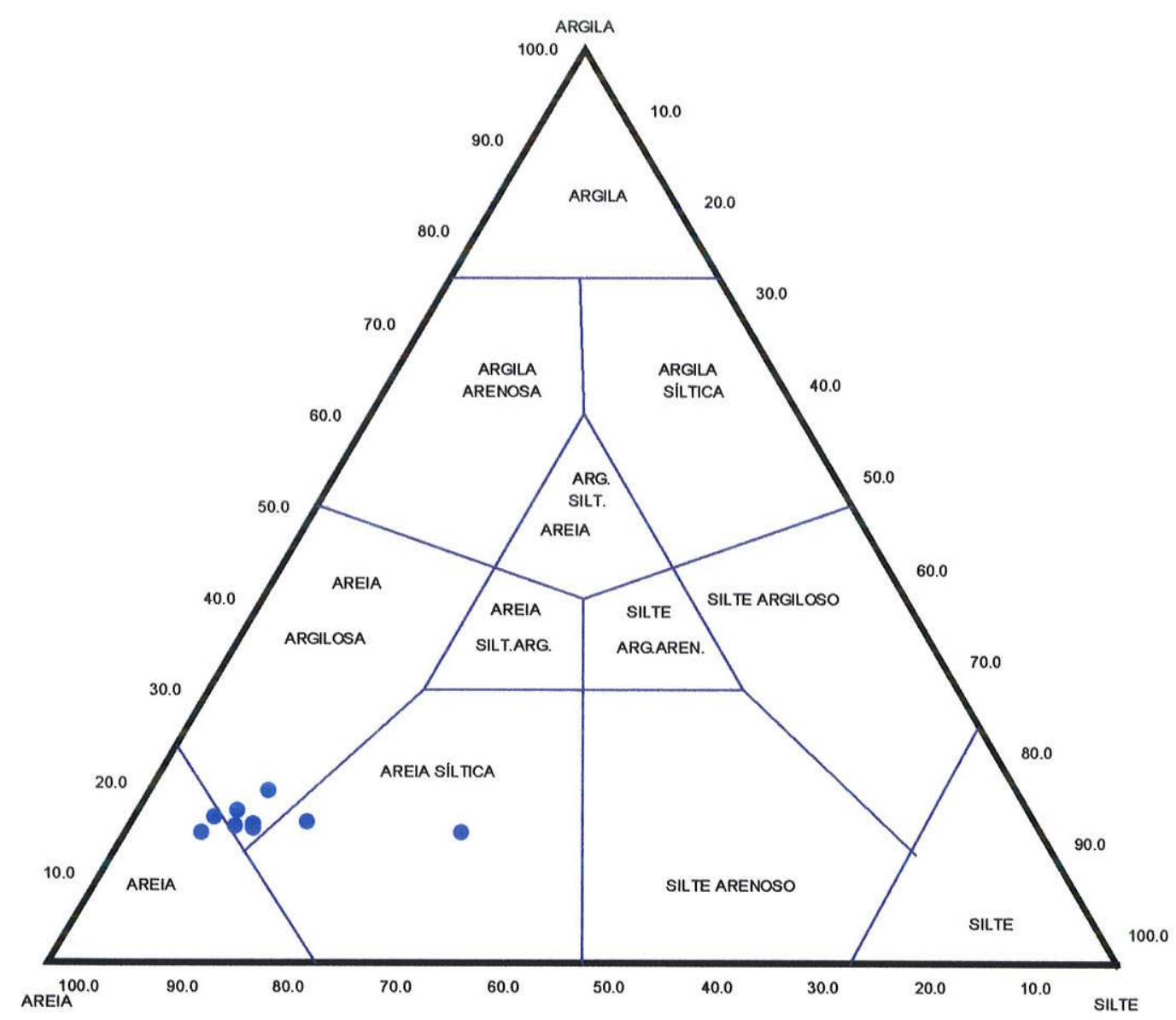

FIGURA 7.1.1: Projeção dos dados granulométricos em diagrama Triangular de Sheppard em amostras de solo e solo/sedimento da área de estudo.

As amostras apresentam predomínio da areia argilosa e, em menores proporções, frações areia e areia síltica.

\section{Difratometria de raios $X$}

$\mathrm{Na}$ TABELA 7.1.2 tem-se os resultados da difração de raios $X$ e nas FIGURAS 7.1.3 a e b, os difratogramas representativos das amostras sólidas. 
TABELA 7.1.2: CONSTITUINTES MINERALÓGICOS DAS AMOSTRAS NA FRAÇÃO <2 MM.

\begin{tabular}{|c|c|}
\hline AMOSTRAS & COMPOSIÇĀO MINERALOGICA \\
\hline S-5 & quartzo, illita, microclínio, magnetita \\
\hline S-610 & quartzo, caulinita, illita, microclinio, gibbsita \\
\hline$S-620$ & quartzo, caulinita, illita, microclínio, gibbsita \\
\hline S-680 & quartzo, caulinita, illita, microclínio, gibbsita \\
\hline S-6135 & quartzo, caulinita, ilita, microclínio \\
\hline S-6160 & quartzo, microclínio, caulinita \\
\hline$S-6215$ & quartzo, caulinita, illita, microclínio \\
\hline$S-90.10$ & quartzo, caulinita, microclínio \\
\hline$S-970$ & quartzo, caulinita, microclínio \\
\hline$S-11_{10}$ & quartzo, mica, flogopita, caulinita, microclínio \\
\hline
\end{tabular}

Os resultados das análises de raios $\mathrm{X}$ indicam, para todas as amostras, presença de quartzo e caulinita, tendo como acessórios gibbisita, microclínio, magnetita e illita. 
S-5

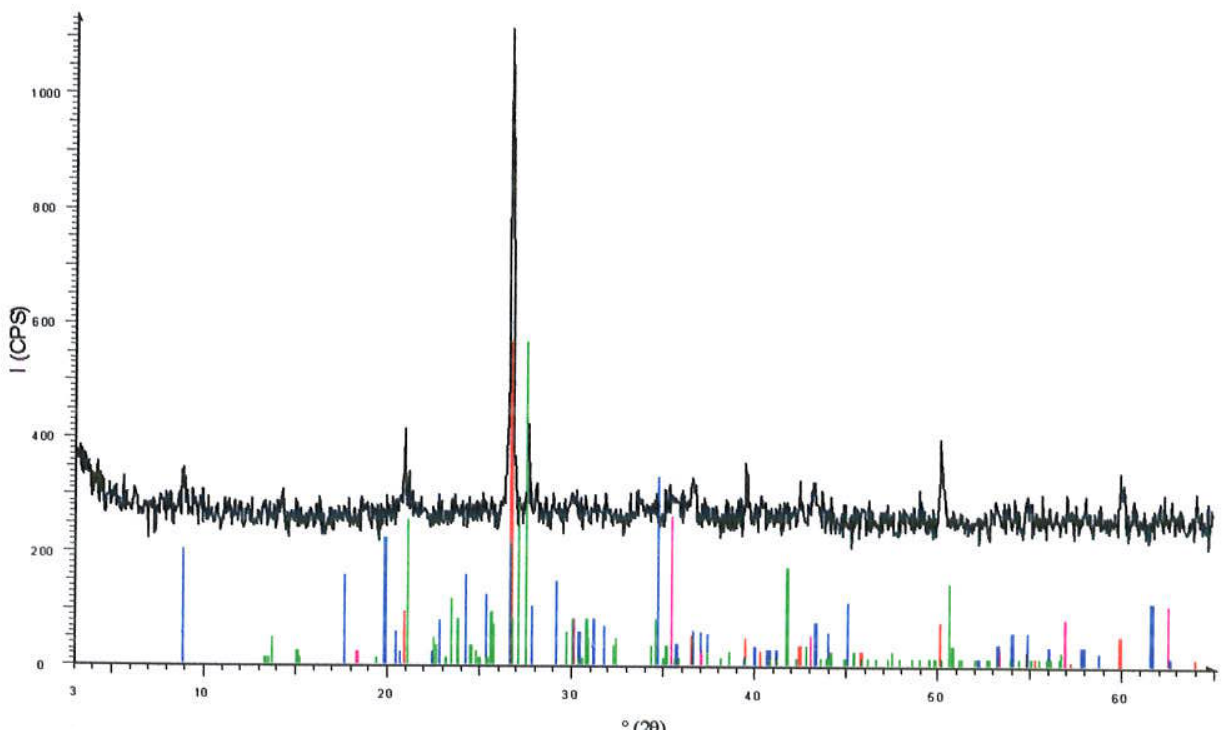

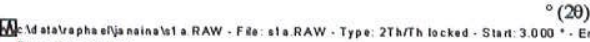

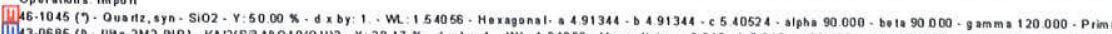

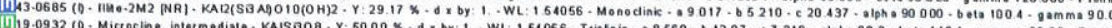

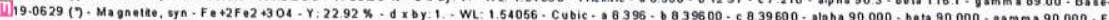

( a) 
S-6

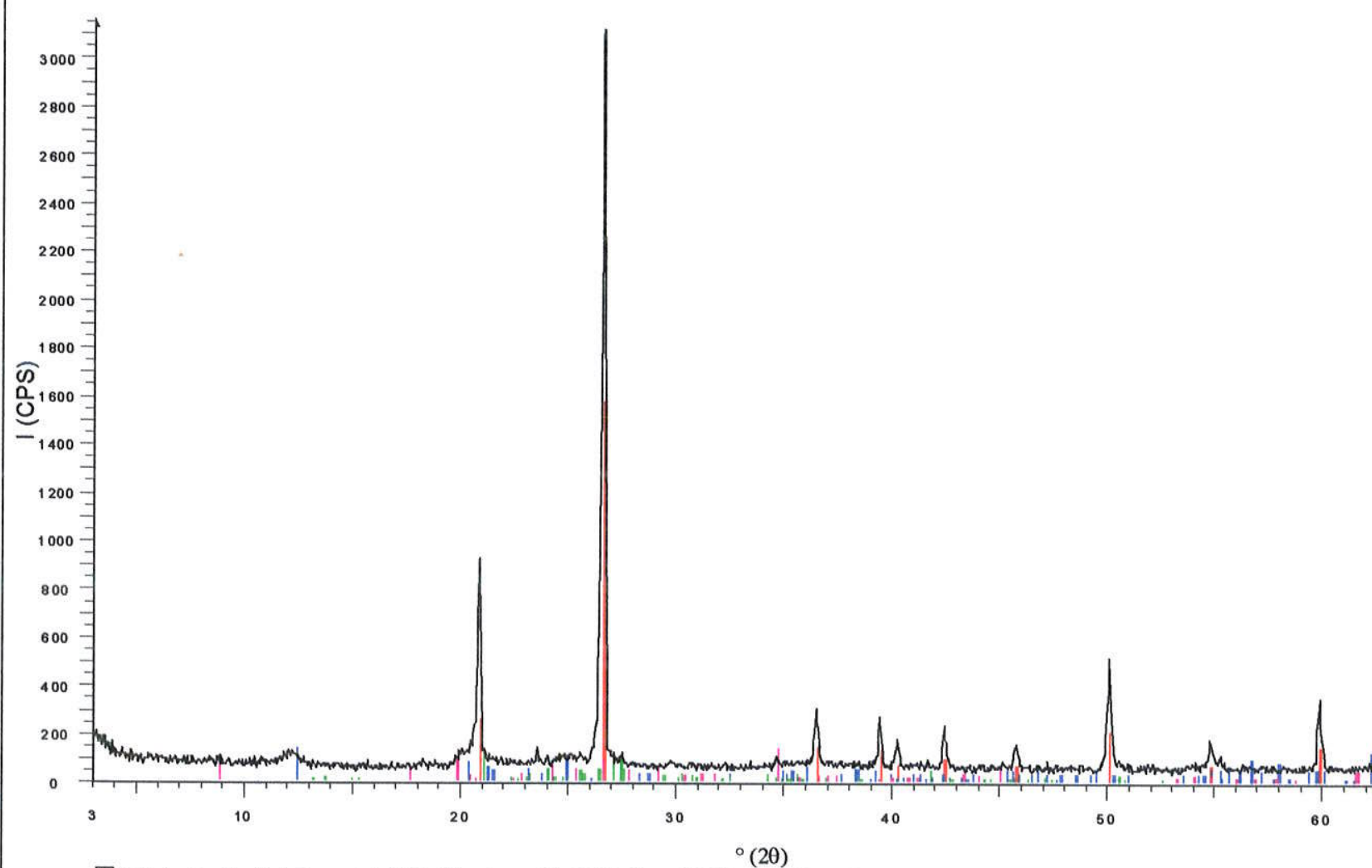

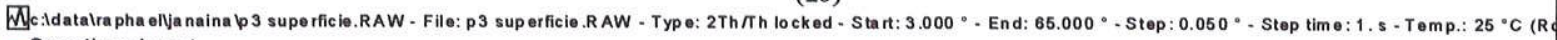
Operation s: Import

1.146-1045 (") - Quartz, syn - SiO2 - Y: $50.00 \%$ - d x by: 1. WL: 1.54056 - Hexagonal-a 4.91344 - b 4.91344 - c 5.40524 - alpha 90.000 - beta 90.000 - gamma 120.000 - Pr

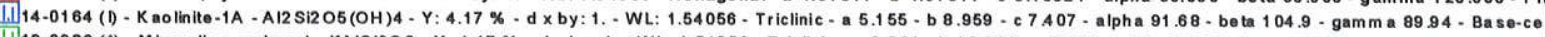

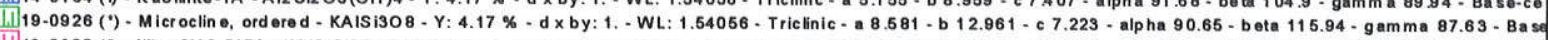

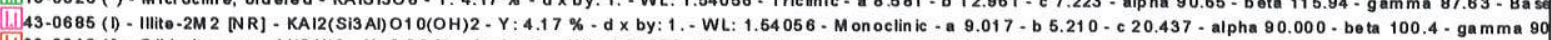

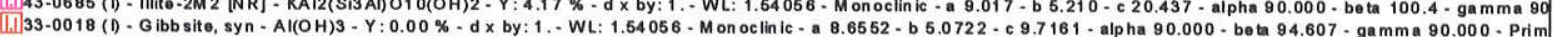

(b)

FIGURAS 7.1.3 : Difratogramas representativos das amostras do material sólido estudado. 


\section{pH e CTC}

$\mathrm{Na}$ TABELA 7.1.4 são apresentados os valores de $\mathrm{pH}$ determinados com solução de $\mathrm{CaCl}_{2}$ e $\mathrm{KCl}$ e de $\Delta \mathrm{pH}$.

TABELA 7.1.4: Valores de $\mathrm{pH}_{\mathrm{CaCl}}$, $\mathrm{pH} \mathrm{K}_{\mathrm{kCl}} \mathrm{e} \Delta \mathrm{pH}$ das amostras representativas S-4, S5, S6 e S9.

\begin{tabular}{|c|c|c|c|}
\hline AMOSTRA & $\mathrm{pH} \mathrm{CaCl}_{2}$ & $\mathrm{pH}_{\mathrm{KCl}}$ & $\Delta \mathrm{pH}$ \\
\hline S-4 10 & 4,50 & 4,30 & $+0,20$ \\
\hline S-4 40 & 4,72 & 4,50 & $+0,22$ \\
\hline S-4 380-420 & 4,25 & 4,17 & $+0,08$ \\
\hline S-5 & 6,90 & 6,80 & $+0,10$ \\
\hline S-620 & 4,61 & 4,41 & $+0,20$ \\
\hline S-680 & 4,25 & 4,18 & $+0,07$ \\
\hline S-6135 & 4,10 & 3,95 & $+0,15$ \\
\hline S-6160 & 4,15 & 4,11 & $+0,04$ \\
\hline S-9 $9_{10}$ & 5,60 & 5,39 & $+0,21$ \\
\hline S-9.95 & 4,11 & 4,10 & $+0,01$ \\
\hline S-970 & 6,20 & 5,80 & $+0,40$ \\
\hline
\end{tabular}

Os valores de $\Delta \mathrm{pH}$ positivos indicam presença quase exclusiva de cargas negativas nas partículas coloidais, portanto, disponíveis para adsorverem íns metálicos.

As análises da Capacidade de Troca Catiônica (CTC) encontram-se na TABELA 7.1.5. 
TABELA 7.1.5: Valores de CTC $\left(\mathrm{mmol}_{\mathrm{c}} \mathrm{dm}^{-3}\right)$ das amostras sólidas representativas.

\begin{tabular}{|c|c|}
\hline Amostras & CTC \\
\hline$S-3_{10}$ & 66,30 \\
\hline S-340 & 58,20 \\
\hline S-3 $380-420$ & 28,90 \\
\hline$S-40.10$ & 65,70 \\
\hline S-4 $455-65$ & 39,00 \\
\hline S-4200-250 & 27,10 \\
\hline S-5 & 268,50 \\
\hline S-60-20 & 33,20 \\
\hline S-680 & 34,90 \\
\hline S-6 $6_{135}$ & 53,80 \\
\hline S-6160 & 48,00 \\
\hline S-6 6215 & 41,80 \\
\hline$S-9_{10}$ & 11,90 \\
\hline$S-925$ & 106,10 \\
\hline S-970 & 57,20 \\
\hline S-11 10 & 246,8 \\
\hline$S-11_{215}$ & 43,80 \\
\hline
\end{tabular}

Devido a principalmente presença predominante de caulinita, conforme verificou-se através dos difratogramas de raios $\mathrm{X}$, como era de se esperar, os valores de CTC são bastante baixos 


\section{2 AMOSTRAS LÍQUIDAS}

\section{Parâmetros medidos em campo}

Durante a amostragem de águas superficiais, subterrâneas e efluentes foram efetuadas medidas de temperatura, oxigênio dissolvido (OD), $\mathrm{pH}$, condutividade elétrica (CE) e alcalinidade total, cujos resultados são apresentados nas TABELAS

\subsection{1 a 7.2.5.}

TABELA 7.2.1: DADOS FÍSICOS, QUÍMICOS E FÍSICO-QUIIMICOS, NOS PERIODOS DE SECA E CHUVA, DAS ÁGUAS SUBTERRÂNEAS DOS POÇOS DE MONITORAMENTO E TUBULAR DA EMPRESA.

\begin{tabular}{|c|c|c|c|c|c|c|c|}
\hline Período de seca & P1 & P2 & P3 & P4 & P5 & P6 & $P T_{120}$ \\
\hline $\mathrm{pH}$ & 5,06 & 3,14 & $\begin{array}{r}6,76 \\
\end{array}$ & 6,11 & 5,82 & 4,89 & 7,20 \\
\hline Eh $(\mathrm{mV})$ & $+207,00$ & $-74,00$ & $-68,00$ & $+98,00$ & $+82,00$ & $+243,00$ & $+85,00$ \\
\hline CE (uS.cm-1) & 19,00 & 1912,00 & 7,00 & 210,00 & 418,00 & 160,00 & 160,00 \\
\hline $\begin{array}{c}\text { Alcalinidade } \\
\left(\mathrm{CaCO}_{3} \mathrm{mg} . d m^{-3}\right)\end{array}$ & 0,05 & 0,10 & 0,60 & 2,50 & 0,13 & 0,11 & 0,75 \\
\hline $\begin{array}{l}\text { Período de } \\
\text { chuva }\end{array}$ & P1 & P2 & P3 & P4 & P5 & P6 & PT 120 \\
\hline $\mathrm{pH}$ & 5,13 & 4,47 & 6,48 & 5,98 & 6,22 & 5,33 & 7,10 \\
\hline Eh $(\mathrm{mV})$ & $+163,00$ & $-155,00$ & $-15,00$ & $+47,00$ & $+83,00$ & $+219,00$ & $+128,00$ \\
\hline CE (uS.cm-1) & 114,00 & 326,00 & 1108,00 & 141,00 & 288,00 & 105,00 & 268,00 \\
\hline $\begin{array}{c}\text { Alcalinidade } \\
\left(\mathrm{CaCO}_{3} \mathrm{mg}^{-\mathrm{L}^{-1}}\right)\end{array}$ & 0,11 & 0,03 & 0,68 & 0,13 & 0,40 & 0,02 & 0,80 \\
\hline
\end{tabular}

Para águas subterrâneas a temperatura média nos diferentes pontos foi de $22,50^{\circ} \mathrm{C}$ 
TABELA 7.2.2: DADOS FÍSICOS, QUIIMICOS E FISICO-QUIMICOS DE AMOSTRAS DE ÁGUAS DOS POÇOS CACIMBA - SITIO SANTA RITA (ÁREA DE REFERÊNCIA).

\begin{tabular}{|c|c|c|c|c|}
\hline Período de seca & PC1 & PC2 & PC3 & Ch2 \\
\hline $\mathrm{pH}$ & 6,09 & 5,69 & 5,45 & 6,00 \\
\hline Eh $(\mathrm{mV})$ & $+114,00$ & $+137,00$ & $+120,00$ & $\overline{n . d^{*}}$. \\
\hline CE (uS.cm-1) & 16,00 & 10,00 & 60,00 & n. $d^{*}$. \\
\hline $\begin{array}{c}\text { Alcalinidade } \\
\left(\mathrm{CaCO}_{3}{\left.\mathrm{mg} . d m^{-3}\right)}^{(2)}\right.\end{array}$ & 0,08 & 0,11 & 0,08 & n.d*. \\
\hline Profund. (m) & 20,00 & 12,00 & 12,50 & n. $d^{*}$. \\
\hline Período de chuva & PC1 & PC2 & PC3 & Ch1 \\
\hline $\mathrm{pH}$ & 5,93 & $\mid 5,94$ & 5,40 & 5.30 \\
\hline$\overline{E h}(\mathrm{mV})$ & $+209,00$ & $+202,00$ & $+229,00$ & n. $d^{*}$. \\
\hline CE (uS.cm-1) & 42,00 & 50,00 & 52,00 & n. $d^{*}$. \\
\hline $\begin{array}{c}\text { Alcalinidade } \\
\left(\mathrm{CaCO}_{3}{\left.\mathrm{mg} . d m^{-3}\right)}^{-}\right.\end{array}$ & $0,11 \|$ & 0,08 & 0,08 & n.d*. \\
\hline Profund. (m) & 20,00 & 12,00 & 12,50 & n.d*. \\
\hline
\end{tabular}

TABELAS 7.2.3: RESULTADOS FISICO-QUÍMICOS DAS AMOSTRAS DE ÁGUAS SUPERFICIAIS EM ÉPOCA DE SECA E CHUVOSA.

(a)

\begin{tabular}{c|r|r|r|r}
\hline Amostragem (seca) & \multicolumn{1}{|c|}{ A $_{\text {RP1 }}$} & \multicolumn{1}{|c|}{ A RP2 } & \multicolumn{1}{c|}{ A $_{\text {RP3 }}$} & \multicolumn{1}{c}{ AL } \\
\hline $\mathrm{pH}$ & 6,45 & 6,52 & 5,90 & 6,52 \\
\hline $\mathrm{Eh}(\mathrm{mV})$ & $+102,00$ & +35 & +162 & $+35,00$ \\
\hline $\mathrm{CE}\left(\mathrm{uS} . \mathrm{cm}^{-1}\right)$ & 5,7 & 3,0 & 104 & 30,00 \\
\hline $\begin{array}{c}\text { Alcalinidade } \\
\left(\mathrm{CaCO}_{3} \mathrm{mg.L}^{-1}\right)\end{array}$ & 0,03 & 0,19 & 0,20 & 0,21 \\
\hline $\mathrm{OD}\left(\mathrm{mg.L}^{-1} \mathrm{O}_{2}\right)$ & 4,91 & 4,89 & 2,73 & 3,50 \\
\hline
\end{tabular}

(b)

\begin{tabular}{|c|c|c|c|c|c|c|c|}
\hline Amostragem( chuva) & ARP1 & $A_{R P 2}$ & $A_{R P 3}$ & $A_{R P 4}$ & $A_{C D 1}$ & $A_{\mathrm{CD} 2}$ & AL \\
\hline $\mathrm{pH}$ & 6,99 & 6,52 & 6,86 & 6,78 & 6,74 & 6,67 & 6,70 \\
\hline Eh $(\mathrm{mV})$ & $+181,00$ & $+82,00$ & $+110,00$ & $+216,00$ & $+128,00$ & $+121,00$ & $+196,00$ \\
\hline CE (uS.cm-1) & 115,00 & 115,00 & 113,00 & 107,00 & 186,00 & 122,00 & 55,00 \\
\hline $\begin{array}{l}\text { Alcalinidade } \\
\left(\mathrm{CaCO}_{3} \mathrm{mg}_{\mathrm{L}} \mathrm{L}^{-1}\right)\end{array}$ & 0,16 & 0,24 & 0,16 & 0,14 & 0,14 & 0,13 & 0,11 \\
\hline $\mathrm{OD}\left(\mathrm{mg} \cdot \mathrm{L}^{-1} \mathrm{O}_{2}\right)$ & 8,60 & 0,34 & 1,21 & 15,76 & 4,00 & 1,27 & 1,12 \\
\hline
\end{tabular}

Para águas superficiais a temperatura média nos diferentes pontos foi de $25,00^{\circ} \mathrm{C}$. 
No período não chuvoso o córrego da Divisa permaneceu seco por quatro meses.

TABELAS 7.2.4: RESULTADOS QUIMIICOS E FISICOQUIMIICOS DAS AMOSTRAS DOS EFLUENTES E DA ÁGUA "TRATADA".

(a)

\begin{tabular}{|c|c|c|c|c|}
\hline Amostragem (seca) & $\mathrm{AE}$ & $A_{T R}$ & $A_{E T}$ & Atcd \\
\hline $\mathrm{pH}$ & 7,46 & 7,00 & $(10,64$ & \\
\hline$E h(\mathrm{mV})$ & $+147,00$ & $+152,00$ & $+42,00$ & $+174,00$ \\
\hline CE (US. & & 4,88 & 6,03 & \\
\hline Ical. $(\mathrm{CaC}$ & 0,55 & 0,05 & 0,16 & 0 \\
\hline $\mathrm{OD}\left(\mathrm{mg} \cdot \mathrm{L}^{-1} \mathrm{O}_{2}\right)$ & 4,60 & 4,82 & 4,76 & 3 \\
\hline
\end{tabular}

(b)

\begin{tabular}{|c|c|c|c|}
\hline Amostragem (chuva) & AE & $A_{T R}$ & $A_{E T}$ \\
\hline $\mathrm{pH}$ & 4,50 & 7,72 & 8,60 \\
\hline$E h(m V)$ & $+35,00$ & $+178,00$ & $+108,00$ \\
\hline CE $(u$ & 20,00 & 1201,00 & 875,00 \\
\hline Alcal. $\left(\mathrm{CaCO}_{3}\right.$ & 0,60 & 0,26 & 0,29 \\
\hline $\mathrm{OD}\left(\mathrm{mg} \cdot \mathrm{L}^{-1} \mathrm{O}^{2}\right)$ & 3,00 & 2,60 & 2,40 \\
\hline
\end{tabular}

A amostra coletada na tubulação subterrânea da Empresa no Córrego Divisa não foi coletada no período de chuva.

\section{Análises químicas}

Os resultados analíticos das amostras de águas subterrâneas, superficiais e efluentes nos dois períodos, de seca e chuva, encontram-se nas TABELAS 7.2.5 a 7.2.8 
TABELAS 7.2.5: DADOS QUÍMICOS (mg. $\left.\mathrm{dm}^{-3}\right)$ DAS ÁGUAS SUBTERRÂNEAS DOS POÇOS DE MONITORAMENTO E TUBULAR NOS PERIODOS DE SECA (a) E CHUVA (b).

(a)

\begin{tabular}{|c|c|c|c|c|c|c|c|}
\hline CÁTIONS & P1 & P2 & P3 & P4 & P5 & P6 & $\mathrm{PT}_{120}$ \\
\hline $\mathrm{Na}^{+}$ & 9,00 & 560,00 & 195,00 & 10,80 & 34,00 & 7,00 & n.d* \\
\hline $\mathrm{K}^{+}$ & 4,10 & 10,00 & 7,20 & 5,30 & 8,20 & 6,20 & 0,03 \\
\hline $\mathrm{Ca}^{2+}$ & 4,05 & 158,15 & 62,75 & 9,35 & 14,40 & 1,30 & 0,09 \\
\hline $\mathrm{Mg}^{2+}$ & 2,15 & 61,10 & 34,30 & 2,75 & 1,40 & 2,55 & n. $d^{*}$. \\
\hline $\mathrm{Fe}_{(t)}$ & $n . d^{*}$. & 20,43 & 0,23 & 1,46 & n. $d^{*}$ & n. $d^{*}$. & n. $d^{*}$. \\
\hline $\mathrm{Mn}^{2+}$ & 0,03 & 1,77 & 1,37 & 0,15 & 0,02 & 0,35 & n. $\mathrm{d}^{*}$. \\
\hline $\mathrm{Al}^{3+}$ & 0,06 & 0,76 & 0,06 & $\mathrm{nd}$ & n. $d^{*}$ & 0,05 & n. $d^{*}$. \\
\hline $\mathrm{Pb}^{2+}$ & n. $\mathrm{d}^{*}$. & 0,10 & n. $\mathrm{d}^{*}$ & $\mathrm{nd}$ & 0,23 & n. $d^{*}$. & 0,01 \\
\hline $\mathrm{Cu}^{2+}$ & 0,02 & 0,01 & n. $\mathrm{d}^{*}$. & nd & n. $d^{*}$. & n. $d^{*}$. & $n . d^{*}$. \\
\hline $\mathrm{Zn}^{2+}$ & 0,02 & 0,03 & 0,06 & 0,01 & 0,03 & 0,05 & n. $d^{*}$ \\
\hline \multicolumn{8}{|l|}{ ÂNIONS } \\
\hline $\mathrm{Cl}^{-}$ & 18,54 & 395,20 & 114,56 & 18,66 & 62,63 & 3,37 & 99,48 \\
\hline $\mathrm{SO}_{4}^{2-}$ & 329,70 & 1.172 .9 & 509,82 & 7,63 & 2,17 & 0,28 & 17,04 \\
\hline
\end{tabular}

n.d*. não detectado

(b)

\begin{tabular}{|c|c|c|c|c|c|c|c|}
\hline CÁTIONS & P1 & P2 & P3 & P4 & P5 & P6 & $\mathrm{PT}_{120}$ \\
\hline $\mathrm{Na}^{+}$ & 194,00 & 45,50 & 152,50 & 12,00 & 30,50 & 7,80 & 16,20 \\
\hline $\mathrm{K}^{+}$ & 6,80 & 1,60 & 6,10 & 3,60 & 6,70 & 6,10 & 3,30 \\
\hline $\mathrm{Ca}^{2+}$ & 3,80 & 6,60 & 22,75 & 4,80 & 15,85 & 0,45 & 18,80 \\
\hline $\mathrm{Mg}^{2+}$ & 2,55 & 3,40 & 13,90 & 1,70 & 2,75 & 3,20 & 6,70 \\
\hline $\mathrm{Fe}_{(t)}$ & 0,60 & 0,17 & 4,18 & 0,17 & 0,02 & 0,66 & 0,13 \\
\hline $\mathrm{Mn}^{2+}$ & 0,04 & 0,16 & 1,87 & 0,07 & 0,08 & 0,36 & 0,10 \\
\hline $\mathrm{Al}^{3+}$ & 1,00 & 0,14 & 0,36 & 0,34 & 0,10 & 1,13 & 0,15 \\
\hline $\mathrm{Pb}^{2+}$ & n. $d^{*}$. & n. $\mathrm{d}^{*}$ & n. $d^{*}$. & n. $d^{*}$. & n. $d^{*}$. & $\mathrm{n} \cdot \mathrm{d}^{*}$ & 0,02 \\
\hline $\mathrm{Cu}^{2+}$ & n.d*. & n. $d^{*}$. & n. $d^{*}$. & n. $d^{*}$. & n. $d^{*}$. & n. d $^{*}$. & 0,01 \\
\hline $\mathrm{Zn}^{2+}$ & 0,04 & n.d. & 0,01 & n.d. & 0,03 & n.d. & 0,45 \\
\hline \multicolumn{8}{|l|}{ ÂNIONS } \\
\hline Cl- & 77,17 & 23,18 & 70,83 & 17,25 & 36,61 & 3,61 & 7,28 \\
\hline $\mathrm{SO}_{4}^{2-}$ & 0,29 & 89,44 & 282,00 & 11,91 | & 19,27 & 0,19 & 4,35 \\
\hline
\end{tabular}


TABELAS 7.2.6: RESULTADO DAS ANÁLISES QUIMICAS (mg.dm ${ }^{-3}$ ) DE AMOSTRAS DE ÁGUAS DOS POÇOS CACIMBAS E DE CHUVAS COLETADAS NO SITIO SANTA RITA PERIODOS DE CHUVA (a) e SECA (b).

(a)

\begin{tabular}{|c|c|c|c|c|}
\hline Cátions & PC1 & PC2 & PC3 & ACh2 \\
\hline $\mathrm{Na}^{+}$ & 1,00 & 1,30 & 0,70 & n.d. \\
\hline $\mathrm{K}^{+}$ & 2,2 & 15,20 & 1,80 & n. d* $^{*}$ \\
\hline $\mathrm{Ca}^{2+}$ & 5,35 & 2,90 & 0,30 & 0,48 \\
\hline $\mathrm{Mg}^{2+}$ & 0,50 & 0,55 & 0,30 & 0,44 \\
\hline $\mathrm{Fe}_{(t)}$ & 0,02 & 0,29 & 0,03 & 0,08 \\
\hline $\mathrm{Mn}^{2+}$ & $n . d^{*}$. & n.d $d^{*}$. & 0,01 & 0,02 \\
\hline $\mathrm{Al}^{+3}$ & 0,15 & 0,53 & 0,13 & 0,06 \\
\hline $\mathrm{Pb}^{2+}$ & n.d & n.d. & n.d & $\overline{0,02}$ \\
\hline $\mathrm{Cu}^{2+}$ & 0,01 & 0,01 & n.d & $\overline{0,02}$ \\
\hline $\mathrm{Zn}^{2+}$ & n.d & 0,02 & 0,01 & 0,01 \\
\hline \multicolumn{5}{|l|}{ Ânions } \\
\hline $\mathrm{Cl}$ & 1,26 & 14,57 & 1,07 & n. $d^{*}$. \\
\hline $\mathrm{SO}_{4}^{2-}$ & 0,26 & 0,31 & 0,11 & n. $d^{*}$. \\
\hline
\end{tabular}

(b)

\begin{tabular}{|c|c|c|c|c|}
\hline Cátions & PC1 & PC2 & PC3 & ACh1 \\
\hline $\mathrm{Na}^{+}$ & 2,10 & 7,00 & 0,40 & n.d* \\
\hline $\mathrm{K}^{+}$ & 2,10 & 6,20 & 1,30 & 0,1 \\
\hline $\mathrm{Ca}^{2+}$ & 1,50 & 1,30 & 0,65 & 0,65 \\
\hline $\mathrm{Mg}^{2+}$ & 0,00 & 2,55 & 0,20 & n.d. \\
\hline $\mathrm{Fe}_{(t)}$ & 0,65 & n.d.* & n.d. ${ }^{*}$ & 1,33 \\
\hline $\mathrm{Mn}^{2+}$ & n.d*. & 0,02 & n.d. & 0,04 \\
\hline $\mathrm{Al}^{\mathrm{l}+3}$ & 0,11 & 0,11 & 0,05 & 0,09 \\
\hline $\mathrm{Pb}^{2+}$ & n. $d^{*}$. & $n . d^{*}$. & n. $d^{*}$. & n. $d^{*}$. \\
\hline $\mathrm{Cu}^{2+}$ & n. $d^{*}$. & n. $d^{*}$. & n.d*. & n.d. ${ }^{*}$ \\
\hline $\mathrm{Zn}^{2+}$ & 0,02 & 0,02 & 0,01 & $\overline{1,92}$ \\
\hline \multicolumn{5}{|l|}{ Ânions } \\
\hline $\mathrm{Cl}$ & 8,28 & 3,37 & 0,39 & 0,32 \\
\hline $\mathrm{SO}_{4}^{2-}$ & 0,38 & 0,28 & 0,09 & $\overline{0,43}$ \\
\hline
\end{tabular}

n. d* $^{*}$ não detectado 
TABELAS 7.2.7 : DADOS QUÍMICOS (mg.dm-3) DAS AMOSTRAS DE ÁGUAS SUPERFICIAIS NO PERIODO DE CHUVA (a) E SECA (b).

(a)

\begin{tabular}{|c|c|c|c|c|c|c|c|}
\hline Cátions & $A_{R P 1}$ & $A_{R P 2}$ & $A_{R P 3}$ & $A_{R P 4}$ & $A_{C D 1}$ & $A_{\mathrm{CD} 2}$ & AL \\
\hline $\mathrm{Na}^{+}$ & 12,00 & 8,60 & 9,4 & 9,6 & 15,00 & 15,80 & 2,3 \\
\hline $\mathrm{K}^{+}$ & 8,60 & 4,80 & $\overline{4,1}$ & 5,2 & 3,10 & 3,70 & 4,3 \\
\hline $\mathrm{Ca}^{2+}$ & 5,90 & 5,65 & 5,25 & 5,95 & 9,90 & 9,80 & 4,05 \\
\hline $\mathrm{Mg}^{2+}$ & 1,95 & 1,90 & 1,80 & 1,85 & 3,05 & 3,10 & 1,25 \\
\hline $\mathrm{Fe}_{(t)}$ & 1,20 & 1,64 & 0,74 & 1,34 & 0,31 & 0,61 & 1,01 \\
\hline $\mathrm{Mn}^{2+}$ & 0,01 & 0,02 & n.d $d^{*}$. & 0,02 & 0,31 & 0,51 & 0,09 \\
\hline $\mathrm{Al}^{+3}$ & 0,36 & 0,94 & 0,31 & 0,50 & 0,11 & 0,09 & $\overline{0,20}$ \\
\hline $\mathrm{Pb}^{+2}$ & n. $d^{*}$. & n.d. & n.d $d^{*}$ & n.d*. & $n . d^{*}$. & n.d*. & n. $d^{*}$. \\
\hline $\mathrm{Cu}^{+2}$ & n. $d^{*}$. & n. $d^{*}$. & n.d*. & n. $d^{*}$. & n. $d^{*}$. & n.d* & n. $d^{*}$. \\
\hline $\mathrm{Zn}^{+2}$ & n. $d^{*}$. & n. $\mathrm{d}^{*}$ & n. $d^{*}$ & n.d* & n. $d^{*}$. & n.d*. & $n . d^{*}$. \\
\hline \multicolumn{8}{|l|}{ Ânions } \\
\hline $\mathrm{Cl}^{-}$ & 28,46 & 10,24 & 11,26 & 5,16 & 22,84 & 24,35 & 3,28 \\
\hline $\mathrm{SO}_{4}^{-2}$ & 9,76 & 4,87 & 11,32 & 5,31 & 14,38 & 14,68 & 1,16 \\
\hline
\end{tabular}

(b)

\begin{tabular}{|c|c|c|c|c|}
\hline Cátions & $A_{\mathrm{RP} 1}$ & $A_{R P 2}$ & $A_{R P 3}$ & $\mathrm{AL}$ \\
\hline $\mathrm{Na}^{+}$ & 3,80 & 12,0 & 12,0 & 12,00 \\
\hline $\mathrm{K}^{+}$ & 5,10 & 3,7 & 7,8 & 3,70 \\
\hline $\mathrm{Ca}^{2+}$ & 3,00 & 5,15 & 3,90 & 5,15 \\
\hline $\mathrm{Mg}^{2+}$ & 0,75 & 1,45 & 1,15 & 1,45 \\
\hline $\mathrm{Fe}_{(t)}$ & 0,48 & 0,62 & 0,48 & 0,62 \\
\hline $\mathrm{Mn}^{2+}$ & 0,02 & n.d.* & 0,04 & nd \\
\hline $\mathrm{Al}^{+}+3$ & 0,14 & 0,30 & 0,24 & 0,30 \\
\hline $\mathrm{Pb}^{+2}$ & n.d.* & n.d.* & n.d.* & n.d.* \\
\hline $\mathrm{Cu}^{+2}$ & n.d. ${ }^{*}$ & n.d. ${ }^{*}$ & n.d.* & n.d. ${ }^{*}$ \\
\hline $\mathrm{Zn}^{+2}$ & 0,02 & 0,03 & n.d. ${ }^{*}$ & $\overline{0,03}$ \\
\hline \multicolumn{5}{|l|}{ Ânions } \\
\hline $\mathrm{Cl}$ & 5,90 & 9,81 & 10,97 & 9,81 \\
\hline $\mathrm{SO}_{4}^{-2}$ & 2,36 & 6,89 & 5,82 & $6, \varepsilon$ \\
\hline
\end{tabular}

n. $\mathrm{d}^{\star}$ não detectado 
TABELA 7.2.8: DADOS QUIMIICOS (mg.dm-3) DAS AMOSTRAS DOS EFLUENTES E DA ÁGUA "TRATADA" (CHUVA (a) E SECA (b)).

(a)

\begin{tabular}{|c|c|c|c|}
\hline Cátions & $\mathrm{AE}$ & $A_{T R}$ & $A_{E T}$ \\
\hline $\mathrm{Na}^{+}$ & 1320,00 & 196,00 & 190,00 \\
\hline $\mathrm{K}^{+}$ & 15,50 & 8,80 & 8,50 \\
\hline $\mathrm{Ca}^{+}$ & 196,40 & 36,20 & 36,25 \\
\hline $\mathrm{Mg}^{+}$ & 33,10 & 12,00 & 11,65 \\
\hline $\mathrm{Fe}_{(t)}$ & 0,26 & 0,23 & 0,13 \\
\hline $\mathrm{Mn}^{2+}$ & 0,80 & 0,13 & 0,11 \\
\hline $\mathrm{Al}^{\mathrm{l}+3}$ & 0,15 & 0,10 & 0,21 \\
\hline $\mathrm{Pb}^{+2}$ & 0,38 & 0,41 & 0,29 \\
\hline $\mathrm{Cu}^{+2}$ & 0,02 & 0,01 & n.d*. \\
\hline $\mathrm{Zn}^{+2}$ & 0,18 & 0,04 & 0,02 \\
\hline \multicolumn{4}{|l|}{ Ânions } \\
\hline $\mathrm{Cl}^{-}$ & 105,40 & 53,54 & 44,11 \\
\hline $\mathrm{SO}_{4}^{-}$ & 3043,80 & 428,30 & 409,7 \\
\hline
\end{tabular}

n. $d^{*}$. não detectado

(b)

\begin{tabular}{|c|c|c|c|c|}
\hline Cátions & $\mathrm{AE}$ & ATR $_{\text {Th }}$ & $A_{E T}$ & Atcd \\
\hline $\mathrm{Na}^{+}$ & 1500,00 & 1062,00 & 1280,00 & 230,00 \\
\hline $\mathrm{K}^{+}$ & 29,00 & 26,00 & 27,00 & 19,00 \\
\hline $\mathrm{Ca}^{+}$ & 106,00 & 72,40 & 72,80 & 37,10 \\
\hline $\mathrm{Mg}^{+}$ & 25,00 & 17,00 & 9,40 & 18,2 \\
\hline $\mathrm{Fe}_{(t)}$ & 0,20 & 0,26 & 0,07 & 2,06 \\
\hline $\mathrm{Mn}^{2+}$ & 0,47 & 0,35 & 0,03 & 1,41 \\
\hline $\mathrm{Al}^{+}+3$ & 0,13 & 0,11 & 0,06 & 0,40 \\
\hline $\mathrm{Pb}^{+2}$ & 0,21 & 0,72 & 0,29 & 0,24 \\
\hline $\mathrm{Cu}^{+2}$ & 0,01 & 0,01 & 0,01 & n.d*. \\
\hline $\mathrm{Zn}^{+2}$ & 0,15 & 0,08 & 0,08 & 1,05 \\
\hline \multicolumn{5}{|l|}{ Ânions } \\
\hline $\mathrm{Cl}$ & 173,13 & 132,20 & 151,44 & 160,31 \\
\hline $\mathrm{SO}_{4}^{-}$ & 3644,96 & 2287,64 & 2754,76 & 416,87 \\
\hline
\end{tabular}


Os dados de $\mathrm{pH}$ das águas dos poços de monitoramento, nos períodos de seca e chuva, mostraram-se ligeiramente ácidos, exceto no poço P2 que apresentou acidez acentuada $(3,14)$.

Os valores de Eh, em ambos os periodos, correspondem a ambiente oxidante, exceto em P2 e P3 que se situam na mesma linha de fluxo das pilhas de escória.

A presença de sulfeto nas diferentes formas, oxidadas e reduzidas, deve-se a oscilação de valores de $\mathrm{pH}$ e Eh em função da distância das pilhas de rejeito, principal fonte de poluente, e também da direção do fluxo de água.

Em P1 e P4 tem-se menor influência dos $\mathrm{S}^{-2}(E h>0)$ por situarem-se afastados das pilhas de escória; o poço P1 está localizado abaixo da linha de fluxo.

P2 e P3 apresentam potencial de oxi-redução negativo, devido a presença de $\mathrm{S}^{-2}$ ainda não transformado totalmente em $\mathrm{SO}_{4}{ }^{-2}$, uma vez que se encontram diretamente na direção do fluxo. $O$ meio redutor nesses pontos refere-se a percolação de íons sulfetos na direção do fluxo, confirmada pela presença de íons sulfatos em P1, P2 e P3, apresentando valores muito mais elevados em P2 e P3 no periodo de seca.

As concentraçöes dos íons sulfato nos poços P1, P2 e P3 no período de seca e somente P3 no período de chuva apresentaram-se a cima dos limites de potabilidade segundo a PORTARIA 36 do Ministério da Saúde (2000). O mesmo ocorreu para cloreto em P2 no período de seca. Assim sendo, no sentido do fluxo, tem-se diminuição dos íons sulfetos e aumento da concentração de sulfato.

Em P6 nota-se pouca influência de sulfeto por não se localizar no sentido do fluxo subterrâneo, à cima das pilhas de escória.

Provavelmente, no sentido do fluxo, a partir de P2 em direção a P4 (aproximadamente a $350 \mathrm{~m}$ de afastamento das pilhas de escória), a pouca formação de $\mathrm{SO}_{4}^{-2}$ deve-se pela diminuição do $\mathrm{S}^{2-}$.

As medidas de condutividade elétrica vem a confirmar os dados analíticos apresentando valores mais elevados principalmente em P2 (período de seca) e P3 (período de chuva).

Os dados das análises químicas para o $\mathrm{Pb}^{2+}$, nos poços $\mathrm{P} 2, \mathrm{P} 5$ e $\mathrm{Pt}_{120}$ encontram-se acima dos valores de referência, lembrando que $\mathrm{Pt}_{120}$ tem sua água utilizada para abastecimento da Empresa, apresentando risco à saúde. 
Os dados físicos, químicos e físico-químicos das amostras de águas dos poços cacimba (referência) coletadas no Sítio Santa Rita apresentaram-se valores normais e constantes em todos os poços. Nesses poços não foram encontrados íons metálicos na água, tanto no período de chuva, como no período de-seca. As concentrações aniônicas das águas dos poços cacimbas (referência) estão bem abaixo dos limites de potabilidade PORTARIA 36 DO MINISTÉRIO DA SAÚDE (2000).

As águas de chuvas acusaram presença dos íons chumbo, zinco e cobre, e pH ligeiramente ácido, resultado da poluição atmosférica causada pela Empresa.

Os teores dos íons analisados nas amostras de águas superficiais apresentaram-se bastante baixos. Os dados de oxigênio dissolvido, com exceção do $A_{R P 1}$ e $A_{R P 4}$, não alcançaram os valores preconizados pela RESOLUÇÃO CONAMA 20/86 em praticamente todos os pontos de coleta.

As amostras da água considerada "tratada" $\left(A_{E T}\right)$ apresentaram $\mathrm{pH}$ elevado $\mathrm{e}$ as da tubulação subterrânea ( $\left.A t_{c d}\right) \mathrm{pH}$ ácido, em meio oxidante. As concentrações de chumbo, zinco e sulfato estão acima dos valores permitidos pelos padrões de qualidade ambiental (RESOLUÇÃO CONAMA 20/86).

O tanque de rejeito $\left(A_{T R}\right)$ apresentou condutividade elétrica mais elevada no período de chuva, com elevadas concentrações dos íons chumbo e sulfato.

$\mathrm{O}$ efluente associado diretamente às pilhas de escória ( $A E)$ apresentou $\mathrm{pH}$ ácido no período de chuva e elevadas concentrações de chumbo, zinco, cobre e sulfato. 


\section{TRABALHOS EXPERIMENTAIS}

Além das às atividades de campo foram realizados grande números de trabalhos laboratoriais.

Com as amostras de escória foram realizados experimentos, sob condições variadas, com extrator do tipo sohxlet.

Foram adaptadas e desenvolvidas novas seqüências de extrações para serem aplicadas nas amostras de solo e solo/sedimento.

Essas amostras foram mantidas em estufa, à temperatura constante de $35^{\circ} \mathrm{C}$.

Cada etapa de extração foi realizada com amostras em duplicata e os resultados acham-se expressos com valores médios.

\subsection{EXTRAÇÃO COM SOHXLET}

A disponibilidade dos íons metálicos da escória, oriunda dos fornos utilizados na recuperação de chumbo, foi realizada com extrator do tipo sohxlet (FIGURA 8.1.1).

Foram coletadas amostras da escória em três pontos da pilha de rejeito base $(E b)$, meio $(E m)$ e topo (Et).

Difrações de raios $X$ dessas amostras indicaram presença de compostos de ferro homólogos a gohetita, hematita e magnetita.

Utilizaram-se nos experimentos massas de $100,0 \mathrm{~g}$ em extratores com $\mathrm{H}_{2} \mathrm{O}$ e com $\mathrm{H}_{2} \mathrm{O} / \mathrm{CO}_{2}$ simulando condições brandas e ácidas semelhante as águas de chuvas. A temperatura média foi de $70^{\circ} \mathrm{C}$ e taxa de fluxo de $200 \mathrm{~mL} . \mathrm{h}^{-1}$ 


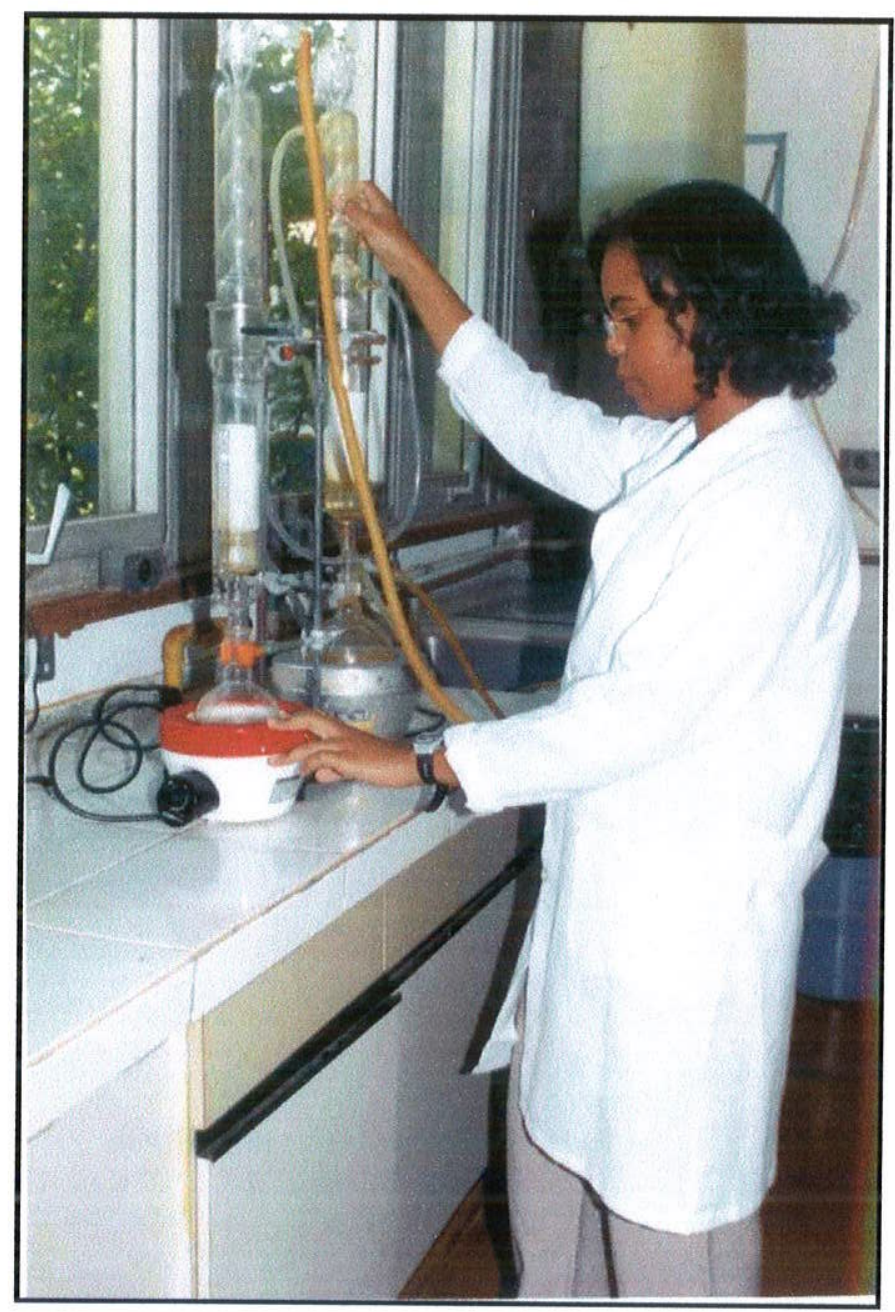

FIGURA 8.1.1: Extratores do tipo sohxlet.

A evolução dos experimentos foi acompanhada por análises diárias de $\mathrm{Na}^{+} \mathrm{e}$ $\mathrm{K}^{+}$em alíquotas de $25 \mathrm{~mL}$ coletadas a cada 6 horas; as extrações foram efetuadas até obtenção de valores constantes de desses íons.

Nos primeiros litros de lixiviação as soluções mostraram-se com coloração levemente acastanhada e posteriormente obtiveram-se precipitações de gipsita $\left(\mathrm{CaSO}_{4} .2 \mathrm{H}_{2} \mathrm{O}\right)$ determinadas por difratrometria de raios $\mathrm{X}$, de cor branca com tonalidades levemente avermelhada devido presença de íons ferro.

Após cada etapa de lixiviação, atingido o equilíbrio térmico, efetuaram-se leituras de $\mathrm{pH}$ (TABELA 8.1.1). 
TABELA 8.1.1:DADOS DE pH ( $\mathrm{pH}_{\mathrm{H} 2 \mathrm{O}}$ e $\mathrm{pH} \mathrm{CO}_{\mathrm{CO}}$ ) E SOMATÓRIO DO VOLUME (L) DAS SOLUÇÕES DE LIXIVIAÇÃO DAS AMOSTRAS DE ESCÓRIA DA BASE (Eb), MEIO (Em) e TOPO (Et) DA PILHA.

\begin{tabular}{c||c||c||c||c||c||c}
\hline \multicolumn{1}{l||}{} & \multicolumn{5}{c}{$\mathrm{pH}$} \\
\hline \hline$\Sigma \mathrm{V}(\mathrm{L})$ & $\mathrm{Et}_{2} \mathrm{O}$ & $\mathrm{Etco}_{2}$ & $\mathrm{Em}_{\mathrm{H}_{2}} \mathrm{O}$ & $\mathrm{Em}_{\mathrm{CO}_{2}}$ & $\mathrm{~Eb}_{\mathrm{H}_{2}} \mathrm{O}$ & $\mathrm{Eb} \mathrm{co}_{2}$ \\
\hline \hline 1 & 3,29 & 3,30 & 3,57 & 3,28 & 3,56 & 4,05 \\
\hline \hline 2 & 3,15 & 2,98 & 3,35 & 3,23 & 3,40 & 4,04 \\
\hline \hline 3 & 2,92 & 2,95 & 3,22 & 3,12 & 3,31 & 4,00 \\
\hline \hline 4 & 2,91 & 2,94 & 3,00 & 3,10 & 3,13 & 3,30 \\
\hline \hline 6 & 2,90 & 2,80 & 2,86 & 2,98 & 3,16 & 3,26 \\
\hline \hline 6 & 2,89 & 2,71 & 2,83 & 2,82 & 3,23 & 3,17 \\
\hline \hline 8 & 2,80 & 2,71 & 2,70 & 2,81 & 3,32 & 2,99 \\
\hline \hline 9 & 2,83 & 2,60 & 2,69 & 2,80 & 3,14 & 2,88 \\
\hline \hline 10 & 2,79 & 2,58 & 2,67 & 2,75 & 3,12 & 2,80 \\
\hline \hline
\end{tabular}

Os valores de $\mathrm{pH}$ projetados em gráficos, em função do somatório de solução lixiviada são apresentados nas FIGURAS 8.1.2 a à c.

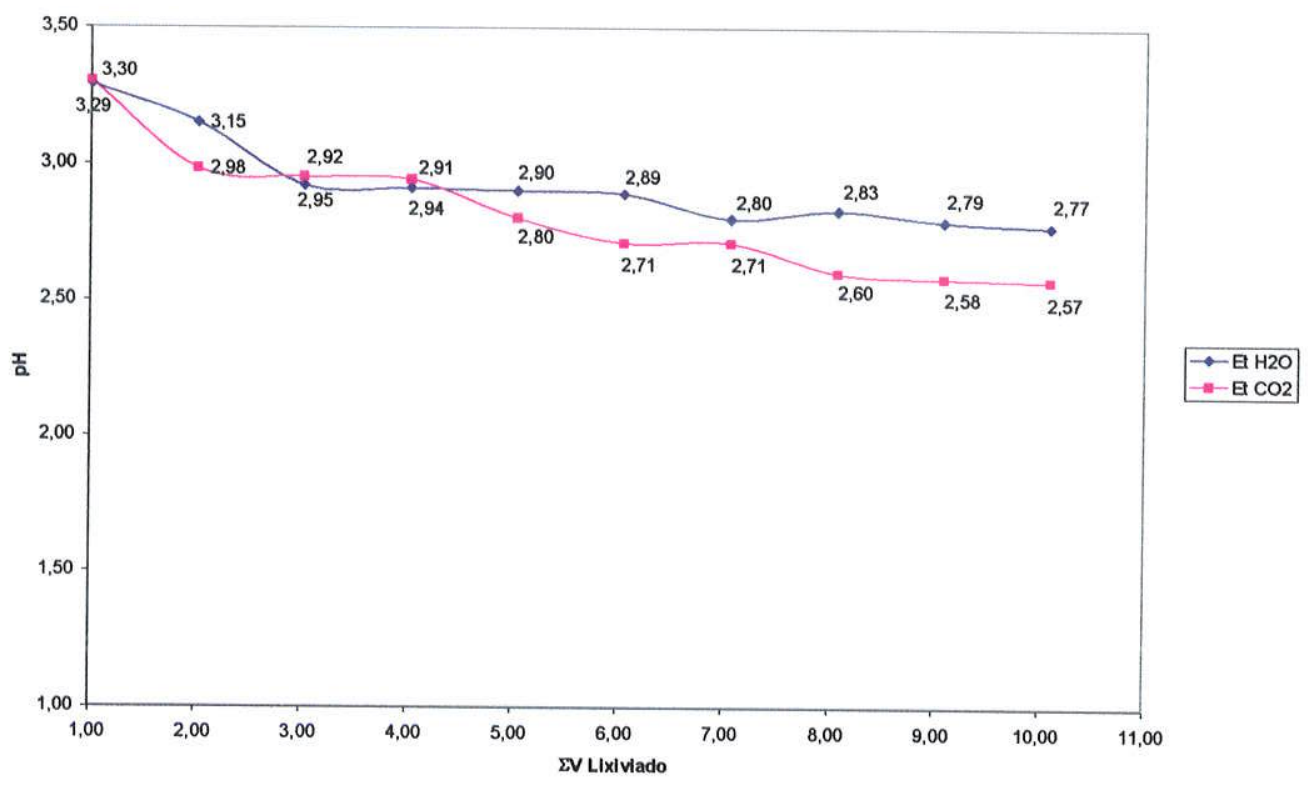

(a) 


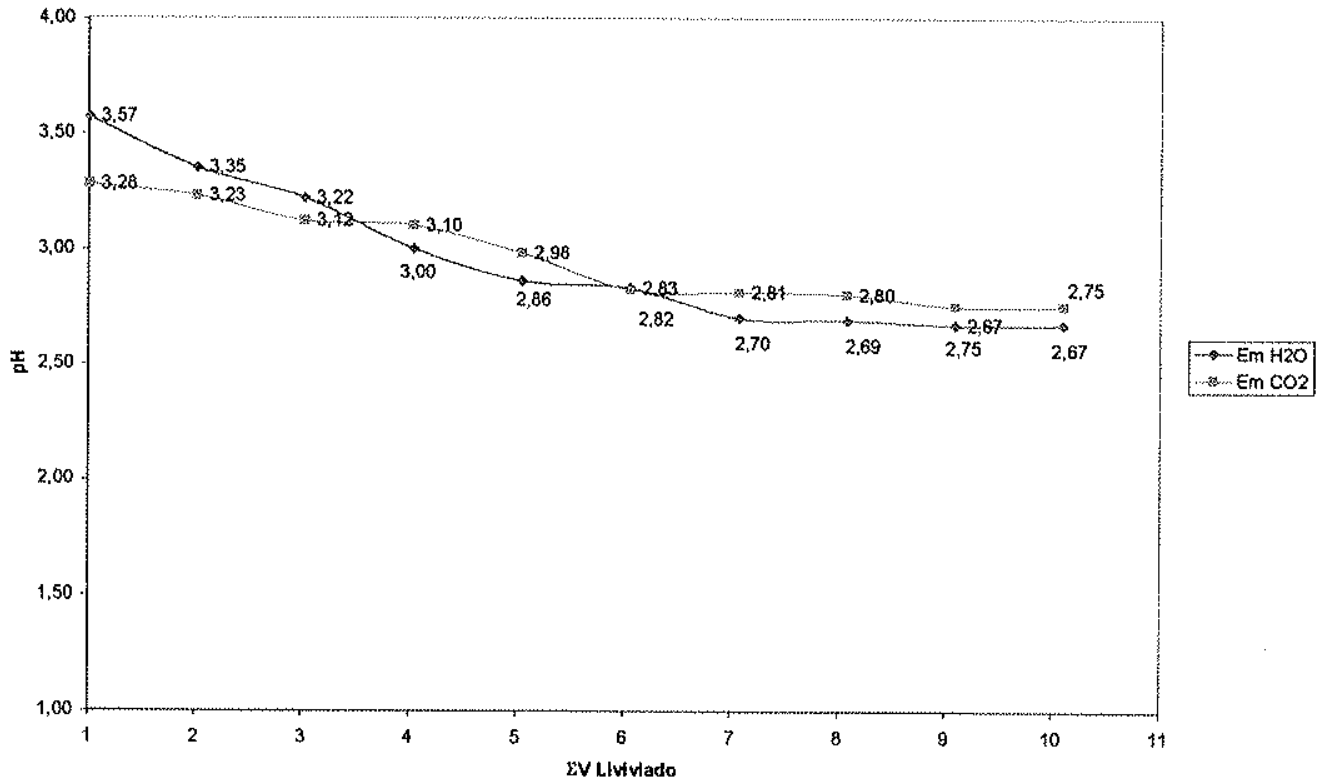

(b)

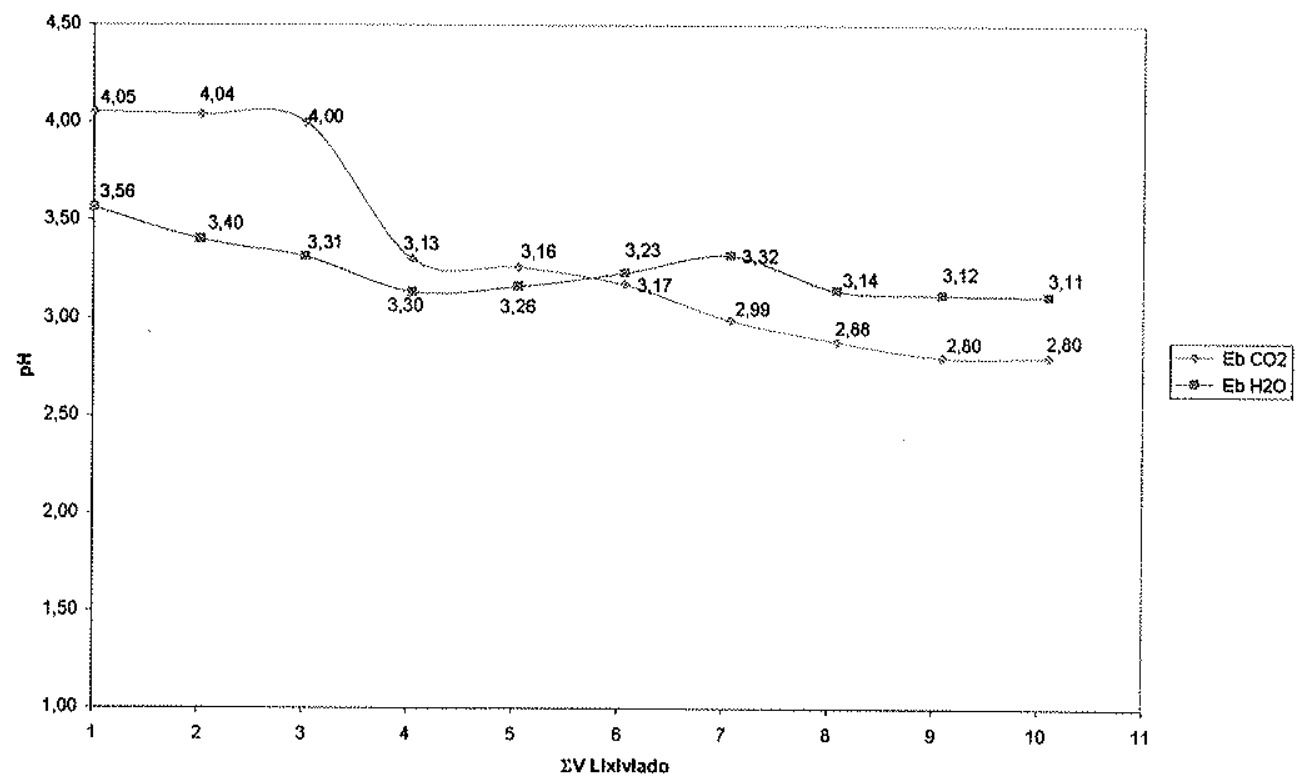

(c)

FIGURAS 8.1.2 a à c: pH da solução em função do somatório de volume lixiviado em experimentos com sohxlet. 
Os valores de $\mathrm{pH}$ nas lixiviações com $\mathrm{H}_{2} \mathrm{O}$ e $\mathrm{H}_{2} \mathrm{O} / \mathrm{CO}_{2}$, nos três pontos da pilha, variaram de forma semelhante, todavia, devido à hidrólise de $\mathrm{S}^{2-}$, em quantidade bastante superior na base, tem-se atenuação da concentração de $\mathrm{H}^{+}$.

$$
\mathrm{S}^{2+}{ }_{(\mathrm{aq})}+\mathrm{H}_{2} \mathrm{O}_{(\mathrm{l})} \leftrightarrows \mathrm{HS}_{(\text {(aq) }}+\mathrm{OH}_{(\text {(aq) }}
$$

Os teores de $\mathrm{Na}^{+}$e $\mathrm{K}^{+}\left(\mathrm{mg} \cdot \mathrm{dm}^{-3}\right)$ dosados nas soluções lixiviadas com água pura e gás carbônico, em função do volume diário, são fornecidos nas TABELAS 8.1.2 a e b e a projeção desses resultados em gráfico encontram-se nas FIGURAS 8.1.3 a à $f$. 

TABELAS 8.1.2: TEORES DE SÓDIO E POTÁSSIO $\left(\mathrm{mg}^{\mathrm{dm}}{ }^{-3}\right)$ DAS SOLUÇÕES LIXIVIADAS
DIARIAMENTE COM ÁGUA PURA E GÁS CARBÔNICO.

(a)

\begin{tabular}{|c|c|c|c|c|c|c|}
\hline \multirow{2}{*}{ Volume (L) } & \multicolumn{2}{|c|}{$\mathrm{Et}_{\mathrm{H}_{2}} \mathrm{O}$} & \multicolumn{2}{|c|}{$\mathrm{Em}_{\mathrm{H}_{2}} \circ$} & \multicolumn{2}{|c|}{$\mathrm{Eb}_{\mathrm{H}_{2}} \circ$} \\
\hline & $\mathrm{Na}^{+}$ & $\mathrm{K}^{+}$ & $\mathrm{Na}^{+}$ & $\mathrm{K}^{+}$ & $\mathrm{Na}^{+}$ & $\mathrm{K}^{+}$ \\
\hline $1^{0}$ & 84,00 & 8,00 & 90,00 & 5,00 & 200,00 & 130,00 \\
\hline $2^{0}$ & 108,10 & 19,30 & 104,75 & 7,62 & 255,00 & 168,25 \\
\hline $3^{0}$ & 130,27 & 38,48 & 112,56 & 10,18 & 268,75 & 171,63 \\
\hline $4^{0}$ & 145,26 & 39,46 & 122,75 & 17,50 & 284,50 & 176,75 \\
\hline $5^{0}$ & 148,63 & 40,99 & 125,50 & 19,09 & 294,05 & 177,63 \\
\hline $6^{0}$ & 149,01 & 41,90 & 126,81 & 20,47 & 307,19 & 178,06 \\
\hline $7^{\circ}$ & 150,03 & 42,01 & 128,09 & 22,30 & 320,00 & 179,35 \\
\hline 80 & 151,60 & 42,30 & 128,10 & 22,50 & 320,05 & 179,40 \\
\hline $9^{0}$ & 152,30 & 42,70 & 128,11 & 22,70 & 320,06 & $\overline{179,43}$ \\
\hline $10^{\circ}$ & 152,40 & 42,75 & 128,12 & 22,71 & 320,07 & $\overline{179,44}$ \\
\hline
\end{tabular}

(b)

\begin{tabular}{c|c|c|c|c|c|c}
\hline \multirow{2}{*}{ Volume (L) } & \multicolumn{2}{|c|}{$\mathbf{E t}_{\mathbf{c o}_{2}}$} & \multicolumn{2}{|c|}{$\mathbf{E m}_{\mathbf{C o}_{2}}$} & \multicolumn{2}{c}{$\mathbf{E b}_{\mathbf{c o}_{2}}$} \\
\hline & $\mathbf{N a}^{+}$ & $\mathbf{K}^{+}$ & $\mathbf{N a}^{+}$ & $\mathbf{K}^{+}$ & $\mathbf{N a}^{+}$ & $\mathbf{K}^{+}$ \\
\hline $\mathbf{1}^{\mathbf{0}}$ & 62,00 & 6,00 & 80,00 & 6,50 & 160,00 & 115,00 \\
\hline $\mathbf{2}^{\mathbf{0}}$ & 66,55 & 9,55 & 92,00 & 12,66 & 166,50 & 152,88 \\
\hline $\mathbf{3}^{0}$ & 107,67 & 22,24 & 98,30 & 12,82 & 169,06 & 161,25 \\
\hline $\mathbf{4}^{0}$ & 110,84 & 28,56 & 100,75 & 18,34 & 017,62 & 163,94 \\
\hline $\mathbf{5}^{0}$ & 151,77 & 37,72 & 110,52 & 20,46 & 174,19 & 166,04 \\
\hline $\mathbf{6}^{0}$ & 154,79 & 41,94 & 160,76 & 37,51 & 176,75 & 169,00 \\
\hline $\mathbf{7 0}^{0}$ & 156,87 & 42,05 & 162,50 & 39,51 & 179,31 & 171,63 \\
\hline $\mathbf{8}^{0}$ & 156,92 & 44,05 & 165,40 & 40,52 & 180,00 & 172,01 \\
\hline $\mathbf{9}^{\mathbf{0}}$ & 157,00 & 44,90 & 166,50 & 41,01 & 180,01 & 172,03 \\
\hline $\mathbf{1 0}^{\mathbf{0}}$ & 157,05 & 44,95 & 166,90 & 41,50 & 180,01 & 172,03 \\
\hline & & & & \multicolumn{3}{c}{} \\
\hline
\end{tabular}




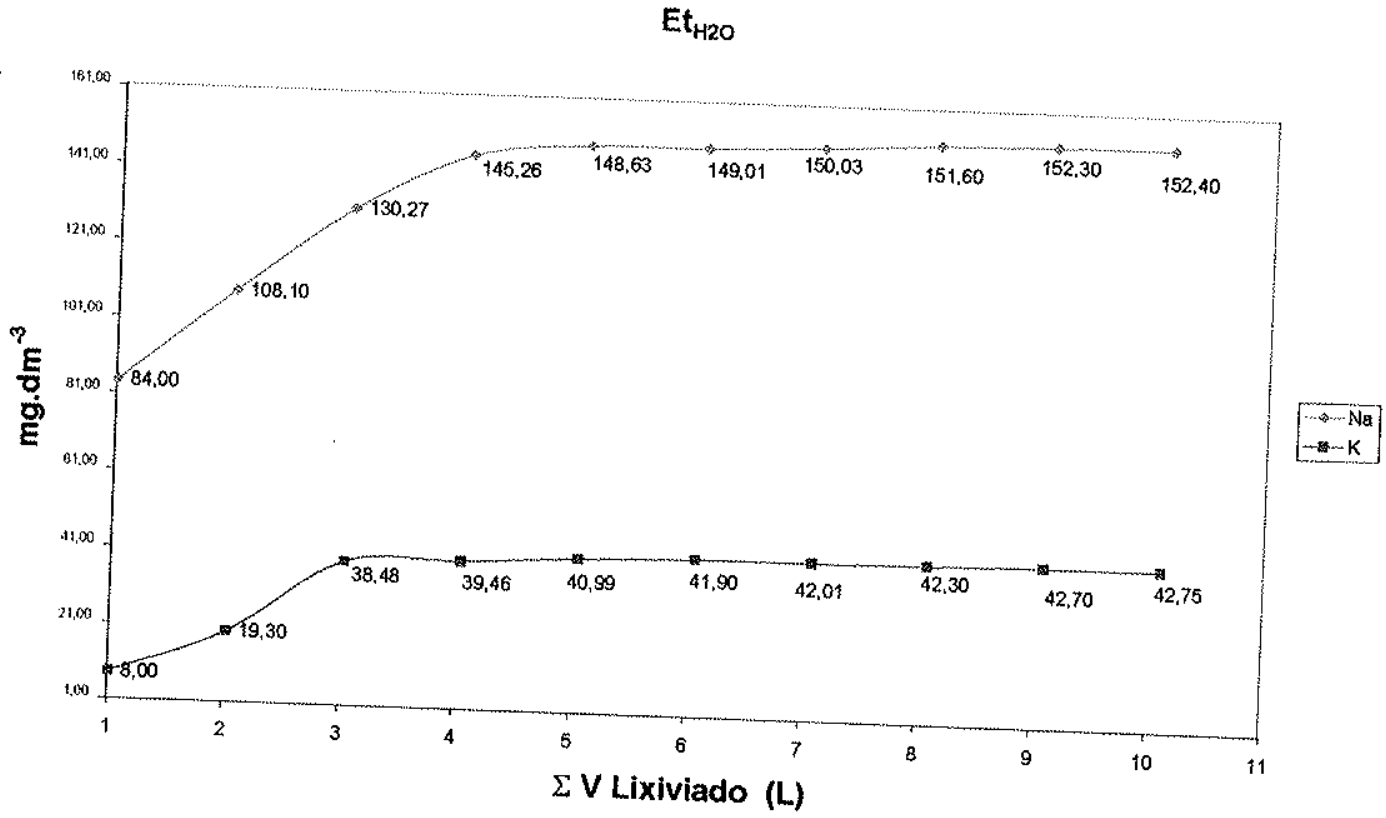

(a)

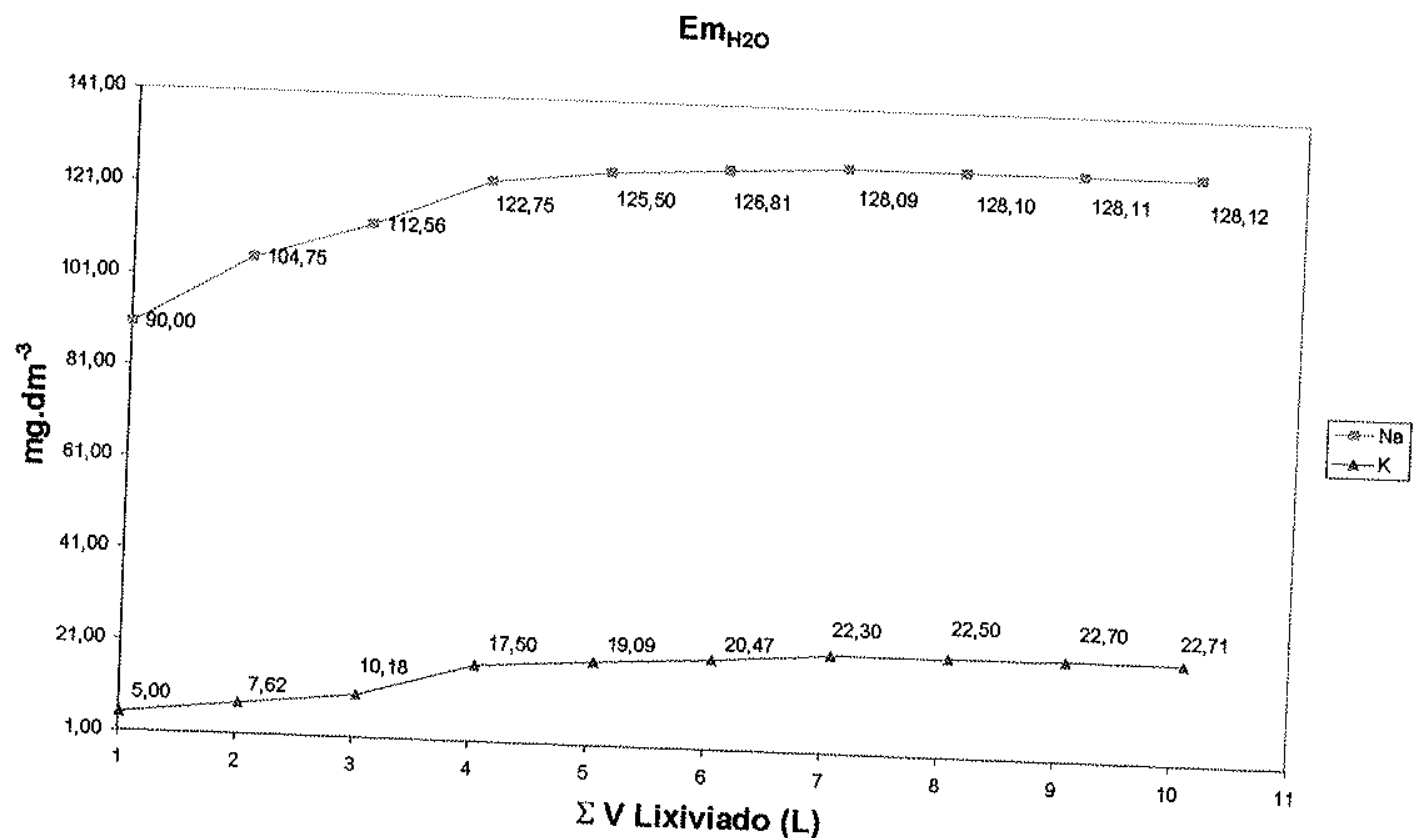

(b) 


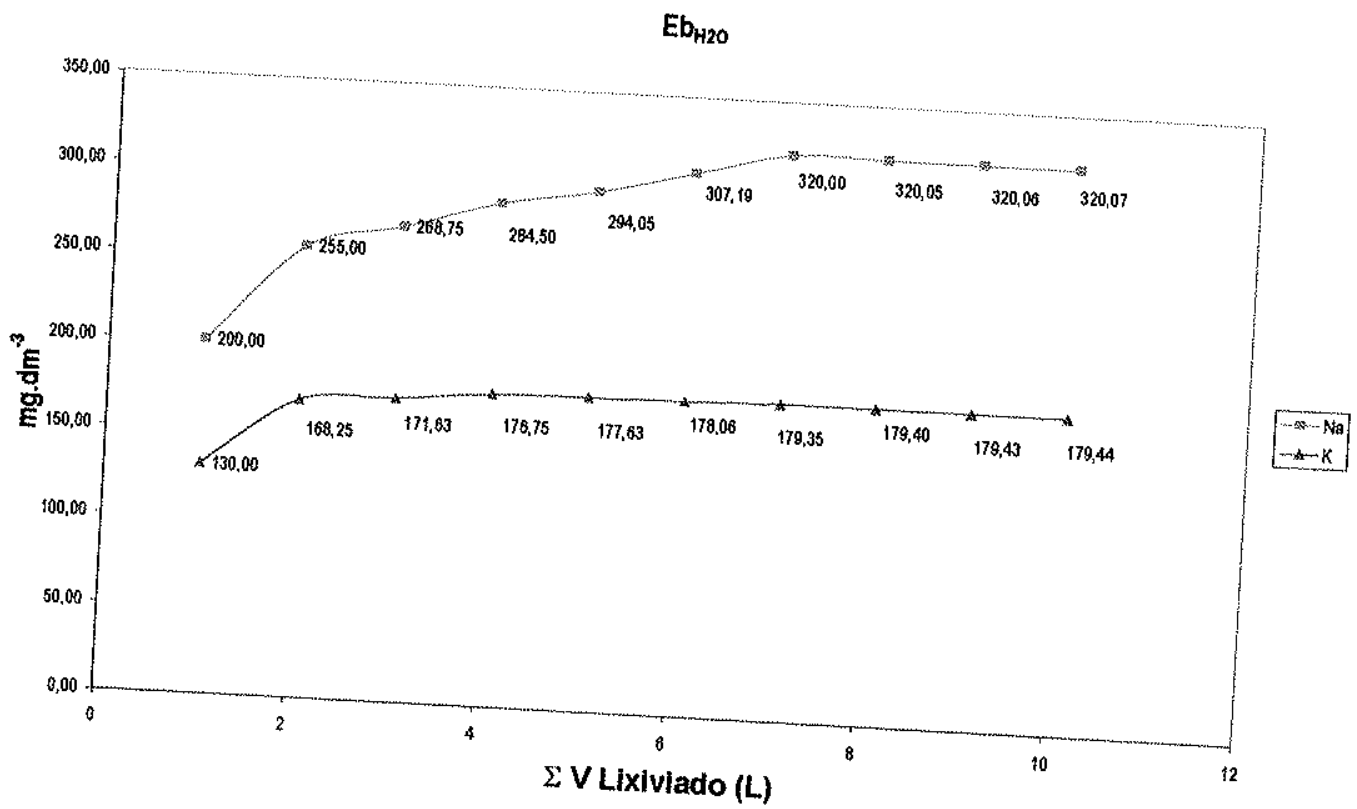

(c)

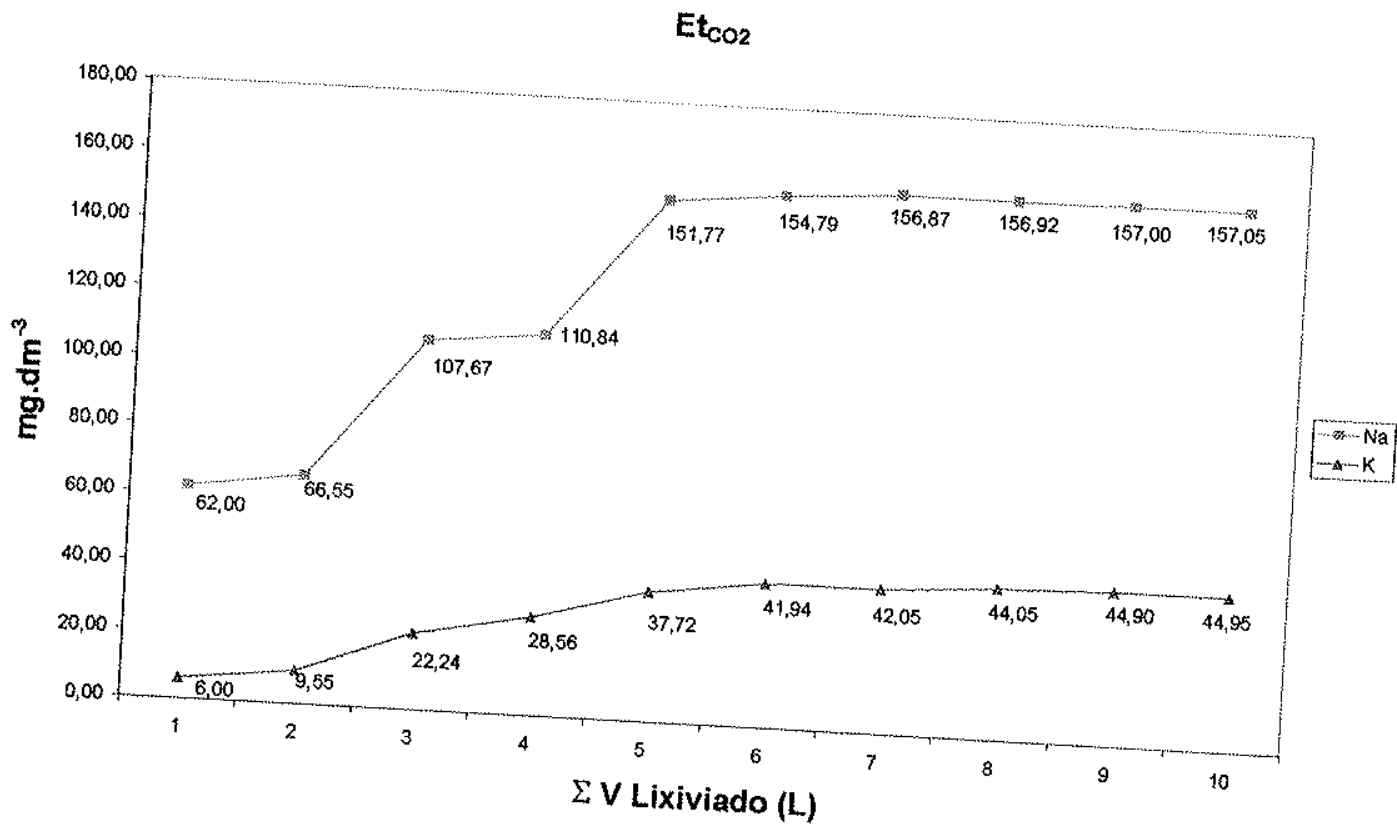

(d) 


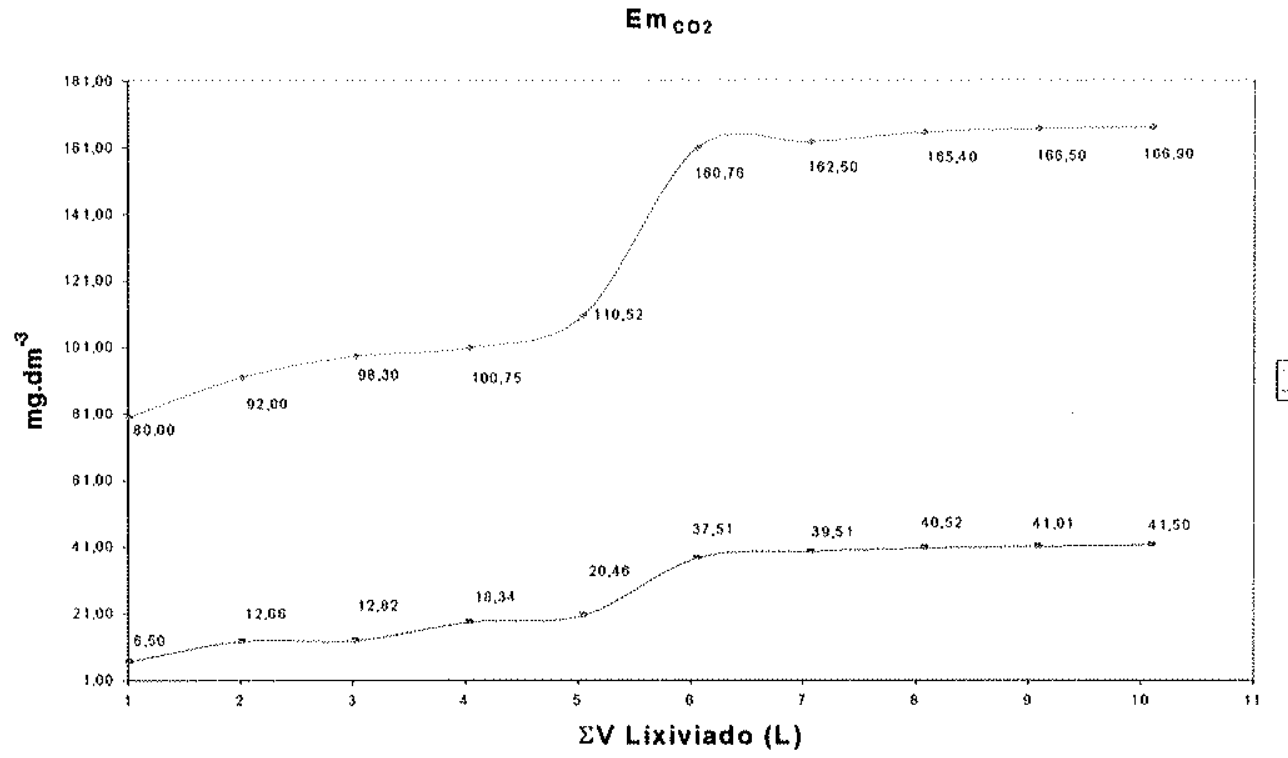

(e)

\section{$\mathrm{Eb}_{\mathrm{cO2}}$}

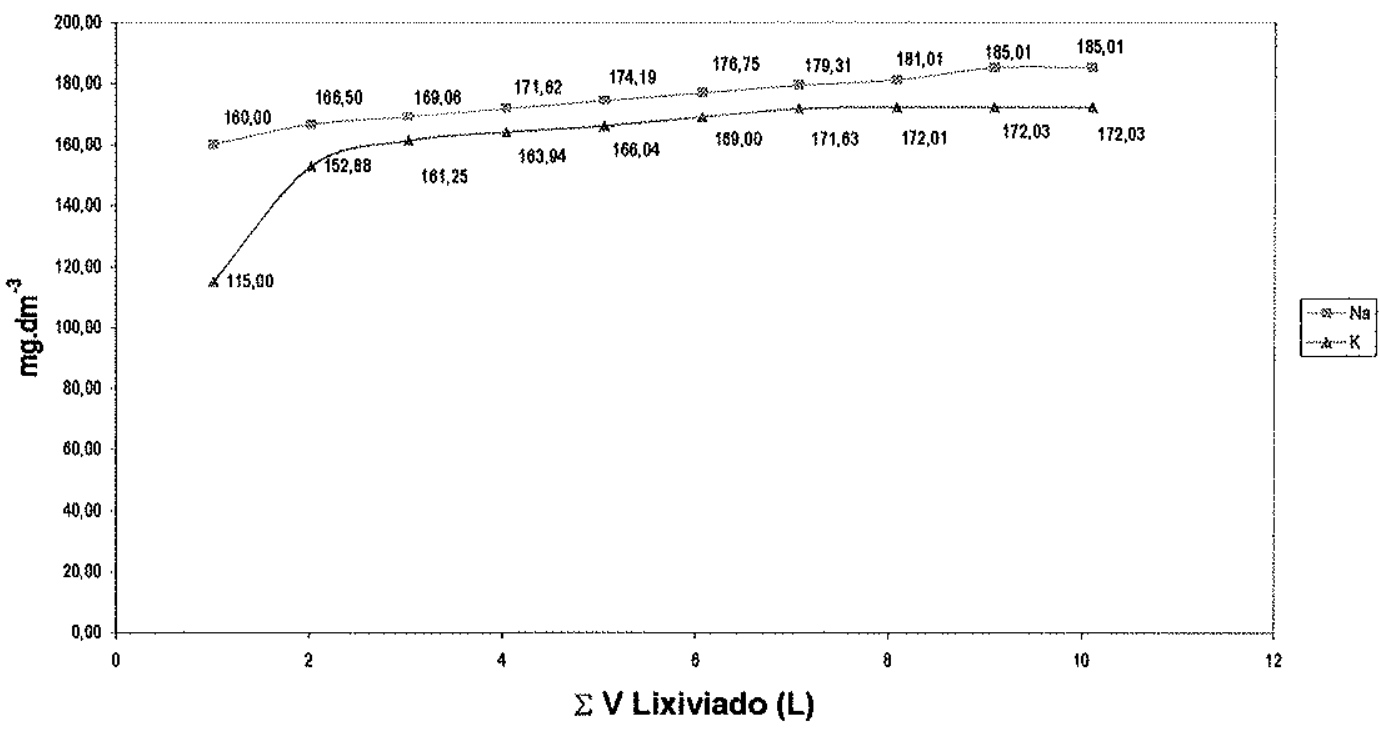

(f)

FIGURAS 8.1.3 a à f: Comportamento dos íons sódio e potássio em função do somatório do volume lixiviado. 
A partir do sexto dia a concentração de sódio e potássio mantém-se constante.

Considerou-se o volume de dez litros, o suficiente para representar o total lixiviado, assim, o comportamento de $\mathrm{SO}_{4}{ }^{2-}, \mathrm{Cl}^{-}, \mathrm{NO}_{3}{ }^{2-}, \mathrm{Pb}^{2+}, \mathrm{Zn}^{2+}$ e $\mathrm{Cu}^{2+}$ é estudado através do conteúdo total lixiviado. (TABELAS 8.1.3 a e b).

As FIGURAS 8.1.4 a à f são projeções das concentrações dos ânions e cátions no topo, meio e base.

TABELAS 8.1.3: ANÁLISE QUIMICA TOTAL $\left(\mathrm{mg}^{\left.-\mathrm{dm}^{-3}\right)}\right.$ de $\mathrm{Pb}^{2+}, \mathrm{Zn}^{2+}, \mathrm{Cu}^{2+}, \mathrm{SO}_{4}{ }^{2-}, \mathrm{Cl}^{-}$e $\mathrm{NO}_{3}$. DA SOLUÇÃO LIXIVIADA $\left(\mathrm{H}_{2} \mathrm{O}\right.$ e H $\left.\mathrm{H}_{2} \mathrm{O} / \mathrm{CO}_{2}\right)$ NAS AMOSTRAS DE ESCÓRIA DO TOPO, DO MEIO E DA BASE.

(a)

\begin{tabular}{c|c|c|c|c|c|c|c|c|c|c|c|c|c|c|c|c|c}
\hline \multicolumn{3}{c|}{$\mathrm{Et}_{\mathrm{H}_{2}} \mathrm{O}$} & \multicolumn{5}{c|}{$\mathrm{Em}_{2} \mathrm{O}$} & \multicolumn{5}{c|}{$\mathrm{Eb}_{\mathrm{H}_{2}} \mathrm{O}$} \\
\hline $\mathrm{Pb}^{+2}$ & $\mathrm{Zn}^{2+}$ & $\mathrm{Cu}^{2+}$ & $\mathbf{s O}_{4}^{2-}$ & $\mathrm{Cl}^{-}$ & $\mathrm{NO}_{3}$ & $\mathrm{~Pb}^{+2}$ & $\mathrm{Zn}^{2+}$ & $\mathrm{Cu}^{2+}$ & $\mathrm{sO}_{4}^{2-}$ & $\mathrm{Cl}^{-}$ & $\mathrm{NO}_{3}$ & $\mathrm{~Pb}^{+2}$ & $\mathrm{Zn}^{2+}$ & $\mathrm{Cu}^{2+}$ & $\mathbf{s O}_{4}^{2-}$ & $\mathrm{Cl}^{-}$ & $\mathrm{NO}_{3}$ \\
\hline 80,96 & 15,94 & 1,20 & 2736,52 & 59,17 & 6,54 & 34,87 & 7,80 & 0,53 & 3020,36 & 89,50 & 6,50 & 18,93 & 9,10 & 0,10 & 4830,20 & 99,34 & 6,60 \\
\hline
\end{tabular}

(b)

\begin{tabular}{|c|c|c|c|c|c|c|c|c|c|c|c|c|c|c|c|c|c|}
\hline \multicolumn{6}{|c|}{$\mathrm{Etco}_{2}$} & \multicolumn{6}{|c|}{$\mathrm{EmCO}_{2}$} & \multicolumn{6}{|c|}{$\mathrm{EbCO}_{2}$} \\
\hline $\mathrm{Pb}^{+2}$ & $\mathrm{Zn}^{2+}$ & $\mathrm{Cu}^{2+}$ & $\mathrm{SO}_{4}^{2-}$ & $\mathrm{cl}^{-}$ & $\mathrm{NO}_{3}$ & $\mathrm{~Pb}^{+2}$ & $\mathrm{Zn}^{2+}$ & $\mathrm{Cu}^{2+}$ & $\mathrm{SO}_{4}^{2-}$ & $\mathrm{cl}^{-}$ & $\mathrm{NO}_{3}$ & $\mathrm{~Pb}^{+2}$ & $\mathrm{Zn}^{2+}$ & $\mathrm{Cu}^{2+}$ & $\mathrm{SO}_{4}^{2-}$ & $\mathrm{Cl}^{-}$ & $\mathrm{NO}_{3}$ \\
\hline 149,42 & 17,42 & 1,62 & 3504,63 & 67,51 & 3,02 & 69,26 & 15,70 & 1,25 & 2507,50 & 53,65 & 1,61 & 12,74 & 8,05 & 0,15 & 3380,92 & 55,91 & 3,01 \\
\hline
\end{tabular}




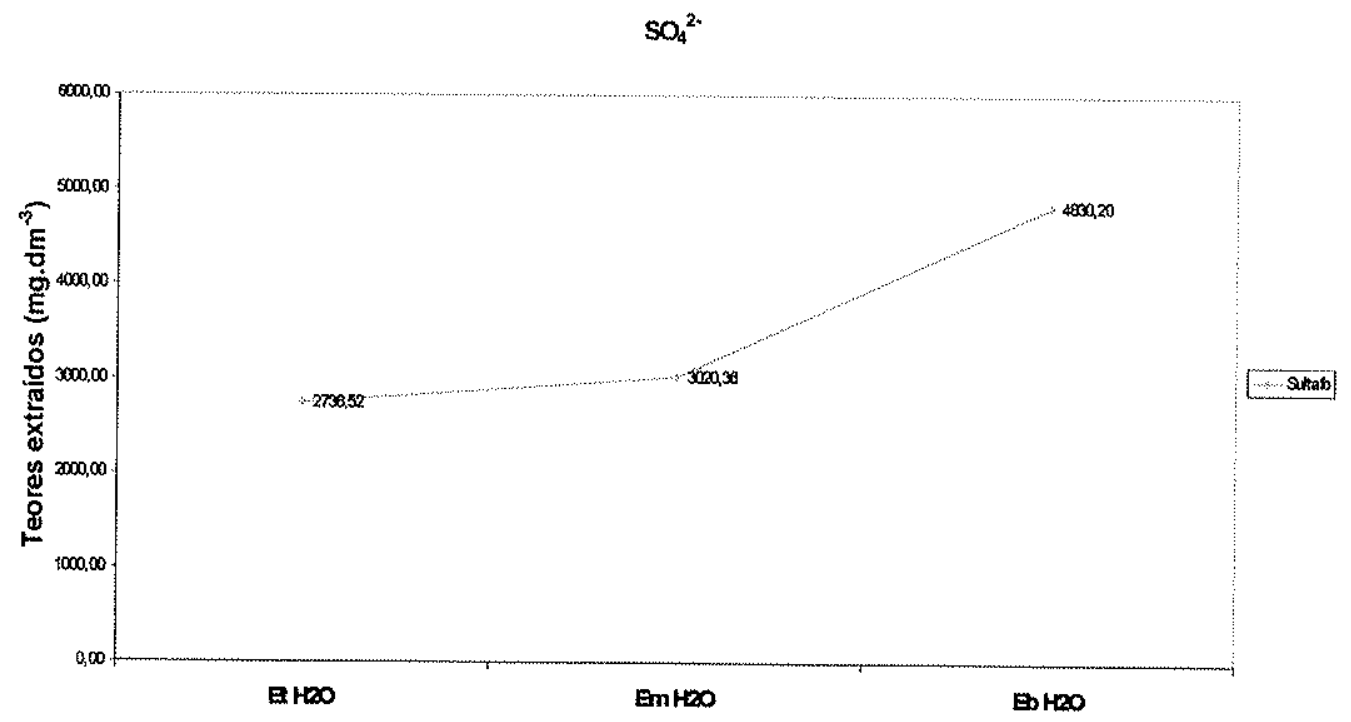

(a)

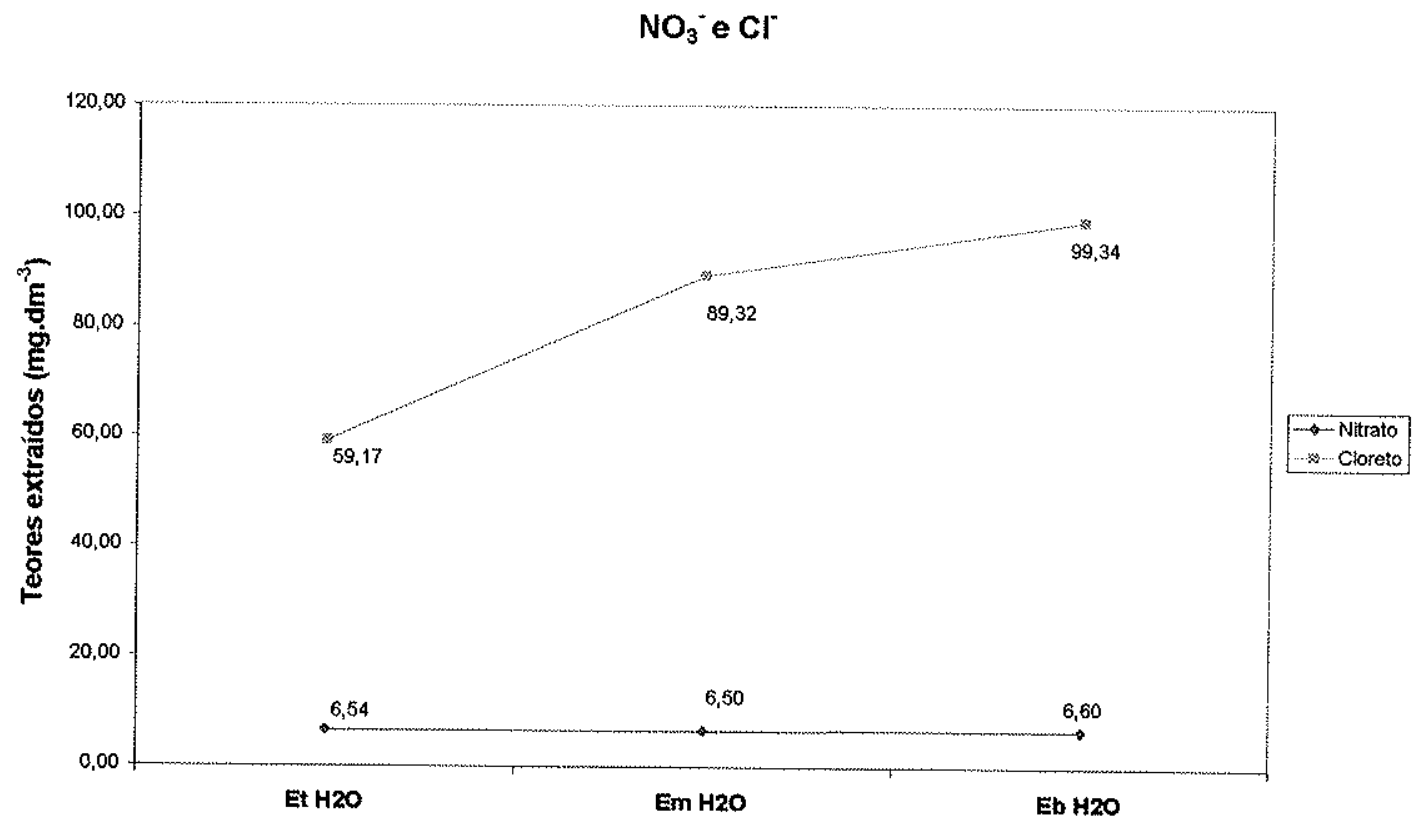

(b) 


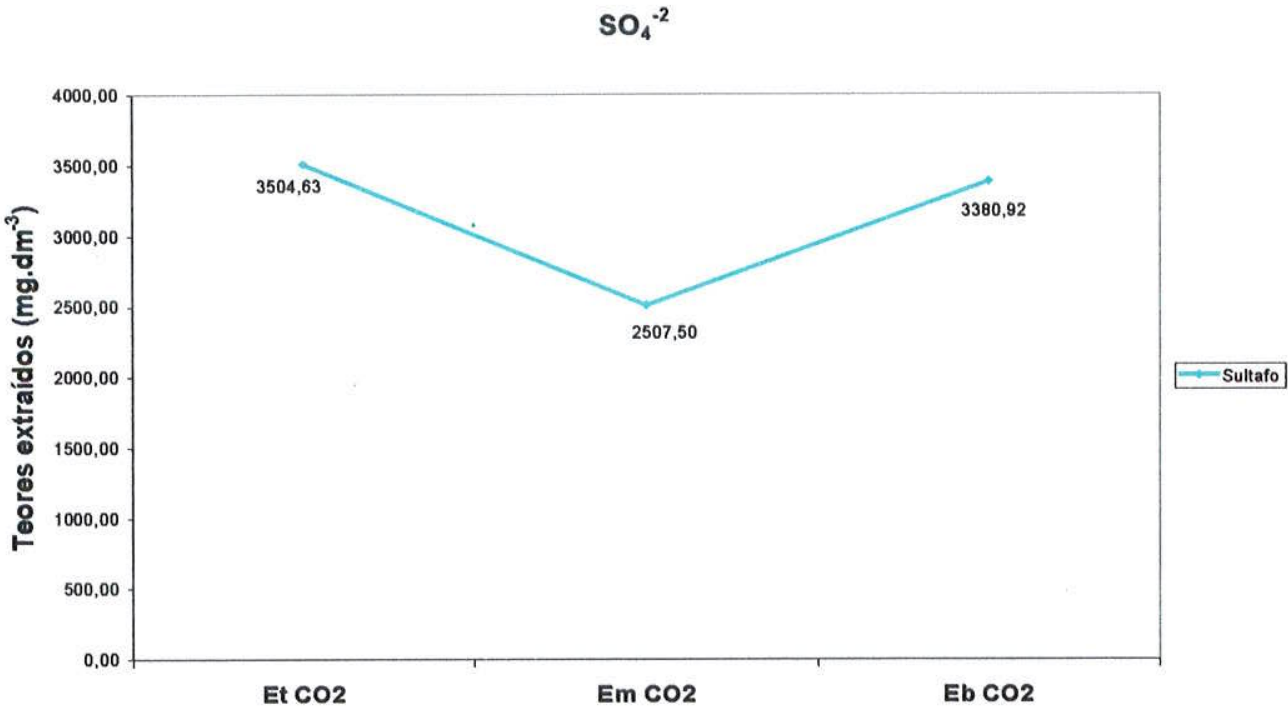

(c)

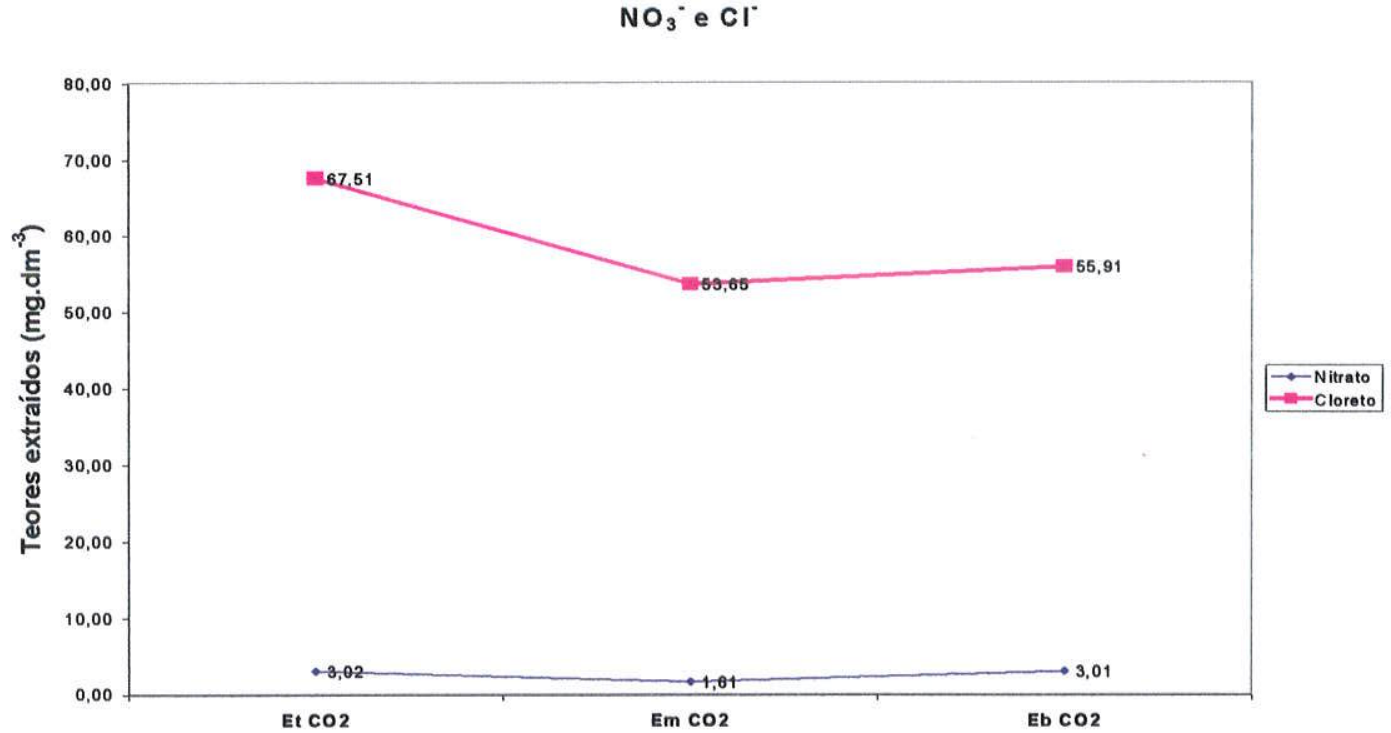

(d) 
$\mathrm{Pb}, \mathrm{Zn} \in \mathrm{Cu}$

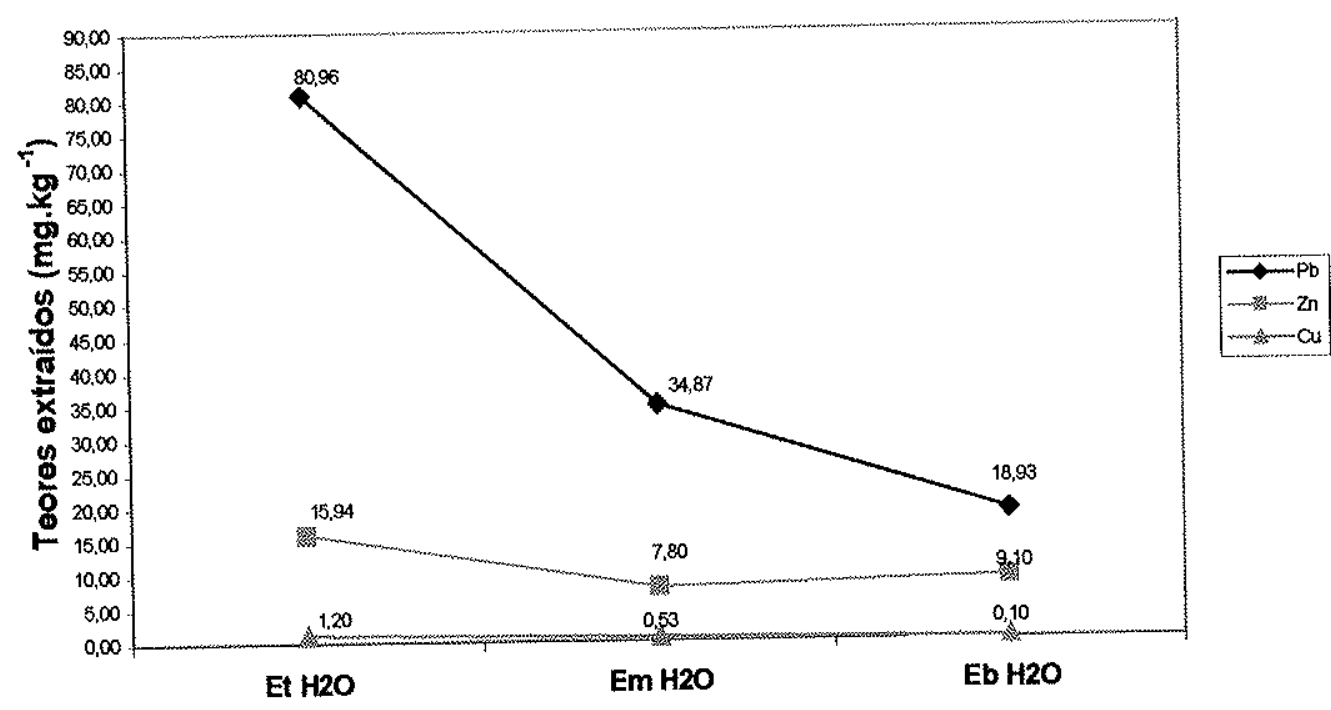

(e)

$\mathrm{Pb}, \mathrm{Zn}$ e Cu

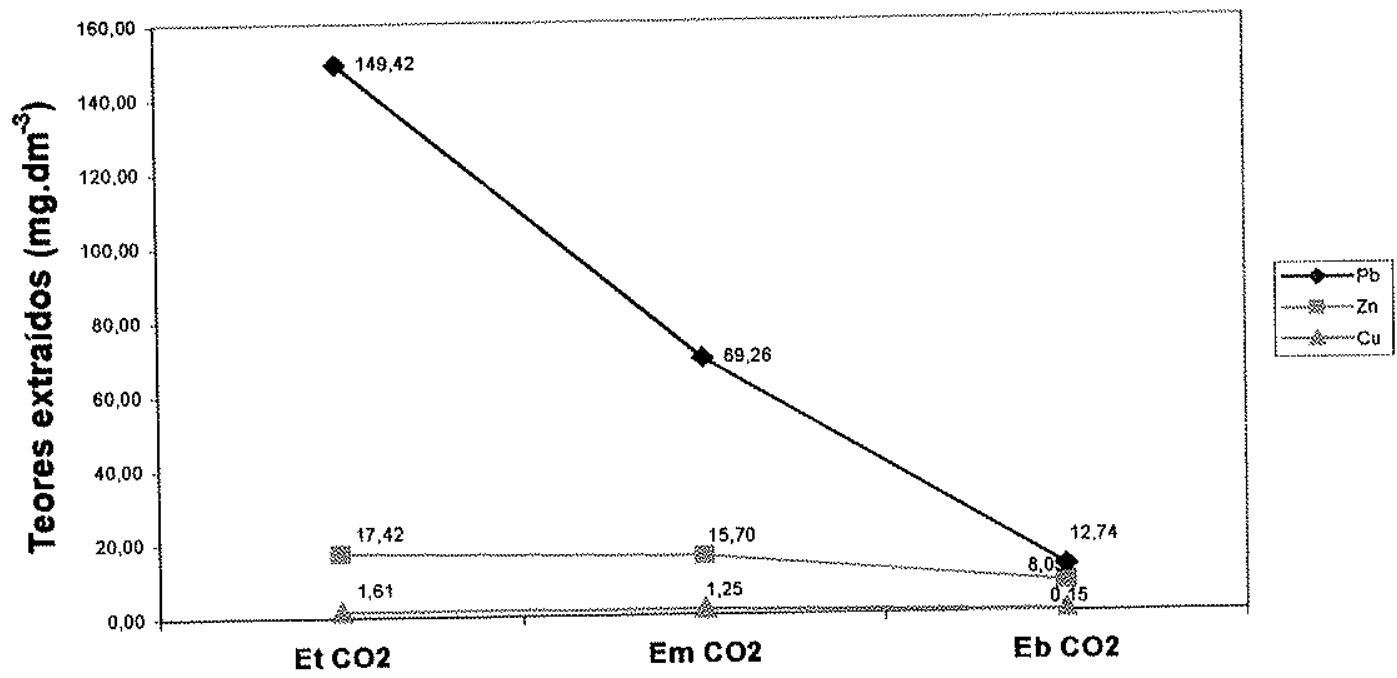

(f)

FIGURAS a à f 8.1.4: Concentração total $\left(\mathrm{mg}^{\left.-\mathrm{dm}^{-3}\right)}\right.$ de chumbo, zinco, cobre, $\mathrm{SO}_{4}{ }^{2-}, \mathrm{Cl}$ e $\mathrm{NO}_{3}{ }^{2-}$ na solução lixiviada no topo, meio e base da pilha. 
Quando se comparam os resultados analíticos de $\mathrm{SO}_{4}{ }^{2-}$ e $\mathrm{Cl}^{-}$nas extrações com $\mathrm{H}_{2} \mathrm{O}$ e $\mathrm{H}_{2} \mathrm{O} / \mathrm{CO}_{2}$, constata-se que seles ão mais eliminados no topo que na base, com valores intermediários na porção mediana.

O nitrato, forma solúvel dos sais, ocorre em baixas concentrações na escória, o que se comprova pela sua contínua mobilidade em todas as porções da pilha.

O comportamento dos cátions também é semelhante em ambos os tipos de extração sendo maior a eliminação $c o m \mathrm{H}_{2} \mathrm{O} / \mathrm{CO}_{2}$.

A disponibilidade do $\mathrm{Zn}^{2+}$ e $\mathrm{Cu}^{2+}$ em ambas as extrações é semeihante e praticamente constante. Seus teores são baixos em relação ao $\mathrm{Pb}^{2+}$.

O chumbo, no topo, encontra-se menos fixo por apresentar-se na porção mais aerada, sob a forma de $\mathrm{HCO}_{3}{ }^{-}$e mesmo como $\left(\mathrm{HSO}_{4}{ }^{-}\right)$, que são as formas mais solúveis produto da oxidação do $\mathrm{S}^{2-}$. A oxidação do $\mathrm{S}^{2-}$ é comprovada também pela maior disponibilidade de $\mathrm{SO}_{4}{ }^{2-}$ no topo e pela eficiência das soluções ácidas geradas principalmente pela hidrólise do $\mathrm{CO}_{2}$.

$$
\begin{aligned}
& \mathrm{CO}_{2(\mathrm{~g})}+\mathrm{H}_{2} \mathrm{O}_{(l)} \rightrightarrows \mathrm{H}_{2} \mathrm{CO}_{3}(\mathrm{aq}) \\
& \mathrm{H}_{2} \mathrm{CO}_{3 \text { (aq) }} \leftrightarrows \mathrm{HCO}_{3 \text { (aq) }}+\mathrm{H}^{+}{ }_{(\mathrm{aq})} \\
& \mathrm{H}^{+}{ }_{(\mathrm{aq})}+\mathrm{PbCO}_{3(\text { aq) }} \doteqdot \mathrm{HCO}_{3^{-} \text {(aq) }}+\mathrm{H}^{+}{ }_{\text {(aq) }}+\mathrm{Pb}^{2+}{ }_{\text {(aq) }} \\
& \mathrm{S}^{2-(\mathrm{aq})}+\mathrm{O}_{2(\mathrm{~g})} \leftrightarrows \mathrm{SO}_{2(\text { (aq) }} \\
& \mathrm{SO}_{2 \text { (aq) }}+\mathrm{H}_{2} \mathrm{O}_{(\mathrm{l})} \leftrightarrows \mathrm{SO}_{3}{ }^{2} \text { (aq) }+2 \mathrm{H}^{+} \text {(aq) } \\
& \mathrm{SO}_{3}{ }^{2-}{ }_{(\mathrm{aq})}+\mathrm{H}_{2} \mathrm{O}_{(\mathrm{l})} \leftrightarrows \mathrm{SO}_{4}{ }^{2-}(\mathrm{aq})+2 \mathrm{H}^{+} \text {(aq) }
\end{aligned}
$$

Por outro lado, na base, além da ausência de $\mathrm{CO}_{3}{ }^{2-}$, a liberação de $\mathrm{SO}_{4}{ }^{-2}$ é menor, indicando presença de $\mathrm{Pb}^{2+}$ na forma de $\mathrm{SO}_{4}{ }^{2-}$ e de $\mathrm{Cl}^{-}$precipitados. 


\subsection{EXTRAÇÃo TOTAL DE CHUMBO, ZINCO E COBRE NO SOLO E SOLOISEDIMENTO.}

Extração Total em solos, de modo geral, refere-se ao tratamento de amostras que possibilita a compreensão da disponibilidade dos ions metálicos associados aos diferentes constituintes.

Geralmente são utilizados ácidos clorídrico, nítrico e acético, com divergência entre os pesquisadores quanto as concentrações e tempos de ataque.

SPOSITO et al. (1982) testaram $\mathrm{HNO}_{3} 2$ e $4 \mathrm{M}$ à $80^{\circ} \mathrm{C}$ dissolvendo sulfetos de cádmio, níquel, chumbo, zinco e parcialmente de cobre.

BECKETT (1989) em estudos específicos sobre extratores para constituintes do solo, cita o ácido nítrico $1 \mathrm{M}$ para dissolver sulfetos.

$\mathrm{O} \mathrm{HCl}$ geralmente é utilizado em concentração $0,1 \mathrm{M}$ para extração dos cátions adsorvidos, sendo capaz de deslocar cádmio, cobalto e zinco associados aos óxidos de ferro e manganês, carbonatos e matéria orgânica. Em concentração 0,5 M dissolve óxidos de cobre, hidrogenocarbonato de cobre e parcialmente sulfeto de cobre (LUOMMA \& JENNE apud BECKET, 1989).

Um outro método de Extração Total refere-se ao ataque com os seguintes reagentes: dietilenodiaminopentacético (ETPA), dietilenodiaminotetracético (EDTA) e EDTA/NH ${ }_{4} \mathrm{Ac}$, formando complexos estáveis com a maioria dos metais pesados (URE et al., 1993; QUEVAUVILLER et al., 1997; e MAZZUR, 1997).

A COMMUNITY BUREAU OF REFERENCE (BCR) indica como método padrão na extração total de íons metálicos, HAc 0,43 M (URE et al., 1992).

$\mathrm{Na}$ tentativa de encontrar um método padrão para extração total dos íons metálicos chumbo, zinco e cobre foram realizados testes em meio nítrico. Escolheuse este ácido devido a presença de sais de chumbo (principal contaminante da área de estudo) que são poucos solúveis em água e nos principais ácidos inorgânicos mas, que no entanto, na maioria das vezes, são solúveis em meio nítrico.

Para os testes foram utilizadas frações de solo menores que $2,00 \mathrm{~mm}$ e $0,063 \mathrm{~mm}$ da amostra S-5. 
Utilizaram-se massas de $1,0000 \mathrm{~g}$ e volume de $50 \mathrm{~mL}$ de ácido nítrico nas concentrações 16,0; 8,0; 3,0; 1,0 e 0,1 M. As misturas foram mantidas em repouso, com eventual agitação, por 2 horas, tempo utilizado na maioria dos trabalhos.

As soluções foram separadas por filtração, os resíduos lavados com $\mathrm{HNO}_{3}$ $0,01 \%$, avolumados e analisados quimicamente.

Os resultados analíticos dos íons chumbo, zinco e cobre encontram-se nas TABELAS 8.2.1 a e b.

TABELAS 8.2.1 : RESULTADOS (mg.dm³ ${ }^{3}$ ) DA EXTRAÇÃO TOTAL COM HNO 3 0,1 M; $1,0 \mathrm{M} ; 3,0 \mathrm{M}$; 8,0 M E 16,0 M NAS FRAÇÕES $<2,00 \mathrm{~mm}$ (a) $\mathrm{E}<0.063 \mathrm{~mm}$ (b) amostra S-5.

(a)

\begin{tabular}{c|c|c|c|c|c|c|c|c|c|c|c|c|c|c|c}
\hline \hline $\mathrm{Pb}^{+2}$ & $\mathrm{Zn}^{+2}$ & $\mathrm{Cu}^{+2}$ & $\mathrm{~Pb}^{+2}$ & $\mathrm{Zn}^{+2}$ & $\mathrm{Cu}^{+2}$ & $\mathrm{~Pb}^{+2}$ & $\mathrm{Zn}^{+2}$ & $\mathrm{Cu}^{+2}$ & $\mathrm{~Pb}^{+2}$ & $\mathrm{Zn}^{+2}$ & $\mathrm{Cu}^{+2}$ & $\mathrm{~Pb}^{+2}$ & $\mathrm{Zn}^{+2}$ & $\mathrm{Cu}^{+2}$ \\
\hline & $0.1 \mathrm{M}$ & & & $1 \mathrm{M}$ & & & $3 \mathrm{M}$ & & & $8 \mathrm{M}$ & & & $16 \mathrm{M}$ & \\
\hline 221,20 & 30,0 & 6,46 & 231,20 & 50,0 & 9,98 & 367,80 & 60,03 & 14,70 & 451,20 & 77,80 & 19,40 & 452,10 & 78,20 & 20,90 \\
\hline \hline
\end{tabular}

(b)

\begin{tabular}{l|l|l|l|l|l|l|l|l|l|l|l|l|l|l}
\hline \hline $\mathrm{Pb}^{+2}$ & $\mathrm{Zn}^{+2}$ & $\mathrm{Cu}^{+2}$ & $\mathrm{~Pb}^{+2}$ & $\mathrm{Zn}^{+2}$ & $\mathrm{Cu}^{+2}$ & $\mathrm{~Pb}^{+2}$ & $\mathrm{Zn}^{+2}$ & $\mathrm{Cu}^{+2}$ & $\mathrm{~Pb}^{+2}$ & $\mathrm{Zn}^{+2}$ & $\mathrm{Cu}^{+2}$ & $\mathrm{~Pb}^{+2}$ & $\mathrm{Zn}^{+2}$ & $\mathrm{Cu}^{+2}$ \\
\hline & $\mathbf{0 . 1 M}$ & & & $1 \mathrm{M}$ & & & $3 \mathrm{M}$ & & & $8 \mathrm{M}$ & & & $16 \mathrm{M}$ & \\
\hline \hline 450,2 & 19,60 & 17,32 & 697,2 & 28,20 & 23,20 & 709,4 & 29,05 & 27,30 & 715,4 & 29,60 & 30,60 & 720,1 & 30,00 & 31,00 \\
\hline \hline
\end{tabular}

Apesar de se obter extração mais elevada dos íons na fração menor que $0,063 \mathrm{~mm}$, como apenas cerca de 0,90\% das amostras de solo correspondem a essa fração, utilizou-se somente aquelas menores que $2 \mathrm{~mm}$.

Obteve-se maior eficiência na extração em que se utilizou concentração $8 \mathrm{M}$ e $16 \mathrm{M}$ de ácido nítrico. Estabeleceu-se para as extrações solução 8M (FIGURAS 8.2.1 a à c). 


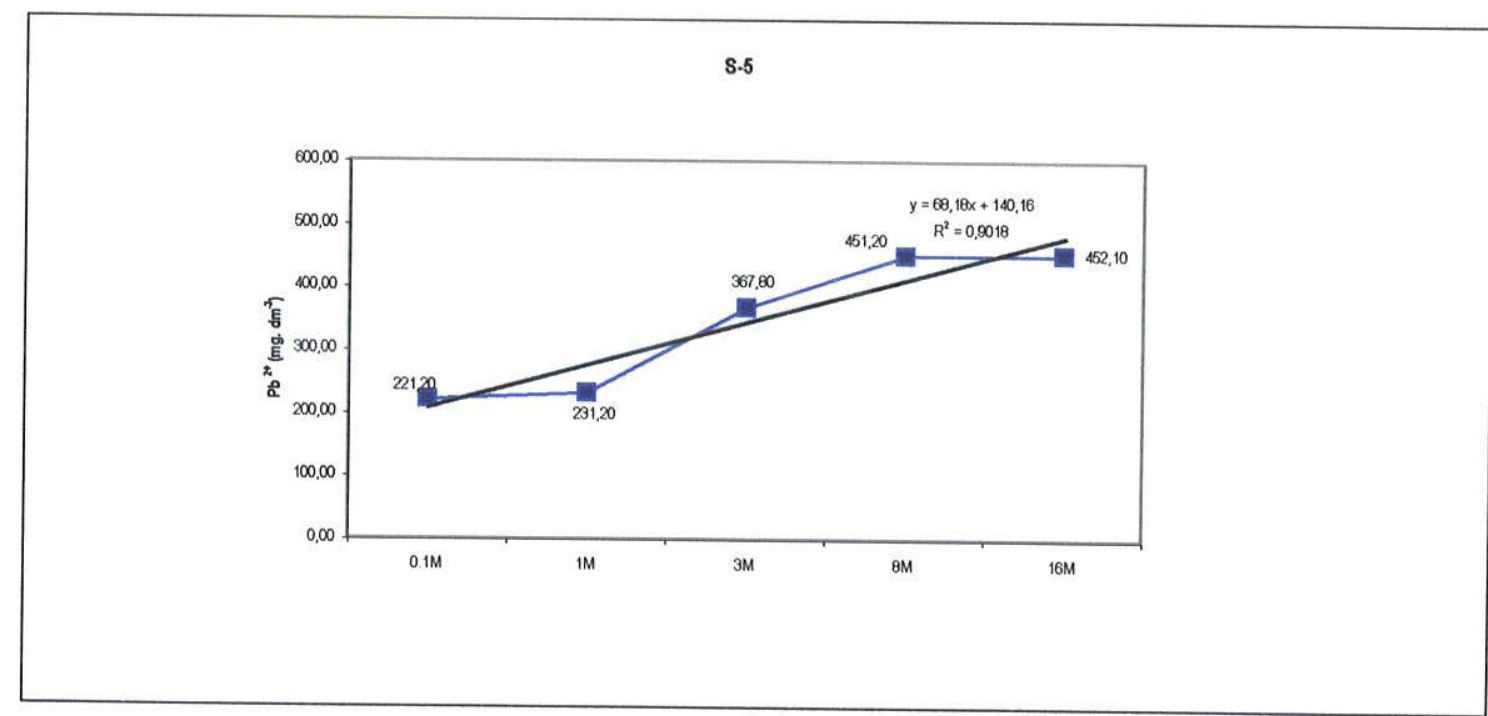

(a)

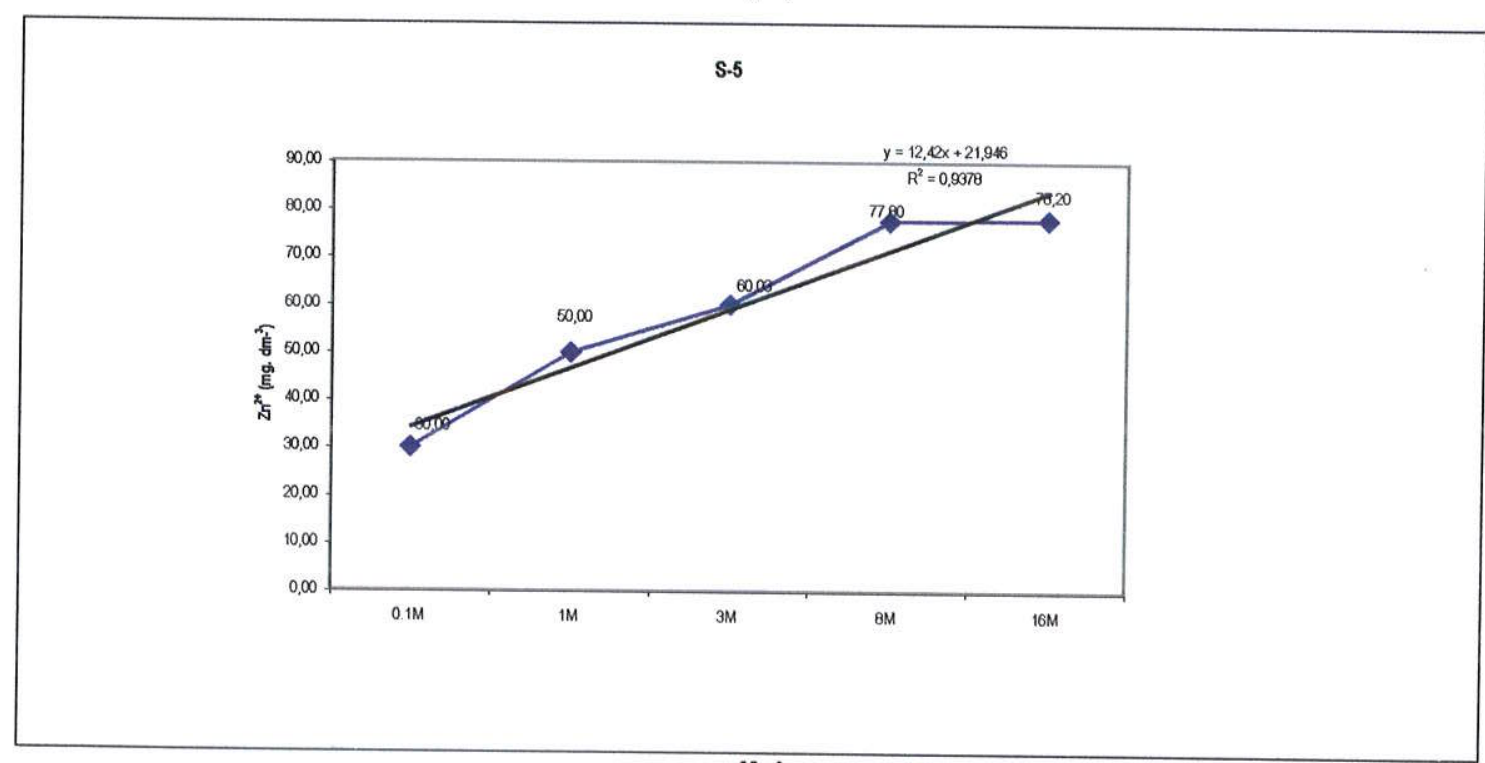

(b)

S-5

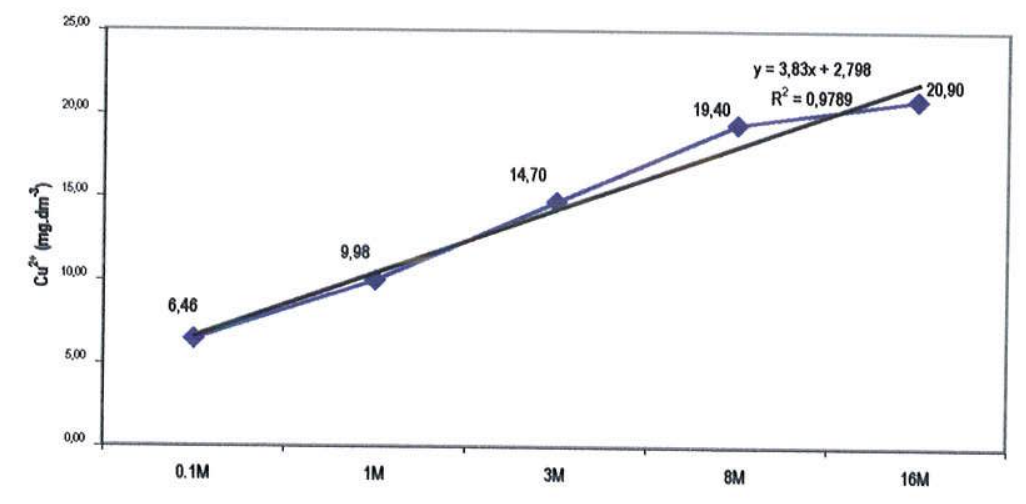

(c)

FIGURAS 8.2.1 a à c: Extração total de $\mathrm{Pb}$, Zn e Cu com $\mathrm{HNO}_{3} 0,1 \mathrm{M} ; 1,0 \mathrm{M} ; 3,0 \mathrm{M} ; 8,0 \mathrm{M}$ e $16,0 \mathrm{M}$ na amostra S-5 (Fração $<2 \mathrm{~mm}$ ). 
Um vez estabelecidas as condições experimentais de trabalho, efetuaram-se extrações de chumbo, zinco e cobre nos perfis S-3, S-4, S-6, S-9 e S-11 (TABELA 8.2.2)

TABELA 8.2.2: RESULTADO (mg.dm-3) DA EXTRAÇÃO TOTAL COM HNO ${ }_{3}$ 8M - AMOSTRAS S3, S4, S-6, S-9 e S-11.

\begin{tabular}{|c|c|c|c|}
\hline Amostra & $\mathrm{Pb}^{2+}$ & $\mathrm{Zn}^{2+}$ & $\mathrm{Cu}^{2+}$ \\
\hline $\mathrm{S}-3_{10}$ & 60,36 & 4,05 & 7,39 \\
\hline S-340 & 20,00 & 3,00 & 2,05 \\
\hline S-3 $380-420$ & 8,90 & 5,00 & 3,50 \\
\hline S-4 20 & 15,99 & 1,90 & 1,63 \\
\hline S-4 $45-60$ & 18,00 & 2,50 & 3,00 \\
\hline S-4200-250 & 14,09 & 2,30 & 2,90 \\
\hline S-6 610 & 150,00 & 20,03 & 2,05 \\
\hline$S-680$ & 15,00 & 6,00 & 3,00 \\
\hline S-6 ${ }_{135}$ & 14,36 & 2,50 & 1,90 \\
\hline$S-6{ }_{160}$ & 12,05 & 3,90 & 1,50 \\
\hline$S-6215$ & 11,05 & 1,90 & 0,50 \\
\hline$S-9_{10}$ & 4,00 & 1,95 & 1,60 \\
\hline$S-9_{45}$ & 3,50 & 1,90 & 0,50 \\
\hline $\mathrm{S}-970$ & 3,40 & 1,50 & 0,45 \\
\hline S-110-10 & 175,00 & 38,45 & 1,05 \\
\hline S-11 $1{ }_{150}$ & 6,00 & 3,50 & 1,01 \\
\hline
\end{tabular}

A Extração Total com ácido nítrico $8 \mathrm{M}$ dos pontos amostrados permitiram concluir que o chumbo está presente em maior quantidade em todos os perfis estudados (FIGURAS 8.2.2 a à e). 


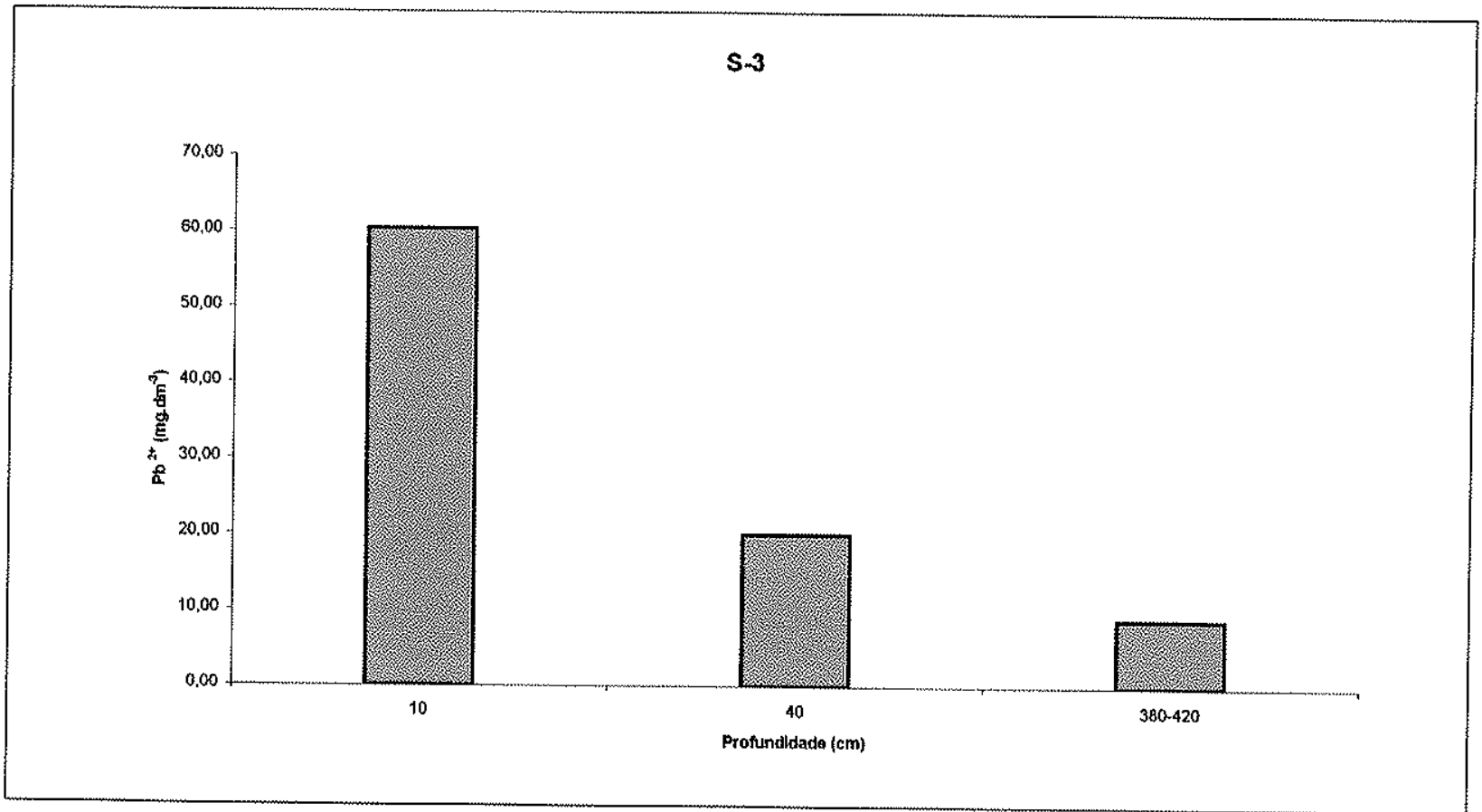

(a)

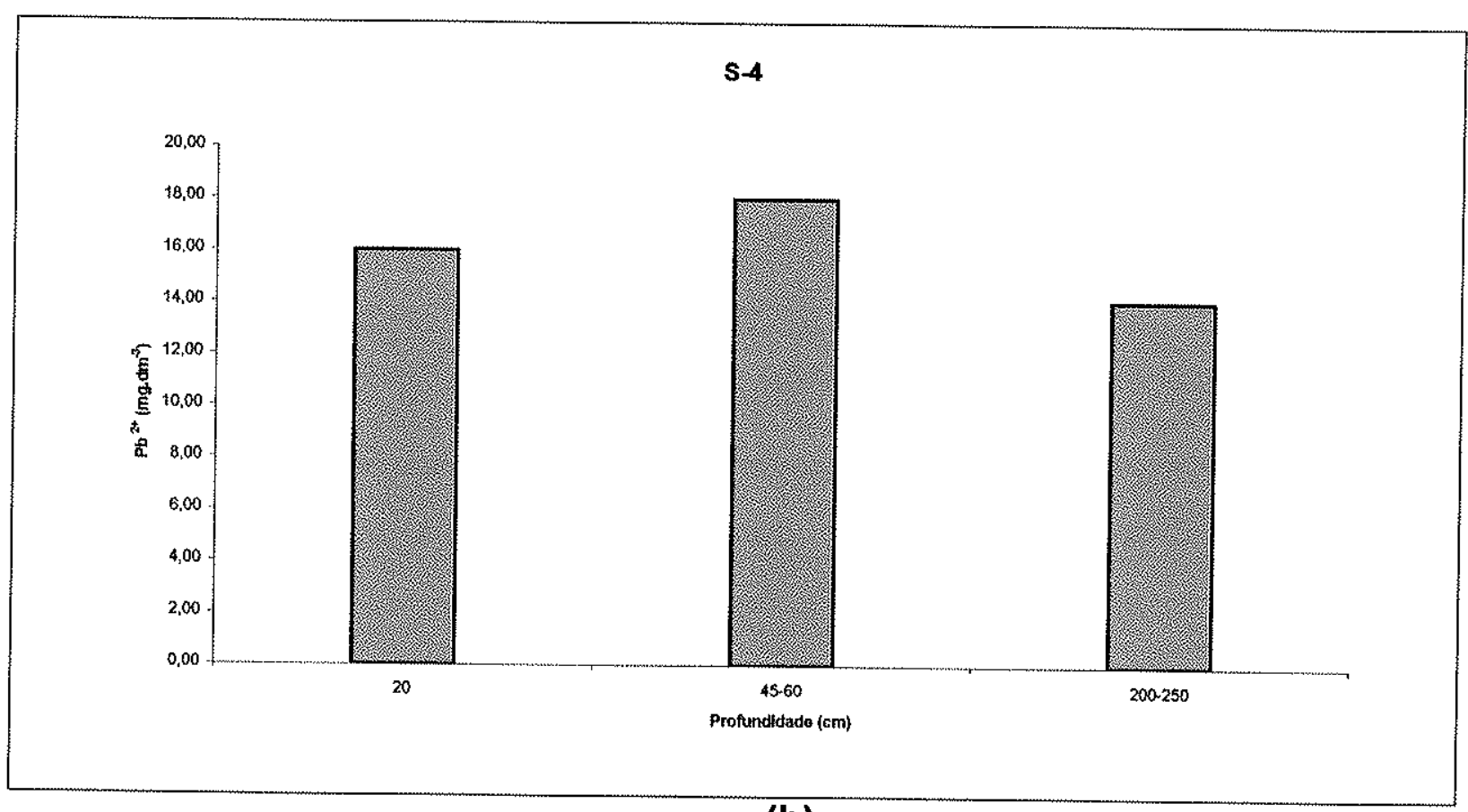

(b) 


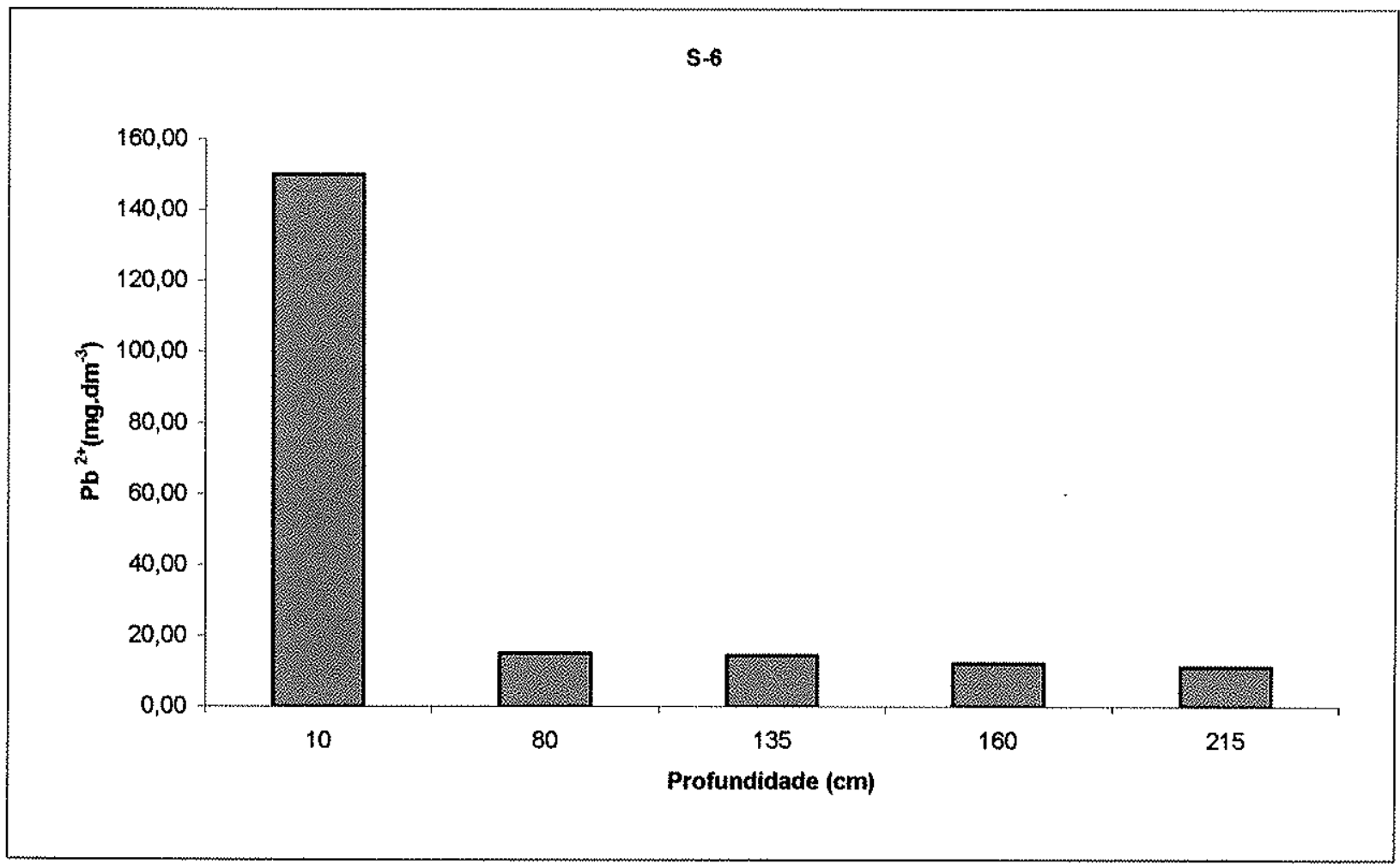

(c)

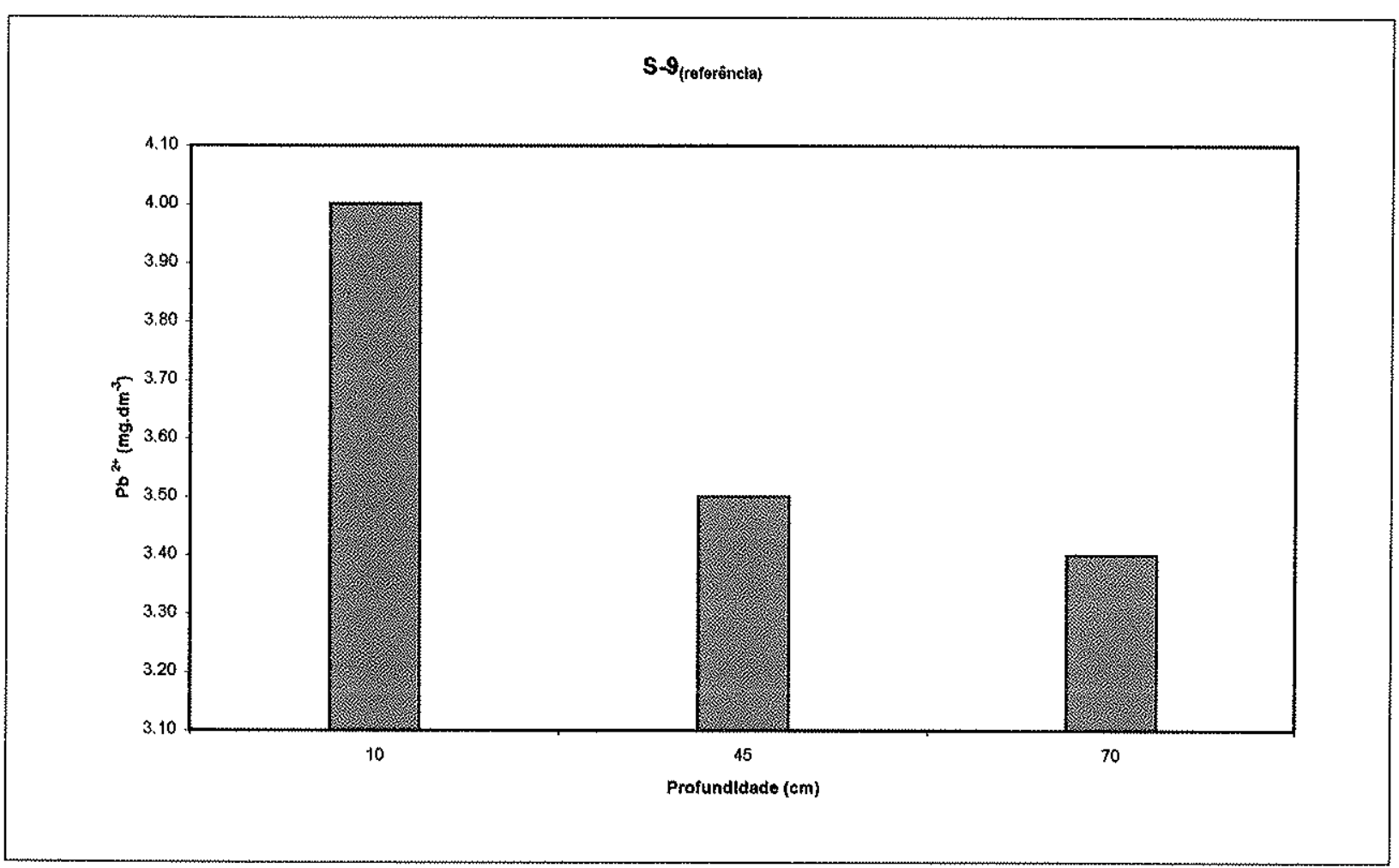

(d) 


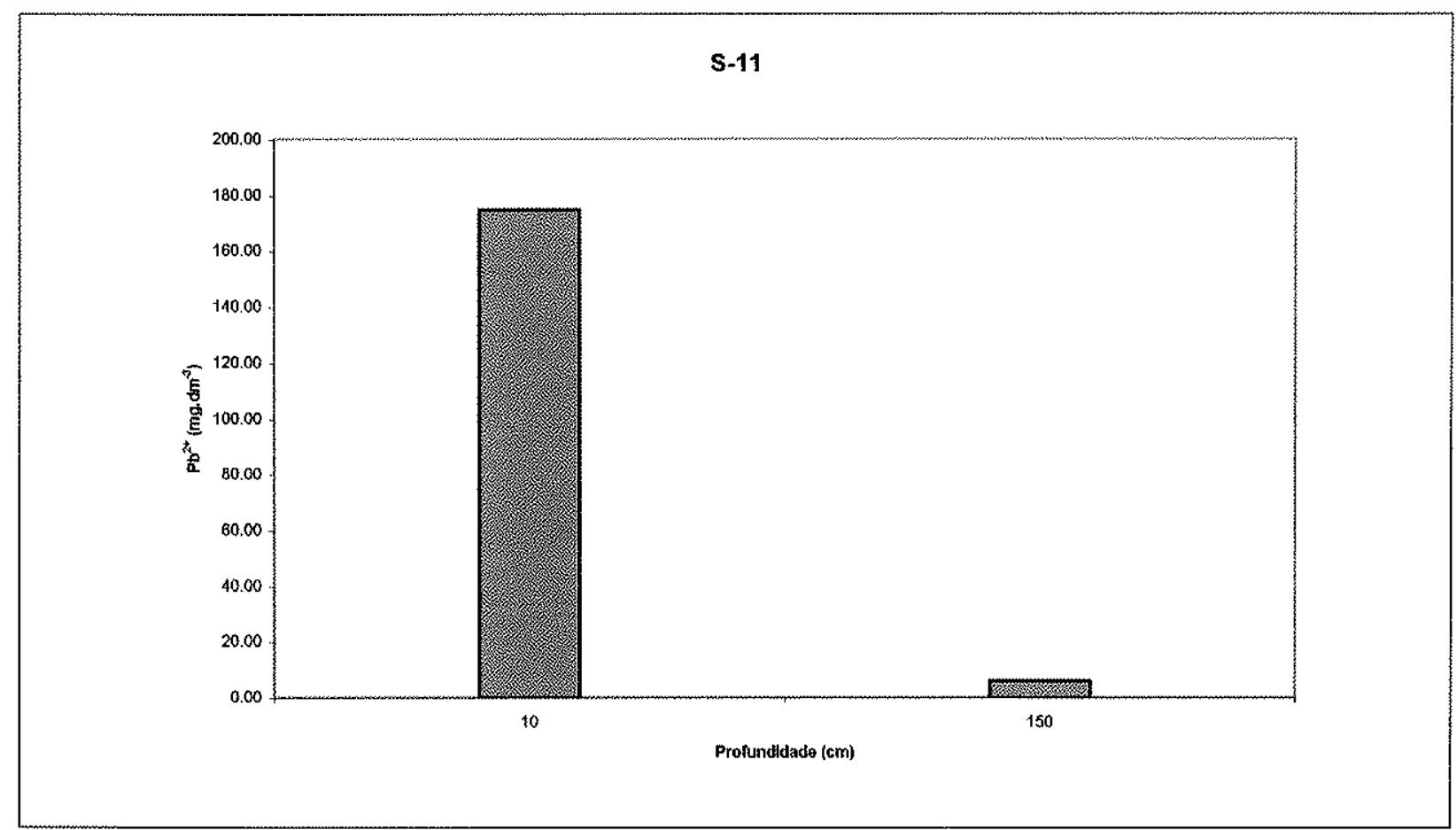

(e)

FIGURAS 8.2.2 a à e: Extração Total de Pb2+ nos perfis S-3, S-4, S-6, S-9 e S-11.

Dos três íons metálicos estudados, o chumbo é encontrado nos primeiros centímetros do em maior quantidade.

O ponto S-6, localizado 50 metros a baixo da pilha de escória, apresenta-se acima dos valores orientadores da CETESB (2002)

Em S-11, perfil correspondente a margem do Córrego Divisa, local de descarga do efluente "tratado" da Empresa, o teor de $\mathrm{Pb}^{2+}$ na porção superficial do perfil é quarenta vezes superior ao ponto $\$ 9$ tomado como referência (branco), também excedendo os índices de orientação preconizados pela CETESB (op.cit).

A amostra composta S-5 associada a pilha de escória é a mais contaminada, apresentando altos teores de $\mathrm{Pb}^{2+}$ devido a presença de grande quantidade de escórias soterradas, já parcialmente decompostas. 


\subsection{EXTRAÇÕES SEQUENCIAIS}

Procedimentos de Extrações Seqüenciais são aplicados em sistemas sólidos, líquidos e gasosos; aqui são estudadas extrações de íns metálicos associados a fase sólida do solo impactado da área de estudos.

As metodologias utilizadas, visando avaliar a especiação de íons metálicos em solos, através de Extrações Seqüenciais, vêm sendo publicadas desde as duas últimas décadas (QUEVAUVILLER et al., 1997). TESSIER et al. (1979) foi um dos primeiros a realizar trabalhos sistemáticos de extrações $e$ as publicações posteriores, de outros autores, acham-se fundamentalmente baseadas em seus trabalhos.

Dos métodos existentes, além do apresentado por TESSIER, destacam-se os de KERSTEN \& FORSTNER (1986); BECKETT (1989); YOUG et al. (1993); DAVIDSON et al. (1994); BEVILACQUA (1996); QUEVAUVILLER et al. (1997); MESTER et al. (1998); CAMPOS et al. (1998); DONG et al. (1999); PÉREZ-CID et al. (1999); TOKALIOGLU et al. (1999); ARIZA et al (2000); MAIZ et al. (2000), GLEYZES et al.(2002), LÃ et al. (2003) e MARQUES et. al (2003).

Os procedimentos para extrações seqüenciais de solo/sedimento consistem em tratar amostras com reagentes adequados sob condições específicas. Estes reagentes são de diferentes naturezas e concentrações variadas que extraem seletivamente os íons trocáveis (fracamente ligados), aqueles associados a carbonatos, a óxidos/hidróxidos de ferro e manganês e matéria orgânica.

Para os testes de extrações seqüenciais, utilizou-se a amostra composta S-5 associada a pilha de escória cuja contaminação foi comprovada através de análises químicas prévias.

A seguir são apresentadas novas seqüências e adaptações das condições experimentais.

Para $\circ$ andamento das extrações seguiu-se o indicado por TESSIER, denominado a partir de agora MT (Método TESSIER), com alterações para facilitar as operações e melhorar os resultados.

Enquanto no material de TESSIER utiliza-se uma única amostra para toda a seqüência extrativa, neste trabalho, para maior precisão, para cada extração utilizouse, resultados, uma única alíquota da amostra S-5, denominado RJ. 
Os andamentos foram realizados em duplicata e os resultados apresentados correspondem aos valores médios.

\section{Fração Intersticial}

A migração iônica que ocorre na zona não saturada depende fundamentalmente das condições químicas e físico-químicas reinantes, além de parâmetros como textura, porosidade etc. A presença de água, no entanto, é decisiva, tratando-se de contaminação de águas subterrâneas é ela o veículo responsável pela mobilidade dos íons até a zona saturada (advecção).

Os materiais sólidos da zona não saturada encontram-se em equilibrio com as fases gasosa e líquida; na fase líquida encontram-se ions dissolvidos denominados intersticiais que são partículas livres hidratadas, não adsorvidas. Essas soluções, dependendo das características dos poros podem, em função das forças de adesão e coesão, fortemente adsorvidas (água higroscópica) ou disponivel nos micros e macroporos constituindo-se na água capilar.

Os íons em solução intersticial que serão estudados a seguir, apresentam-se na forma aquocomplexa, hidratada, fazendo parte da água capilar.

Normalmente para coleta da água intersticial, são utilizados lisímetros de sucção e dependendo de fatores como permeabilidade, porosidade, granulometria do solo etc. a coleta de água da zona não saturada constitui-se num processo, na maioria das vezes lento, chegando, em alguns casos, a apenas alguns mililitros após muitas horas de sucção.

Os lisímetros, em geral, são constituídos por cápsulas porosas de cerâmica, teflon ou politetrafluoretano (PTFE).

MAITRE et al. (1991), Mc GUIRE et al. (1992), ASTM (1996) e GONZÁLEZ et al. (1999) efetuaram grande número de experimentos e constataram adsorção de elementos como $\mathrm{Na}^{+}, \mathrm{Ca}^{2+}, \mathrm{K}^{+}, \mathrm{Mg}^{2+}, \mathrm{Cd}^{2+}, \mathrm{Co}^{2+}, \mathrm{Cr}^{3+}, \mathrm{Zn}^{2+}, \mathrm{Cl}^{-}, \mathrm{SO}_{4}{ }^{2-}, \mathrm{CO}_{3}{ }^{2-}, \mathrm{HCO}_{3}{ }^{2-}$ $\mathrm{NO}_{3}{ }^{-} \mathrm{e} \mathrm{NH}_{4}{ }^{+}$nas placas porosas dos lisímetros; esta perda pode comprometer os resultados analíticos das amostras coletadas.

A amostra coletada com auxílio de lisímetro possui baixa representatividade, uma vez que, apesar da placa porosa situar-se em pontos convenientes de um perfil, extraem amostras com diferentes gradientes de concentração, função da distância, do tempo de sucção, potência do vácuo, da permeabilidade, porosidade do solo etc. 
Em casos onde a coleta da água intersticial é bastante demorada, por exemplo, solos com textura argilosa, também em regiões áridas onde os solos apresentam-se secos, o resultado da composição das amostras líquidas deve ser considerado como o valor médio de várias amostras coletadas (ASTM op.cit.).

A imprecisão da coleta de água intersticial com lisímetros é ressaltada nos trabalhos de Biggar \& Nielsem e Law (apud ASTM 1996), que consideram os resultados qualitativos.

É necessário ainda ressaltar que as águas intersticiais coletadas através de lisímetros, devido às limitações físicas do equipamento, acham-se dentro de limites de pressão que variam de 450 a $650 \mathrm{mmHg}$; comprovando que acima desses valores, ainda tem-se presença de águas intersticiais (ASTM op.cit.).

A AMERICAN SOCIETY FOR TESTING MATERIALS (1996) sugere, como alternativa, antes de iniciar a sucção com lisímetro, que se adicione certa quantidade de água para disponibilizar os ions metálicos, método também considerado qualitativo.

Como conseqüência da baixa representatividade das coletas, ou seja do baixo grau de confiabilidade, pouca importância tem-se dado aos íns intersticiais, tanto que, nos processos de Extrações Sequenciais raramente são estudados.

É necessário, contudo, lembrar que esses íons são, nos processos de lixiviação, os mais disponíveis e os primeiros a migrarem para a zona saturada.

A constituição iônica dos íons intersticiais pode parecer, muitas vezes, a primeira vista, negligenciável, no entanto, quando se leva em conta sua contribuição global, em uma área de solo razoável passa a ser relevante.

Têm sido raras as tentativas para estudos da contribuição dos íns de agentes contaminantes instersticiais, podendo-se citar SPOSITO et al. (1982), Sims \& Patrick (apud BECKKET 1989) e Lund et al. (apud BECKKET 1989). Mesmo assim, KELLER \& VÉDY (1994) passaram a considerar a ação desses ions juntamente com aqueles trocáveis.

Seria de grande interesse um método com real representatividade de amostragem e facilidade de execução nos processos de extração dos íns intersticiais. Assim, o ideal seria uma amostragem pontual de solo, contendo íns intersticiais que seriam extraídos com um agente com as mesmas características da solução intersticial - água. 
A validade da quantificação dos ions intersticiais dependerá, em grande parte da representatividade da amostragem, sendo assim, é de extrema importância que se delimite bem a área de estudo e que se realize coletas pontuais no perfil em profundidades de interesse.

Dada a proibição por parte da Empresa, não foi possível instalar uma Estação Experimental na área de estudos. Desta forma, delimitou-se uma área, escolhida ao acaso, de aproximadamente $4 \mathrm{~m}^{2}$ no Campus da Cidade Universidade, junto ao Instituto de Geociências, para estudar os processos de extraçöes de ions intersticiais.

Em um quadrado de $1 \times 1 \mathrm{~m}$, dentro da área escolhida, após limpeza da superfície, inicialmente foi coletado material considerado como referência (branco). $\mathrm{Na}$ extremidade direita do quadrado foi realizada, com trado manual $(\varnothing=10 \mathrm{~cm})$, uma perfuração de $45 \mathrm{~cm}$ de profundidade, coletando-se amostras a cada $15 \mathrm{~cm}$.

Para os trabalhos experimentais, assim, como para as caraterizações das amostras, dada a homogeneidade do solo, utilizou-se uma amostra composta - SL.

Os resultados da Capacidade de Troca Catiônica e pH encontram-se na TABELA 8.3.1 e na FIGURA 8.3.1 tem-se o Difratograma de raios $X$. Os dados granulométricos projetados em diagrama de Sheppard são apresentados na TABELA 8.3.2. 
TABELA 8.3.1: VALORES DE $\mathrm{pH}, \triangle \mathrm{pH}$ E CTC $\left(\mathrm{mmol}_{\mathrm{c}} \mathrm{dm}^{-3}\right)$ DA AMOSTRA SL (COLETADA NO CAMPUS DA UNIVERSIDADE DE SÃO PAULO).

\begin{tabular}{c|c|c|c|c}
\hline \hline AMOSTRA & $\mathrm{pH}_{\mathrm{CaCl} 2}$ & $\mathrm{pH}_{\mathrm{KCl}}$ & $\Delta \mathrm{pH}$ & CTC \\
\hline $\mathrm{SL}$ & 5,90 & 5,80 & $+0,10$ & 77,6 \\
\hline \hline
\end{tabular}

TABELA 8.3.2 : DISTRIBUIÇÃO DAS FRAÇÕES GRANULOMÉTRICAS NO SOLO DA AMOSTRA SL E RESPECTIVA CLASSIFICAÇÃO TEXTURAL DE SHEPPARD (1954).

\begin{tabular}{|c|c|c|c|c|}
\hline \multicolumn{4}{|c|}{ Fração Granulométrica (\%) } & $\begin{array}{l}\text { Classificação } \\
\text { de SHEPARD }\end{array}$ \\
\hline Amostra & Argila & Silte & Areia & \\
\hline $\mathrm{SL}$ & 17,83 & 18,56 & 63,61 & Areia síltica \\
\hline
\end{tabular}




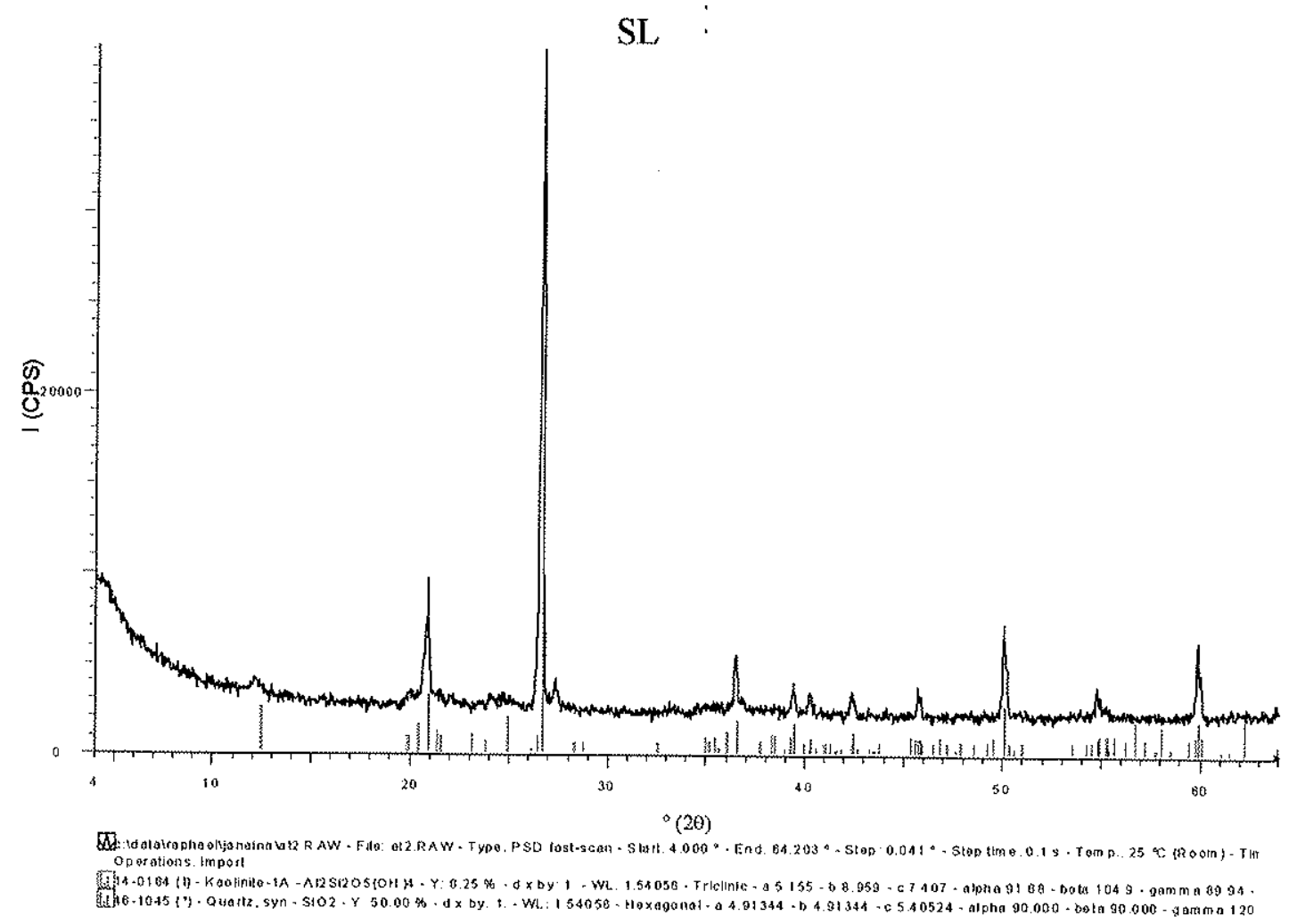
caulinita.

FIGURA 8.3.1: Difratograma da amostra SL evidenciando a predominância de quartzo e

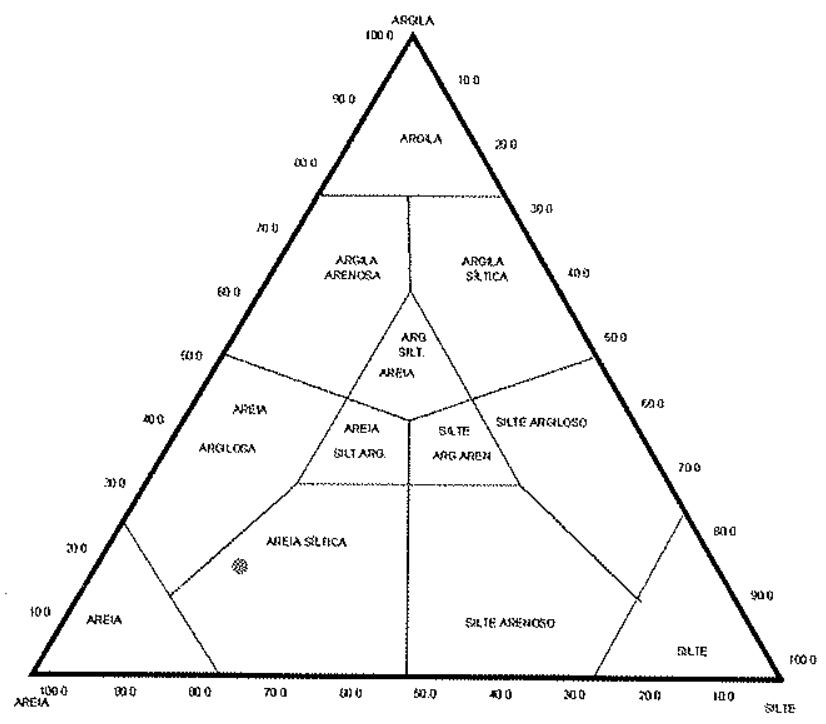

FIGURA 8.3.2: Projeção dos dados granulométricos em diagrama Triangular de Sheppard da amostra SL. 
A seguir, distribuindo-se a solução uniformemente na superfície, adicionaramse $20 \mathrm{~L}$ de solução de $60 \mathrm{mg}^{-\mathrm{dm}^{-3}}$ de cobre (correspondente ao valor de referência para solos indicado pela CETESB), $152 \mathrm{mg} \cdot \mathrm{dm}^{-3}$ de potássio e $92 \mathrm{mg} \cdot \mathrm{dm}^{-3}$ de sódio (escolhidos arbitrariamente).

Após 3 dias, com trado manual $(\varnothing=10 \mathrm{~cm})$, na região central, perfurou-se um poço com $45 \mathrm{~cm}$ de profundidade e coletaram-se amostras a cada $15 \mathrm{~cm}$ sendo a última coletada na altura da placa porosa do lisímetro (amostra $\mathrm{SL}_{45}$ ).

Nesse poço instalou-se um lisímetro segundo as normas da ASTM (1996) constituído de placa porosa com $6 \mathrm{~cm}$ de altura, poros de 1 a $3 \mu \mathrm{m}$, construído para suportar até $650 \mathrm{mmHg}$.

Num período de $72 \mathrm{~h}$ coletaram-se $47 \mathrm{~mL}$ de solução com $\mathrm{pH}$ da áuga, medido no local, de 6,80.

A seguir, em laboratório, efetuou-se extração com água de $1,0000 \mathrm{~g}$ de amostra (SL45) com igual volume daquela extraída pelo lisímetro - $47 \mathrm{~mL}$.

Os resultados das análises químicas dos dois experimentos encontram-se na TABELA 8.3.3.

TABELA 8.3.3: TEORES DE $\mathrm{Na}^{+}, \mathrm{K}^{+}$e $\mathrm{Cu}^{2+}$ $\left(\mathrm{mg}^{\left.-\mathrm{dm}^{-3}\right)}\right.$ DA EXTRAÇÃO DOS IONS INTERSTICIAIS COM LISIMETRO (AL) E COM ÁGUA (SL45).

\begin{tabular}{c|c|c|c}
\hline AMOSTRA & $\mathrm{Na}^{+}$ & $\mathrm{K}^{+}$ & $\mathrm{Cu}^{2+}$ \\
\hline $\mathbf{A L}$ & 4,73 & 3,73 & 0,05 \\
\hline $\mathrm{SL}_{45}$ & 8,5 & 5,50 & 0,3 \\
\hline
\end{tabular}

$\mathrm{Na}$ FIGURA 8.3.3 tem-se a projeção em colunas dos dados analíticos dos dois experimentos. 


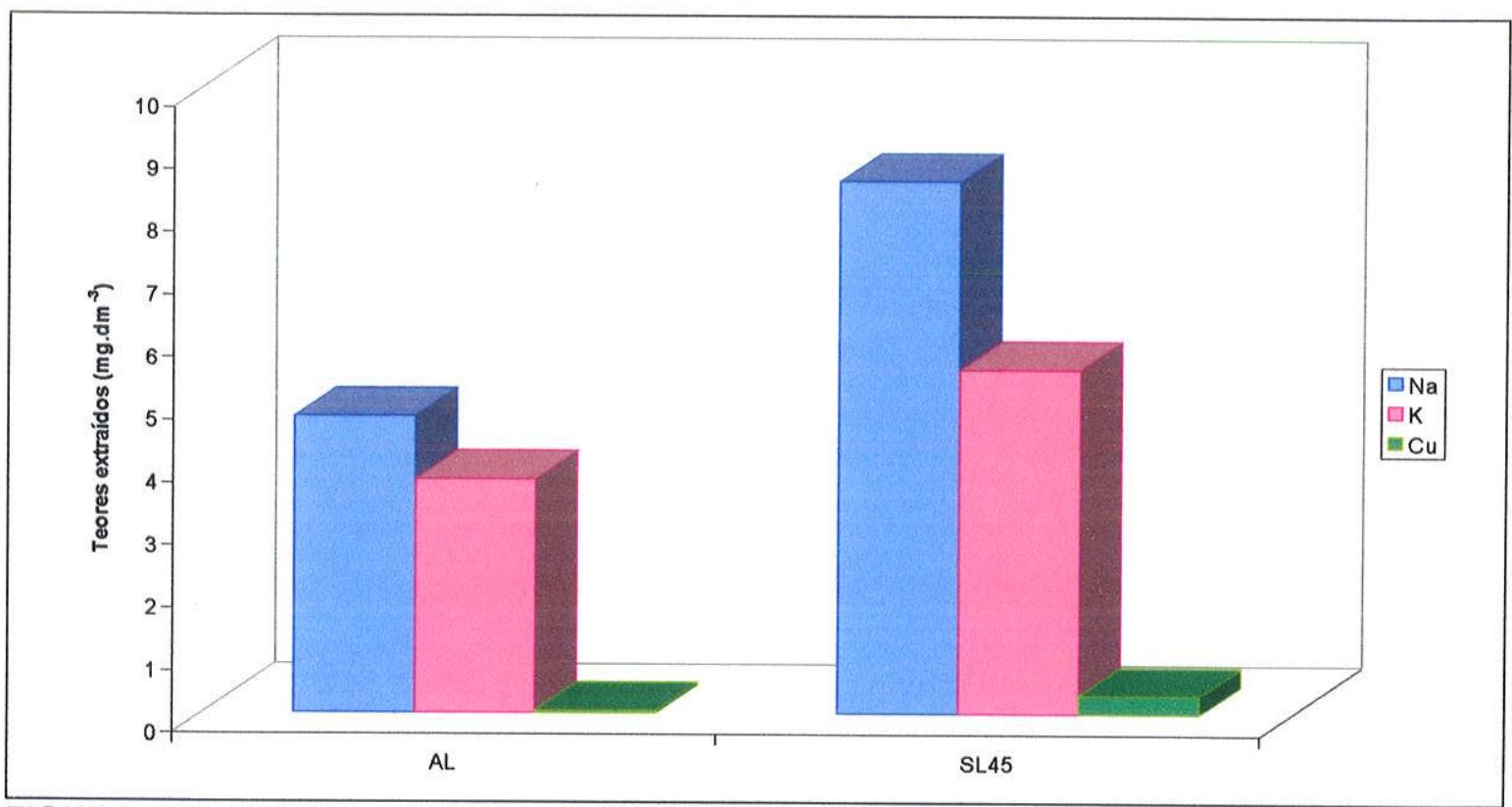

FIGURA 8.3.3: Média dos teores extraídos de $\mathrm{Na}^{+}, \mathrm{K}^{+}$e $\mathrm{Cu}{ }^{2+}\left(\mathrm{mg}^{2} \mathrm{dm}^{-3}\right)$ com lisímetro (amostra AL) e com água (amostra SL45).

Os experimentos mostram melhores resultados na extração com água do que aquela com lisímetro.

Uma vez comprovada a eficiência da extração com água, determinaram-se as condições ideais de trabalho.

Para as experiências escolheu-se a amostra S-5 do solo contaminado da área de estudos.

Todos os experimentos foram realizados em ambiente inerte $\left(\mathrm{N}_{2}\right)$, à temperatura ambiental média de $24,8^{\circ} \mathrm{C}$ e assim, foram determinadas as massas e volumes ideais de operação.

Efetuaram-se testes com volumes entre 5 e $250 \mathrm{~mL}$, massas de $1,0000 \mathrm{~g} \mathrm{e}$ 3,0000 g, usando como controle analítico $\mathrm{Na}^{+}$e $\mathrm{K}^{+}$(TABELA 8.3.4 e FIGURAS 8.3.4 a e b).

Obtiveram-se os mesmos resultados para massas de $1,0000 \mathrm{~g}$ e $3,0000 \mathrm{~g}$, optando-se para os trabalhos $1,0000 \mathrm{~g}$.

Para se determinar o melhor tempo para contato solo/solução, as amostras foram mantidas em repouso de 30 minutos a 4 horas. Após estes tempos as soluções foram separadas por filtração e determinaram-se os teores de $\mathrm{Na}^{+}$e $\mathrm{K}^{+}$ (TABELA 8.3.5).

O exame do gráfico da FIGURA 8.3.5 indica que 2 h é o tempo suficiente para extração com água dos íons intersticiais. 
TABELA 8.3.4: RESULTADOS ANALITICOS DE

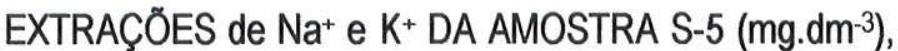
COM DIFERENTES VOLUMES DE ÁGUA E MASSAS DE $1,0000 \mathrm{~g}$.

\begin{tabular}{c|c|c}
\hline $\begin{array}{c}\text { Vagua } \\
(\mathrm{mL})\end{array}$ & $\mathrm{Na}^{+}$ & $\mathbf{K}^{+}$ \\
\hline 5,0 & 535,00 & 15,00 \\
\hline 10,0 & 546,00 & 20,00 \\
\hline 20,0 & 760,00 & 30,00 \\
\hline 50,0 & 780,00 & 30,00 \\
\hline 80,0 & 785,00 & 32,30 \\
\hline 250,0 & 790,00 & 32,60 \\
\hline
\end{tabular}

TABELA 8.3.5: INFLUENCIA DO TEMPO NA EXTRAÇÃO DE $\mathrm{Na}^{+}$e $\mathrm{K}^{+}$ COM ÁGUA DA AMOSTRA S-5.

\begin{tabular}{c|c|c|c|c}
\multirow{2}{*}{} & \multicolumn{4}{|c}{ Tempo } \\
\cline { 2 - 5 } & 30 min. & $1 \mathrm{~h}$ & $2 \mathrm{~h}$ & $4 \mathrm{~h}$ \\
\hline $\mathbf{N a}^{+}\left(\mathbf{m g} \cdot \mathbf{d m}^{-3}\right)$ & 730,00 & 920,00 & 950,00 & 950,00 \\
\hline $\mathbf{K}^{+}\left(\mathbf{m g}^{-} \cdot \mathbf{d m}^{-3}\right)$ & 25,00 & 30,00 & 35,00 & 35,00 \\
\hline
\end{tabular}




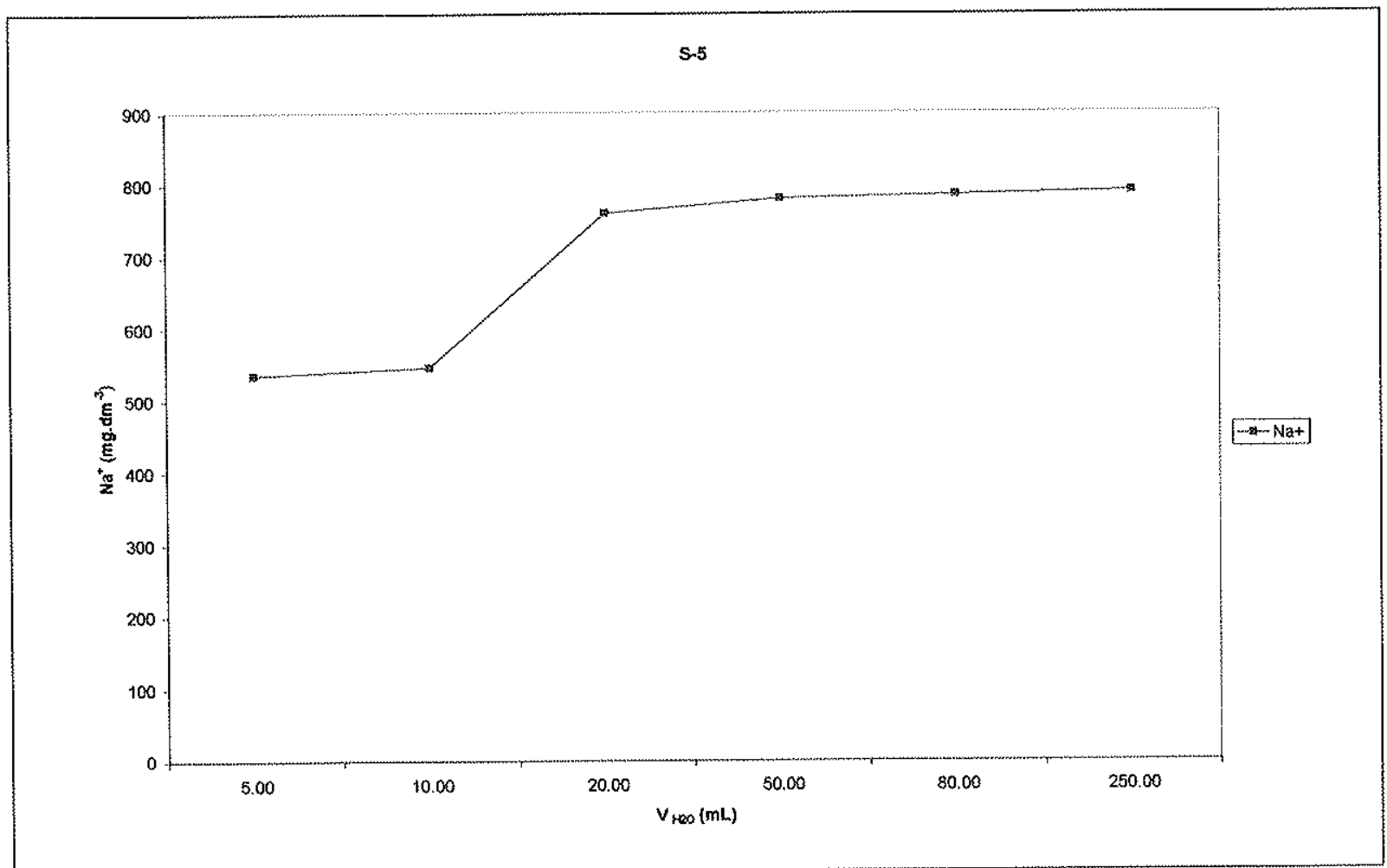

(a)

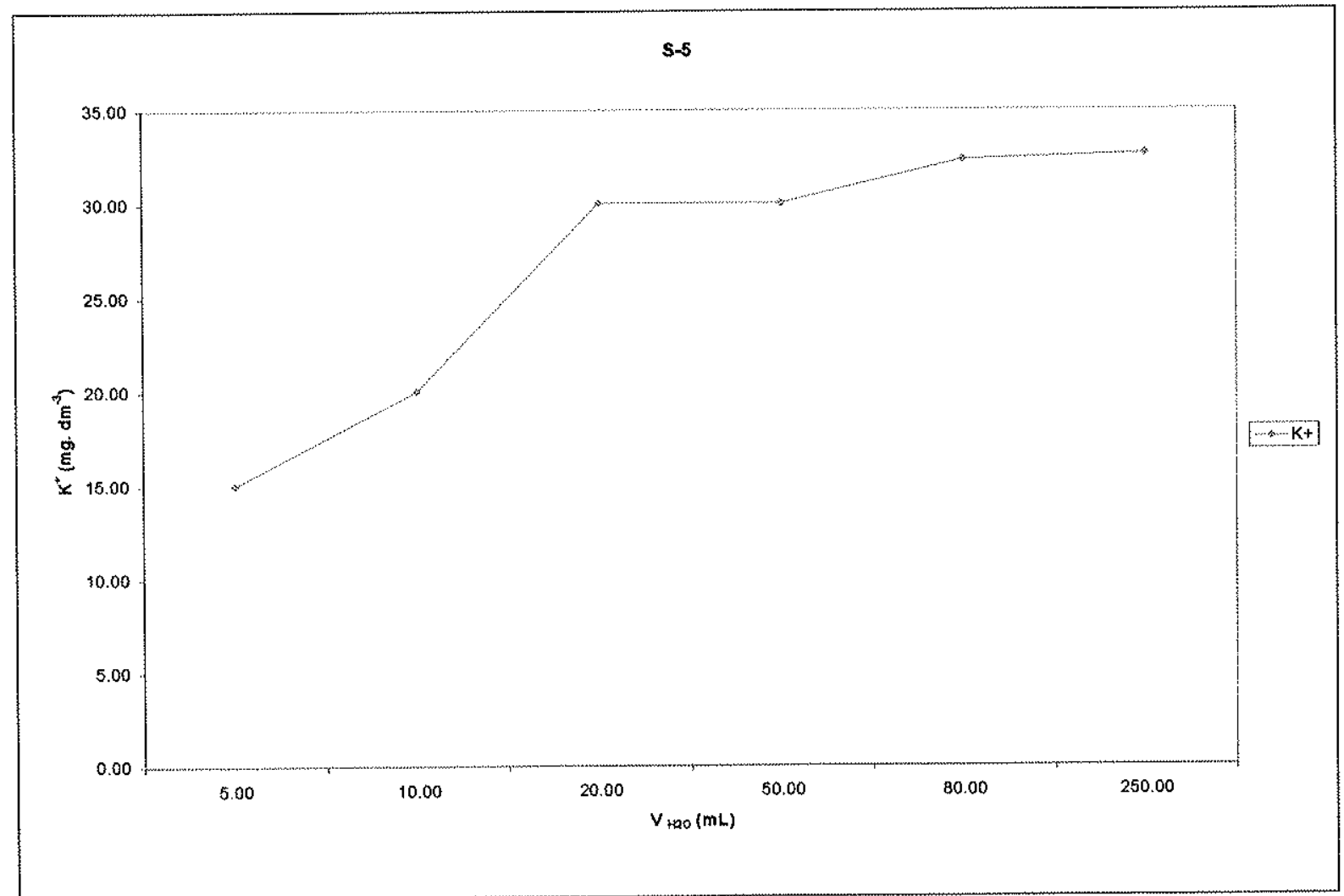

(b)

FIGURAS 8.3.4: Teores de $\mathrm{Na}^{+}$e $\mathrm{K}^{+}$em função do volume adicionado de água em 1,0000 e $3,0000 \mathrm{~g}$ da amostra S-5. 


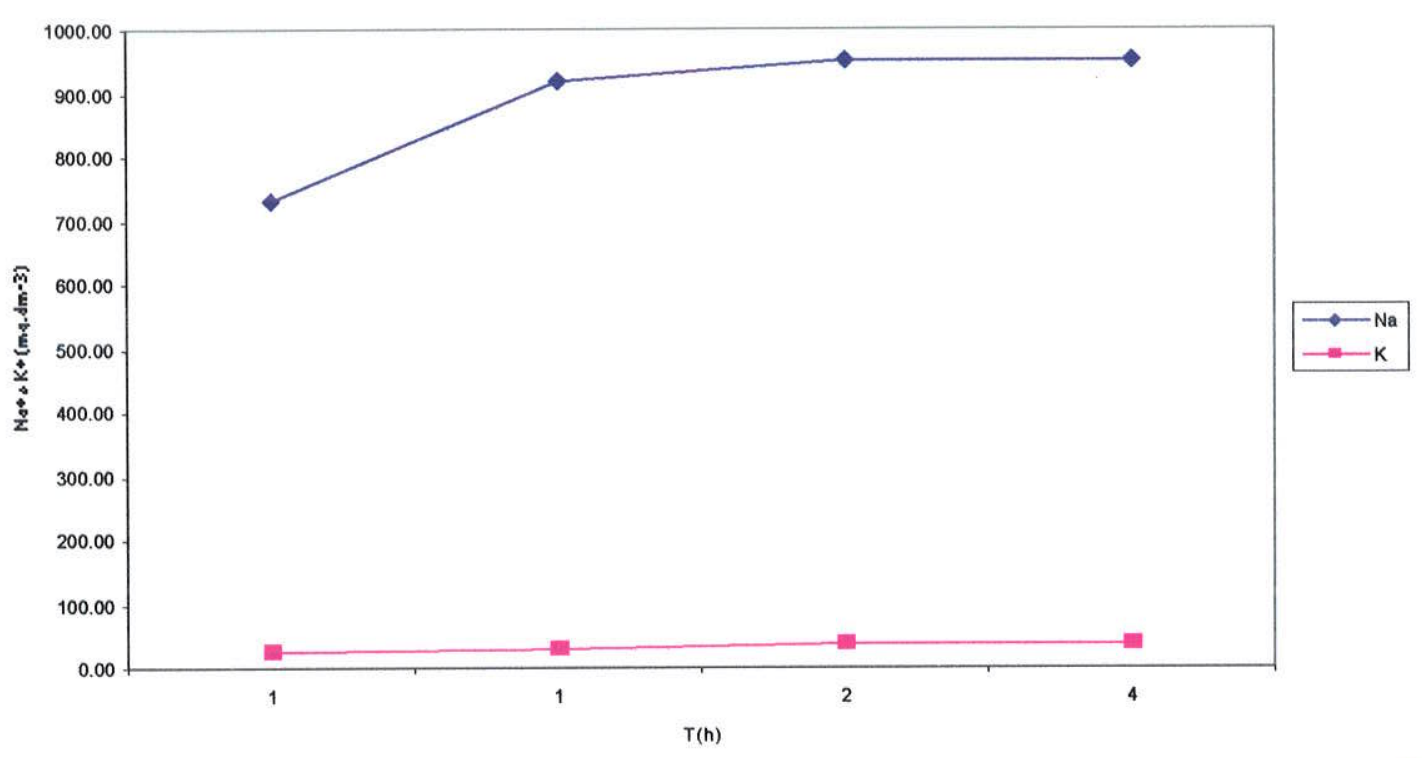

FIGURA 8.3.5: Teores de $\mathrm{Na}^{+}$e $\mathrm{K}^{+}$extraídos da amostra S-5 em função do tempo.

As extrações devem, portanto, ser efetuadas com 1,0000 g do material, $50 \mathrm{~mL}$ de água em duas horas.

Estabelecidas as condições experimentais foram efetuadas as extrações de chumbo, zinco e cobre, obtendo-se para $\mathrm{Pb}^{2+}, 4,90 \mathrm{mg} \cdot \mathrm{dm}^{-3} ; \mathbf{Z n}^{2+}, 0,40 \mathrm{mg} \cdot \mathrm{dm}^{-3} \mathrm{e}$ para $\mathrm{Cu}^{2+}, 1,00 \mathrm{mg} \cdot \mathrm{dm}^{-3}$. 


\section{Fração Trocável}

Adsorção é um fenômeno de adesão relacionada aos íons em solução que se associam aos materiais sólidos do solo. Trata-se de íons adsorvidos nas superfícies, com fraca interação eletrostática cuja disponibilidade ocorre por processos de troca iônica - são as partículas trocáveis.

Os reagentes utilizados na extração desses íons são eletrólitos em solução aquosa principalmente de sais neutros.

Para extração dos ions de metais trocáveis, alguns autores, a exemplo de TESSIER et al. (1979), recomendam o uso de solução $1 \mathrm{M}$ de $\mathrm{MgCl}_{2}$; sal com alta capacidade de troca catiônica em relação capacidade de complexação do cloreto. Trata-se de um reagente que não ataca a matéria orgânica, silicatos ou sulfetos, chegando a dissolver carbonatos ( 2 a $3 \%$ ); este fato, pode ser contornado com diminuição do tempo de extração.

O NH${ }_{4} A c$ é utilizado para deslocamento de partículas em sítios de adsorção, revelando-se muito eficiente na extração de $\mathrm{Zn}^{2+}, \mathrm{Cu}^{2+}$ e $\mathrm{Mn}^{2+}$ estudados por BEVILACQUA (1996). Este tratamento pode ser realizado em pH 5 trazendo como vantagem a diminuição de interferências analíticas no método por Espectofotometria de Absorção Atômica (ARIZA, 2000). Tem, ainda como vantagem que os íons complexos formados com acetato são mais estáveis que aqueles com cloreto. Ele favorece a troca e diminui a re-adsorção ou mesmo a precipitação dos ions metálicos extraídos, devido a capacidade tampão do meio. Neste caso, a fração carbonática também pode ser atacada e, para evitar esse tipo de problema, pode-se reduzir a concentração desse reagente para 0,01 M (GLEYZES et al., 2002).

CHAPMAN (apud TESSIER op.cit.) testou o NaAc $(1 \mathrm{M}, \mathrm{pH} 8,2)$ e $\mathrm{NH}_{4} \mathrm{Ac}(\mathrm{pH}$ 7) e obteve resultados mais satisfatórios que o $\mathrm{NH}_{4} \mathrm{Ac}$. TESSIER realizou testes com $\mathrm{NaAc}$ e $\mathrm{MgCl}_{2}$ constatando melhores resultados com o $\mathrm{MgCl}_{2}$.

TOKALIOGLU (2000) para extraçōes de ions de metais trocáveis e associados a carbonatos, indica o método da COMUNITY BUREAU OF REFERENCE onde são utilizados $32 \mathrm{~mL}$ de $\mathrm{HAc}$, com aquecimento a $50^{\circ} \mathrm{C}$.

MAIZ et al. (2000) testaram o $\mathrm{CaCl}_{2}(0,01 \mathrm{M})$ e ácido dietiltriaminapentacético (DTPA 0,005 M) nas extrações de metais lábeis obtendo resultados razoáveis. 
A eficiência dos extratores, em geral, depende da força iônica que, por sua vez, está relacionada à concentração de eletrólitos, com influência na atividade dos íns em solução ( LINDSAY, 1979; KELLER \& VÉDY,1994 e Mc BRIDE,1994).

Os principais métodos de extração para os íons trocáveis, acham-se resumidos na TABELA 8.3.6.

TABELA 8.3.6: REAGENTES E CONDIÇÕES UTILIZADOS NAS EXTRAÇÕES DE IONS DE METAIS TROCÁVEIS COM RESPECTIVAS REFERÊNCIAS BIBLIOGRÁFICAS.

\begin{tabular}{|c|c|c|c|}
\hline REAGENTE & CONCENTRAÇÃO & pH & REFERÊNCIA \\
\hline $\mathrm{MgCl}_{2}$ & $1 \mathrm{M}$ & 7 & TESSIER et al. (1979) \\
\hline $\mathrm{KCl}$ & $2 \mathrm{M}$ & n.m. & $\begin{array}{l}\text { Himes \& Barber (apud } \\
\text { BECKETT, 1989). }\end{array}$ \\
\hline $\mathrm{LaCl}_{3}$ & $0,3 \mathrm{M}$ & n.m. & $\begin{array}{c}\text { Jarvis (apud BECKETT, } \\
\text { 1989). }\end{array}$ \\
\hline \multirow{3}{*}{$\mathrm{Ca}\left(\mathrm{NO}_{3}\right)_{2}$} & $0,25 \mathrm{M}$ & n.m. & $\begin{array}{c}\text { Miller et al. (apud BECKETT, } \\
\text { 1989). }\end{array}$ \\
\hline & $0,5 \mathrm{M}$ & n.m. & $\begin{array}{c}\text { Tiller et al. (apud BECKETT, } \\
\text { 1989). }\end{array}$ \\
\hline & $0,1 \mathrm{M}$ & 7 & $\begin{array}{c}\text { Mc Laren (apud GLEYZES, } \\
\text { 2002) }\end{array}$ \\
\hline $\mathrm{BaCl}_{2}$ & $1 \mathrm{M}$ & 7 & $\begin{array}{l}\text { Meguellati et al. (apud } \\
\text { GLEYZES, 2002) }\end{array}$ \\
\hline $\mathrm{Mg}\left(\mathrm{NO}_{3}\right)_{2}$ & $1 \mathrm{M}$ & 7 & $\begin{array}{l}\text { Gommy (apud GLEYZES, } \\
\text { 2002). }\end{array}$ \\
\hline \multirow{3}{*}{$\mathrm{CaCl}_{2}$} & $0,5 \mathrm{M}$ & 7 & $\begin{array}{l}\text { Krishnamurti et al. (apud } \\
\text { GLEYZES, 2002). }\end{array}$ \\
\hline & $0,1 \mathrm{M}$ & 7 & $\begin{array}{l}\text { Mac Grath et al. (apud } \\
\text { GLEYZES, 2002). }\end{array}$ \\
\hline & $0,01 \mathrm{M}$ & 7 & $\begin{array}{l}\text { Mac Grath et al. (apud } \\
\text { GLEYZES, 2002) }\end{array}$ \\
\hline $\mathrm{KNO}_{3}$ & $1 \mathrm{M}$ & 7 & $\begin{array}{l}\text { Gupta et al. (apud GLEYZES, } \\
\text { 2002). }\end{array}$ \\
\hline \multirow{3}{*}{$\mathrm{CH}_{3} \mathrm{COONH}_{4}$} & $1 \mathrm{M}$ & 7 & $\begin{array}{l}\text { Gupta et al. (apud GLEYZES, } \\
\text { 2002). }\end{array}$ \\
\hline & $1 \mathrm{M}$ & 8 & Lin (apud GLEYZES, 2002). \\
\hline & $0,01 \mathrm{M}$ & 7 & $\begin{array}{l}\text { Arunachalan (apud } \\
\text { GLEYZES, 2002). }\end{array}$ \\
\hline $\mathrm{NH}_{4} \mathrm{Cl}$ & $1 \mathrm{M}$ & 7 & $\begin{array}{c}\text { Rigol et al (apud GLEYZES, } \\
\text { 2002). }\end{array}$ \\
\hline $\mathrm{NH}_{4} \mathrm{NO}_{3}$ & $1 \mathrm{M}$ & 7 & $\begin{array}{c}\text { Zeien et al. (apud GLEYZES, } \\
\text { 2002). }\end{array}$ \\
\hline
\end{tabular}


Utilizando frações da amostra de solo S-5 a fração trocável foi realizada utilizando como extratores os reagentes já testados e que produziram melhores resultados. Foram utilizados $\mathrm{CaCl}_{2} \cdot 2 \mathrm{H}_{2} \mathrm{O}(0,01 \mathrm{M}), \mathrm{KCl}(1 \mathrm{M})$ ) e $\mathrm{MgCl}_{2}$ (1M) com forças iônicas variadas. (método RJ).

A influência do volume na extração também foi verificada com os três sais.

Alíquotas de $1,0000 \mathrm{~g}$ da amostra foram introduzidas em frascos plásticos de $250 \mathrm{~mL}$ e adicionaram-se soluções com volumes variados de $\mathrm{Mg}^{2+}, \mathrm{K}^{+}$e $\mathrm{Ca}^{2+}(5 \mathrm{~mL}$, $10 \mathrm{~mL}$ e $50 \mathrm{~mL})$, em ambiente inerte $\left(\mathrm{N}_{2}\right)$.

As amostras permaneceram em repouso por $1 \mathrm{~h}$ (TESSIER, 1979), com eventual agitação. Após esse tempo, os resíduos foram filtrados, lavados com solução $0,01 \%$ de cada sal, acidulados e avolumados.

Os teores de $\mathrm{Pb}^{2+}, \mathrm{Zn}^{2+}$ e $\mathrm{Cu}^{2+}$ foram dosados e os resultados subtraídos da fração intersticial acham-se na TABELA 8.3.7.

TABELA 8.3.7: TEORES EXTRAÍDOS DE CHUMBO, ZINCO E COBRE COM DIFERENTES SOLUÇÕES DE SAIS DE $\mathrm{Mg}^{2+}, \mathrm{K}^{+}$e $\mathrm{Ca}^{2+}, \mathrm{E}$ RESPECTIVOS PH DE EQUILIBRIO.

\begin{tabular}{|c|c|c|c|c|c|}
\hline REAGENTE & pH & $\begin{array}{c}\text { Volume } \\
(\mathrm{mL})\end{array}$ & $\begin{array}{c}\mathrm{Pb}^{2+} \\
\left(\mathrm{mg}^{2+} \mathrm{dm}^{-3}\right)\end{array}$ & $\begin{array}{c}\mathrm{Zn}^{2+} \\
\left(\mathrm{mg} \cdot \mathrm{dm}^{-3}\right)\end{array}$ & $\begin{array}{c}\mathrm{Cu}^{2+} \\
\left(\mathrm{mg}^{\left.2+\mathrm{dm}^{-3}\right)}\right.\end{array}$ \\
\hline \multirow{3}{*}{$\begin{array}{l}\mathrm{MgCl}_{2} \\
(1 \mathrm{M})\end{array}$} & \multirow{3}{*}{6,85} & 5 & 5,00 & 0,60 & 0,40 \\
\hline & & 10 & 3,30 & 0,40 & 0,30 \\
\hline & & 50 & 1,98 & 0,42 & 0,10 \\
\hline \multirow{3}{*}{$\begin{array}{l}\mathrm{KCl} \\
\text { (1M) }\end{array}$} & \multirow{3}{*}{6,10} & 5 & 0,68 & 0,20 & 0,02 \\
\hline & & 10 & 0,10 & 0,10 & 0,02 \\
\hline & & 50 & 0,10 & 0,18 & 0,02 \\
\hline \multirow{3}{*}{$\mathrm{CaCl}_{2}(0,01 \mathrm{M})$} & \multirow{3}{*}{5,71} & 5 & 0,10 & 2,00 & 0,02 \\
\hline & & 10 & 0,10 & 0,16 & 0,02 \\
\hline & & 50 & 0,10 & 0,10 & 0,02 \\
\hline
\end{tabular}

Nas FIGURAS 8.3.6 a à c, tem-se a projeção dos volumes em função dos teores de $\mathrm{Pb}^{2+}, \mathrm{Zn}^{2+} \mathrm{e} \mathrm{Cu}^{2+}$. 


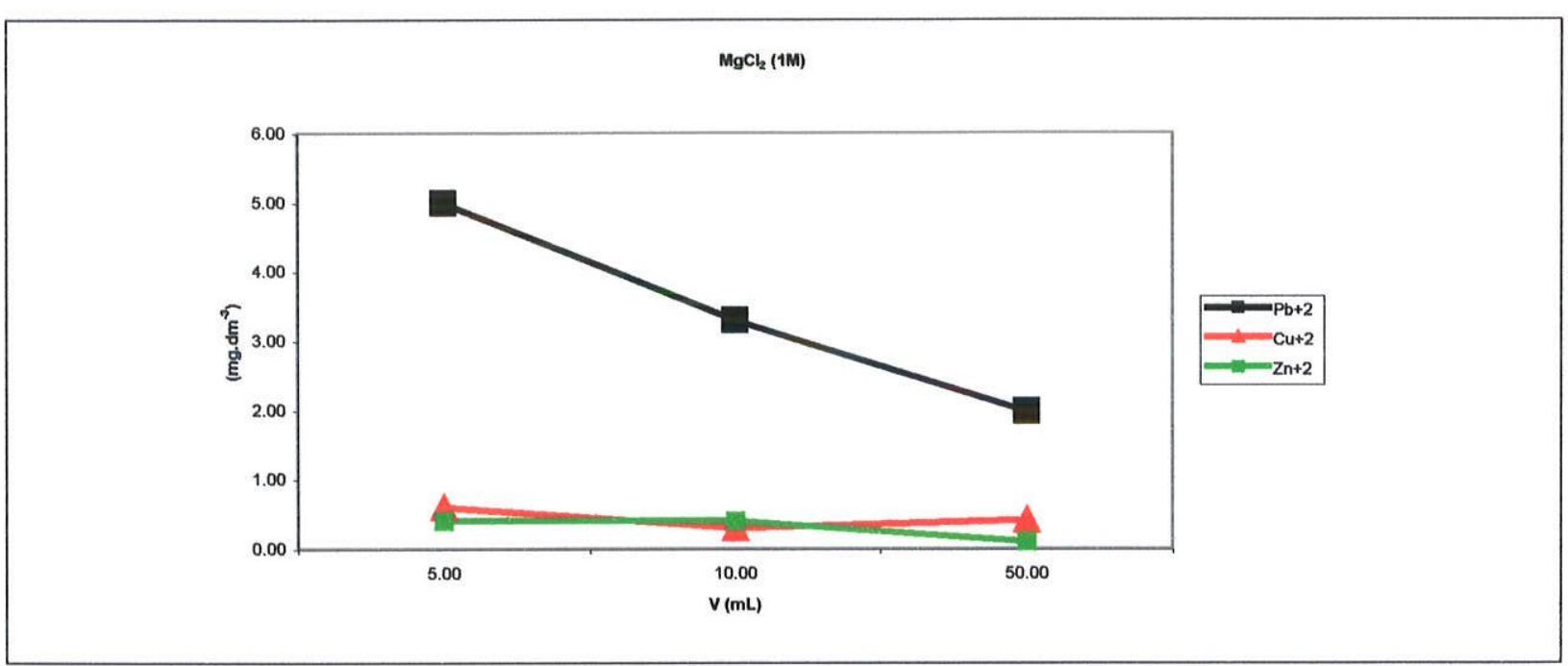

(a)

KCI (1M)

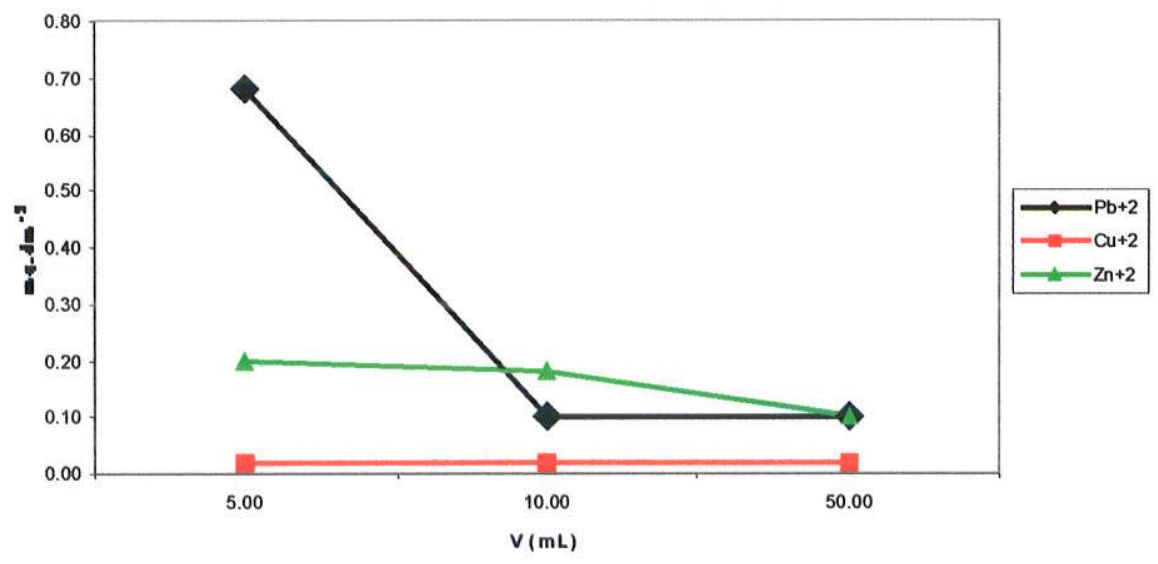

(b)

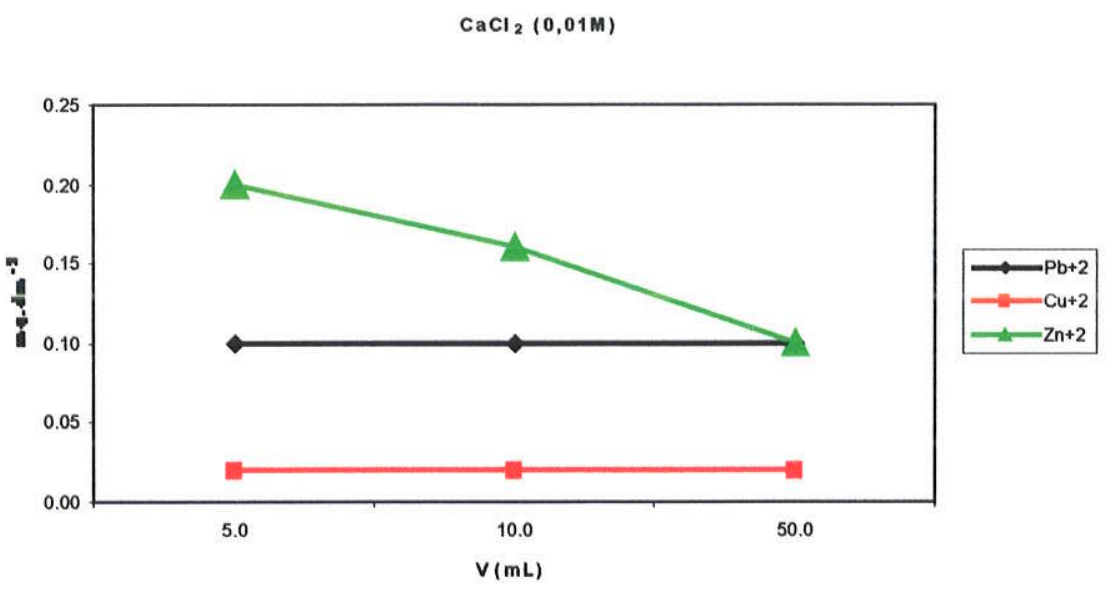

(c)

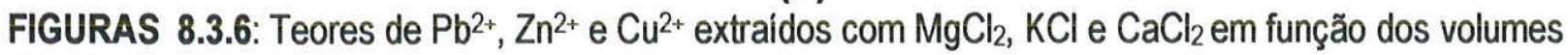
de soluções. 
Examinando os resultados de extração dos íons trocáveis, comprova-se maior eficiência ao serem utilizados volumes de $5 \mathrm{~mL}$ do sal de magnésio em concentração $1 \mathrm{M}$.

Efetuaram-se também experimentos segundo andamento indicado por TESSIER. Agitou-se por $1 \mathrm{~h}$ uma mistura de $1,0000 \mathrm{~g}$ da amostra S-5 com $8 \mathrm{~mL}$ de solução de $\mathrm{MgCl}_{2}(1 \mathrm{M}) \mathrm{em} \mathrm{pH}$ 7. Após esse tempo, a fase líquida foi separada por centrifugação (30 min e 10000 rpm).

Como a fração líquida apresentou-se com material em suspensão, centrifugou-se por mais quatro horas. Apesar da solução ainda apresentar-se turva, separou-se a fase líquida que foi acidulada com $\mathrm{HNO}_{3}$ e destinada à análises químicas.

Para certificar-se da eficiência separação por da centrifugação efetuou-se, (com $10 \mathrm{~mL}$ de água), lavagem da fase residual descompactada, denominada (TR); os resultados analíticos (RJ, MT e TR) encontram-se na TABELA 8.3.8.

TABELA 8.3.8: RESULTADOS DAS ANÁLISES QUIMICAS $\left(\mathrm{mg}^{\mathrm{d}} \mathrm{dm}^{-3}\right)$ DAS EXTRAÇÕES SEQÜENCIAIS DA FRAÇÃO TROCÁVEL, PELOS MÉTODOS RJ, MT E TR.

\begin{tabular}{c|c|c|c}
\hline Método & $\mathbf{P b}^{2+}$ & $\mathrm{Zn}^{2+}$ & $\mathbf{C u}^{2+}$ \\
\hline $\mathbf{R J}^{*}$ & 5,00 & 0,60 & 0,40 \\
\hline $\mathbf{M T}$ & 38,00 & 2,66 & 1,67 \\
\hline $\mathrm{TR}$ & 2,57 & 0,20 & 0,07 \\
\hline
\end{tabular}

* Resultados com subtração dos íons intersticiais.

Os resultados mostram que para amostras com as características de S- 5 o método RJ é o mais eficiente, certamente pela perda de soluções presas junto ao material sólido centrifugado no material de TESSIER e, principalmente, material em suspensão na fração líquida. 


\section{FRAÇÃO CARBONÁTICA}

A presença de carbonatos no solo ocorre no meio natural dependendo principalmente do $\mathrm{pH}$ do meio e presença de $\mathrm{CO}_{2}$.

$\mathrm{O}$ ions metálicos associados aos carbonatos são sensíveis à mudanças de $\mathrm{pH}$ e a liberação desses íons é alcançada pela dissolução em meio tamponado com $\mathrm{pH}$ 5 .

Como sistema tampão, usa-se acetato de sódio juntamente com o ácido acético $\left(\mathrm{CH}_{3} \mathrm{COONa} / \mathrm{HAc}\right)$.

A reação química que ocorre pode ser representada pela equação:

$$
\begin{aligned}
& \mathrm{MeCO}_{3}+\mathrm{H}^{+}{ }_{(\mathrm{aq})} \rightarrow \mathrm{HCO}_{3}^{-}{ }_{(\mathrm{aq})}+\mathrm{Me}^{2+}{ }_{(\mathrm{aq})} \\
& \mathrm{Me}=\mathrm{Pb}^{2+}, \mathrm{Zn}^{2+} \mathrm{ou} \mathrm{Cu}^{2+}
\end{aligned}
$$

CAMPOS et al. (1998), PÉREZ-CID et al. (1999), TESSIER (1979), KERSTEN E FORSTNER (1986), utilizaram solução tampão de NaAc/Hac $1 \mathrm{M}$, nas extrações e QUEVAUVILLER (1997), TOKALIOGLU et al. (2000) e MESTER et al. (1998) indicaram o mesmo reagente com concentração $0,11 \mathrm{M}$.

GLEYZES et al. (2002) recomendam a mistura 1:25 de sólido e líquido e adaptações do procedimento de acordo com o conteúdo de carbonato da amostra, indica também, a utilização do acetato de sódio mais concentrado (5M) até pH 4,74, ajustado com HAc.

$\mathrm{O}$ uso do $\mathrm{NaAc} / \mathrm{HAc}$, como agente extrator em $\mathrm{pH} 5$, tem sido encontrado em praticamente todas as bibliografias.

$\mathrm{Na}$ extração efetuada com $\mathrm{MgCl}_{2}$, foi testada também a eficiência com $\mathrm{CaCl}_{2}$ e com sal de $\mathrm{K}^{+}$.

Constatou-se que os íons monovalentes, alcalinos muito pouca influência exerce no deslocamento de sítios de troca dos materiais sólidos do solo.

O uso de meio tamponado $\mathrm{HAc} / \mathrm{NaAc}$, além de se comportar como íon inerte $\left(\mathrm{Na}^{+}\right)$no deslocamento, possibilita a dissolução da fração carbonática, uma vez que se tem $\mathrm{pH} 5$.

Para a amostra S-5 seguiu-se o RJ utilizando extração com uma única alíquota e filtraçäo. 
Massas de 1,0000 $\mathrm{g}$ foram transferidas para frascos plásticos, adicionaram-se $8 \mathrm{~mL}$ de $\mathrm{NaAc}(1 \mathrm{M})$ em pH 5 ajustado com HAc, em meio inerte $\left(\mathrm{N}_{2}\right)$.

A solução foi mantida em repouso durante 6 horas com eventual agitação. $O$ resíduo foi filtrado, lavado com a solução tampão, acidulado e analisado quimicamente.

Como em todos os andamentos, paralelamente, o MT também foi testado. $\mathrm{Na}$ TABELA 8.3.9 tem-se os resultados analíticos dos dois procedimentos com subtração da fração intersticial no RJ.

TABELA 8.3.9: RESULTADOS DAS ANÁLISES QUIMICAS (mg.dm ${ }^{-3}$ ) DAS EXTRAÇÕES SEQÜENCIAIS DA FRAÇÃO CARBONÁTICA, PELOS MÉTODOS RJ E MT.

\begin{tabular}{c|c|c|c}
\hline Método & $\mathrm{Pb}^{2+}$ & $\mathrm{Zn}^{2+}$ & $\mathbf{C u}^{2+}$ \\
\hline $\mathbf{R J}^{*}$ & 275,00 & 20,75 & 10,25 \\
\hline $\mathbf{M T}$ & 712,50 & 59,38 & 2,63 \\
\hline
\end{tabular}

* Resultados com subtração dos íons intersticiais.

Novamente, constatou-se na fração sobrenadante, após centrifugação, presença de materiais em suspensão, responsáveis pelos teores mais elevados dos cátions $\mathrm{Pb}, \mathrm{Zn}$ e $\mathrm{Cu}$. 


\section{FRAÇÃO REDUTORA}

No solo, o ferro e manganês normalmente encontram-se sob a forma de óxidos/hidróxidos.

Ocorrem na fração argila, em mistura com argilominerais podendo formar películas que revestem as partículas do solo. Em regiões de clima tropical chegam ser mais abundantes que os próprios argilominerais, preenchendo vazios por precipitações secundárias (ALLOWAY, 1995).

No solo os óxidos/hidróxidos de Fe e Mn ocorrem na forma sólida no estado de oxidação mais elevado: Fe III, Mn III e Mn IV. Sob a forma reduzida, no entanto são móveis e no processo de extração seqüencial utiliza esta propriedade tratando a amostra com agentes redutores.

A eficiência do reagente é determinada pelo seu potencial de redução e pela habilidade em atacar as diferentes formas de $\mathrm{Fe}$ e $\mathrm{Mn}$.

Os reagentes mais utilizados são o ditionito de sódio $\left(\mathrm{Na}_{2} \mathrm{~S}_{2} \mathrm{O}_{4}\right)$ em mistura com citrato de sódio em meio cítrico (Na-citrato/H-cítrico) e cloreto de hidroxilamina em meio acético $\left(\mathrm{NH}_{2} \mathrm{OH} . \mathrm{HCl} / \mathrm{HAc}\right)$.

$\mathrm{O}$ ditionito de sódio é um agente fortemente redutor dissolvendo, em $\mathrm{pH} 7$ a 8 , os óxidos/hidróxidos de Fe e Mn.

TESSIER et al. (1979) baseados nos experimentos de GUPTA \& CHEN (1975), utilizaram cloreto de hidroxilamina em meio fortemente ácido (pH 2).

Trabalhos como os de ROSS et al. (1993), efetuam extrações com ditionito/citrato, por terem apresentando melhor eficiência na remoção dos óxidos/hidróxidos de ferro não cristalizados, hematita, gohetita.

DAVIDSON et al. (1994), URE et al. (1993), utilizaram cloreto de hidroxilamina 0,1 mol L-1 e PÉREZ-CID et al. (1999), baseados no método de TESSIER, usaram 0,04 mol. $L^{-1}$ do reagente.

Como se nota o cloreto de hidroxilamina é amplamente utilizado nas extrações de íons associados à fração redutora com divergências quanto a concentração, temperatura e tempo de extração.

No método de extração aqui estudado, em que se utiliza uma alíquota para cada fase de extração, não se pode ter interferência de reagentes que possam atacar outros compostos do solo de frações anteriores, a não ser aquele de interesse. 
O ditionito de sódio mostrou-se ser ideal para a liberação dos cátions adsorvidos na fração redutora. Além de suas propriedades redutoras atua em meio ligeiramente alcalino ( $\mathrm{pH}$ 7-8 que não reage $\mathrm{com} \mathrm{CO}_{3}{ }^{-2}$ ) podendo ser utilizado na forma de sal sódico que, como já foi visto não influi no deslocamento dos íons trocáveis. Além disso, por se tratar de agente redutor, mantém estável a fase orgânica que é tratada na próxima etapa de extração.

Utilizou-se o procedimento modificado de ROSS et al. (1993), onde massas de $1,0000 \mathrm{~g}$ da amostra S- 5 foram transferidas para frascos plásticos de $250 \mathrm{~mL}$. 25 $\mathrm{mL}$ de citrato de sódio $\left(\mathrm{Na}_{3} \mathrm{C}_{6} \mathrm{H}_{5} \mathrm{O}_{7}\right)$ 0,68 $\mathrm{M}$ foram adicionados juntamente com $0,4 \mathrm{~g}$ de ditionito de sódio $\left(\mathrm{Na}_{2} \mathrm{~S}_{2} \mathrm{O}_{4}\right)$ em meio inerte $\left(\mathrm{N}_{2}\right)$.

A solução foi mantida em repouso por 6 horas com eventual agitação, o resíduo filtrado, lavado, acidulado e destinado às análises químicas dos metais pesados de interesse.

Aplicou-se, neste caso, também o método MT ao resíduo da fração carbonática: $20 \mathrm{~mL}$ de $\mathrm{NH}_{2} \mathrm{OH} . \mathrm{HCl}(0,04 \mathrm{M}), \mathrm{pH} 2$, repouso por 6 horas, a temperatura de $96^{\circ} \mathrm{C}$ e centrifugação por duas horas.

Na TABELA 8.3.10 acham-se os resultados analíticos da extração de chumbo, zinco e cobre da amostra S-5 pelos métodos MT e RJ, este, com subtração da fração intersticial.

TABELA 8.3.10: RESULTADOS DAS ANÁLISES QUIMICAS $\left(\mathrm{mg}^{\left.-\mathrm{dm}^{-3}\right)}\right.$ DAS EXTRAÇŐES SEQÜENCIAIS DA FRAÇÃO REDUTORA, PELOS MÉTODOS RJE MT.

\begin{tabular}{c|c|c|c}
\hline Método & $\mathbf{P b}^{2+}$ & $\mathrm{Zn}^{2+}$ & $\mathbf{C u}^{2+}$ \\
\hline $\mathbf{R J}^{*}$ & 10,25 & 33,52 & 1,04 \\
\hline $\mathbf{M T}$ & 330,00 & 40,05 & 1,50 \\
\hline
\end{tabular}

* Resultados com subtração dos íons intersticiais. 


\section{FRAÇÃO ORGÂNICA}

As matérias orgânicas presentes no solo podem ser húmicas e não húmicas. As primeiras são amino-ácidos, carboidratos, ácidos orgânicos, lipídios, óleos, graxas etc. As não húmicas (humina, ácidos húmicos e fúlvicos) são substâncias amorfas, ácidas, com grupos funcionais variados (carboxila, fenóis etc.), de coloração amarelada, marrom a preta, poli-eletrolíticas (TAN, 1993).

Além de se apresentarem envolvidas em mecanismos de CTC, as substâncias húmicas também formam complexos metálicos.

Os íns de metais pesados podem estar associados às várias formas de matéria orgânica e um tratamento oxidante pode, consequentemente, pela sua eliminação, liberar esses íons presentes nesta fração.

O peróxido de hidrogênio juntamente com ácido nítrico são os agentes oxidantes mais utilizados para extração de íons metálicos desta fração. O hipoclorito de sódio também pode ser utilizado, no entanto, pode atacar parcialmente alguns silicatos (TESSIER, 1979 e GLEYZES, 2002).

Nas extrações de metais associados à matéria orgânica, muitos autores utilizaram $\mathrm{H}_{2} \mathrm{O}_{2}(30 \%)$ e $\mathrm{HNO}_{3}(0,01$ ou $0,02 \mathrm{M}$ em pH 2) a temperatura ambiente (RENDELL et al., 1980) ou à $85-100^{\circ} \mathrm{C}$ (HARRISON et al., 1981).

DAVIDSON et al. (1994) utilizaram $\mathrm{H}_{2} \mathrm{O}_{2}\left(8,8 \mathrm{~mol} \mathrm{~L}^{-1}\right)$, acetato de amônia $\left(\mathrm{CH}_{3} \mathrm{COONH}_{4}\right) 1 \mathrm{~mol} \mathrm{~L}^{-1} \mathrm{em} \mathrm{pH} 2$ para extração dos metais associados a matéria orgânica e sulfetos.

ANDRADE \& PATCHINEELAM (2000) obtiveram os metais associados ao material orgânico digerindo a amostra com $\mathrm{H}_{2} \mathrm{SO}_{4}$ por $2 \mathrm{~h}$.

Em URE (apud GLEYZES, 2002) o ácido etilenodiaminotetracético (EDTA) é utilizado, em particular, para extração de chumbo em lodos ou solos, resultado da reciclagem de baterias.

Foi escolhido para a extração dos íns metálicos associados a fração orgânica apenas $\mathrm{o}_{2} \mathrm{O}_{2}(30 \%)$, por ser um agente oxidante, que ataca as matérias orgânicas e disponibiliza os íns associados a elas.

Para $1,0000 \mathrm{~g}$ da amostra S-5 um volume de $50 \mathrm{~mL}$ de $\mathrm{H}_{2} \mathrm{O}_{2}$ mostrou-se ser suficiente para eliminação da matéria orgânica, com liberação dos cátions adsorvidos. A mistura foi aquecida brandamente $\left(70^{\circ} \mathrm{C}\right)$ até cessar a efervescência. 
$\mathrm{O}$ resíduo foi filtrado, lavado com solução de $\mathrm{H}_{2} \mathrm{O}_{2} \quad 0,01 \%$, acidulado e destinado à leituras dos íons metálicos de interesse (TABELA 8.3.11).

TABELA 8.3.11: TEORES EXTRAÍDOS DE CHUMBO, ZINCO E COBRE DA AMOSTRA S-5 - FRAÇÃO ORGÂNICA.

\begin{tabular}{c|c|c|c|c}
\hline REAGENTE & $\begin{array}{c}\text { Volume } \\
(\mathbf{m L})\end{array}$ & $\begin{array}{c}\mathrm{Pb}^{2+} \\
\left(\mathbf{m g}^{2+} \mathrm{dm}^{-3}\right)\end{array}$ & $\begin{array}{c}\mathrm{Zn}^{2+} \\
\left(\mathrm{mg}^{2+} \mathrm{dm}^{-3}\right)\end{array}$ & $\begin{array}{c}\mathrm{Cu}^{2+} \\
\left(\mathrm{mg}^{2+} \mathrm{dm}^{-3}\right)\end{array}$ \\
\hline $\begin{array}{c}\mathrm{H}_{2} \mathrm{O}_{2} \\
(\mathbf{3 0 \%})\end{array}$ & 50,0 & 5,25 & 1,21 & 1,03 \\
\hline
\end{tabular}

O método MT foi aplicado ao resíduo da fração redutora, adicionando-se $3 \mathrm{~mL}$ de $\mathrm{HNO}_{3} 0,02 \mathrm{M}, 5 \mathrm{~mL}$ de $\mathrm{H}_{2} \mathrm{O}_{2} 30 \%$ ajustado para $\mathrm{pH} 2$ com $\mathrm{HNO}_{3}$ e aquecimento à $85^{\circ} \mathrm{C}$ em banho-maria por duas horas.

Em seguida adicionaram-se mais $3 \mathrm{~mL}$ de $\mathrm{H}_{2} \mathrm{O}_{2} 30 \%$ com aquecimento por mais 3 horas e finalmente acrescentaram-se $5 \mathrm{~mL}$ de $\mathrm{NH}_{4} \mathrm{Ac} 3,2 \mathrm{M}$ em $\mathrm{HNO}_{3} 20 \%$ e $20 \mathrm{~mL}$ de água, centrifugação por duas horas e posterior análise química dos íons chumbo, zinco e cobre.

Para objeto de comparação na TABELA 8.3.12 são apresentados os resultados da extração pelos métodos MT e RJ com subtração da fração intersticial.

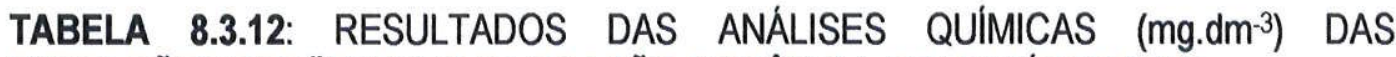
EXTRAÇÕES SEQÜENCIAIS DA FRAÇÃO ORGÂNICA, PELO MÉTODO MT.

\begin{tabular}{c|c|c||c}
\hline Método & $\mathrm{Pb}^{2+}$ & $\mathrm{Zn}^{2+}$ & $\mathrm{Cu}^{2+}$ \\
\hline $\mathbf{R J}^{*}$ & 5,25 & 1,21 & 1,03 \\
\hline $\mathbf{M T}$ & 156,60 & 15,80 & 5,10 \\
\hline
\end{tabular}

* Resultados com subtração dos ions intersticiais.

Constatou-se que em todas as amostras a Extração pelo processo MT é muito superior àqueles obtidos com a Extração Total $\left(\mathrm{HNO}_{3} 8 \mathrm{M}\right)$, com exceção do cobre que apresentou resultados inferiores.

Os valores tão elevados pelo $\mathrm{MT}$, como já mencionado, referem-se a presença de material adsorvido associado às partículas em suspensão, não separáveis por centrifugação e que contém materiais que superam aqueles perdidos nos espaços intergranulares.

A comparação da eficiência entre os dois resultados de extração pode ser analisada graficamente (FIGURAS 8.3.6 a e b). 


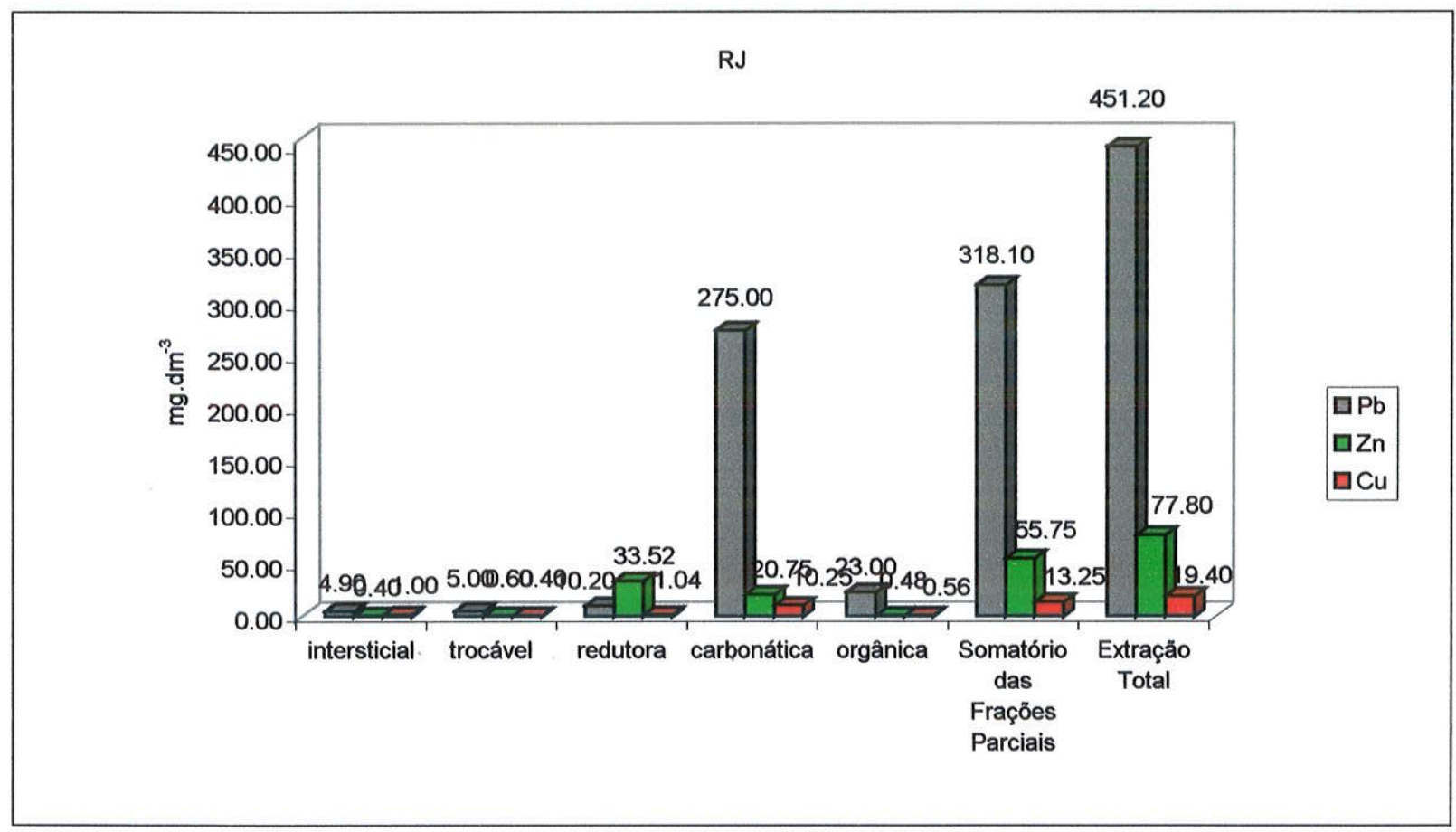

(a)

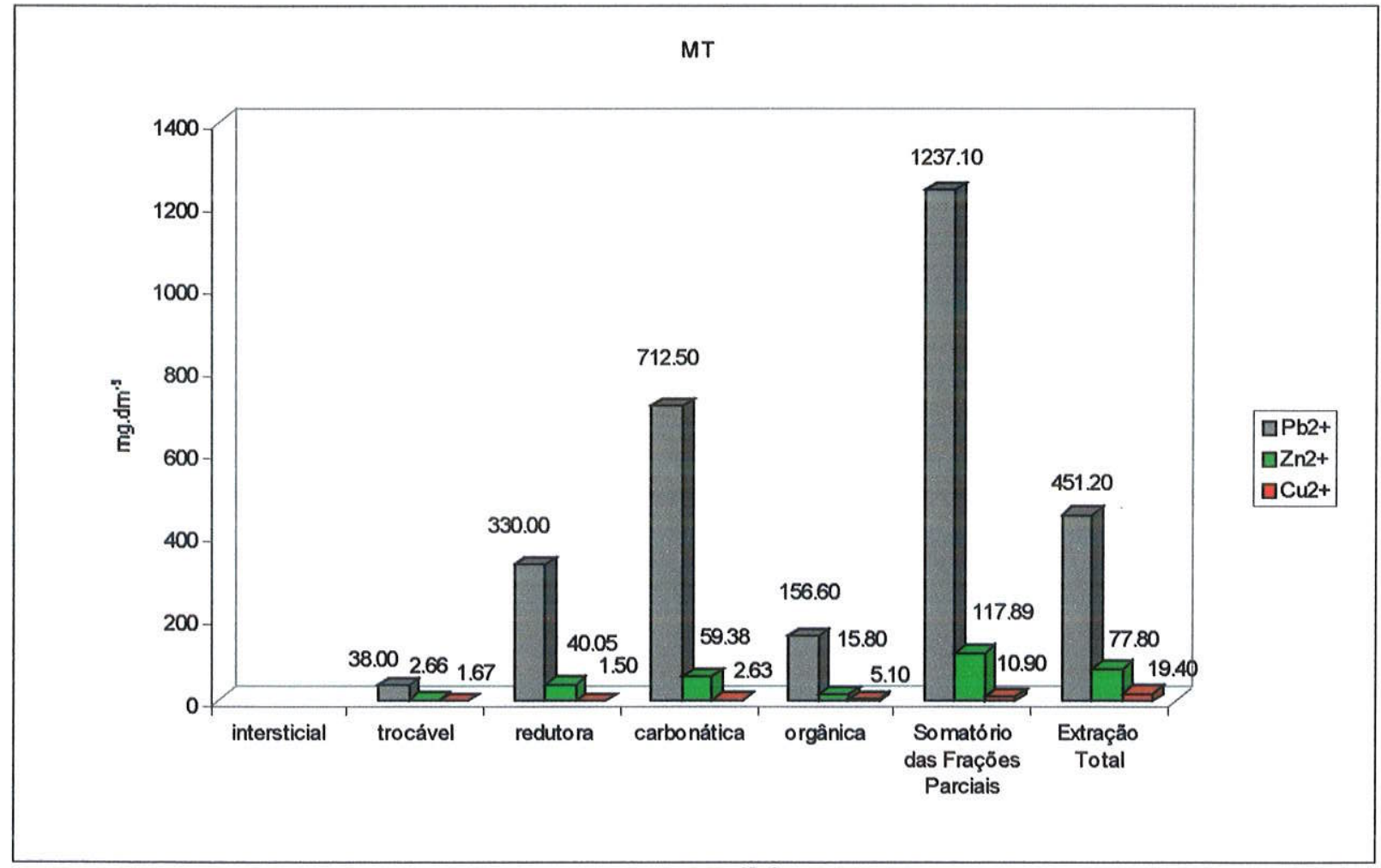

(b)

FIGURAS 8.3.6: Teores de chumbo, zinco e cobre $\left(\mathrm{mg}^{\left.-\mathrm{dm}^{-3}\right)}\right.$ extraídos pelos métodos RJ e MT na amostra S-5. 
Os dois métodos aplicados a amostra S-5, escolhida por localizar-se associada às pilhas de rejeito, evidenciam presença em maiores concentrações de chumbo e cobre na fração carbonática e zinco na fração redutora pelo método RJ. Pela seqüência através de MT o chumbo e o zinco estão presentes na fração carbonática, entretanto, ele acha-se distribuído também na fração redutora e orgânica.

A análise dos resultados mostram claramente a maior eficiência do método RJ em relação ao $\mathrm{MT}$.

$\mathrm{O}$ comportamento dos íons $\mathrm{Pb}, \mathrm{Zn}$ e Cu foi, então, estudado pelo método $\mathrm{RJ}$ com amostras de cinco pontos da área, estrategicamente escolhidos: S-3 e S-4 afastados da pilha de escória, S-6 a $50 \mathrm{~m}$ abaixo da pilha, S-11 é o local de descarga da tubulação subterrânea da Empresa no Córrego Divisa e S-9, ponto de referência (branco).

Os resultados em função dos teores $\left(\mathrm{mg} \cdot \mathrm{dm}^{-3}\right)$ de cada extração, acham-se nos gráficos e tabelas das FIGURAS 8.3.7, 8.3.8, 8.3.9, 8.3.10 e 8.3.11 


\section{Perfil S-3}

$\mathrm{S}-3_{10}$

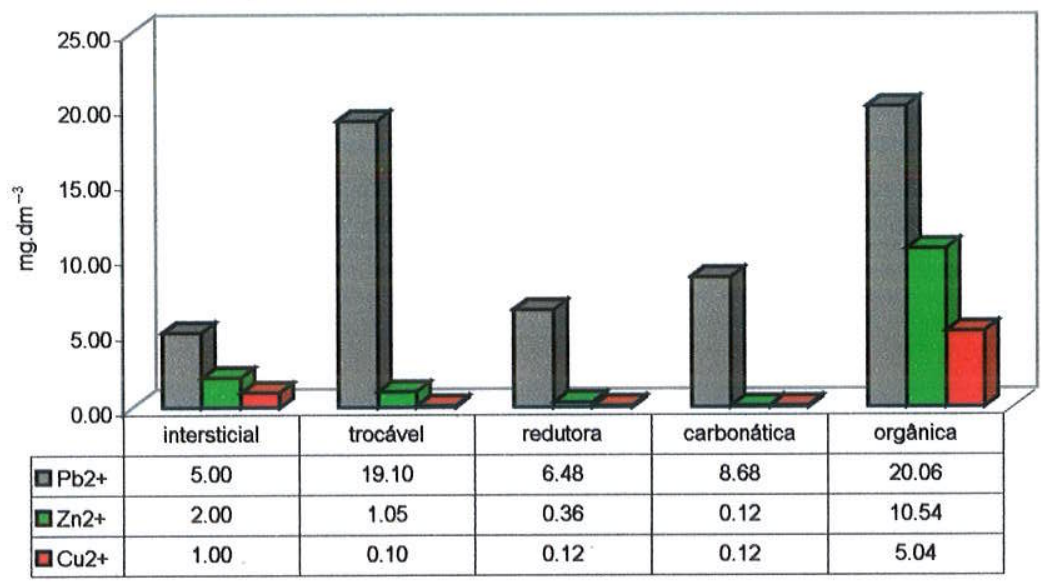

$\mathrm{S}-3_{40}$

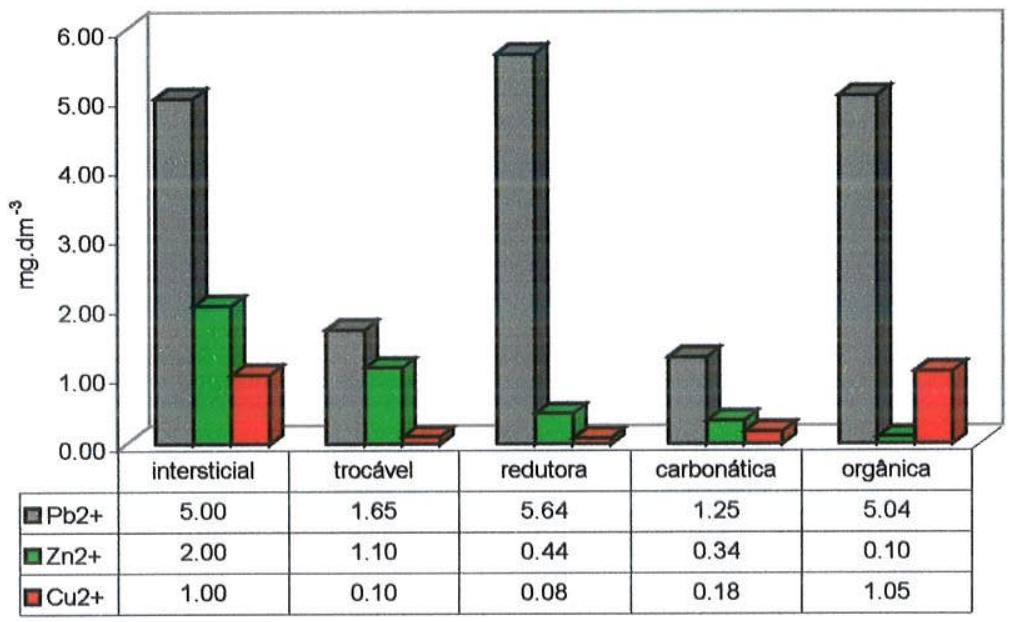

$5-3380-420$

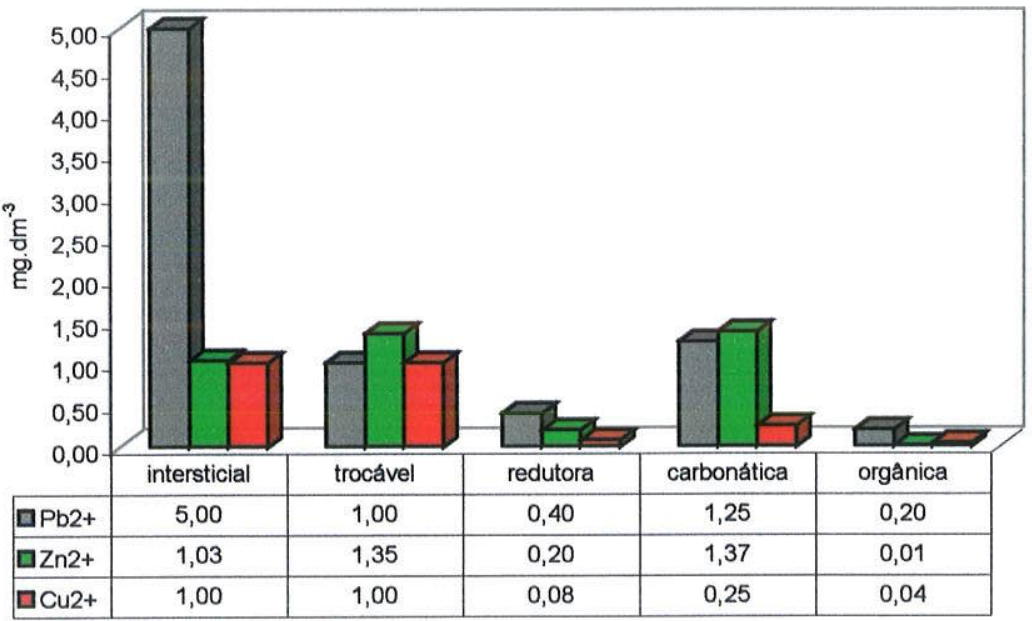

FIGURA 8.3.7: Dados obtidos (mg.dm³), através de Extrações Seqüenciais (RJ), do perfil S-3. 
Perfil S-4

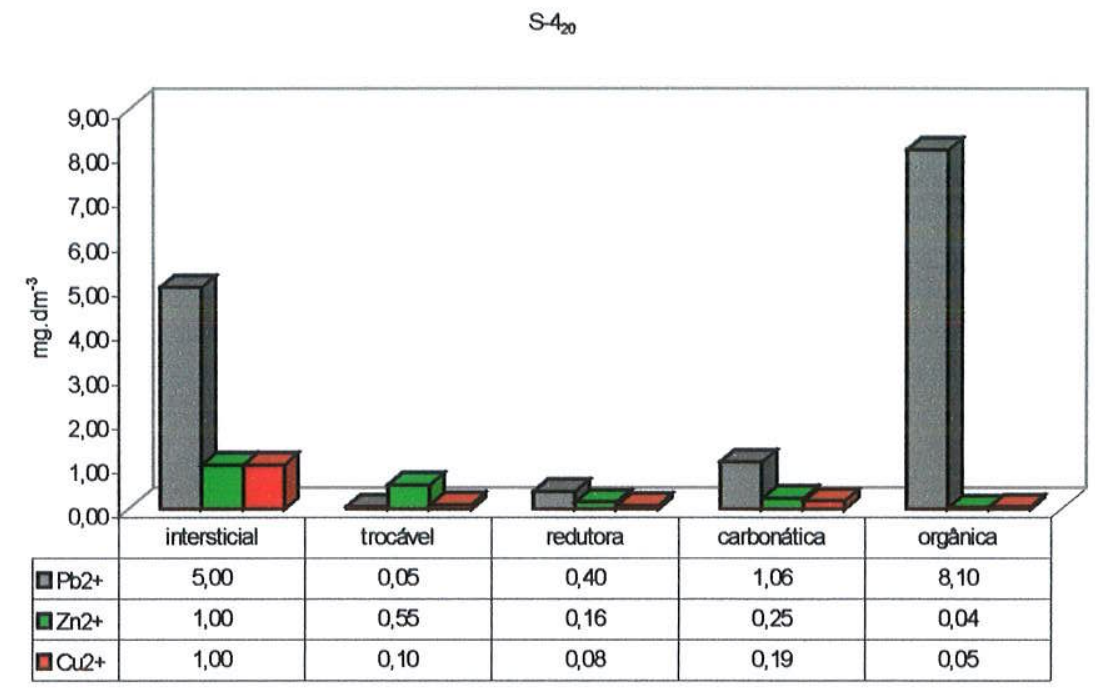

S. $4_{45-60}$

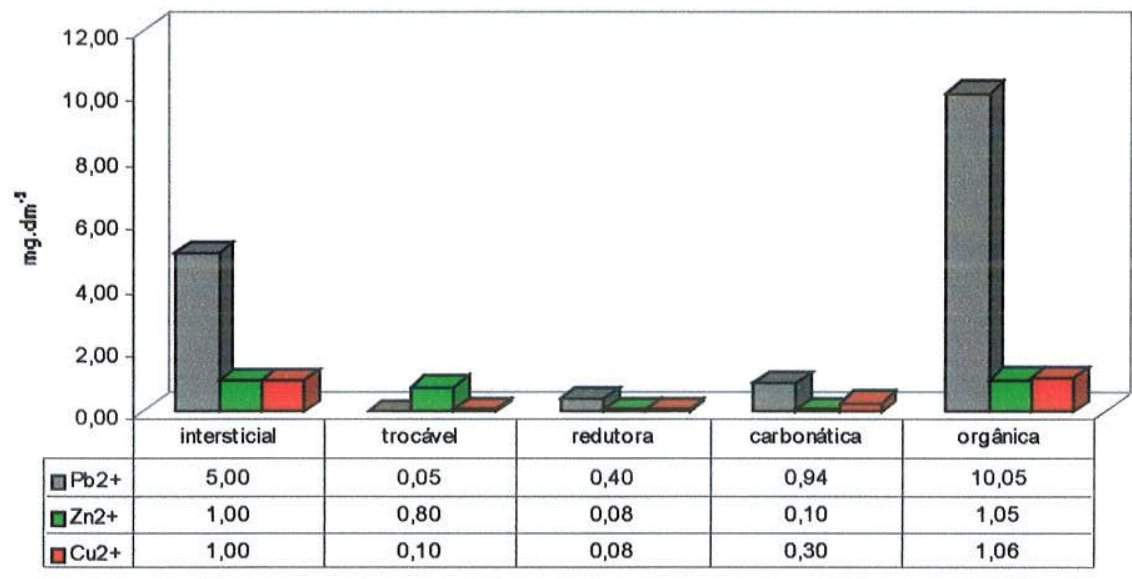

S-4 $200-250$

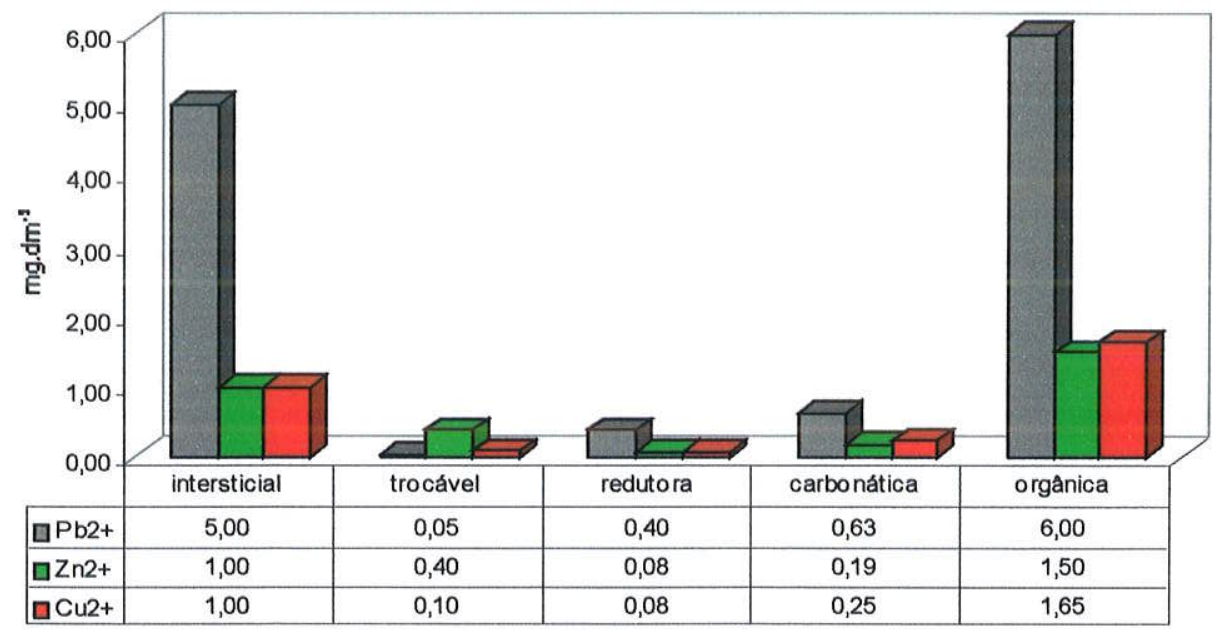

FIGURA 8.3.8: Dados obtidos $\left(\mathrm{mg}_{\mathrm{dm}} \mathrm{dm}^{-3}\right)$, através de Extrações Seqüenciais (RJ), do perfil S-4. 
Perfil S-6

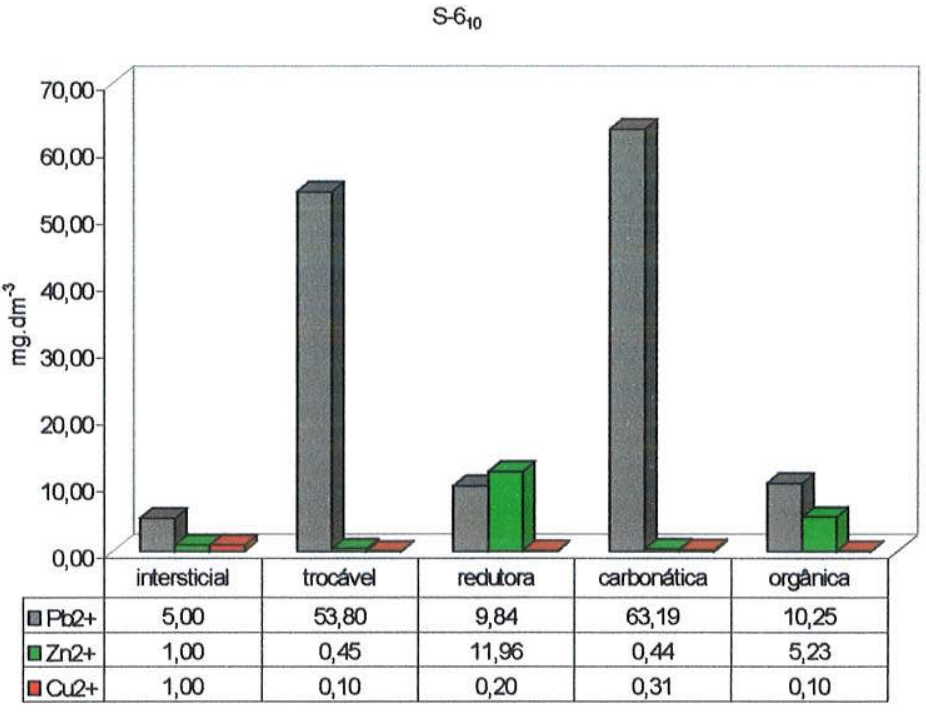

$5-6_{20}$

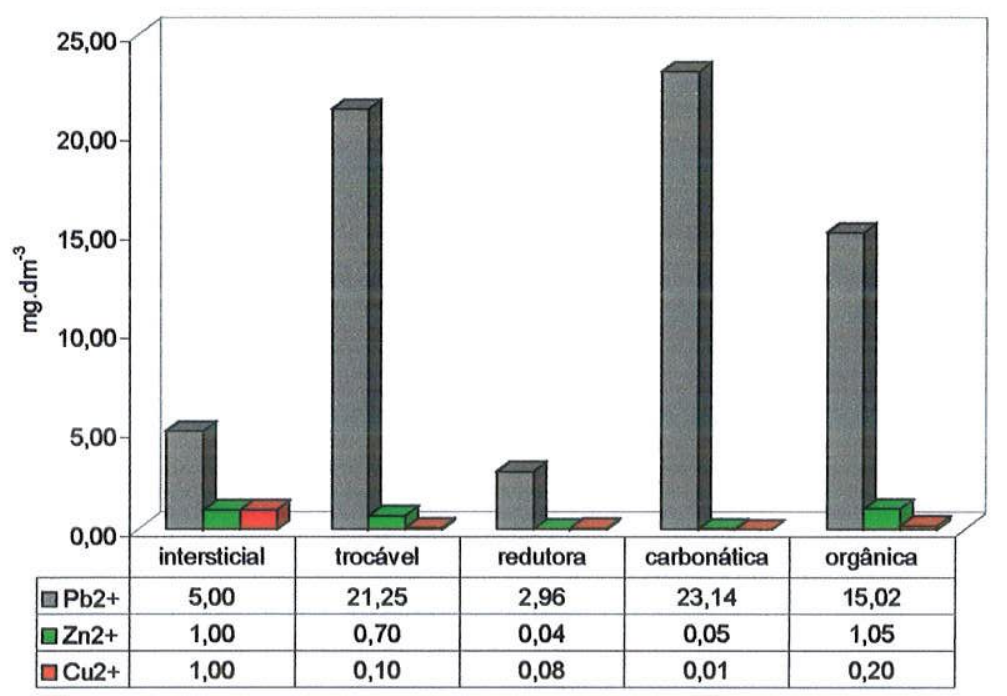

$S-60$

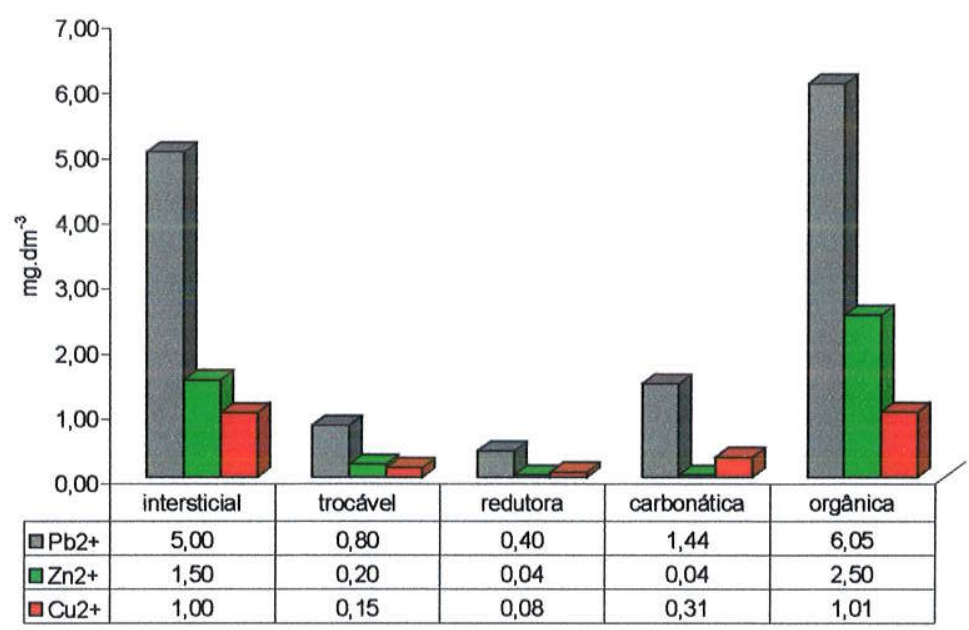

FIGURA 8.3.9 : Dados obtidos $\left(\mathrm{mg}_{\mathrm{dm}} \mathrm{dm}^{-3}\right)$, através de Extrações Seqüenciais (RJ), do perfil S-6. 


\section{Continuação}

Perfil S-6
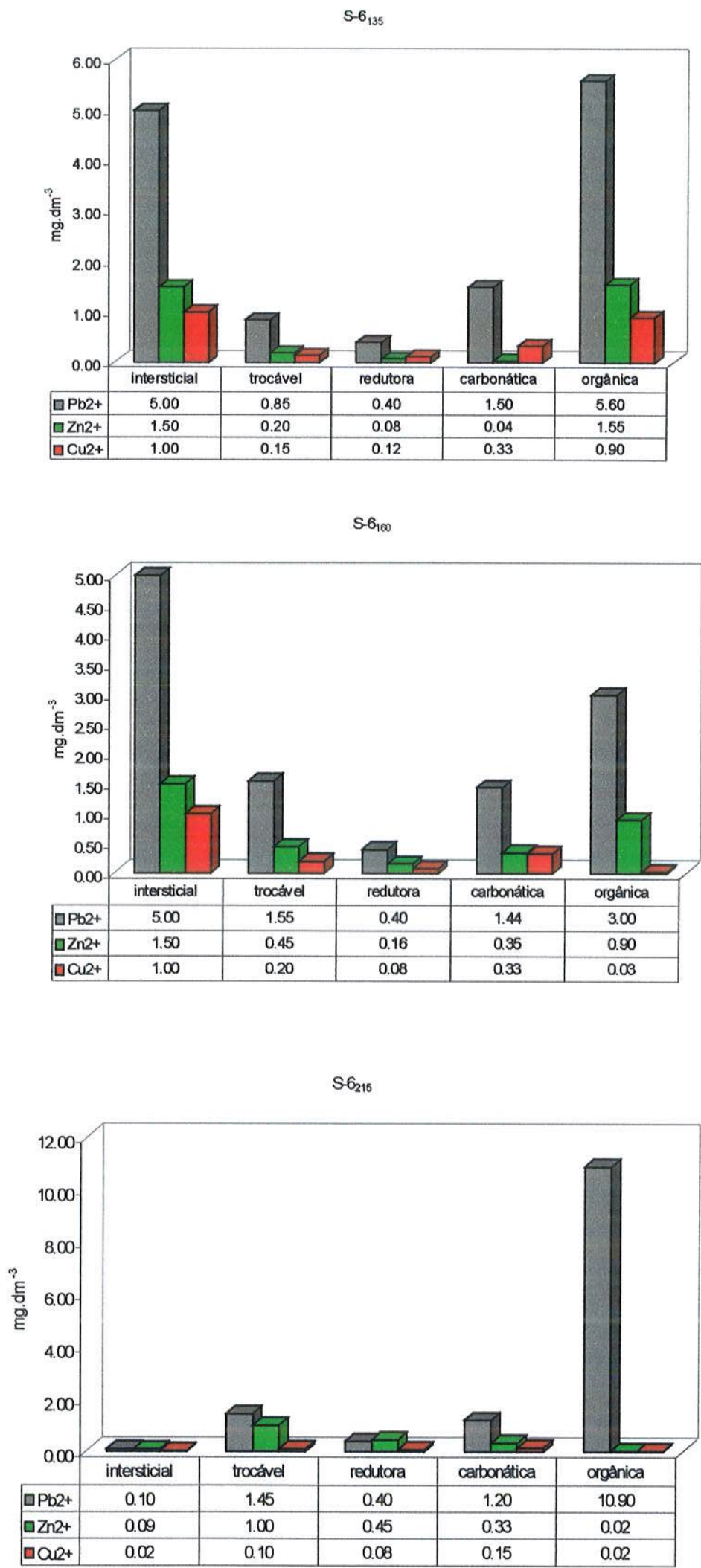

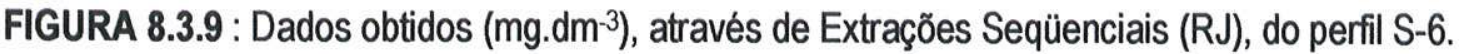


Perfil S-9
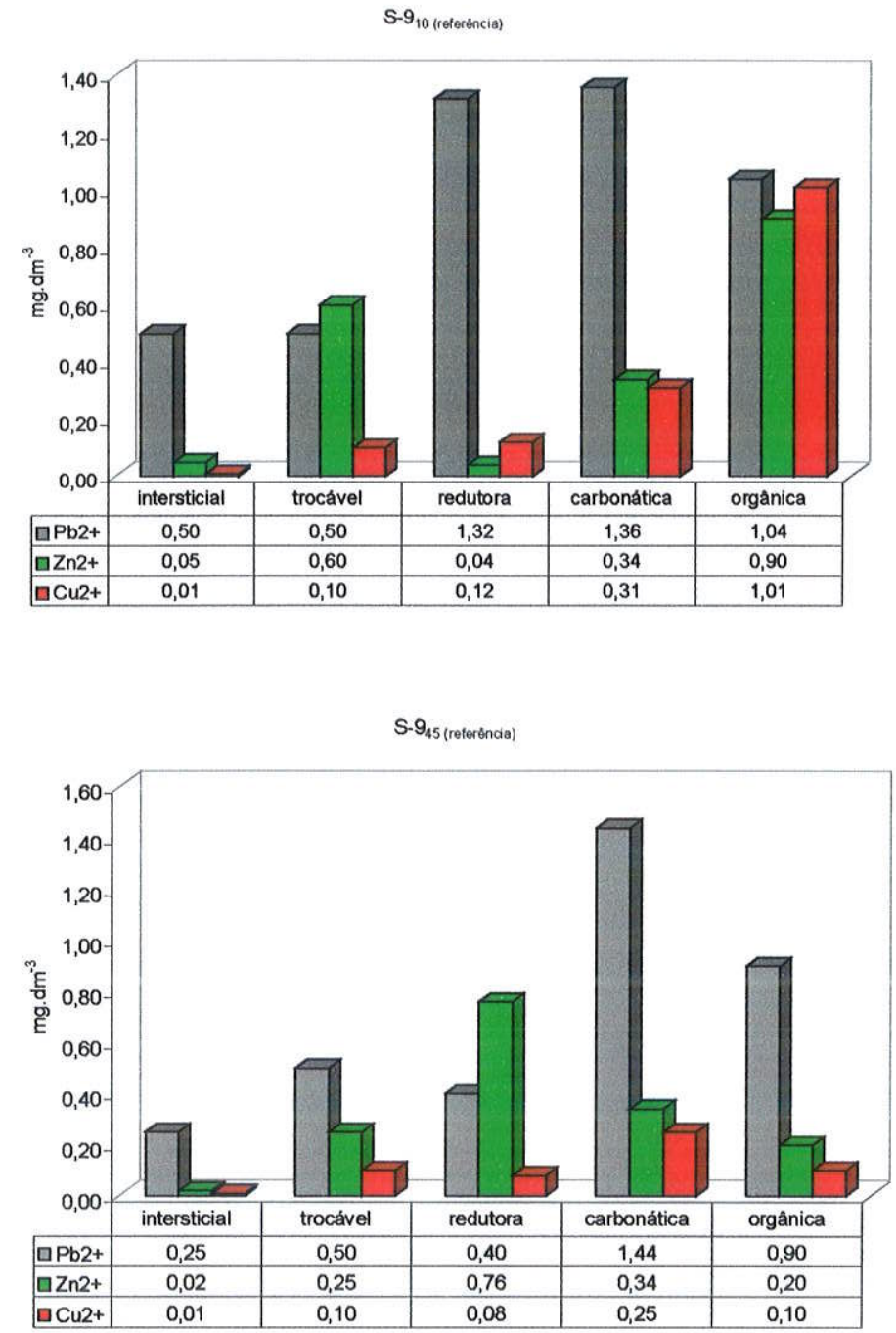

S-9 9 (reteréncia)

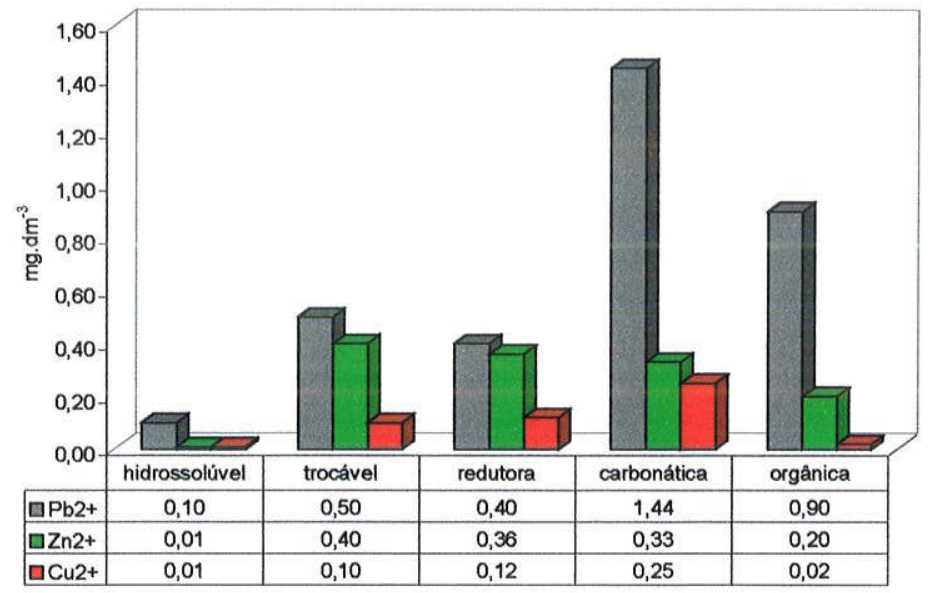

FIGURA 8.3.10 : Dados obtidos (mg.dm³), através de Extrações Seqüenciais (RJ), do perfil S-9 (referência). 


\section{Perfil S-11}

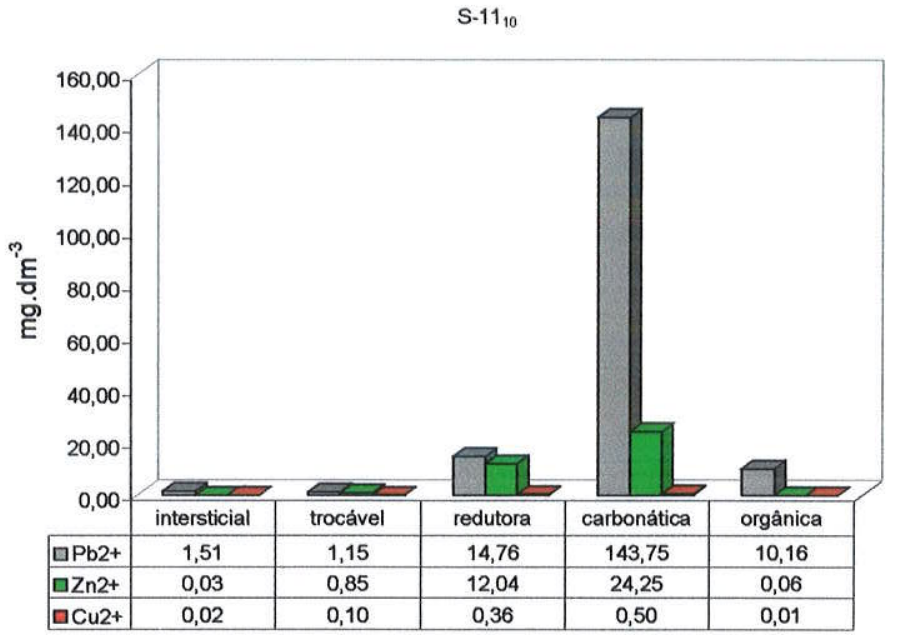

S-11 150

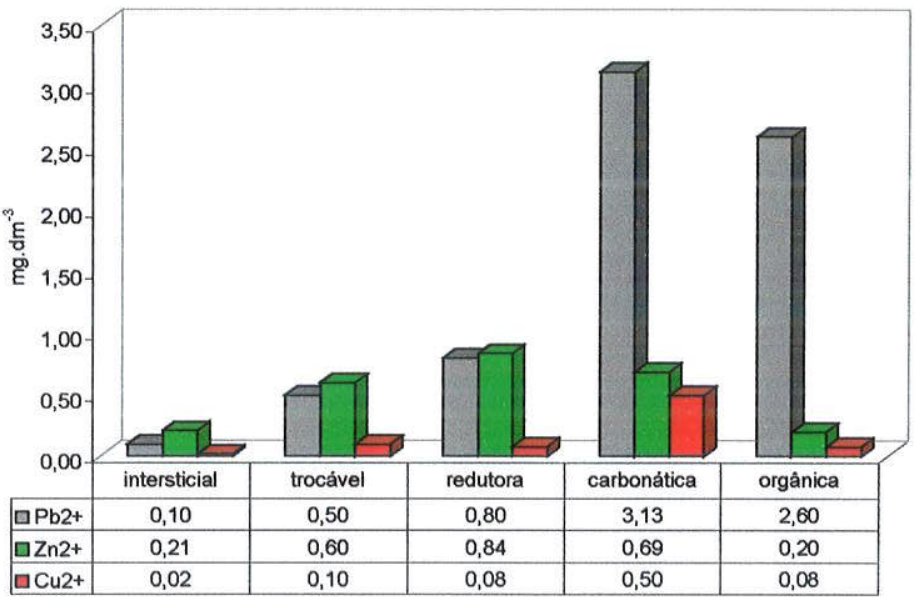

FIGURA 8.3.11: Dados obtidos $\left(\mathrm{mg}^{-\mathrm{dm}^{-3}}\right.$ ), através de Extrações Seqüenciais (RJ), do perfil S-11. 
Os metais pesados chumbo, zinco e cobre encontram-se em todas as frações, sendo o chumbo dentre esses íons, o cátion mais disponível nos solos e solo/sedimento.

No perfil S-3, a porção superficial apresentou maior associação do chumbo, zinco e cobre à matéria orgânica. A $40 \mathrm{~cm}$, o chumbo distribuiu-se praticamente igual pela fração intersticial, orgânica e redutora; o zinco concentrou-se na fração intersticial e o cobre na fração orgânica. Em profundidade, alcançando o nível d'água (380 a $420 \mathrm{~cm}$ ), o chumbo associou-se em quantidades mais elevadas à fração intersticial; o cobre igualmente na fração intersticial e trocável, enquanto que, o zinco à fração carbonática e trocável.

Em S-4 o comportamento do chumbo se tem de forma semelhante da superfície até $250 \mathrm{~cm}$ de profundidade (nivel đ’água), associando-se a matéria orgânica. O zinco e o cobre na porção superficial estão presentes em maiores quantidades nos interstícios do solo e em profundidade os resultados das frações orgânica e intersticial são muito semelhantes.

O perfil S-6 mostra que o chumbo nas porções superficiais está distribuído igualmente na fração trocável e carbonática e em profundidade à fração intersticial e orgânica; o mesmo não acontece com o zinco que associou-se nos primeiros dez centimetros à fração redutora e em profundidade, às frações intersticial e orgânica. O cobre está presente em todo o perfil na solução intersticial.

No ponto de referência S-9, os baixos valores obtidos para chumbo e cobre estão distribuídos, na porção superficial, entre as frações carbonática e redutora e a $70 \mathrm{~cm}$ somente na fração carbonática. O zinco associou-se à matéria orgânica superficialmente, à redutora a $45 \mathrm{~cm}$ e à fração trocável a $70 \mathrm{~cm}$.

Finalmente em S-11 os três cátions associaram-se à fração carbonática em todo o perfil. 


\section{CONCLUSÕES}

A área de estudo e suas circunvizinhanças já há 25 anos, têm sofrido fortes impactos ambientais e, graças a suas características, foi escolhida para estudos de fenômenos de retenção, mobilidade e distribuição de íons metálicos associados a solos e águas.

A escória dos fornos rotativos, produto da reciclagem do chumbo, é armazenada a céu aberto desde o início das atividades da indústria e em todo terreno e seus arredores tem-se espalhada grande quantidade de escória.

A principal fonte de poluição ambiental, refere-se a disponibilidade dos íons $\mathrm{Pb}, \mathrm{Zn}, \mathrm{Cu}, \mathrm{Cr}, \mathrm{Cd}$ e compostos de $\mathrm{S}$, sendo apenas os três primeiros de interesse neste trabalho.

Inicialmente a escória foi caracterizada química e mineralogicamente, mostrando-se rica em $\mathrm{Pb}, \mathrm{Zn}$ e $\mathrm{Cu}$, que fazem parte de materiais amorfos e de compostos de ferro homólogos a gohetita, hematita, magnetita etc.

O comportamento dos íns metálicos da escória (topo, meio e base) foi estudado, simulando lixiviações naturais através de extrator do tipo sohxlet em experimentos com $\mathrm{H}_{2} \mathrm{O}$ e $\mathrm{H}_{2} \mathrm{O} / \mathrm{CO}_{2}$. A eliminação mais intensa foi verificada no sistema $\mathrm{H}_{2} \mathrm{O} / \mathrm{CO}_{2}$ obtendo-se maior mobilidade no topo e menor na base das pilhas. Isto ocorre devido a presença de compostos neoformados mais solúveis na porção mais exposta à atmosfera, como por exemplo, hidróxidos, carbonatos e produtos da oxidação do $S^{2 *}$.

A maior ou menor disponibilidade dos cátions chumbo, zinco e cobre no solo foi estudada com o material associado a pilha de escória (S-5), principal fonte poluidora da área.

A deteç̧ão dos íons metálicos nas diferentes frações do solo foi efetuada através de extrações com reagentes químicos específicos.

Devido a solubilidade dos ions de interesse em $\mathrm{HNO}_{3}$, especialmente o chumbo, estudou-se a Extração Total com este ácido; definindo como $8 \mathrm{M}$ a melhor concentração, a temperatura ambiente de duas horas de digestão.

Essa extração aplicada aos solos e solo/sedimentos da área, mostrou contaminação por $\mathrm{Pb}^{2+}$ no ponto $\mathrm{S}-5$ e nas porções superiores dos perfis S-6 e S-11. As concentrações de cobre e zinco apresentaram-se menores que as detectáveis 
por Espectofotometria de Absorção Atômica, sugerindo ligações muito estáveis desses cátions junto à escória.

A disponibilidade dos cátions $\mathrm{Pb}, \mathrm{Zn}$ e $\mathrm{Cu}$ no solo e solo/sedimento foi testada através de Extração Seqüencial pelo método TESSIER utilizando também a amostra S-5. Este método não se mostrou adequado, com o somatório dos resultados parciais das Extrações Seqüenciais, superiores àqueles da Extração Total. Em vista disso buscou-se nova metodologia que se aplicasse ao material em estudo.

Com S-5 foram efetuados testes de Extração Seqüencial, ora procurando adaptar a metodologia de TESSIER, ora aplicando novas técnicas.

Constatou-se experimentalmente que, ao invés de uma única fração é possivel, variando-se volume, natureza dos reagentes, concentração e tempo de ataque, efetuar extrações iônicas, em cada conjunto de componentes do solo que guardam propriedades próprias, como matéria orgânica, carbonatos, fases oxidadas, adsorvidas etc.

A extração apresentada por TESSIER é efetuada com uma única amostra na seguinte seqüência: íons trocáveis, carbonatos, óxidos/hidróxidos de ferro e manganês e matéria orgânica; não leva em conta a fase liquida intersticial que pode conter dissolvidos íons de interesse.

Normalmente para obtenção das soluções intersticiais da zona não saturada são utilizados lisímetros de sucção. A extração com esse dispositivo é semiquantitativa, principalmente pela não representatividade das coletas.

Neste trabalho desenvolveu-se nova técnica que permite coleta quantitativa das soluções intersticiais com maior rapidez e representatividade. Trata-se de amostragens pontuais, extração com água em meio inerte $\left(\mathrm{N}_{2}\right)$ seguida de análises químicas.

Paralelamente a esse novo procedimento, efetuou-se, a título de comparação, o andamento proposto por TESSIER.

Obtiveram-se com o novo andamento, excelentes resultados; constatando-se que é possível a determinação quantitativa dos cátions associados às frações tratadas de modo independente. A seqüência de extração do novo método (RJ) pode ser assim esquematizada. 


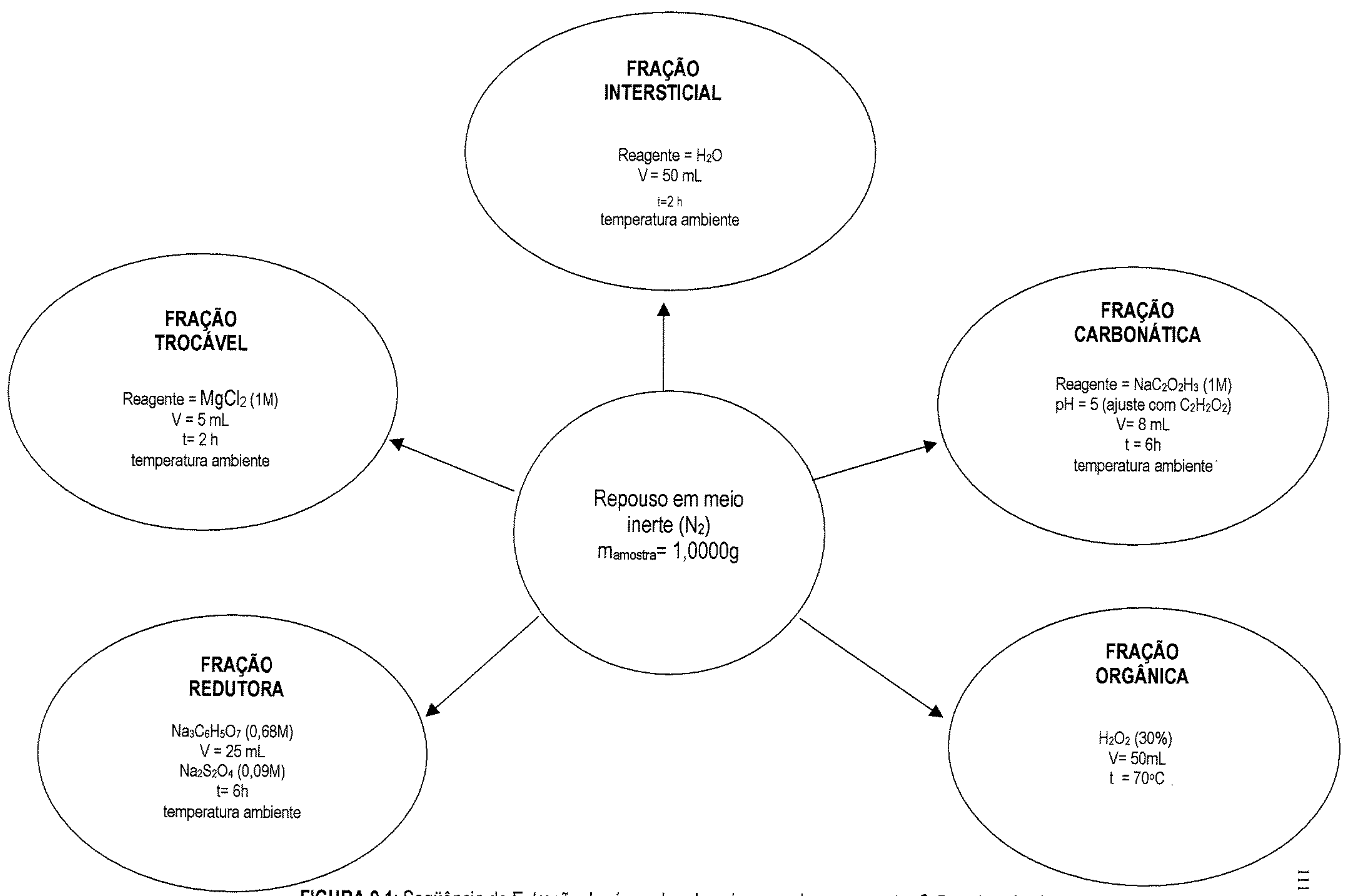

FIGURA 9.1: Seqüência de Extração dos ions chumbo, zinco e cobre na amostra S-5, pelo método RJ. 
Uma vez estabelecida técnicas de Extrações Seqüenciais para os íons chumbo, zinco e cobre, ela foi aplicada para se determinar a distribuição catiônica nos diferentes componentes do solo da área de estudos.

Os dados analíticos permitem concluir que os teores dos íns metálicos são função da textura, direção de fluxo e dependem, principalmente, de sua posição em relação a pilha de escória.

Dos cátions estudados, o que oferece perigo real é o chumbo por suas características nocivas ao homem, pelo efeito cumulativo no organismo e por encontrar-se disponivel em grande quantidade na área. Sua disponibilidade é muito mais acentuada que os íons cobre e zinco.

O chumbo, zinco e cobre encontram-se fortemente ligados às partículas do solo e apesar do fluxo descendente desses íons ser muito lento, sua migração é fortemente influenciada pela presença de eletrólito, ions complexantes e, principalmente, do $\mathrm{pH}$, uma vez que sua fixação ocorre junto aos carbonatos.

$\mathrm{Na}$ amostra composta S-5, junto a fonte de poluição, onde está localizado o foco da contaminação da área, os íons $\mathrm{Pb}, \mathrm{Zn}$ e $\mathrm{Cu}$ estão associados à fração carbonática; o chumbo em maior escala.

A influência do $\mathrm{pH}$ é ressaltada pela presença de $\mathrm{Pb}^{2+}$ nas águas dos poços $\mathrm{P} 2$, P5 e $\mathrm{Pt}_{120}$ e ausência de $\mathrm{Zn}^{2+}$ e $\mathrm{Cu}^{2+}$ devido a formação de óxidos/hidróxidos.

Graças às suas características, o solo com grandes quantidades de rejeitos soterrados, nem sempre representa o material original; a adsorção dos íns metálicos apresentaram-se bastante variada e, desta forma, pode-se generalizar para os cátions $\mathrm{Pb}, \mathrm{Zn}$ e $\mathrm{Cu}$ as seguintes associações: $\mathrm{Pb}$ ligado a matéria orgânica e a carbonatos, cobre associado aos carbonatos e $\mathrm{Zn}$ distribuído em todas as frações.

Mais uma vez é necessário ressaltar a importância dos íons intersticiais, detectados graças a nova metodologia. Eles apresentaram significativa contribuição iônica nos processos de lixiviação e são os primeiros a migrarem para a zona saturada.

Na recuperação do chumbo utiliza-se a fração já separada do tratamento das baterias, contendo em $6 \mathrm{~kg}$ de pasta com $\mathrm{PbSO}_{4}(60 \%), \mathrm{Pb}(21 \%), \mathrm{PbO}_{2}(19 \%)$. A escória contém $75 \%$ de ferro e $9 \%$ de chumbo.

No processo de decomposição da escória tem-se os seguintes mecanismos de disponibilidade do chumbo. 
Nos rejeitos, os silicatos e sulfetos são os ânions dominantes; os primeiros são estáveis e os sulfetos sofrem hidrólise:

$$
\begin{aligned}
& \mathrm{S}^{2-}{ }_{(\mathrm{aq})}+\mathrm{H}_{2} \mathrm{O}_{(\mathrm{l})} \leftrightarrows \mathrm{HS}_{(\mathrm{aq})}^{-}+\mathrm{OH}_{(\mathrm{aq})}^{-} \\
& \mathrm{HS}_{(\mathrm{aq})}^{-}+\mathrm{H}_{2} \mathrm{O}_{(\mathrm{l})} \leftrightarrows \mathrm{H}_{2} \mathrm{~S}_{(\mathrm{g})}+\mathrm{OH}_{(\mathrm{aq})}^{-}
\end{aligned}
$$

Nas proximidades da pilha de rejeito a presença do gás sulfídrico é facilmente identificada pelo forte odor característico.

Grande é o número de produtos formados pela oxidação do $\mathrm{S}^{2-}\left(\mathrm{H}_{2} \mathrm{~S}, \mathrm{~S}_{2} \mathrm{O}_{3}{ }^{2-}\right.$ $\mathrm{SO}_{2}, \mathrm{SO}_{3}, \mathrm{SO}_{4}{ }^{2-}$ ), sendo de maior interesse para o mecanismo de decomposição da escória a oxidação do $\mathrm{H}_{2} \mathrm{~S}$ pelo $\mathrm{Fe}^{3+}$ :

$$
\begin{aligned}
& \mathrm{Fe}^{3+}{ }_{(\mathrm{aq})}+\mathrm{e} \leftrightarrows \mathrm{Fe}^{2+}{ }_{(\mathrm{aq})} \\
& \mathrm{H}_{2} \mathrm{~S}_{(\mathrm{g})} \leftrightarrows \mathrm{SO}_{4}{ }^{2+}{ }_{(\mathrm{aq})}+2 \mathrm{e}
\end{aligned}
$$

O ferro metálico, que ocupa a maior parte da escória, inicialmente com a presença de $\mathrm{O}_{2}$ do ar e água oxida-se a $\mathrm{Fe}^{2+}$ e em seguida a $\mathrm{Fe}^{3+}$.

$$
\begin{aligned}
& \mathrm{Fe}_{(\mathrm{s})} \leftrightarrows \mathrm{Fe}^{2+}{ }_{(\mathrm{aq})}+2 \mathrm{e} \\
& \mathrm{Fe}^{2+}{ }_{(\mathrm{aq})} \leftrightarrows \mathrm{Fe}^{3+}{ }_{(\mathrm{aq})}+2 \mathrm{e}
\end{aligned}
$$

Como o $\mathrm{S}^{2-}$ é um agente fortemente redutor, tem-se facilitada a formação de $\mathrm{Fe}^{2+}$ que é a forma segundo a qual o ferro torna-se disponibilizado ao meio ambiente.

O meio ligeiramente ácido que domina o ambiente da área, devido principalmente a hidrólise do $\mathrm{Fe}^{3+}$, vem facilitar a liberação do $\mathrm{Fe}^{2+}$.

$$
\mathrm{Fe}^{3+}{ }_{(\mathrm{aq})}+\mathrm{H}_{2} \mathrm{O}_{(\mathrm{l})} \leftrightarrows \mathrm{Fe}(\mathrm{OH})_{3(\mathrm{~s})}+\mathrm{H}^{+}{ }_{(\mathrm{aq})}
$$

Por outro lado, a precipitação do ferro, que pode levar a forma de óxido/hidróxido, explica seus teores relativamente baixos nas águas subterrâneas e superficiais. 
O chumbo na escória encontra-se predominantemente na forma metálica, podendo encontrar-se também como sulfetos, óxidos etc.

Apesar de tratar de compostos pouco solúveis, a reação de água sobre a ganga produz hidróxidos, carbonatos e mesmo $\mathrm{Pb}^{2+}$ que é a forma mais estável em solução.

Se de um lado, a hidrólise do $\mathrm{Fe}^{3+}$ diminui o $\mathrm{pH}$, a do $\mathrm{S}^{2-}$ em $\mathrm{H}_{2} \mathrm{O}$ produz $\mathrm{OH}^{-}$. A dissolução dos compostos de chumbo, cobre e zinco, dependerão dessas duas reações químicas, lembrando que a presença do $\mathrm{Pb}^{2+}$ independe da concentração de $\mathrm{SO}_{4}{ }^{2-}$.

$$
\begin{aligned}
& \mathrm{PbCO}_{3(\mathrm{~s})}+\mathrm{H}^{+}{ }_{(\mathrm{aq})} \leftrightarrows \mathrm{Pb}^{2+}{ }_{(\mathrm{aq})}+\mathrm{H}_{2} \mathrm{O}_{(\mathrm{l})}+\mathrm{CO}_{2(\mathrm{~g})} \\
& \mathrm{PbS}_{(\mathrm{s})}+\mathrm{H}^{+}{ }_{(\mathrm{aq})} \leftrightarrows \mathrm{Pb}^{2+}{ }_{(\mathrm{aq})}+\mathrm{H}_{2} \mathrm{~S}_{(\mathrm{g})} \\
& \mathrm{Pb}(\mathrm{OH})_{(\mathrm{s})}+\mathrm{H}^{+}{ }_{(\mathrm{aq})} \leftrightarrows \mathrm{Pb}^{2+}{ }_{(\mathrm{aq})}+\mathrm{H}_{2} \mathrm{O}_{(1)}
\end{aligned}
$$

O cobre e o zinco encontram-se fortemente ligados à escória sob a forma metálica, provavelmente como ligas e também terão sua disponibilidade em função da hidrólise do ferro e sulfeto.

Esses cátions, portanto, dependendo do $\mathrm{pH}$ do meio, podem fixar-se no solo sob as formas de óxidos/hidróxidos e carbonatos ou disponibilizarem-se nas soluções.

$\mathrm{Na}$ atmosfera o chumbo ocorre associado a particulados e sob a forma de $\mathrm{PbO}, \mathrm{PbSO}_{4} \mathrm{e} \mathrm{PbCO}_{3}$, comprovado pelas análises químicas das águas de chuvas.

O chumbo é o principal metal pesado de maior disponibilidade na área de estudo, tanto nas águas subterrâneas como no solo e, devido suas características nocivas ao homem, pelo efeito cumulativo no organismo, recomenda-se controle sistemático do índice de plumbemia da população vizinha.

Os íons metálicos estudados, quando relacionados a grande quantidade de escória, cuja estabilidade é função das condições do meio, representam ao ambiente um perigo potencial. 


\section{BIBLIOGRAFIA}

ABNT - Associação Brasileira de Normas Técnicas (1987) NBR 10004. Resíduos Sólidos - Classificação. Rio de Janeiro, ABNT.

ADRIANO, D.C. (1986) Trace Elements in the Terrestrial Environment. New York, Springer-Verlag, p.533.

ALLOWAY, B. J. (1995) Heavy Metals in Soils. Blackie Academic \& Professional, 368 p.

ANDRADE B. C. R.; PATCHINEELAM R. S. (2000) Especiação de Metais-Traço em Sedimentos de Florestas de Manguezais com Avicennia e Rhizophora. Química Nova, v. $23(6)$, p. 733-736.

ARIZA, G. L. J.; GIRÁLDEZ, I.; RODAS-SÁNCHEZ, D.; MORALES, E. (2000) Metal Sequential Extraction Procedure Optmized for Heavily Polluted and Iron Oxide Rich Sediments. Analytica Chimica Acta, v.414, p. 151-164.

ASTM COMMITTEE D-18 ON SOIL AND ROCK (1996) ASTM Standards on Ground Water and Vadose Zone Investigations: Drilling, Sampling, Well Installation and Abandonment Procedures. Designation D 4696-92: Satandard Guide for PoreLiquid Sampling form The Vadose Zone, ASTM Publication, n 03-418196-38, $p$. 68-98.

BARCELOUX, D. G. (1999) Copper. Clin.Toxicol., v. 37 n$^{\circ}$ 2, p. 217-230.

BECKETT, P. H. T. (1989) The Use Extractants in Studies on Trace Metals in Soils, Sewage Sludges, and Sludge-Treated Soils. Springer - Verlag New York Inc. Advandces in soil Science, v. 9 p.144-176.

BEVILACQUA, J. E. (1996) Estudo Sobre Caracterização e a Estabilidade de Amostras de Sedimentos do Rio Tietê, SP. Dissertação (Doutorado). Instituto de Química. Universidade de São Paulo.

BROOKINS D. G. (1988) Eh-pH Diagrams for Geochemistry. New York, SpringerVerlag, p.176.

CAMPOS, E.; BARAHONA, E.; LACHICA, M. \& MINGORANCE, M. D. (1998). A Study of the Analytical Parameters Important for the Sequential Extraction Procedure Using Microwave Heating for $\mathrm{Pb}, \mathrm{Zn}$ and $\mathrm{Cu}$ in Calcareous Soils. Analytica Chimica Acta, v. 369(3), p. 235-243.

CETESB - COMPANHIA DE TECNOLOGIA DE SANEAMENTO AMBIENTAL. (1989) Niveis de plumbemia em grupo populacional vizinho a uma indústria de chumbo. CETESB p. 21-54 (Relatório Técnico Processo DCFT-J 126/88)

CETESB - COMPANHIA DE TECNOLOGIA DE SANEAMENTO AMBIENTAL (1994). Avaliação dos teores de chumbo nas imediações da indústria Tonolli do Brasil no 
Município de Jacareí, SP. CETESB p.30-46 (Relatório Técnico Processo 38/00083/94)

CETESB - COMPANHIA DE TECNOLOGIA DE SANEAMENTO AMBIENTAL (1997). Uso das águas subterrâneas para abastecimento público no Estado de São Paulo. CETESB, Relatório Técnico, p. 35.

CETESB - COMPANHIA DE TECNOLOGIA E SANEAMENTO AMBIENTAL (1999) Avaliação da Pluma de Contaminação na área Industrial da Tonolli. CETESB. p.156-300 (Relatório Técnico, Processo 38/00020/00).

CETESB - COMPANHIA DE TECNOLOGIA E SANEAMENTO AMBIENTAL (2002) Manual de Gerenciamento de áreas contaminadas. São Paulo, CETESB. p. 389.

CPRM - SERVIÇO GEOLÓGICO DO BRASIL (http://www.cprm.gov.br/bases/aguareg.php?codigo $=$ SP00000700) Acesso realizado em 2003.

DAEE - DEPARTAMENTO DE ÁGUAS E ENERGIA ELÉTRICA. (1977) Estudos de Águas Subterrâneas, Região Administrativa 3. São Paulo, DAEE p.160.

DAEE - DEPARTAMENTO DE ÁGUAS E ENERGIA ELÉTRICA (2000) Rede de monitoramento pluviométrico da prefeitura municipal de São Paulo. (http://www. daee.sp.gov.br/servicos/relatorios/pluvpmsp/pluvpmsp.htm) Acesso realizado em 2003.

DAVIDSON, C. M.; THOMAS, R. P.; McVEY. S. E.; PERALA, R.; LITTLEJOHN, D. URE, A. M. (1994) Evaluation of a Sequential Extraction Procedure for the Speciation of Heavy Metals in Sediments. Analytica Chimica Acta, v. 291, p. 277286.

DONG, Y.; MA, L. Q.; RHUE, D. R. (1999) Relation of Enhanced Pb Solubility to $\mathrm{Fe}$ Partitioning in Soils. Environmental Pollution, v. 110, p. 515-522.

GLEYZES C.; TELLIER S.; ASTRUC M. (2002) Fraction Studies of Trace Elements in Contaminated Soil and Sediments: a Review of Sequential Extraction Procedures. Analytical Chemistry, v.21, n 6+7, p.451-467.

GONZÁLES A.; ROMERO E.; ORIHUELA D.; GARRIDO R. (1999) Evaluación de Tomamuestras de Agua de Suelo en la Parcela Experimetal de la Rábida, Palos de La Frontera, Huelva. Estudios de La Zona No Saturada del Suelo. Eds.R. Muñoz-Carpena, A. Ritter, C. Tascón. ICIA: Tenerife. ISBN 84-699-1258-5, p. 1924.

HARRISON, R. M., LAXE, D. P. H., WILSON S. J. (1981) Chemical Associations of Lead, Cadmium, Copper and Zinc in Street Dusts and Roadside Soils. Environ. Sci. Technol. v. 15, p. $1378-1383$. 
HYPOLITO, R. (2003) Geoquímica da Interação solo/rocha/água (GGE-800). Metais Pesados. Parte I. Programa de Recursos Minerais e Hidrogeologia. CEPAS- IGCUSP, Texto Didático, p.67.

HYPOLITO, R. (2003) Geoquímica da Interação solo/rochalágua (GGE-800). Alcalinidade. Parte II. . Programa de Recursos Minerais e Hidrogeologia. CEPAS-1Gc-USP, Texto Didático, p.67.

HYPOLITO, R. (2003) Geoquímica da Interação solo/rocha/água (GGE-800). Determinação de $\mathrm{pH}$ de solo. Parte $\mathrm{V}$. Programa de Recursos Minerais e Hidrogeologia. CEPAS- IGc-USP, Texto Didático, p.67.

IPT - INSTITUTO DE PESQUISAS TECNOLÓGICAS DO ESTADO DE SÄO PAULO. (1981a) Mapa Geológico do Estado de São Paulo. São Paulo. IPT/PRÓMinério. (Escala 1:500.000).

IPT - INSTITUTO DE PESQUISAS TECNOLÓGICAS DO ESTADO DE SÃO PAULO. (1981b). Mapa Geomorfológico do Estado de São Paulo. São Paulo. IPT/PRÓ-Minério. (Escala 1:1.000.000).

LÃ, R. O.; BARRA, C. M.; SOBRINHO, N.M.B.; MAZUR, N.; VELLOSO, A. C. X. (2003) Avaliação dos Métodos de Extração Seqüencial de Tessier, Keller e Miller na Determinação de Ferro Nativo em Três Tipos de Solos: Orgânico, Brunizem e Latossolo. Química Nova, v. 26, n 3, p. 323-330.

LICCO A. E. (2000). Chumbo Secundário: A reciclagem das baterias chumbo-ácido. Tese de doutoramento. Departamento de Saúde Ambiental da Faculdade de Saúde Pública da Universidade de Säo Paulo. p. 221.

LINDSAY, W. L. (1979) Chemical Equilibria in Soils. Viley, New York.

MAITRE V.; BOURRIE G.; CURMI P. (1991) Contamination of Collected Soil Water Samples by the Dissolution of the Mineral Constituents of Porous P.T.F.E. Cups. Soil Science, v. 152, n 4, p. 289-293.

MAIZ, I.; ARAMBARRI, I.; GARCIA, R.; MILLÁN, E. (2000) Evaluation of Heavy Metal Availability in Polluted Soils by two Sequential Extraction Procedures Using Factor Analysis. Environmental Pollution, v. 110, p. 3-9.

MARQUES, J.; HYPOLITO, R.; PUGAS, M.; NASCIMENTO, S.C.; SANTOS, H.L. (2003) Extração Seqüencial e Total no Estudo do Comportamento de ĺons Metálicos $(\mathrm{Pb}, \mathrm{Zn}$ e $\mathrm{Cu})$ em Solo Impactado por Resíduo Sólido Industrial Oriundo da Reciclagem de Baterias Chumbo-Ácido. Congresso Brasileiro de Engenharia Sanitária e Ambiental, 22, Joinville, 2003. Boletim dos Trabalhos Técnicos.

MATIAZZO-PREZOTTO, M.E. (1994) Comportamento de Cobre, Cádmio, Crômio, Níquel e Zinco Adicionados a Solos de Clima Tropical em Diferentes Valores de 
pH. Tese de livre docência da Escola Superior de Agricultura Luiz de Queiroz, Universidade de São Paulo.

McBRIDE, M. B. (1994) Environmental Chemistry of soils. Oxford University Press. New York Toronto, p. 406.

Mc GUIRE P. E.; LOWERY B.; HELMKE P. A. (1992) Potential Sampling Error: Trace Metal Adsorption on Vacuum Porous Cup Samplers. Soil Sci. Soc. Am. J., v. 56, p. $74-82$.

MESTER, Z.; CERMISINI, C. GHIARA, E.; MORABITO, R. (1998) Comparison of Two Sequential Extration Procedures for Metal Fractionation in Sediment Samples. Analytica Chimica Acta, v. 359 (1-2), p. 133-142.

MOLISANI, M.M.; SALOMÃO, M.S.M.B.; OVALLE, A.R.C.; REZENDE, C. E.; LACERDA, L.D.; CARVALHO, C. E.V. (1999) Heavy Metals in Sediments of Lower Paraíba do Sul River and Estuary, RJ. Bull.Environ.Contam. Toxicol., v. 63, p. $682-690$.

PÉREZ-CID,B.; LAVILLA, I.; BENDICHO, C. (1999) Application of Microwave Extraction for Partitioning of Heavy Metals in Sewage Sludge. Analytica Chimica Acta, v. 378, p. 201-210.

KELLER C.; VÉDY J. C. (1994) Distribuition of Copper and Cadmium Fractions in Two Forest Soils. Environ. Qual, v. 23 p. 987-999.

KERSTEN, M.; FORSTNER, U. (1986). Methodology of Sequential Extraction of Metals. Wat. Sci. Techn, v 18, p.121.

PAOLIELLO, M. B.; CHASIN A. A. M. (2001) Ecotoxicologia do Chumbo e Seus Compostos. Centro de Recursos Ambientais. Cadernos de referência ambiental. Bahia, v.2, p.144.

PEDROZO, M.F.M.; LIMA, I.V. (2001) Ecotoxicologia do Cobre e Seus Compostos. Centro de Recursos Ambientais. Cadernos de referência ambiental. Bahia, v.2, p.128.

PLANO ESTADUAL DE RECURSOS HÍDRICOS (a) - Disponibilidade Hídrica do Estado de São Paulo. Conselho Estadual de Recursos Hídricos. (http://www.sigrh.sp.gov.br/sigrh/basecon/perh90/perh9010b.htm) Acesso realizado em 2003.

PLANO ESTADUAL DE RECURSOS HÍDRICOS (b) Sistema Integrado de Gerenciamento de Recursos Hídricos. Banco de Dados Hidrometeorológicos/Pluviais. (http://www.sigrh.sp.gov.br). Acesso realizado em 2003.

PREFEITURA MUNICIPAL DE JACAREÍ . (http:I/WWW.CONELESTE.COM.BR). Acesso realizado em 2003. 
PORTARIA 36 DO MINISTÉRIO DA SAÚDE (1999) N 1469, de 29 de novembro de 2000.

QUEVAUVILLER, PH.; RAURET,G.; SÁNCHEZ-LÓPEZ, J.F.; RUBIO, R. URE, A.; MUNTAU H. (1997) Certification of Trace Metal Extractable Contents in a Sediment Reference Material Following a Three-steps Sequencial Extraction Procedure. Science of the Total Environment, v. 205, p. 223-234.

YONG, R. N.; CLOUTIER, G. R. (1993) Selective Sequential Extraction Analysis of Heavy-Metal Retention in Soil. Can. Geotech. J, v. 30, p. 834-845.

RENDELL, P. A, BATLEY, G. E., CAMERON A.J. (1980) Adsorption as a Control of Metal Concentrations in Sediment Extracts. Environ. Sci. Technol. v. 14, p. 314 318.

RESOLUÇÃO CONAMA Nº 20 (1986) Decreto 88.351, $1^{\circ}$ de julho de 1983 - art. $7^{\circ}$ inciso IX.

RESOLUÇÃO CONAMA Nº 257 (1999) Decreto 99.274, 6 de junho de 1990. http://www.mma.gov.br/conama/res/res99/res25799.html (acesso realizado em 2003).

RICCOMINI C.; COIMBRA, A. M.; SUGUIO, K.; MIHÁLY, P.; MATURANA, E. C. (1991) Nova Unidade Litoestratigráfica Cenozóica da Bacia de Taubaté, SP: Formação Pindamonhangaba, Boletim IGc - USP, Publicação Especial, N N 9, p.111-115.

ROBSON, A.D.; REUTER, D.J. (1981) Diagnosis of Copper Deficiency and Toxicity. Copper in soils and Plants. Academic press. London and Orlando, p. 287-312.

ROSS, G. J.; WANG C. (1993) EXTRACTABLE Al, Fe, Mn and Si. Soil Sampling and Methods of Analysis. Canadian Society of Soil Science, p.239-245.

SANTOS, H.L; Marques, J.F; Filho, E.S. (2001) Poluição Industrial. Ministério Público de Jacareí. Processo Preparatório de Inquérito Civil N 83/2001.

SHEPARD, F.P. (1954) Revised Nomenclature for Depositional Coastal Features. Ameri. Ass. Pet. Geol. Bull., Tulsa. v.36, nº 10, p.1902-1912.

SPOSITO, G.;LUND, L.J.; CHANG, A.C. (1982) Trace Metal Chemistry in Arid Zone Field Soil Amended With Sewage Sludge. Fractionation of $\mathrm{Ni}, \mathrm{Cu}, \mathrm{Zn}$ and $\mathrm{Pb}$ in Solid Phases. Soil Science Society American Journal, v. 46, 260-264p.

STANDARD METHODS FOR THE EXAMINATION OF WATER AND WASTEWATER (1985) American Public Health Association. American Water Works Association Water Environmental Federation. Ed.19

STUM, W.; MORGAN, J. J. (1996) Aquatic Chemistry Chemical Equilibira and Rates in Natural Waters. New York, John Wiley \& Sons. Ed. $3^{\text {nd }}, \mathrm{p} 1022$. 
TAN, K. H. (1993) Principles of Soil Chemistry Marcel Dekker. Ed. $2^{\text {nd }}$, New York, $361 \mathrm{p}$.

TESSIER, A, CAMPBELL, P.G.C.; BISSON, M. (1979). Sequencial Extraction Procedure for the Speciation of Particulate Trace Metals. Analytica Chemistry. V. 51, n. 7, p. $844-850$.

TOKALIOGLU, S.; KARTAL, S.; ELCI, L. (2000). Determination of Heavy Metais and Their Especiation in Lake Sediments by Flame Atomic Absorption Spectrometry After a Four-stage Sequential Extraction Procedure. Analytica Chimica ACTA, v. 413, p. $33-40$.

URE, A.; QUEVAUVILLER, PH.; MUNTAU, H; GRIEPINK, B. (1993) Speciation of Heavy Metal in Soils and Sediments. An account of the Improvement and Harmonization of Extraction Techniques Undertaken the Commission of the European Communities. Inter. J. Environ. Anal. Chem., v 51, p.135-151.

WHO - WORLD HEALTH ORGANIZATION (1998) Copper. Geneva: WHO. (Environmental Health Criteria 200). 